\title{
Advanced imaging of the aortic valve and thoracic aorta
}

Citation for published version (APA):

Adriaans, B. P. (2021). Advanced imaging of the aortic valve and thoracic aorta: Moving beyond diameters. [Doctoral Thesis, Maastricht University]. Maastricht University. https://doi.org/10.26481/dis.20210702ba

Document status and date:

Published: 01/01/2021

DOI:

10.26481/dis.20210702ba

Document Version:

Publisher's PDF, also known as Version of record

\section{Please check the document version of this publication:}

- A submitted manuscript is the version of the article upon submission and before peer-review. There can be important differences between the submitted version and the official published version of record.

People interested in the research are advised to contact the author for the final version of the publication, or visit the DOI to the publisher's website.

- The final author version and the galley proof are versions of the publication after peer review.

- The final published version features the final layout of the paper including the volume, issue and page numbers.

Link to publication

\footnotetext{
General rights rights.

- You may freely distribute the URL identifying the publication in the public portal. please follow below link for the End User Agreement:

www.umlib.nl/taverne-license

Take down policy

If you believe that this document breaches copyright please contact us at:

repository@maastrichtuniversity.nl

providing details and we will investigate your claim.
}

Copyright and moral rights for the publications made accessible in the public portal are retained by the authors and/or other copyright owners and it is a condition of accessing publications that users recognise and abide by the legal requirements associated with these

- Users may download and print one copy of any publication from the public portal for the purpose of private study or research.

- You may not further distribute the material or use it for any profit-making activity or commercial gain

If the publication is distributed under the terms of Article $25 \mathrm{fa}$ of the Dutch Copyright Act, indicated by the "Taverne" license above, 


\title{
Advanced imaging of the aortic valve and thoracic aorta Moving beyond diameters
}

\author{
PROEFSCHRIFT \\ ter verkrijging van de graad van doctor aan de Universiteit Maastricht, \\ op gezag van de Rector Magnificus, Prof. dr. Rianne M. Letschert \\ volgens het besluit van het College van Decanen, \\ in het openbaar te verdedigen op \\ vrijdag 2 juli 2021 om 16.00 uur
}

door

Bouke Piet Adriaans 


\section{Promotores}

Prof. dr. J.E. Wildberger

Prof. dr. H.J.G.M. Crijns

Copromotor

Dr. S.M. Schalla

\section{Beoordelingscommissie}

Prof. dr. G.W.H. Schurink (voorzitter)

Prof. dr. M. Das (Helios Kliniken, Duisburg, Germany)

Prof. dr. M.W. de Haan

Prof. dr. A.W.J. van 't Hof

Prof. dr. J.W. Roos-Hesselink (Erasmus MC)

Financial support by Stichting de Weijerhorst for the research presented in this thesis is gratefully acknowledged.

Financial support by the Dutch Heart Foundation for the publication of this thesis is gratefully acknowledged.

ISBN:

9789464028430

Graphic design and layout by

M. Mafirad

Printed by:

Gildeprint | www.gildeprint.nl 


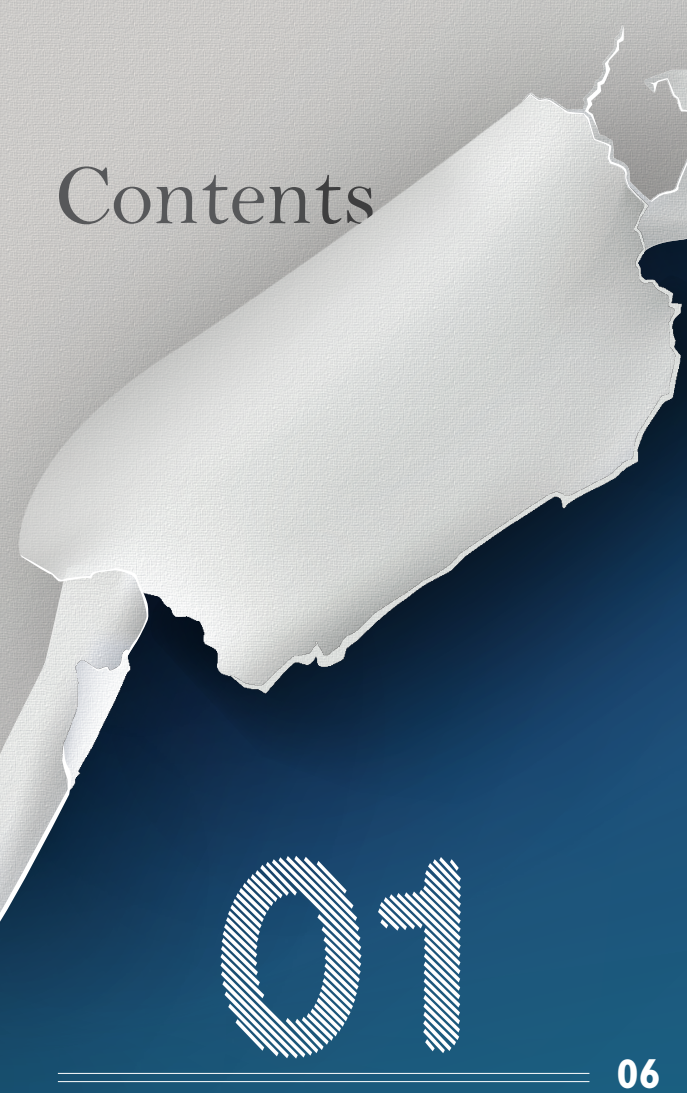

General introduction and thesis outline

06

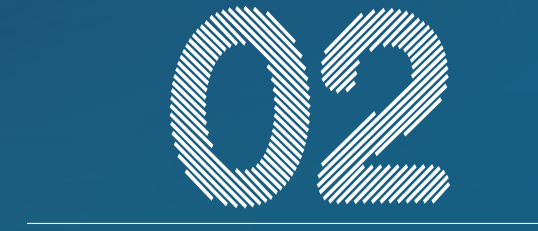

16

Predictive imaging for thoracic aortic rupture and dissection: moving beyond diameters

European Radiology 2019 Dec;29(I2):6396-404

\section{PART I}

\section{ANATOMIC IMAGING}

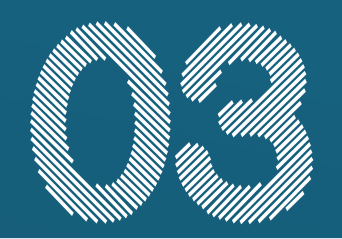

34

Determining the optimal interval for imaging surveillance of ascending aortic aneurysms

Netherlands Heart Journal, in press

Aortic elongation Part I: the normal aortic ageing process

Heart. 2018 Nov;104(21):1772-1777
Aortic elongation Part II: the risk of acute type $\mathbf{A}$ aortic dissection Heart. 2018 Nov;104(21):1778-1782

\section{Editorial}

Age-dependent aortic elongation: a new predictor for type $\mathbf{A}$ aortic dissection? Heart. 2018 Nov; 104(21):1729-1730

\section{PART ॥}

\section{HEMODYNAMIC IMAGING}

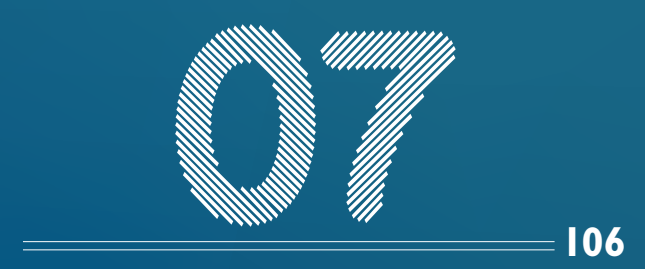

Clinical assessment of aortic valve stenosis: comparison between 4D flow MRI and transthoracic echocardiography J Magn Reson Imaging. 2020 Feb;5I (2):472-480

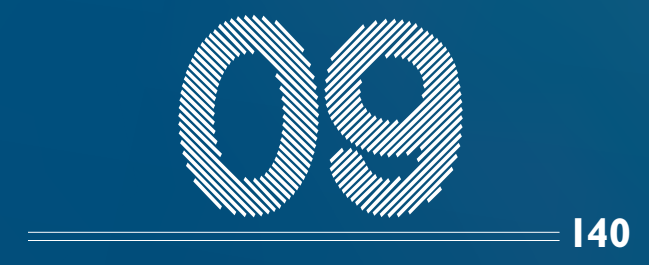

Summary, general discussion and future outlook
Evaluating the diagnostic accuracy of maximal aortic diameter, length and volume for prediction of aortic dissection Heart. 2020 Jun; 106(I2):892-897

74 Editorial

Prediction of aortic dissection Heart. 2020 Jun; 106(I2):870-87I

.

Characterization of ascending aortic flow in patients with degenerative nance study

Investigative Radiology, in press

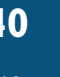

(n)

Glossary of terms
Scientific and socie

Scientific and societal impact

Nederlandse samenvatting

Dankwoord

About the author

List of publications aneurysms: a 4D flow magnetic reso- 


\section{General introduction}

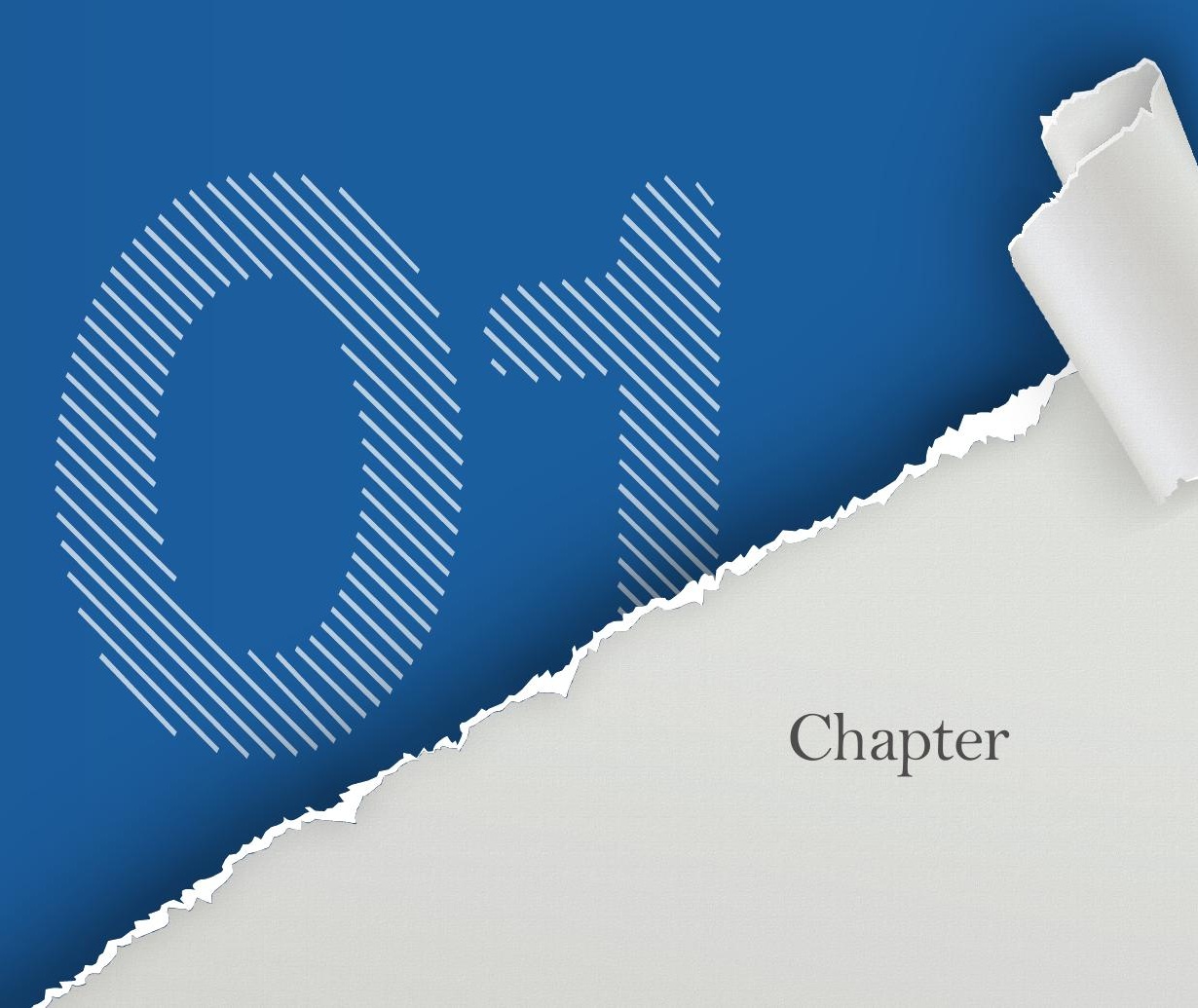




\section{THE ANATOMY OF THE AORTIC VALVE AND THORACIC AORTA}

The aorta is the largest artery in the human body. During the average lifetime it transports approximately 250 million liters of oxygenated blood from the heart to the tissues. The vessel is divided into five main anatomic segments: the bulb-shaped aortic root, the ascending aorta, the aortic arch (from the brachiocephalic trunk to the left carotid artery), the descending thoracic aorta (from the left carotid artery to the diaphragm), and the abdominal aorta (Figure I)(I). The latter terminates at the level of the lumbar vertebrae by bifurcating into the left and right common iliac arteries.

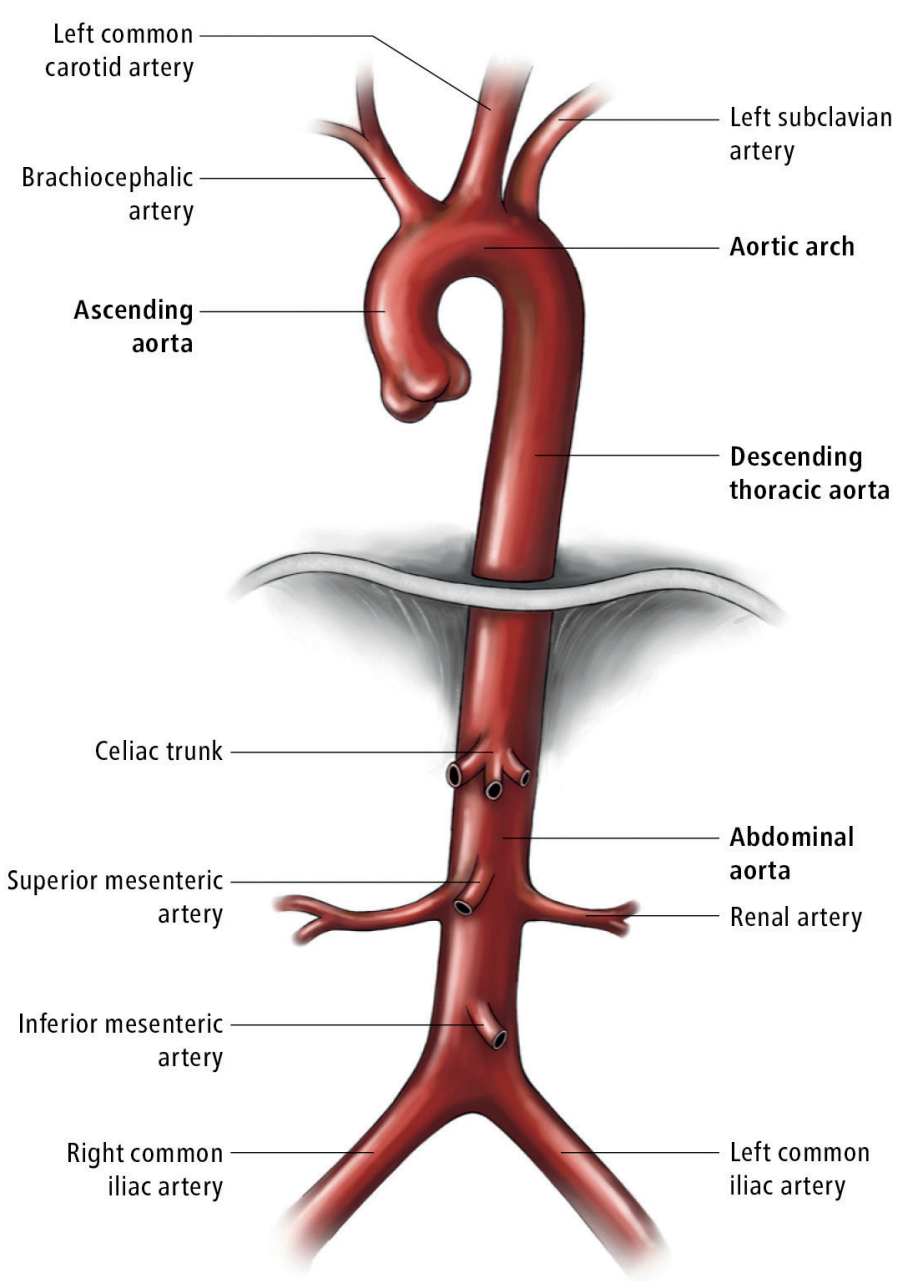

Figure I. The anatomy of the healthy aorta. Illustration courtesy of S.X. Zhang, MD.
The aortic vessel wall consists of three layers (Figure 2a)(2). The tunica intima is in direct contact with the blood flow and comprises a basement membrane lined with a single layer of endothelial cells. The thick tunica media consists of smooth muscle cells and elastic laminae, and provides the elasticity needed for the aorta to modulate its circulatory role and to endure the pulsatile cardiac output. The outer layer (or adventitia) is mainly composed of collagen. Although this layer is thin, it provides great tensile strength. Furthermore, it contains the vasa vasora, which nourish the major part of the aortic vessel wall.

\section{AORTIC DISSECTION: CLASSIFICATION AND EPIDEMIOLOGY}

Acute aortic syndromes (AAS) comprise a spectrum of medical emergencies that have similar presentations but distinct demographic and pathophysiological characteristics(3). Among various AAS, aortic dissection is the most prevalent(4). It is characterized by a tear in the intimal layer of the vessel wall, which allows blood to enter and create an alternative (or 'false') lumen (Figure 2b). While propagating, dissection can restrict blood flow into aortic side branches and cause severe end-organ ischemia(5). The disease can quickly lead to death when the intimal tear progresses into the coronary arteries, aortic valve, pericardium, or in case of complete aortic rupture $(6,7)$.

Aortic syndromes are classified according to the location and extent of involvement of the aorta(8). The Stanford classification system, which is most widely used, divides dissections into type $A$ (in case of involvement of the ascending aorta) and type B (all other dissections). Population studies have reported an annual incidence of 2.6-5.9 dissections per 100.000 inhabitants per year(9-12)

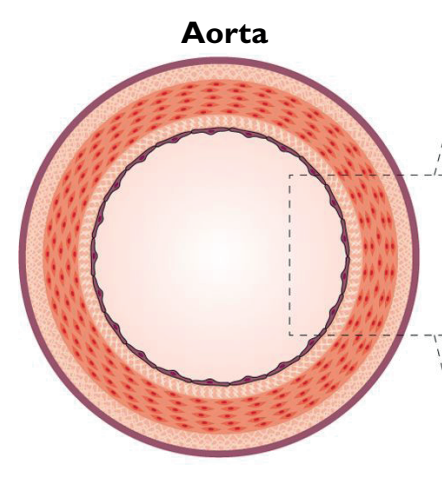

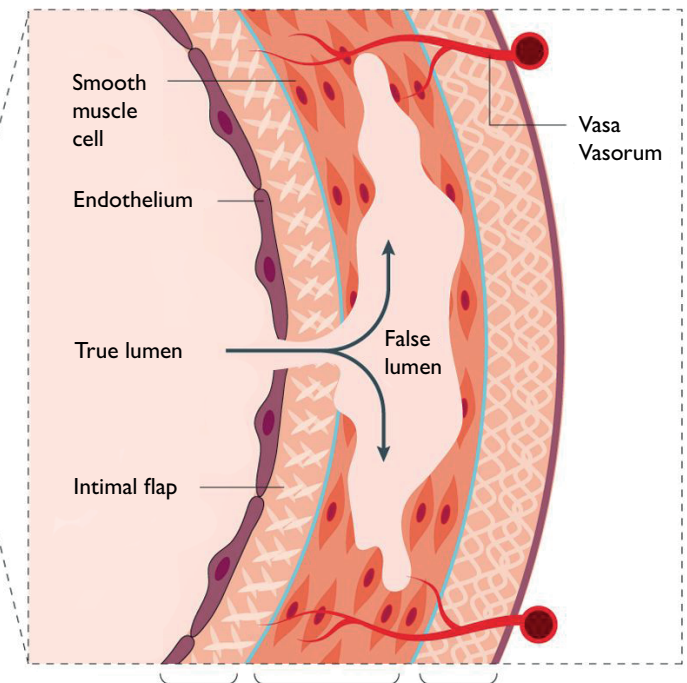

B

Figure 2. Schematic representation of the healthy (A) and dissected (B) aortic vessel wall. Adapted from Nienaber et al,, Aortic dissection, Nat Rev Dis Primers. 2016 Aug 25:2:1607l, with permission from Springer Nature 
Approximately two-thirds of those are classified as type $A(13)$. The disease more often develops in men (68\%), while women are generally older at the time of presentation (67 vs. 60 years)(13, 14). Systemic hypertension and aortic dilatation are common precipitating factors and present in $77 \%$ and $92 \%$ of cases, respectively $(14,15)$. Fifty percent of younger dissection patients (under age 40 years) are diagnosed with an underlying genetically mediated connective tissue disorder (such as Marfan or Loeys-Dietz syndrome)(16). Despite its relatively low incidence, aortic disease is among the top 15 most lethal diseases in patients aged $\geq 50$ years(17). It was reported to be the cause of 1.035 out of $153.363(0.7 \%)$ deaths in the Netherlands in 2018(18). Studies using post-mortem computed tomography (CT) have reported that more than half of patients with acute type $\mathrm{A}$ aortic dissection (ATAAD) experience circulatory arrest before arrival at the hospital(19,20). Of those who reach the hospital alive and undergo emergency surgery, $20-44 \%$ die postoperatively due to malperfusion syndromes such as cerebral, visceral or spinal ischemia $(9,21-24)$

\section{THORACIC AORTIC ANEURYSM: DEFINITION AND ETIOLOGY}

Aortic dilatation is the primary anatomic risk predictor for the occurrence of ATAAD(25). Large studies have established normal values for the diameters of different aortic segments and demonstrated their correlation with age, gender, and body surface area (BSA)(26-3I). Thoracic aortic aneurysm (TAA) is defined as a focal dilatation $\geq 50 \%$ of one or more segments of the aorta within the thoracic cavity(32). Most likely, these involve the ascending aorta $(60 \%)$ or descending aorta (40\%)(33). Aneurysms of the aortic arch and thoracoabdominal aorta are less prevalent (both 10\%)(33).

The pathophysiology of ascending aortic aneurysm formation is characterized by degeneration of the medial layer of the vessel wall. This process involves loss of smooth muscle cells and elastin content, which occurs - to some extent - as a normal consequence of aging(34). Excessive loss of structural integrity can result in weakening of the aortic vessel wall and subsequent luminal dilatation(35). Most TAAs are degenerative (i.e., sporadic) in nature and occur in association with hypertension(36-39). Medial degeneration in young patients is classically associated with connective tissue disease, familial thoracic aortic aneurysm and dissection syndrome, or presence of a bicuspid aortic valve (BAV)(40-44). Although rare, aneurysms can also form as a consequence of aortic infection or systemic autoimmune processes(45). Atherosclerosis underlies aneurysm formation of the descending and abdominal aorta but is a less common cause of ascending aortic aneurysms(37-39).

\section{THORACIC AORTIC ANEURYSM: LINK WITH AORTIC VALVE DISEASE}

\section{The aortic valve is the door to the aorta and opens up to three billion times in a lifetime. There is} an evident association between narrowing of the aortic valve (either congenital or acquired) and ascending aortic aneurysm formation. The coexistence of both is generally referred to as 'poststenotic dilatation' and occurs in patients with calcific aortic stenosis (AS), stenotic and non-stenotic BAV, and following aortic valve replacement $(46,47)$. Prevalence is higher in patients with bicuspid valves compared to those with tricuspid valves (83\% vs. 15-33\%)(47). There has been controversy as to whether BAV aortopathy is due to a vessel wall defect or whether it is caused by abnormal hemodynamic stress on the vessel wall. On the one hand, BAV disease shows similarities with Marfan's syndrome, since the vessel walls of both patient groups exhibit cystic medial necrosis other hand, there is evidence that increased wall stresses play a role in the pathophysiology of poststenotic dilatation. Early studies showed that patients with mild AS accompanied by a thrill develop aneurysms at the point downstream of the maximal vibration(5I, 52). It was postulated that these aneurysms represented structural fatigue as a consequence of the 'acoustic energy resulting from flow turbulence'. More recently, simulation studies have shown that flow through a bicuspid valve is intrinsically eccentric and turbulent, even in the absence of a significant transvalvular pressure gradient(53). The occurrence of a dilated aorta with an abnormal tricuspid valve further supports the concept of a hemodynamic cause, as opposed to an inherent tissue weakness(47, 54). Emerging imaging techniques (such as four-dimensional flow magnetic resonance [4D flow MR]) afford a detailed visualization of flow patterns in the heart and great vessels and can shed light on the pathogenesis of poststenotic aortic dilatation(55).

PREVENTIVE TAA MANAGEMENT: ROLE OF CARDIOVASCULAR IMAGING

TANAGEMENT: ROLE OF CARDIOVASCULAR IMAGING been well-described(56). The risk of type A dissection is $<1 \%$ per year in the mildly dilated aorta (40-55 $\mathrm{mm}$ ) but increases to $6.9 \%$ once the diameter reaches $60 \mathrm{~mm}(57,58)$. To avoid expansion towards this critical point, societal guidelines recommend pre-emptive extirpation of aneurysms $\geq 55 \mathrm{~mm}$ (or $\geq 50 \mathrm{~mm}$ in patients who are at increased risk for adverse outcomes) (25, 59-61). Patients with asymptomatic TAAs who do not meet criteria for prophylactic surgery should undergo conservative management. This includes lifestyle modification, aggressive blood pressure control to limit further dilatation, and genetic counseling to identify inheritable vascular syndromes $(25,59)$. Furthermore, all TAA patients require periodic imaging for follow-up of aneurysm diameters and re-assessment of surgical criteria(25, 59-61). Ultrasound, computed tomography (CT), and MR are all reasonable first-line modalities for TAA surveillance. Transthoracic echocardiography (TTE) is particularly useful for evaluation of the aortic valve, aortic root, proximal ascending aorta, and upper abdominal aorta(62). The distal ascending aorta, arch, and descending aorta are often incompletely imaged by TTE and require assessment by CT or MR. Since each technique has pros and cons in terms of resolution, acquisition time, radiation exposure, contrast agent administration and costs, the choice of study should be individualized and based on patient characteristics and the diagnostic questions to be answered(I). Current cardiovascular guidelines recommend (semi-)annual CT or MR in all TAA patients, but are not substantiated by data demonstrating the need for this approach $(59,61)$.

Despite the association between aortic size and the relative risk of complications, it has been shown that the majority of dissections occur in aortas with diameters below the cut-offs for prophylactic surgery $(15,63-66)$. The explanation for this so-called 'aortic size paradox' lies in the right-skewed distribution of TAA sizes, with a relatively large pool of patients with small aneurysms(67). The aortic size paradox has fueled the debate about the actual value of diameter measurements and underlines the need for research aiming to improve individual risk profiling. Advanced genetic testing, blood biomarkers, and novel imaging techniques are currently being investigated as potential additional markers of disease activity. Chapter $\mathbf{2}$ of this thesis reviews emerging imaging methods that hold promise to predict aortic disease at an early stage.

\section{GAPS IN KNOWLEDGE}

Guidelines for management of aortic disease provide well-substantiated recommendations for diagnosis and treatment of (suspected) dissection. However, evidence on prevention of AAS and the role of imaging herein is limited. Although the decision as to refer patients for pre-emptive 
aneurysmectomy depends on aortic diameter measurements, it is unknown how (and how often) these should be measured. Moreover, an increasing body of literature demonstrates that diameter measurements are incapable of predicting the majority of dissection cases. In elderly patients, radiologic reports often mention that the aorta is 'elongated', yet the role of aortic elongation in the pathophysiology of dissection has not been investigated. Also, no previous study has assessed the potential of aortic volumetry in prediction of acute adverse events. Although volume measurements have shown high reproducibility and have been adopted in many medical fields (such as to assess tumor sizes in oncology), their use in predicting aortic disease has not been evaluated. Hemodynamic imaging by means of 4D flow MRI has contributed to the unraveling of the pathophysiological mechanism in BAV disease, but has not been applied in patients with calcified tricuspid valves. The added value of this technique in prediction of TAA progression is yet unknown.

\section{AIM AND OUTLINE OF THIS THESIS}

The aim of this thesis is to assess novel anatomic and functional imaging parameters that may help to predict acute aortic syndromes and add value in the preventive management of aortic disease.

Chapter $\mathbf{I}$ is the general introduction and outline of this thesis. Chapter $\mathbf{2}$ reviews considerations regarding aortic diameter measurements and highlights emerging imaging techniques that have shown promise to improve dissection risk assessment.

Societal guidelines recommend annual or semi-annual CT or MR for all TAAs $\geq 40 \mathrm{~mm}$. However, these recommendations are not backed up by data showing the necessity of this approach. Chapter 3 aims to determine a standardized imaging interval for TAA patients by evaluating growth rates and predictors for disease progression.

Modern acquisition and post-processing techniques facilitate high-resolution three-dimensional imaging of the aorta, which - in turn - affords measurements of aortic volume and length. At surgery, the dissected aorta often looks markedly elongated in its course through the thorax. Chapter 4 investigates the normal evolution of longitudinal aortic dimensions during life. By using a propensity-matched strategy, Chapter $\mathbf{5}$ investigates the potential role of aortic elongation in the pathophysiology of dissection. Chapter $\mathbf{6}$ compares the diagnostic accuracies of maximal aortic diameter, length and volume for prediction of acute type A dissection.

Over recent years, four-dimensional (4D) flow magnetic resonance (MR) has emerged as a non-invasive imaging technique that enables the comprehensive assessment of intra-cardiac and -aortic hemodynamics. Chapter 7 aims to validate 4D flow-derived velocities and pressure gradients in the aortas of patients with calcified aortic valve stenosis, by comparing them to the clinical reference standard (transthoracic echocardiography).

To assess the role of aberrant hemodynamics in aneurysm formation, Chapter 8 compares flow patterns and hemodynamic markers (including wall shear stress) between TAA patients and healthy controls.

\section{REFERENCES}

ista A, Abbara S, Arai A, Asch FM, Badano $L P$, et al. Multimodality imaging of diseases of the thoracic aorta in adults: from the American Society of Cardiovascular Imaging: endorsed by the Society of Cardiovascular Computed Tomography and Society for diogr 2015:28(2): $\cdot 119-82$.

2. TintoiulC, Elefteriades/A, Ursulescu A, Underwood MI. Droc I. New approaches to aortic diseases from valve to abdominal bifurcation: Academic Press; 2017.

3. Tsai TT, Nienaber CA, Eagle KA. Acute aortic syndromes. Circulation. 2005;112(24):3802-13.

Lemaire SA, Russell L. Epidemiology of thoracic aortic

Williams DM, Lee DY, Hamilton BH, Ma

Narasimham DL, Kazanjian SN, et al. The dissected aorta: part III. Anatomy and radiologic diagnosis of branch-vessel compromise. Radiology. 1997;203():37-44 Mehta RH, Suzuki T, Hagan PG, Bossone E, Gilon D, Llovet A, et al. Predicting death in patients with acute
type A aortic dissection. Circulation 2002:105(2):200-6.

7. Hagan PG, Nienaber CA, Isselbacher EM, Bruckman D, Karavite DJ, Russman PL, et al. The International Registry of Acute Aortic Dissection (IRAD): new

8. Dld disease. JAMA. 2000;283(7):897-903. Debakey ME, Henly WS, Cooley DA, Morris GC, Jr. dissecting aneurysms of the aorta. J Thorac Cardiovasc Surg. 1965;49:130-49.

9. Howard DP, Banerjee A, Fairhead JF, Perkins J, Silver LE, Rothwell PM. Population-based study of incidence and outcome of acute aortic dissection and pre-morbid riskfactor control: 10-year results from the Oxford Vascular

10. Meszaros I, Morocz J, Szlavi J, Schmidt J, Tornoci L, Nagy L, et al. Epidemiology and clinicopa
dissection. Chest. 2000; I17(5):1271-8.

11. Melvinsdottir IH, Lund SH, Agnarsson BA, Sigvaldason K Gudbjartsson T, Geirsson A. The incidence and mortality of acute thoracic aortic dissection: results from a whole

Clouse WD. Hallett JW Schaff HV Spittell PC Rowland CM, Ilstrup DM, et al. Acute aortic dissection: population-based incidence compared with degenerative aortic aneurysm rupture. Mayo Clin Proc; 2004: Elsevier.
Nienaber CA, Fattori R, Mehta RH, Richartz BM, Nienaber CA, Fattori R, Mehta RH, Richartz BM,
Evangelista A, Petzsch M, et al. Gender-related differEvangelista $A$, Petzsch $M$, et al. Gender-related differences in acute a

14. Evangelista A, Isselbacher EM, Bossone E, Gleason TG, Eusanio MD, Sechtem $U$, et al. Insights from the International Registry of Acute Aortic Dissection: a 20-year experience of collaborative clinical research. Circulation. 2018;:137(17):1846-60.

15. RyIski B, Branchetti E, Bavaria JE, Vallabhajosyula P, Szeto size in acute type A dissection: more than $90 \%$ artic meet the guidelines for elective ascending replacement. Thorac Cardiovasc Surg. 2014;148(3):944-8. el.

16. Januzzi JL, Isselbacher EM, Fattori R, Cooper JV, Smith DE, Fang J, et al. Characterizing the young patient with aortic Dissection (IRAD). I Am Coll Cardiol. 2004:43 (4) :665-9.
17. Centers for Disease Control, Prevention (CDC) National Center for Injury Prevention and Contro. WISQARS
CDC. 2007 . Centraal Bureau voor de Statistiek, accessible via https:/ opendata.cbs.nil/statline/\#/CBS/n//dataset/7233/tab Ta

NaraS, et al Prevalence of type A acute artic dissection, in patients with out-of-hospital cardiopulmonary arrest. Am J Cardiol. 2016;:117(II):1826-30.

20. Moriwaki Y, Tahara Y, Kosuge T, Suzuki N. Etiology of out-of-hospital cardiac arrest diagnosed via detaile raphy. J Emerg Trauma Shock. 2013;6(2):87.

21. Reutersberg B, Salvermoser M, Trenner M, Geisbüsch S, Zimmermann A, Eckstein $\mathrm{HH}$, et al. Hospital incidence and in-hospital mortality of surgically and interventionally treated aortic dissections: secondary data analysis of the nationwide German diagnosis-related 2019;8(8):e011402. Peterson MD, et al. Clinical presentation, management, and short-term outcome of patients with type A acute dissection complicated by mesenteric malperfusion: observation Thorac Cardiovass Surg 2013:145(2):385-90 Aic Dissection.

. Paini D, Leone A, Belotti LM, Fortuna D, G

Pacini D, Leone A, Belotti LM, Fortuna D, Gabbieri D. cance of multiorgan malperfusion. Eur J Cardiothora Surg. 2013:43(4):820-6.

24. Geirsson A, Szeto WY, Pochettino A, McGarvey ML, Keane MG, Woo YJ, et al. Significance of malperfusion type A dissection: outcomes and need for additional revescularizations. Eur J Cardiothorac Surg. 2007:32(2):255-62

25. Erbel R, Aboyans V, Boileau C, Bossone E, Di Bartotomeo R, Eggebrecht H, et al. 2014 ESC Guidelines on the diagnosis and treatment of aortic diseases. Eur Heart

26. Campens L, Demulier L, De Groote K, Vandekerckhove chocardiographic assessment al. Reference values for aortic root and ascending aorta spanning all age categories. Am J Cardiol. 2014;|l I4(6):914-20.

27. Lin FY, Devereux RB, Roman MJ, Meng J, Jow VM, Jacobs , et al. Assessment of the thoracic aorta by multidetecto values in adults without evident cardiovascular disease. J Cardiovasc Comput Tomogr. 2008; 2(5):298-308.

28. Roman MJ, Devereux RB, Kramer-Fox R, O'Loughlin Two-dimensional echocardiographic aortic root dimensions in normal children and adults. Am J Cardio

Rager A, Kaemmerer H, Rapp-Bernhardt U, Blücher S, aorta throughout life as measured with helical compute tomography.J Thorac Cardiovasc Surg. 2002; 123(6):1060-6.

30. Mensel B, HeBelbarth L, Wenzel M, Kühn J-P, Dör M Völzke $\mathrm{H}$, et al. Thoracic and abdominal aortic diameters association with age and cardiovascular risk factors. Eur Radiol. 2016:26(4)969-78. 
31. Turkbey EB, Jain A, Johnson C, Redheuil A, Arai AE, Gomes AS, et al. Determinants and normal values of ascending aortic dameter by age, gender, and race/ (MESA). J Magn Reson Imag. 2014:39(2):360-8.

32. Creager MA, Belkin M, Bluth El, Casey DE, Chaturvedis, Dake MD, et al. 2012 ACCF/AHA/ACR/SCAI/SIR/ STS/SVM/SVN/SVS Key data elements and definitions for peripheral atherosclerotic vascular disease: a report Americn Heart Association Task Force on Clinicalion/ Standards (Writing Committee to develop Clinical Dat Standards for peripheral atherosclerotic

33. Isse Coll Cardiol. 2012,59(3):24-357. aneurysms. Circulation. 2005;III(6):816-28. thoracic and abdominal aortic aneurysms. Ann NY Acad

Karimi A, Milewicz DM. Structure of the elastincontractile units in the thoracic aorta and how genes that cause thoracic aortic aneurysms and dissections disrup

36. Guo D, Hasham S, Kuang S-Q, Vaughan CJ, Boerwinkle $\mathrm{E}, \mathrm{Chen} \mathrm{H}$, et al. Familial thoracic aortic aneurysms and dissections: genetic heterogeneity with a major locus
mapping to 5 q $13-14$. Circulation. 2001; 103(20):2461-8.

37. Agmon Y, Khandheria BK, Meissner I, Schwartz GL, Sicks JD, Fought AJ, et al. Is aortic dilatation an atherosclerosis-related process?: Clinical, laboratory, and
transesophageal echocardiographiccorrelates of thoracic aortic dimensions in the populationwith implications for thoracic aortic aneurysm formation. I Am Coll Cardiol. 2003;42(6):1076-83.

38. VapnikJS, Kim JB, Isselbacher EM, Ghoshhajra BB, Cheng Y, Sundt III TM, et al. Characteristics and outcomes of ascending versus descending thoracic aortic aneurysms.

Hashimoto $\mathrm{H}$, et al. Differences in profiles between patients with thoracic and abdomina

aortic aneurysms. Am J Cardiol. 2008; 101(5):696-9.

40. Jeremy RW, Huang $H, H$ wa J, McCarron $H$, Hughes $C F$, . Cardiol. 1994:74(4):369-73.

41. Milewicz DM, Chen H, Park E-S, Petty EM, Zaghi H, Pai $G S$, et al. Reduced penetrance and variable expressivity of familial thoracic aortic aneurysms/dissections. Am

Cardiol. $1998,82(4) .4749$

Willing MC, Guo D-c, Muilenburg A, He R, Tran VT, et al. Mapping a locus for familial thoracic aortic lation. 2003;107(25):3184-90

43. de Sa M, Moshkovitz Y, Butany J, David TE. Histologic abnormalities of the ascending aorta and pulmonary trunk in patients with bicuspid aortic valve disease ovasc Surg. 1999;118(4):588-96.

44. Huntington K, Hunter AG, Chan K-L. A prospective study to assess the frequency of familial clustering of congenita bicuspid aorticvalve.J Am Coll Cardiol. 1997;30(7):1809-12. 45. Nuenninghoff D, Hunder G, Christianson T, McClelland R, Matteson E. Mortalty or large antery complication patients with glant cell arteritis: a population-based 50 years. Arthritis Rheum. 2003;48:3522-31.
46. Wilton E, Jahangiri M. Post-stenotic aortic dilatation. Cardiothorac Surg. 2006; I(7).

Arangalage D, Nguyen V, Mathieu T, Vatients with tricuspid and bicuspid dilatation rates in COFRASA/GENERAC study. Eur Heart I Cardiovasc

48. Nataatmadja M, West M, West J, Summers K, Walker Nagata M, et al. Abnormal extracellular matrix protein vascular smooth muscle cells in Marfan syndrome and bicuspid aortic valve thoracic aortic aneurysm. Circulation. 2003;108(10 suppl I):|I-329-1|-34.

49. Fedak PW, Verma S, David TE, Leask RL, Weisel RD, Butany J. Clinical and pathophysiological implications of

bicuspid aortic valve. Circulation. 2002;106(8):900-4.

I, et al. Vascular matrix remodeling in patients with bicuspid aortic valve malformations: implications for aortic dilatation. J Thorac Cardiovasc Surg. 2003;126(3):797-805.

1. Holman E. The obscure physiology of poststenotic diatation; its relation to the development of aneurysms.

.

Observations on post-stenan E, Stofer R. Experimental ovasc Surg. 1959;38:662-9.

53. Ferencik M, Pape LA. Changes in size of ascending aorta aortic valve function with time in patients with congenitally bicuspid aortic valves. Am f Cardio

2003, $2(1) .43-6$.

A critical review of the American College of Cardiology/American Heart Association ascending aorta. Am J Cardiol. 2008; 102(I):107-10.

55. Markl M, Frydrychowicz A, Kozerke S, Hope M, Wieben C.4D flow MRI.JMagn Resonlmaging. 2012;36(5):1015-36.

U Kopf GS, et al What is the appropriate size criterion for resection of thoracic aortic aneurysms? I Thorac Cardiovasc Surg. 1997; I I3(3):476-91.

57. Davies RR, Goldstein L], Coady MA, Tittle SL, Rizzo JA, Kopf GS, et al. Yearly rupture or dissection rates for size. Ann Thor Surs 200273(1) 17.28 cion based

. Kim AB Spotnitz M. 202,75(1) ME

(t) moderately dilated ascending aorta. J Am Coll Cardiol. 2016;68(II):1209-19.

59. Hiratzka LF, Bakris GL, Beckman JA, Bersin RM, Carr VF. SCA/SCAI/SIR/STS/SVM guidelines for the diaSA and manal J Am Coll Cardiol. 2010;55(14):e27-el29.

60. Svensson LG, Adams DH, Bonow RO, Kouchoukos NT, Miller DC, O'Gara PT, et al. Aortic valve and ascending aorta guidelines for management and quality measures.

61. JCS Joint Working Group. Guidelines for diagnosis and 2011). Circ . 2013;77(3):789-828.

62. Evangelista A, Flachskampf FA, Erbel R, Antonin Canterin F, Vlachopoulos C, Rocchi G, et al. Echocardiggraphy in aortic diseases. EAE recommendations for

6. Pape

Evangelista $A$, et al. Aortic diameter $\geq 5.5 \mathrm{~cm}$ is not from the International Registry of Acute Aortic

64. Trimarchis, Jonker FH, HutchisonS, Isselbache EM. LA, Patel HJ et al. Descending aortic diameter of $5.5 \mathrm{~cm}$ or greater is not an accurate predictor of acute type $B$ aortic dissection.J J Thorac Cardiovasc Surg 2011;142(3): $101-7$.

65. Kim EK, Choi SH, Sung K, Kim WS, Choe YH, Oh JK, et al. Aortic diameter predicts acute type $A$ aortic rome.J Thorac Cardiovas Surg. 2014;:147(5): 1505 -10. MGS, Bavaria JE, et al. Aortic size in acute type A dissection: implications for preventive ascending aortic

67. Elefteriades AA, Farkas EA. Thoracic 2009 tic (6) 9416 . clinically pertinent controversies and uncertinties. IAn Coll Cardiol. 2010:55(9):841-57. 


\section{Predictive imaging for thoracic aortic dissection and rupture: moving beyond diameters}

Bouke P. Adriaans $s^{1,2,3}$

Joachim E. Wildberger ${ }^{1,3}$

Jos J.M. Westenberg

Hildo J. Lamb 4

Simon Schalla
Sil,

I. Department of Radiology and Nuclear Medicine, Maastricht University Medical Center+, Maastricht, the Netherlands.

2. Department of Cardiology, Maastricht University Medical Center+, Maastricht, the Netherlands.

3. Cardiovascular Research Institute Maastricht (CARIM), Maastricht, the Netherlands.

4. Department of Radiology, Leiden University Medical Center, Leiden, the Netherlands.

European Radiology 2019 Dec;29(12):6396-404

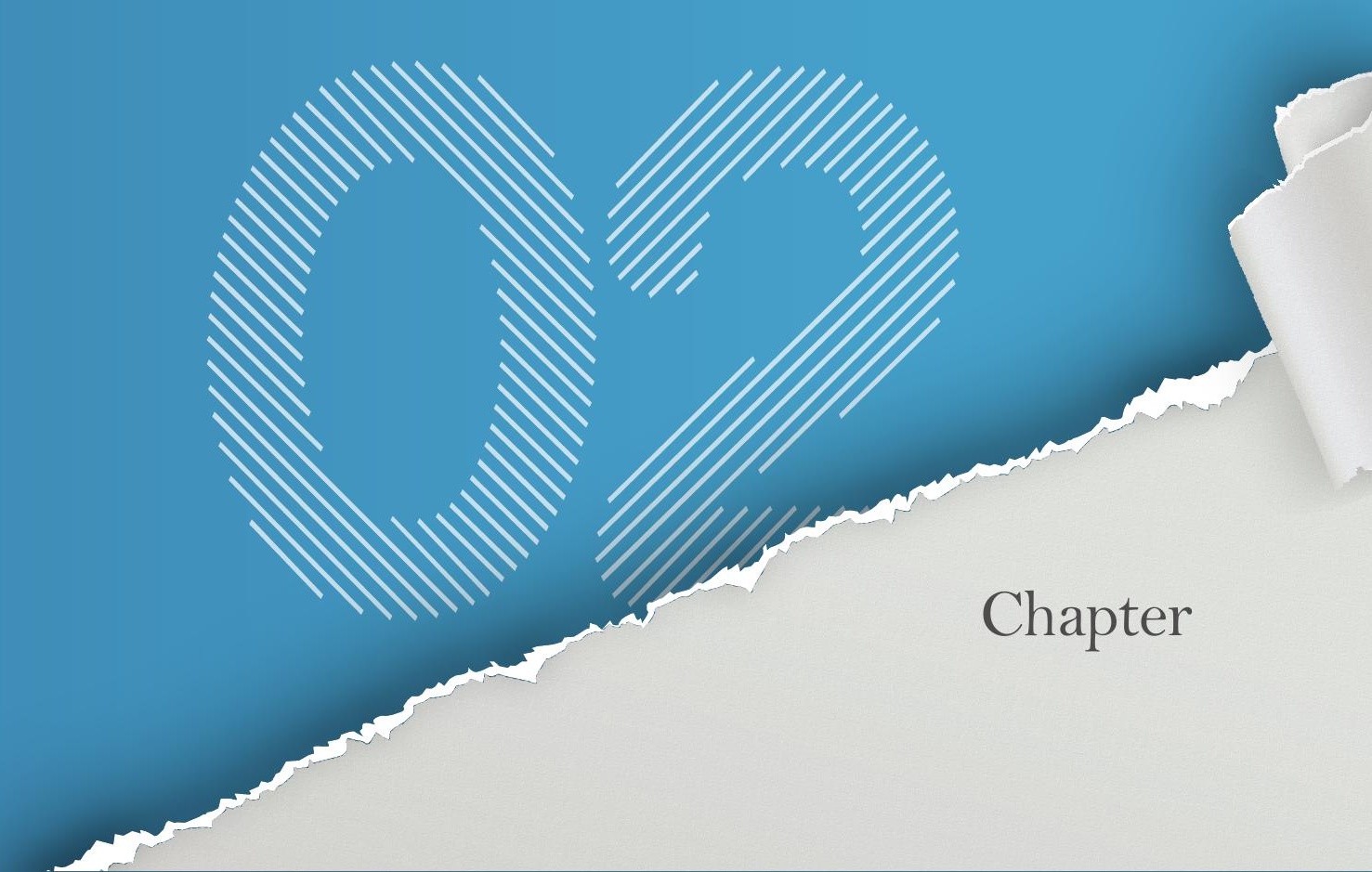


Acute aortic syndromes comprise a group of potentially fatal conditions that result from weakening of the aortic vessel wall. Pre-emptive surgical intervention is currently the occurrence of dissection and rupture in aortas with diameters below surgical thresholds. Modern imaging techniques (such as hybrid PET-CT and 4D flow MRI) afford the non-invasive assessment of anatomic, hemodynamic and molecular features of the aorta, and may provide for a more accurate selection of patients who will benefit from preventative surgical intervention. In the current review, we summarize evidence and considerations regarding predictive aortic imaging and highlight evolving imaging modalities that have shown promise to improve risk assessment for the occurrence of dissection and rupture.
INTRODUCTION

Upon examining the heart, its pericardium was found distended with a quantity of coagulated blood, nearly sufficient to fill a pint cup; the whole heart was so compressed as to prevent any blood contained in the veins from being forced into the auricles; therefore the ventricles were found absolutely void of blood; and, in the trunk of the aorta, we found a transverse fissure on its inner side, about an inch and a half long, through which some blood had recently passed...

In 1760, King George II of Great Britain died unexpectedly while 'straining on the toilet', and so became subject of the first ever case report on acute type $A$ aortic dissection(I). At autopsy, the King's personal physician described findings of an intimal vessel wall tear and subsequent cardiac tamponade, which - as we now know - is one of the most feared complications of dissection. Along with pathophysiologically distinct entities like aneurysm rupture and intramura hematoma (IMH), dissection belongs to the spectrum of acute aortic syndromes (AAS). Despite best efforts, these have proven challenging to predict, and annual incidence rates have been stable at approximately 10 per 100.000 over the past decades $(2,3)$. Cardiovascular imaging plays a central role in the preventative management of aortic disease, since guidelines traditionally depend on diameter criteria for stratification towards prophylactic surgical intervention $(4,5)$. In the current review, we summarize evidence and considerations regarding predictive aortic imaging and highlight modern imaging techniques that have shown promise to improve risk assessment for the occurrence of dissection and rupture.

\section{BEST CURRENT PRACTICE - AORTIC DIAMETERS}

\section{Normal Diameters}

The aorta is the largest artery in the body and runs from the aortic valve until the abdominal bifurcation. From proximal to distal, it consists of the aortic root, ascending aorta, aortic arch, descending thoracic aorta, and abdominal aorta (Figure I). Cross-sectional diameters are influenced by gender, patient habitus, and hypertension, and increase in an indolent manner by approximately $0.1 \mathrm{~mm} /$ year(6). Reference values for the different anatomic segments have been established by multiple imaging modalities, including echocardiography, CT, and MRI(7-9). Imaging guidelines provide specific measurement recommendations for each of these techniques and emphasize that there exists no standardized method across modalities $(10)$. Therefore, diameters can vary slightly depending on trigger time (end-systolic vs. end-diastolic) and edge selection (leading edge-to-leading edge vs. inner edge-inner edge vs. outer edge-outer edge). In general, it is stressed that measurements should be performed perpendicular to the aortic centerline (i.e., on double oblique images), and that measurement location and methodology should be specified in order to provide for accurate follow-up in individuals with an indication for repetitive imaging(II-13)

\section{KEYWORDS}

Aorta, aortic dissection, aortic aneurysm, type A dissection, aortic rupture.

\section{KEY POINTS}

- Guidelines for the preventative management of aortic disease depend on maximal vessel diameters, while these have shown to be poor predictors for the occurrence of catastrophic acute aortic events.

- Evolving imaging modalities (such as 4D flow MRI and hybrid PET-CT) afford a more comprehensive insight into anatomic, hemodynamic and molecular features of the aorta and have shown promise to detect vessel wall instability at an early stage.

\section{Thoracic aortic aneurysm (TAA)}

An aneurysm is defined as a localized arterial dilatation of $\geq 2$ standard deviations (SDs) above the expected vessel diameter(14). The underlying pathophysiological mechanisms differ partially for aneurysms at various locations along the aorta. Whereas TAA results from excessive degeneration of the medial layer of the vessel wall (also known as cystic medial necrosis), the formation of abdominal aortic aneurysms (AAA) is mainly associated with atherosclerosis(15). However, the net result - extensive remodeling of the extracellular matrix of the vessel wall with loss of vascular smooth muscle cells (VSMCs) and elastin content - is similar for all aneurysms(I5). 


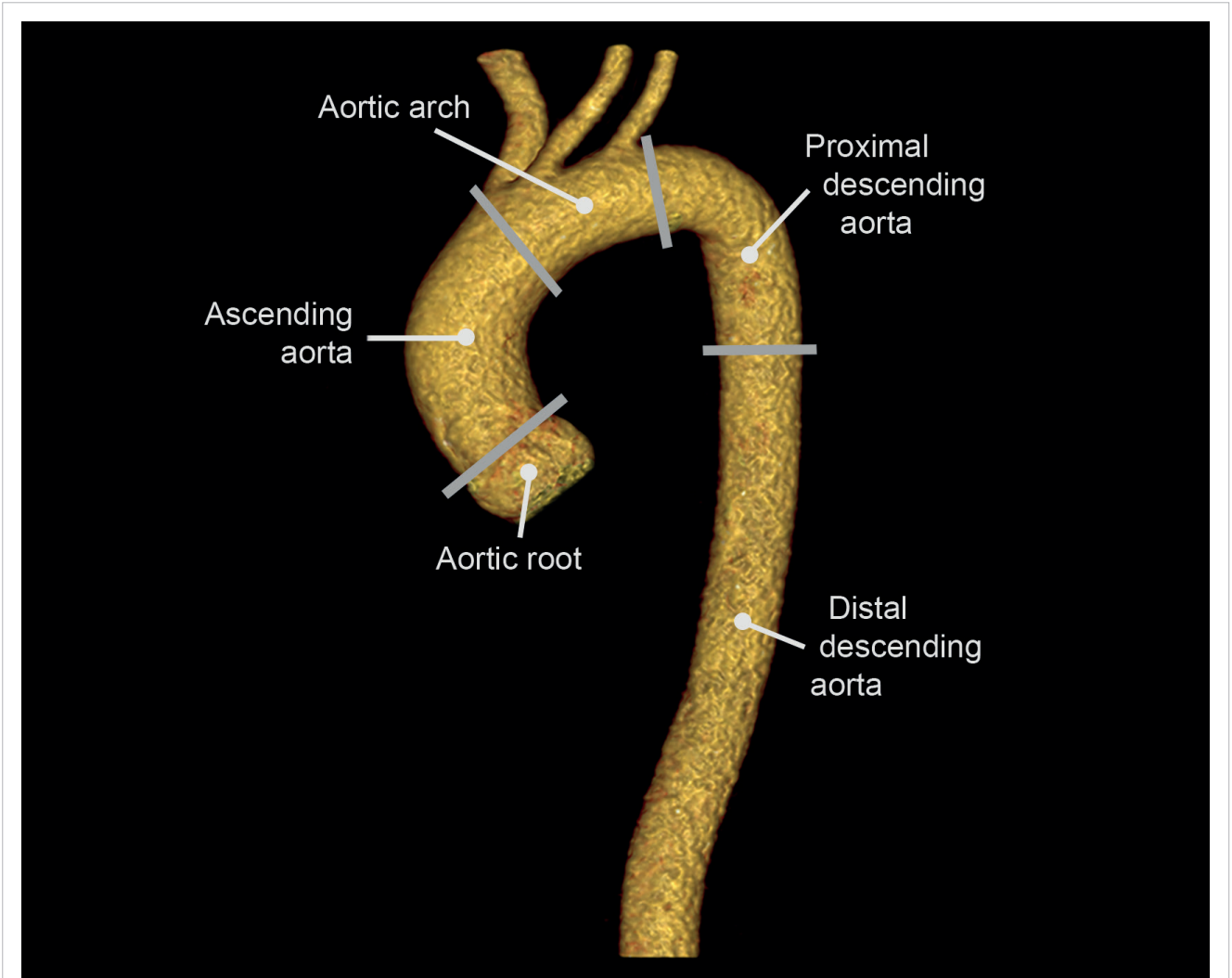

Figure I. Three-dimensional CT reconstruction of a healthy thoracic aorta. The ascending aorta runs from the sinotubular junction until the first branch vessel (brachiocephalic trunk), while the aortic arch is defined as the segment that contains the three branch vessels. The descending thoracic aorta is divided into two parts. a proxim

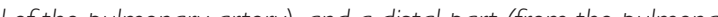
the pulmonary artery to the diaphragm).

Progressive aortic dilatation is a well-acknowledged risk factor for the occurrence of both acute dissection and rupture. While these natural complications are rare in ascending aortic aneurysms arly rupture or dissection risk of 50 and $55 \mathrm{~mm}$, respectively), a sharp step-up in their occurrence - to $6.9 \%$ yearly - is observed when the diameter exceeds $60 \mathrm{~mm}$ (Figure 2)(16-18). In descending thoracic aneurysms, a similar 'hinge point' is identified at $70 \mathrm{~mm}(18)$. In order to avoid aneurysm expansion beyond these critical points, the general consensus is to refer patients for pre-emptive surgery at $55 \mathrm{~mm}$ (ascending aorta) or 55 to $60 \mathrm{~mm}$ (descending thoracic aorta, depending on the eligibility for an endovascular approach) $(4,5,19)$. More frequent surveillance imaging and lower surgical cut-offs apply to patients with connective tissue diseases (such as Marfan syndrome), who are at increased risk for negative outcomes(5). In these patients, surgery is indicated at diameters $\geq 50 \mathrm{~mm}$, or even $\geq 45 \mathrm{~mm}$ in the co-presence of additional risk factors (growth rate $>3 \mathrm{~mm} /$ year, familial history of dissection, or severe valvular regurgitation). Patients with bicuspid aortic valve (BAV) and concomitant risk factors are also considered for surgery at a lower than normal threshold $(\geq 50 \mathrm{~mm})$, although evidence for this approach is lacking $(4,5,20)$. Admittedly, BAV is overrepresented in large dissection

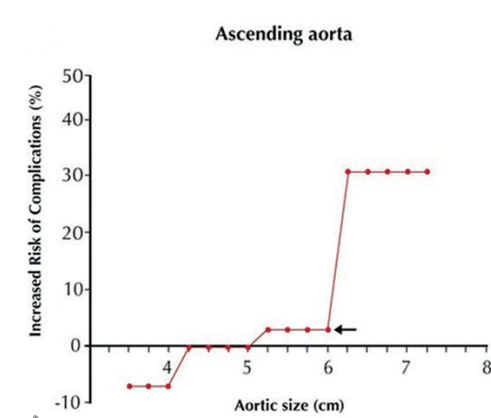

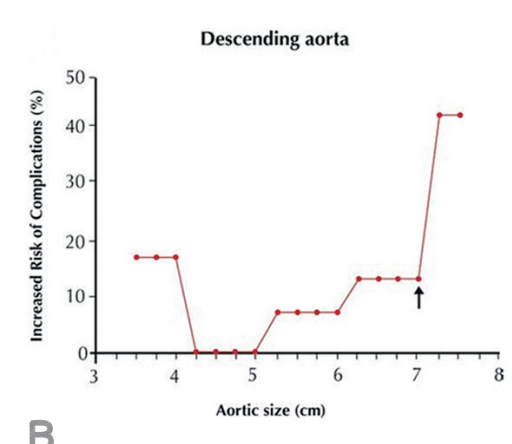

Figure 2. Lifetime probability of dissection or rupture at various sizes of the thoracic aorta. Note the 'hinge points' at $6 \mathrm{~cm}$ (ascending aorta) and $7 \mathrm{~cm}$ (descending thoracic aorta), at which the natural complication risk suddenly escalates. Reprinted, with permission, from Elefteriades et al., J Am Coll Cardiol 20 10;55(9):841-57.

cohorts, but the higher number of aortic events in this patient group cannot be seen independent from its increased TAA prevalence (I7, 2I). At any given TAA diameter, the yearly aortic complication risk for bicuspid and tricuspid valves has shown to be comparable(22).

\section{Aortic size paradox}

Despite the evident link between TAA formation and unfavorable outcomes, the vast majority of dissections occur in aortas with diameters below the threshold for preventative surgery - the so-called 'aortic size paradox'. Retrospective studies have shown that only $30-41 \%$ of patients with type $A$ and $18 \%$ of patients with type B dissection had diameters $\geq 5.5 \mathrm{~cm}$ at the time of presentation(23-26). Since the aorta dilates by about one-third of its size directly after dissection onset, the number of events that could have been prevented by current diameter cut-offs is probably even lower(27-29). Nevertheless, it is questionable if lowering the thresholds for surgical intervention would bear a long-term mortality benefit. Given the large population at risk, it would more likely expose a considerable number of patients with smaller TAAs - and thus, minimal yearly risk of natural complications - to the $3.7-8.3 \%$ mortality risk associated with elective surgery $(30)$. In conclusion, it could be stated that the aortic diameter predicts rupture and dissection on a populational level, but is an insufficient parameter to identify individuals at risk. For this reason, recent research interests have shifted to the deciphering of additional risk factors for AAS, in an attempt to enhance personalized risk assessment and clinical decision-making.

\section{MODERN PERSPECTIVES - MOVING BEYOND DIAMETERS}

\section{Aortic elongation and volume}

One drawback of maximal diameter measurements is that they do not adequately represent the three-dimensional process of aortic growth. Aneurysm lengthening and cylindrical deformation are two scenarios of positive remodeling that are not necessarily accompanied by an increase of maximal diameters(3I). Since more advanced acquisition and post-processing techniques are required to assess the three-dimensional geometry of the aorta, data on its length and volume is relatively scarce. Similar to its diameters, norma aortic length has shown to increase with age $(32,33)$. With the vessel being confined within the thoracic cavity, this lengthening process 


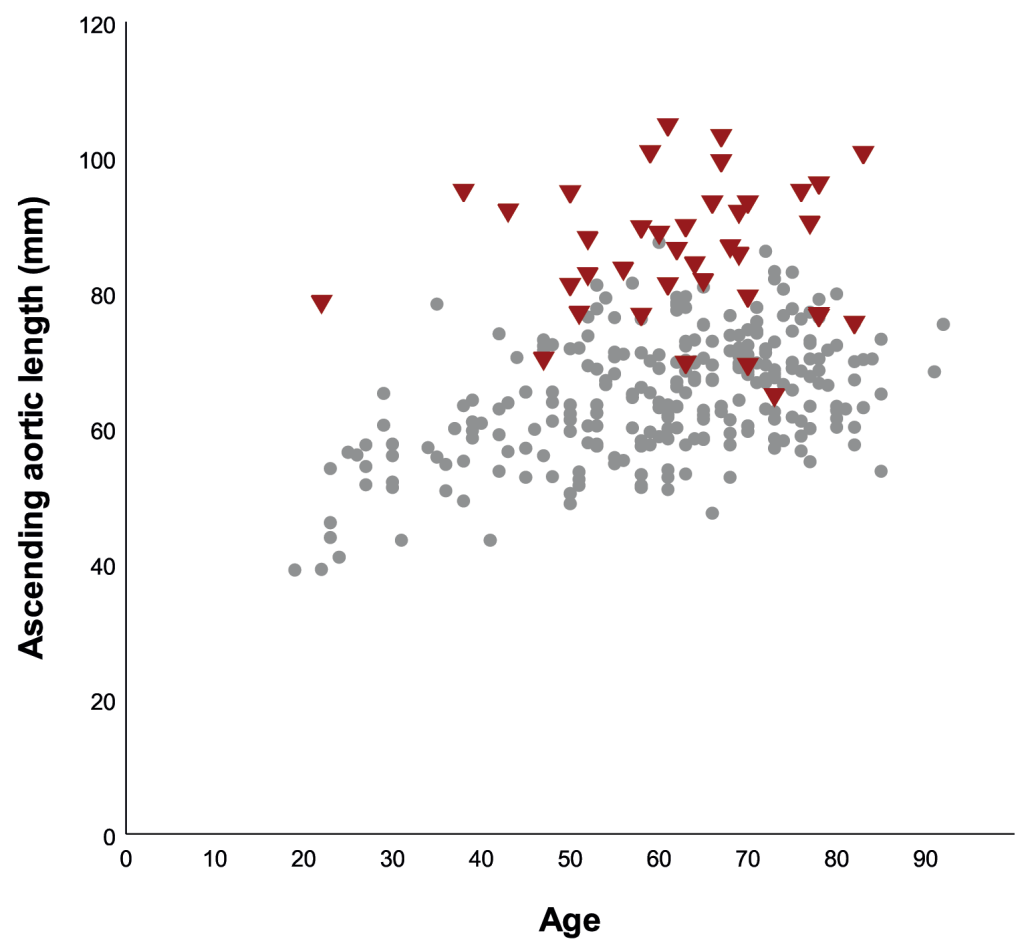

Figure 3. Scatter plot depicting the length of the ascending aorta in patients with acute type A dissection (red) and healthy controls (grey). In the majority of dissection patients, the aorta was evidently lengthened (mean difference of $2.0 \mathrm{~cm}$ when compared to propensity-matched healthy controls).

naturally causes the artery to become more tortuous(32). Driven by observations that the intimal entry tear runs in the transverse direction in the majority of cases (i.e., results from disruptive stretch in the longitudinal direction), recent studies have investigated the role of excessive elongation in the pathophysiology of dissection $(34,35)$.

They found that increased vessel curvature significantly elevates the forces acting on the aortic wall and that vessel length serves as independent risk factor for the occurrence of both type $A$ and type $B$ dissection (Figure 3)(36-39).

To date, the added value of volume measurements in the management of thoracic aortic disease is not fully understood. Several AAA studies have suggested improved sensitivity for detection of aneurysm growth by reporting that substantial volume expansion can occur even while the maximal diameter remains stable(40-43). This finding is important, since it implicates (rapid) growth in regions proximally or distally from the widest portion of the aneurysm sac. Volumetry has also shown improved intra- and interobserver variability when compared to diameter measurements, which is another argument in favor of its use in clinical aneurysm follow-up(44). Although no causal link with adverse outcomes has yet been established, the cited studies have demonstrated that aortic length and volume can be measured on routinely obtained CT using commercially available software packages. This widespread availability makes them feasible predictive parameters for use in a clinical setting, although longitudinal - and, preferably, prospective - studies are now required as the next step in their validation process.

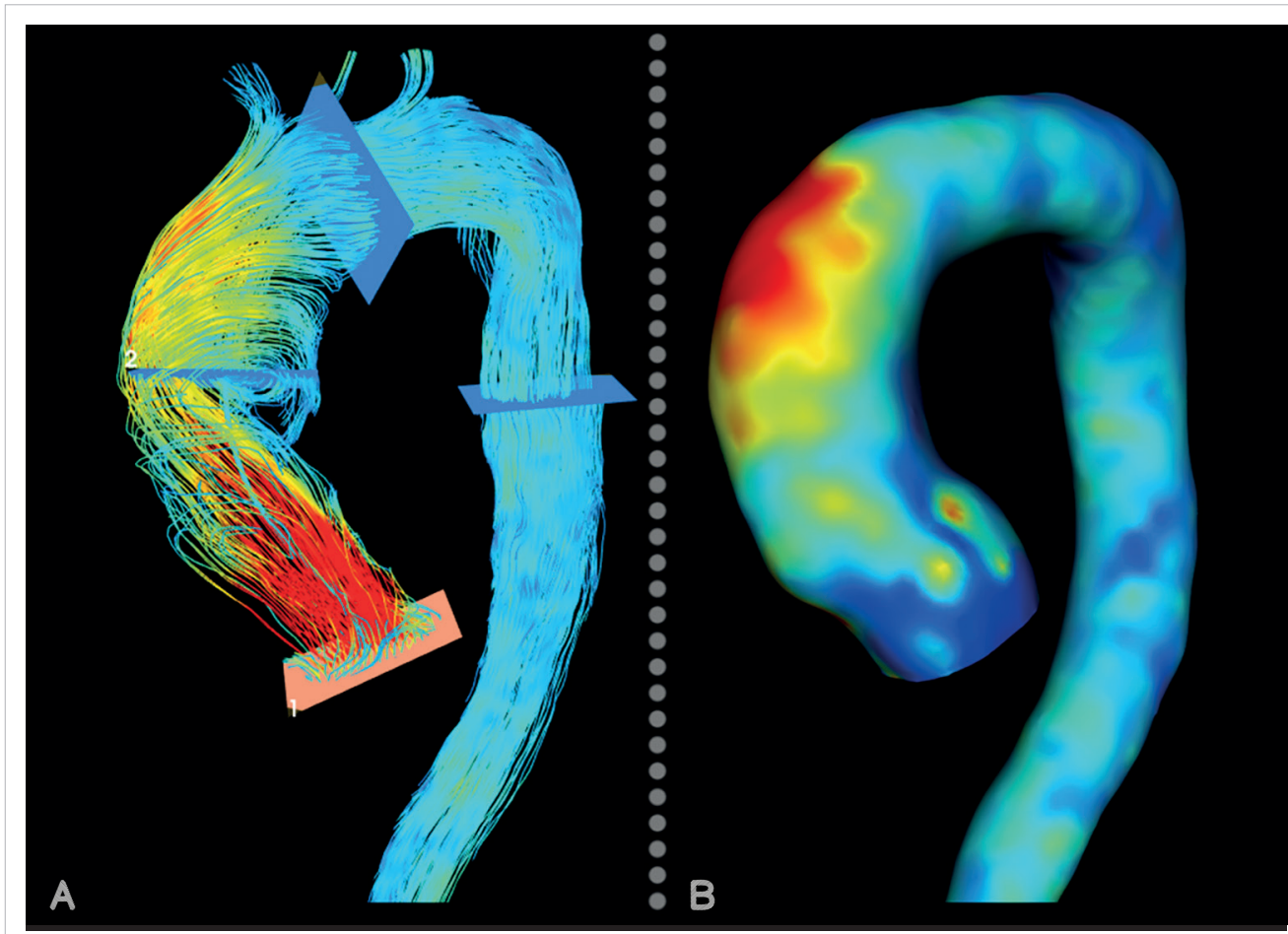

Figure 4. (A) Streamline visualization of a BAV patient, showing a pronounced eccentric and helical flow pattern The adjacent WSS map (B) shows elevated wall stress in the greater curvature of the aorta, at the location of impingement between the eccentric jet and the vessel wall.

\section{Aortic hemodynamics}

The role of hemodynamics in the pathogenesis of aortopathy has been subject of a long-standing debate. Especially in BAV patients, who exhibit enlarged aortic diameters even in the absence of valvular dysfunction, there has been controversy regarding the origin of aneurysm formation(45) Two theories explain the accelerated aortic growth rates and high prevalence of TAA in this patient group: i) a genetic theory, which rests on evidence that BAV is a congenital condition with considerable genetic heterogeneity, and ii) a hemodynamic theory, in which abnormal flow patterns and turbulence cause elevated wall stress and subsequent vessel remodeling(46). Several genes (such as NOTCHI, ACTA2, and GATA5) have been associated with abnormal development of the aortic valve $(46,47)$. Given that the aortic cusps and the medial layer of the ascending aorta are embryologically linked (i.e., both originate from the neural crest), it is conceivable that the genes responsible for BAV formation can also affect the development of the aortic vessel wall. Other arguments in support of the genetic theory include observations that $\mathrm{BAV}$ aortopathy is not uncommon in children and adolescents, and that progressive diameter increase can occur even after replacement of the aortic valve(48, 49). Initially, the histologic presence of cystic medial necrosis was also presented as an argument for disease inheritability, as this was believed to resemble findings in those with Marfan syndrome(50). However, later work has demonstrated that medial degeneration is a common feature of all TAAs and dissected aortas, regardless of their underlying etiology $(15,51)$. 
Over the past few years, the hemodynamic theory has become increasingly popular, along with the evolvement of functional imaging modalities that afford a more comprehensive insight into aortic hemodynamics. In flow MRI, phase-contrast (PC) techniques are used to generat image contrast between moving protons (such as in blood) and stationary protons (most soft tissues). The underlying concept is based on the feature of protons to accumulate an MRI phase shift that is proportional to the speed at which they move along a magnetic gradient field. Phase-contrast MRI is traditionally performed using a manually positioned two-dimensional (2D) acquisition that encodes velocity in one principal direction. This approach generates time-resolved velocity maps, which can be used to quantify flow rates and velocities of blood moving through the imaging slice. As such, it enables evaluation of a broad spectrum of cardiovascular diseases, including assessment of shunt fractions and valvular regurgitant volumes. Over recent years, methodological advances have facilitated the acquisition of time-resolved, three-dimensional, three-directionally encoded velocity data. This technique, commonly known as $4 \mathrm{D}$ flow MRI, affords a uniquely detailed flow visualization within the heart and large vessels and allows post-hoc flow quantification at any location within an acquired volume(52). urthermore, the obtained velocity data can be used for estimation of various flow-derived hemodynamic parameters, including wall shear stress (WSS) and normalized flow displacement. In BAV patients, 4D flow MRI has revealed markedly eccentric and helical flow with highest flow velocities and WSS located along the aortic vessel wall (Figure 4)(53, 54). For each BAV cusp fusion type, a typical WSS distribution pattern with elevated shear stress at the location of impingement between flow jet and vessel wall was identified(55). Subsequently, raphe-specific WSS patterns have shown to correspond with the phenotype of BAV aortopathy (i.e., left-right coronary cusp fusion leads to sole dilatation of the tubular ascending aorta, whereas a raphe between the right- and non-coronary cusps causes more diffuse dilatation with involvement of the aortic root, tubular ascending aorta and aortic arch)(56, 57). In a recent contribution, Guzzardi et al. have also demonstrated a more direct association between WSS and histologic changes of the aortic vessel wall(58). In their study, BAV patients who were scheduled for ascending aortic replacement underwent pre-operative WSS mapping. During surgery, paired tissue samples of aortic regions with normal and elevated WSS were collected to show that increased WSS was associated with dysregulation of the extracellular matrix and degeneration of elastin fibers (Figure 5).

Flow displacement is another 4D flow MRI parameter that has shown potential to predic progression of aortic disease. It provides a quantitative measure of flow eccentricity by calculatin the distance between the location of peak systolic flow and vessel center in a 2D imaging plane(59). Like WSS, the degree and direction of flow displacement depend on the underlying aortic valve phenotype(56). As yet, it is the only 4D flow MRI parameter that has been associated with aortic growth in a (small) longitudinal cohort study. In this study (mean follow-up duration: over 4 years) BAV patients with eccentric aortic flow exhibited faster diameter growth than those with laminar flow profiles ( $1.2 \mathrm{~mm} /$ year vs. $0.3 \mathrm{~mm} /$ year, respectively)(60). Larger longitudinal studies that aim to acquire the clinical relevance of various 4D flow MRI parameters are currently ongoing.
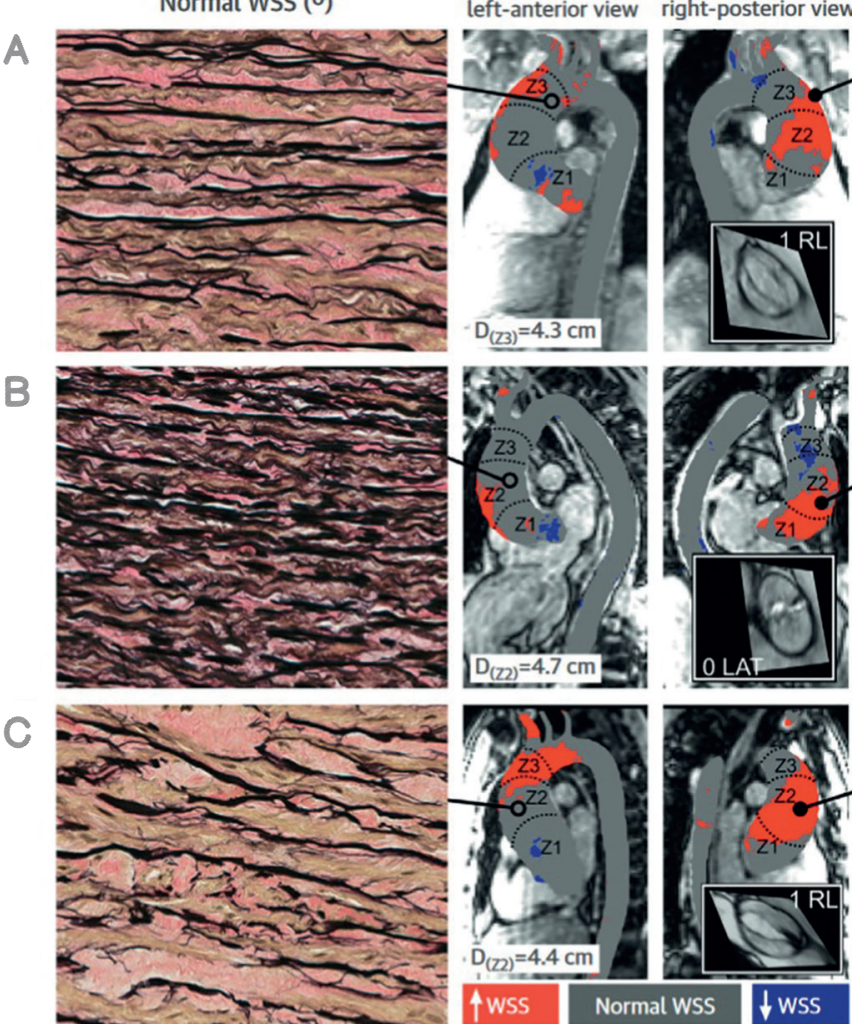

12

(a) $(a, b, c)$ patients with BAV aortopathy (40x magnification). Note the decreased number of elastin fibers (black) in the context of elevated WSS. Center panel: 4D flow MRI-based maps depicting areas with increased (red) and depressed (ble) WSS. Reprinted with permission from Gazzord et ab Valve-related hemodynanics m human bicuspid aortopahy. J Am Coll Cardiol 2015:66:892-900.

Vessel wall inflammation

Immunohistochemical studies have reported extensive inflammatory activity within the aneurysmatic vessel wall(I5). Whereas the presence of lymphocytes and activated macrophages is rare in the healthy aorta, elevated numbers of $\mathrm{CD}^{+}$and $\mathrm{CD} 68^{+}$cells were found throughout the medial layer of TAAs(5I). Of note, infiltration of these cells has shown to be even more pronounced in the dissected aorta, raising the question whether the degree of inflammation can be used to discriminate between low- and high-risk patients(5I). Since leukocytes demand glucose for their accelerated metabolic processes, areas of increased inflammatory activity can be detected using positron emission tomography (PET). This imaging modality depends on measurements of radioactivity emitted after administration of a radioactive tracer, most commonly the glucose derivative I8-fluoro-2-deoxyglucose (FDG; >95\% of all PET examinations). FDG is transported into cells by glucose transporters and becomes phosphorylated to form FDG-6-phosphate. Unlike glucose-6-phosphate, FDG-6-phosphate is not further metabolized along the glycolytic pathway and becomes trapped within the cell in a concentration that is in 

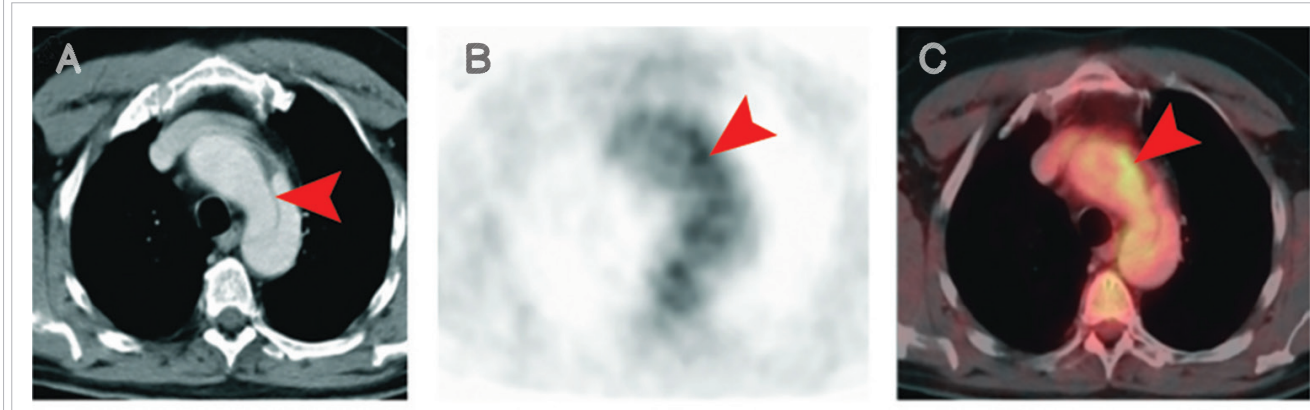

Figure 6. (A) Contrast-enhanced CT depicting type B dissection (arrow) in a patient with acute chest pain. Adjacent PET (B) and PET/CT (C) examinations revealed regions of elevated FDG-uptake in the dissected vessel wall (arrows). Adapted by permission from BMJ Publishing Group Limited, from Kuehl et al., Heart 2008:94:1472-1477.

proportion to that cells' glucose consumption. In animal experiments, FDG avidity has shown to be positively correlated with macrophage content of the arterial vessel wall (61, 62). A similar association has been observed in vivo in patients with abdominal aneurysms $(63,64)$. Furthermore, the AAA study by Reeps et al. reported FDG uptake to be associated with a decrease of collagen content and VSMCs - factors that determine the stability of the aortic wall. However, despite these promising results, studies that sought to investigate the use of FDG-PET for prediction of AAA expansion and rupture have reported conflicting results. Whereas two prospective studies have demonstrated elevated tracer uptake to be associated with disease progression, others could not establish such a relationship(65-70). As yet, only one study has investigated the use of $\mathrm{PET} / \mathrm{CT}$ in thoracic aortic disease. In a small sample of hemodynamically stable patients with various acute aortic conditions (i.e., type B dissection, penetrating ulcer or IMH), this longitudinal study showed increased FDG-uptake to be associated with the risk of disease progression (Figure 6)(7I). Of the eleven included patients with increased FDG uptake, nine (82\%) showed progression of wall pathology under conservative treatment requiring emergency medical intervention, and three of these nine patients died. In contrast, only ten of the twenty-two (45\%) PET-negative patients experienced disease progression (two deaths).

In conclusion, no clear relation between FDG-PET and clinical outcomes in thoracic and abdominal aneurysm patients has yet been demonstrated, although it should be noted that the inconsistency between studies partly relates to their small and heterogeneous study populations. Prospective studies with larger patient cohorts are warranted to assess the actual clinical value of FDG-PET. Also, future work could address the clinical value of novel radiotracers that have shown potential to target other processes within the inflammatory pathway of aneurysmal disease, such as expression of matrix metalloproteases (MMPSense 680), active vascular calcification (I8F-NaF) and chemokine receptor 4 expression (68-Ga-pentixafor)(72-74). The recent integration of PET and MRI into PET/MRI scanners has afforded the synchronized evaluation of anatomic, physiologic and molecular imaging features, and could serve as promising imaging platform in the future.

\section{CONCLUSIONS}

Excessive aortic dilatation (diameter $\geq 5.5 \mathrm{~cm}$ ) poses a significant risk for the occurrence of acute aortic events, and patients with aneurysms beyond this size should be referred for prophylactic surgical intervention. However, the majority of acute aortic events occur in aortas with diameters below surgical thresholds. Therefore, these patients would not have qualified for preventative surgery, even when screened appropriately prior to event onset. Several modern imaging techniques (such as hybrid PET/CT and 4D flow MRI) have shown promise to detect vessel wall instability at an early stage. Studies that aim to demonstrate a causal link with the occurrence of acute aortic syndromes are currently ongoing and could lead to the integration of these techniques into clinical practice guidelines. 


\section{REFERENCES} Howard DP, Banerjee A, Fairhead JF, Perkins I, Silver LE, Rothwell PM. Population-based study of incidence and outcome of acute aortic dissection and pre-morbid riskStudy. Circulation. 2013;21(127(2)):2031-7.

3 Olsson $C$, Thelin $S$, Stähle E, Ekbom A, Granth F Thoracic aortic aneurysm and dissection: increasing prevalence and improved outcomes reported in nationwide population-based study of more than 14000 casesfrom 1987 to 2002. Circulation. 2006; 114 (24):2611-8. 4rbel R, Aboyans V, Boileau C, Bossone E, Di Bartothe diagnosis and treatt, $2014: 35(41): 2873-926$
Cat

5. Hiratzka LF, Bakris GL, Beckman JA, Bersin RM, Carr VF, Casey DE, et al. 2010 ACCF/AHA/AATS/ACR/ASA SCA/SCAI/SIR/STS/SVM guidelines for the diagnosis and management of patients with thoracic aortic disease.

Roman MJ, Devereux RB, Kramer-Fox R, O'Loughlin J. sions in normal children and adults. Am J Cardiol. 1989;64(8):507-12.

Burman ED, Keegan], KilnerPJ. Aortic rootmeasurement by cardiovascular magnetic resonance: specification of normal values. Circ: Cardiovasc Imas 2008: 1 (2): 104-13.

8. Wolak A, Gransar H, Thomson LE, Friedman JD, Hachamovitch R, Gutstein A, et al. Aortic size assessment by limits by age, gender, and body surface area. J Am Coll

Hager A, Kaemmerer H, Rapp-Bernhardt U, Blücher S. Rapp K, Bernhardt TM, et al. Diameters of the thoracic aorta throughout life as measured with helical computed tomography.J Thorac Cardiovasc Surg. 2002;123(6):1060-6. 10. Goldstein SA, Evangelista A, Abbara S, Arai A, Asch FM, Badano LP, et al. Multimodality imaging of diseases of the thoracic aorta in adults. from the American Society of Cardiovascular Imaging: endorsed by the Society of Cardiovascular Computed Tomography and Society for Cardiovascular Magnetic Resonance. J Am Soc Echocardiogr. 2015;28(2):119-82.

. Bireley WR, Diniz LO, Groves EM, Dill K, Carroll TJ, Carr JC. Orthogonal measurement of thoracic aorta contrast-enhanced MR angiography I Magn Reson Imaging. 2007;26(6):1480-5.

12. Mendoza DD, Kochar M, Devereux RB, Basson CT, Min JK, Holmes K, et al. Impact of image analysis methodology on diagnostic and surgical classification of patients with thoraci

13. Rudaraknchana N, Bickell C Cheshire N Burfte $N$ Chapman A. Hamady M, et al Variation in maximum diameter measurements of descending thoracic aortic aneurysms using unformatted planes versus images corrected to aortic centerline. Eur J Vasc Endovasc Surg

14. Goldfinger IZ, Halperin JL, Marin ML, Stewart AS, Eagle Am Coll Cardiol. 2014:64(16):1725-39.
15. Guo DC, Papke CL, He R, Milewicz DM. Pathogenesis of minal aortic aneurysms. Ann NY Aca Sci. 2006;1085(1):339-52

16. Davies RR, Goldstein L], Coady MA, Tittle SL, Rizzo JA, Kopf GS, et al. Yearly rupture or dissection rates for horacic aortic aneurysms: simple prediction based on

Kim JB, Spotnitz M, Lindsay ME, MacGillivray TE, moderately dilated ascending aorta. J Am Coll Cardiol. 2016;68(II):1209-19.

18. Elefteriades JA, Farkas EA. Thoracic aortic aneurysm cinically pertinent controversies and uncertainties. J A Riamba $V$ Böckler D, B

Drunkwall J, Cao P, Chiesa R. Coppi G, et al. Management of descending thoracic European Society for Vascular Surgery (ESVS). Eur J Vasc Endovasc Surg. 2017;53(I):4-52.

20. Nishimura RA, Otto CM, Bonow RO, Carabello BA, the management of patients with valvular heart disease: a report of the American College of Cardiology/ American Heart Association Task Force on Practice Guidelines. J Am Coll Cardiol. 2014;63(22)::57-el85.

. Michelena HI, Khanna AD, Mahoney D, Margaryan E, tions in patients with bicuspid aortic valves. JMA 2011;306(10):1104-12.

22. Davies RR, Kaple RK, Mandapati D, Gallo A, Botta DM, Elefteriades JA, et al. Natural history of ascendin aortic aneurysms in the setting of an unreplaced bicuspid

aortic valve. Ann Thorac Surg. 2007;83(4): 1338-44.

MGS, Bavaria JE, et al. Aortic size in , John-Sutto dissection: implications for preventive ascending aortic replacement. Eur J Cardiothorac Surg. 2009;35(6):941-6.

24. Kim EK, Choi SH, Sung K, Kim WS, Choe YH, Oh JK, et al. Aortic diameter predicts acute type $A$ aortic dissection in patients with Marfan syndrome but not patients without Marfan syndrome

Evangelista A, et al. Aortic EM, Oh JK, O'Gara PT, good predictor of Type A aortic dissection observation from the International Registry of Acute Aortic

Trimarchi S Jonker FH, Hutchison S, Is

Trimarchi S, Jonker FH, Hutchison S, Isselbacher EM, Pape
LA Patel , et al. Descending aortic diameter of $5.5 \mathrm{~cm}$. greater is not an accurate predictor of acute type $B$ aortic dissection. J Thorac Cardiovasc Surg 2011; 142(3):el0 I-7.

77. Rylski B, Blanke P, Beyersdorf F, Desai ND, Milewsk RK, Siepe M, et al. How does the ascending aorta geometry change when it dissects? J Am Coll Cardio

28. Rylski B, Branchetti E, Bavaria JE, Vallabhajosyula P, Szeto WY, Milewski RK, et al. Modeling of predissection aortic size in acute type $\mathrm{A}$ dissection: more than $90 \%$ fail to Thorac Cardiovasc Surg. 2014;148(3):944-8. el.

29. Mansour AM, Peterss S, Zafar MA, Rizzo JA, Fang H Charilaou P, et al. Prevention of aortic dissectio for intervention. Cardiology. 2018;139(3):139-46.
30. Gazoni LM, Speir AM, Kron IL, Fonner E, Crosby IK. lective thoracic aortic aneurysm surgery: better outcomes from high
2010;210(5):855-9.

31. Martufi G, Auer M, Roy J, Swedenborg J, Sakalihasan N, Panuccio $G$, et al. Multidimensional growth measurements of abdominal aortic aneurysms. J Vasc Surg. 2013;58(3):748-55. 32. Adriaans BP, Heuts S, Gerretsen S, Cheriex EC, Vos R. Natour E, et al. Aortic elongation part I: the norm

3. Sugawaral. HayashiK YokoiT Tanaka H A e-associa elongation of the ascending aorta in adults. $\mathrm{Am} \mathrm{Coll}$ Cardiol Img. 2008; (6):739-48.

34. O'Rourke M, Farnsworth A, O'Rourke J. Aortic Dimensions and Stiffness in Normal Adults. I Am Coll Cardio

Img. 2008; (6):749-51.
3. Hirst AE, John VJ, Kime SW. Dissecting aneurysm of the Poullis MP, Warwick R, O० A, Poole RJ. Ascending aortic curvature as an independent risk factor for type $A$ mathematical model. Eur J Cardiothorac Surg.

37. Heuts S, Adriaans BP, Gerretsen S, Natour E, Vos R, Cheriex EC, et al. Aortic elongation part II: the risk of

8. Krüger T, Oikonomou A, Schibilsky D, Lescan M, Brege $K$, Vöhringer $L$, et al. Aortic elongation and the risk for dissection: the Tubingen Aortic Pathoanatomy (TAIPAN)

project. Eur J Cardiothorac Surg. 2017;51(6):I119-26.

$H$, Blumenstock $G$ et al. Aortic Elongation and Stanford B Dissection: The Tübingen Aortic Pathoanatomy (TAIPAN) Project. Eur J Vasc Endovasc Surg. 2017;54(2):164-9.

40. Renapurkar RD, Setser RM, O'Donnell TP, Egger J,
Lieber ML, Desai MY, et al. Aortic volume as an indicator Lieber ML, Desai MY, et al. Aortic volume as an indicato of disease progression eatlonts 2012:81(2)

41. Kauffmann C, Tang A, Therasse É, Giroux M-F, Elkouri S, Melanson $P$, et al. Measurements and detection of abdominal aortic aneurysm growth: accuracy and reproducibility of a segmentation software. European journa of radiology. 2012,81(8):1688-94.

42. Liliegvist ML, Hulgren R, Gasser TC, Roy J. Volume baseline volume and increasing finite element analysis derived rupture risk.J Vasc Surg. 2016;63(6):1434-42 e3. 3. den Hartog AW, Franken R, de Witte P, Radonic T, Marquering HA, van der Steen WE, et al. Aortic disease in patients with Marfan syndrome: aortic volume

44. Trinh B. Dubin I Rahman O. Botelho MPF, Naro N Carr IC, et al. Aortic Volumetry at Contrast-enhanced MR Angiography: Feasibility as a Sensitive Method for Monitoring Bicuspid Aortic Valve Aortopathy. Investi-

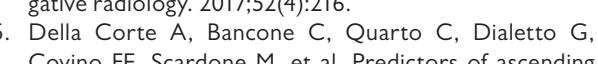
Covino $\mathrm{FE}$, Scardone $\mathrm{M}$, et al. Predictors of ascending spectrum of disease expression. Eur $\rfloor$ Cardiothorac Surg. 2007;31 (3):397-405.

46. Siu SC, Silversides CK. Bicuspid aortic valve disease. JAm Coll Cardiol. 2010;55(25):2789-800

R, King IN, ent Muthe valve disease. Nature. 2005:437(7056):270.
48. Gurvitz M, Chang R-K, Drant S, Allada V. Frequency of ortic root dilation in children with a bicuspid aortic

ta-Kuroda Y, Bando , Kobayashi J, et al. Failure to prevent progressive dilation . wich

. Nalve. Circulation. 2003; I08 (IO supp I):II-29I-II-4.

Nagata $M$, et al. Abnormal extracellutar matrix prer transport associated with increased apoptosis of vascular smooth muscle cells in Marfan syndrome and bicuspid aortic valve thoracic aortic aneurysm. Circulation. 2003;108(10 supp I):II-329-|I-34.

He R, Guo D-C, Estrera AL, Safi HJ, Huynh TT, Yin Z, et al. Characterization of the inflammatory and apoptotic Surtic aneurysms and dissections. I Thorac Cardiovasc Surg. 2006; $|3|(3): 67 \mid-8$.

52. Markl M, Frydrychowicz A, Kozerke S, Hope M, Wiebe O.4D flow MRI.JMagn Resonlmaging. 2012;36(5):1015-36. Barker AJ, Mark M, BurkJ, Lorenz R, Bock J, Bauer S, et . Bicuspid aortic valve is associated with altered wal mag. 2012:5(4):457-66.

Hope MD, Hope TA, Crook SE, Ordovas KG, Urbania TH, Alley MT, et al. 4D flow CMR in assessment of valve related ascending aortic disease. J Am Coll Cardiol Img

55. Bissell MM, Hess AT, Biasiolli L, Glaze SJ, Loudon M, Pitcher

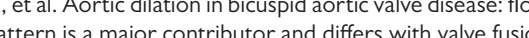
type. Circ: Cardiovasc Imag. 2013;6(4):499-507.

56. Mahadevia R, Barker AJ, Schnell S, Entezari P, Kansal Fedak PW, et al. Bicuspid aortic cusp fusion morphology alters aortic three-dimensional outflow patterns, wa shear stress, and expression 0

KangJ-W, Song HG, Yang DH, Baek S, Kim D-H, Song J-M, . Association between bicuspid aortic valve phenotype patterns of valvular dysfunction and bicuspid echocardiography. J Am Coll Cardiol Img. 2013;6(2): I50-6

Puzthumana IJ, Belke DD, et al. Valve-related heme SC, namics mediate human bicuspid aortopathy: insights from wall shear stress mapping. I Am Coll Cardiol. 2015;66(8):892-900.

59. Sigovan M, Hope MD, Dyverfeldt P, Saloner D. Companon of four $M D, D$ Dronal llow parameters for Magn Reson I

60. Hope MD, Sigovan M, Wrenn SI, Saloner D, Dyverfeldt P. MRI hemodynamic markers of progressive bicuspid aortic valve-related aortic disease. J Magn Reson Imaging. 2014:40(I):140-5.

61. Tawakol A, Migrino RQ, Hoffmann U, Abbara S, Houser of vascular inflammation with $\mathrm{F}-18$ fluorodeoxyglucose positron emission tomography, I Nucl Cardio. 2005; 12(3):294-301.

62. Hyafil F, Cornily J-C, Rudd JH, Machac J, Feldman L, ayad ZA. Quantification of inflammation within rabbit CT contrast agent Nu177: a come macrophage-specific PET/CT and histology-J Nucl Med. 2009:50(6):947-53.

Predictive imaging for thoracic aortic dissection and rupture 
63. Reeps C, Essler M, Pelisek J, Seidl S, Eckstein H-H, Krause B-J. Increased I8F-fluorodeoxyglucose uptake in computed tootic aneurysms in positron emission/ aortic wall instability and acute symptoms. | Vasc Surg. 2008;48(2):417-23.

64. Courtois A, Nusgens BV, Hustinx R, Namur G, Gomez P, Somja J, et al. I8F-FDG uptake assessed by PET/CT in abdominal aortic aneurysms is associated with cellular .

Gomez P, Seidel L, et al. Multifactorial relationship between I8F-fluoro-deoxy-glucose positron emission tomography signaling and biomechanical properties in 2014:7(1):82-91. Sakalihasan $\mathrm{N}$,

CM Nusgens B, Damme H, Gomez P, Rigo P, Lapier (PET) evaluation of abdominal aortic aneurysm (AAA). Eur J Vasc Endovasc Surg. 2002;23(5):431-6.

67. Kotze CW, Groves AM, Menezes LI, Harvey R, Endozo R, Kayani IA, et al. What is the relationship between (I)(8) growthrate? Eur|NuclMed Mollmaging. 2011:38(8): $1493-9$.

6. Barwick TD, Lyons OT, Mikhaeel NG, Waltham M. O'Doherty MJ. I8F-FDG PET-CT uptake is a feature of both normal diameter and aneurysmal aortic wall and is not related to aneurysm size. Eur I Nucl Med Mo

69. Morel O, Mandry D, Micard E, Kauffmann C, Lamiral Z, Verger A, et al. Evidence of Cyclic Changes in the MetabPhases: (I)(8)F-FDG PET Sequential Observational Study. J Nucl Med. 2015;56(7):1030-5.

70. Jalalzadeh $H$, Indrakusuma R, Planken RN, Legemate DA, Koelemay MJ, Balm R. Inflammation as a Predictor Systematic Review of Imaging Biomarkers. Eur I Vase Endovasc Surg. 2016;52(3):333-42.

71. Kuehl H, Eggebrecht H, Boes T, Antoch G, Rosenbaum S, Ladd S, et al. Detection of inflammation in patients With acute aortic syndrome. Comparison of FDG-PET/ Heart. 2008;94(II): 1472-7.

72. Forsythe RO, Dweck MR, McBride OMB, Vesey AT, Semple SI, Shah ASV, et al. (18)F-Sodium Fluoride Uptake in Abdominal Aortic Aneurysms: The SoFIA(3)

Study. J Am Coll Cardiol. 2018;71(5):513-23.
Michineau S, Franck G, Wagner-Ballon O, Dai J, Allaire E,

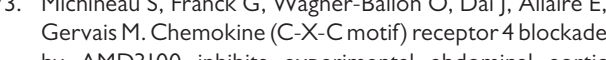
by AMD3100 inhibits experimental abdominal aortic aneurysm expansion through anti-inflammatory effecics.

Arterioscler Thromb Vasc Biol. 2014:34(8):1747-55.

74. Kaijzel EL, van Heijningen PM, Wielopolski PA, Vermeij
M, Koning GA, van Cappellen WA, et al. Multimodality imaging reveals a gradual increase in matrix metallopromice. Circ Cardiovasc Imaging 2010:3(5):567-77. 


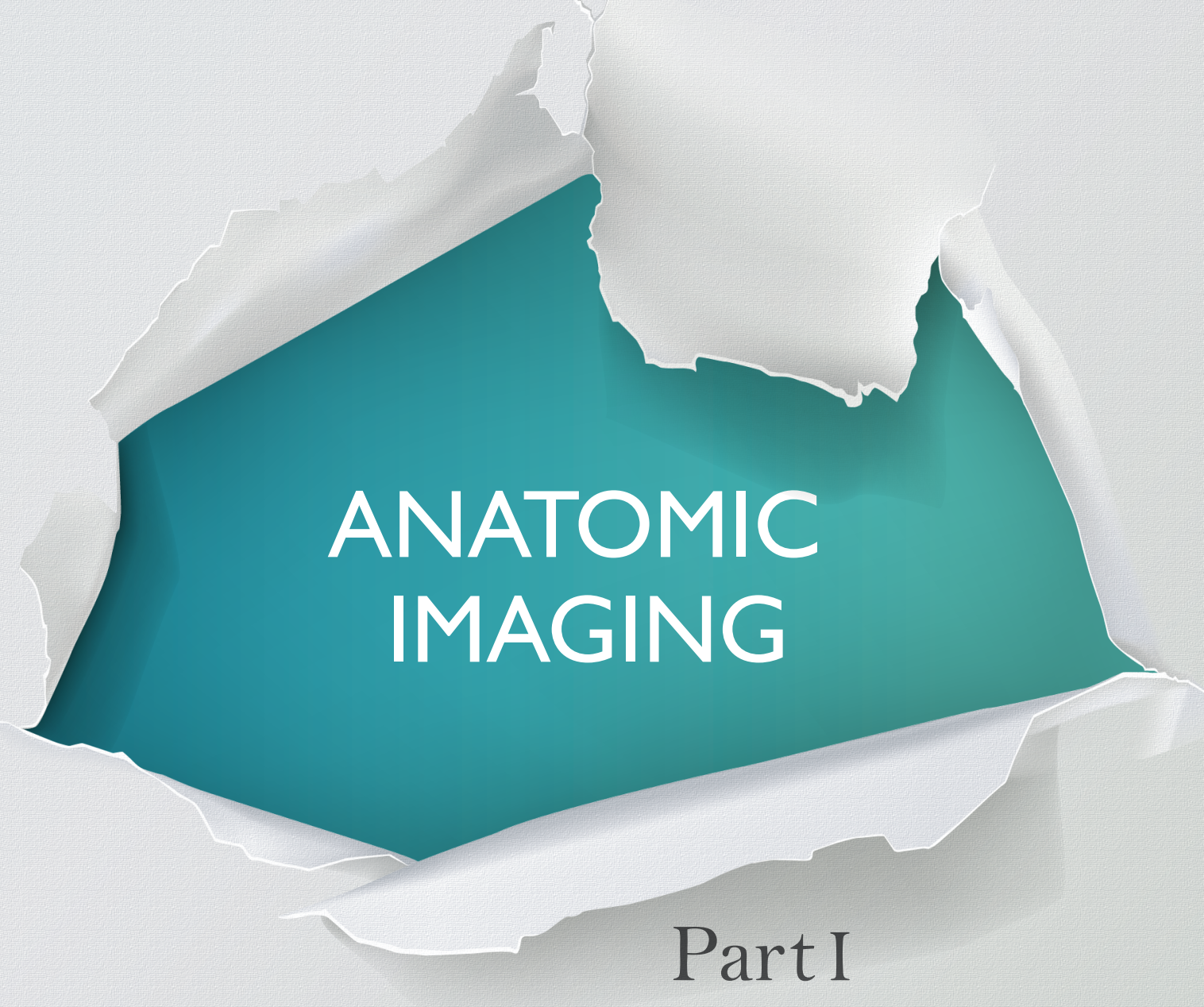




\section{Determining the optimal interval for imaging surveillance of ascending aortic aneurysms}

Bouke P. Adriaans, MD',2,3

Mitch J.F.G. Ramaekers, MD $1,2,3$

Samuel Heuts, MD, PhD ${ }^{3,4}$

Harry J.G.M. Crijns, MD, PhD2,3

Sebastiaan C.A.M. Bekkers, MD, PhD 2,3

Jos J.M. Westenberg, PhD

Jos J.M. Westenberg, PhD
Hildo J. Lamb, MD, PhD

Joachim E. Wildberger, MD, PhD 1,3

Simon Schalla, MD, PhD ${ }^{1,2,3}$

I. Department of Radiology and Nuclear Medicine, Maastricht University Medical Center+, Maastricht, the Netherlands.

2. Department of Cardiology, Maastricht University Medical Centert, the Netherlands.
3. Cardicht the Netherlans.

3. Cardiovascular Research Institute Maastricht (CARIM), Maastricht, the Netherlands.

4. Department of Cardiothoracic Surgery, Maastricht University Medical Center+, Maastricht, the Netherlands.

5. Department of Radiology, Leiden University Medical Center (LUMC), Leiden, the Netherlands.

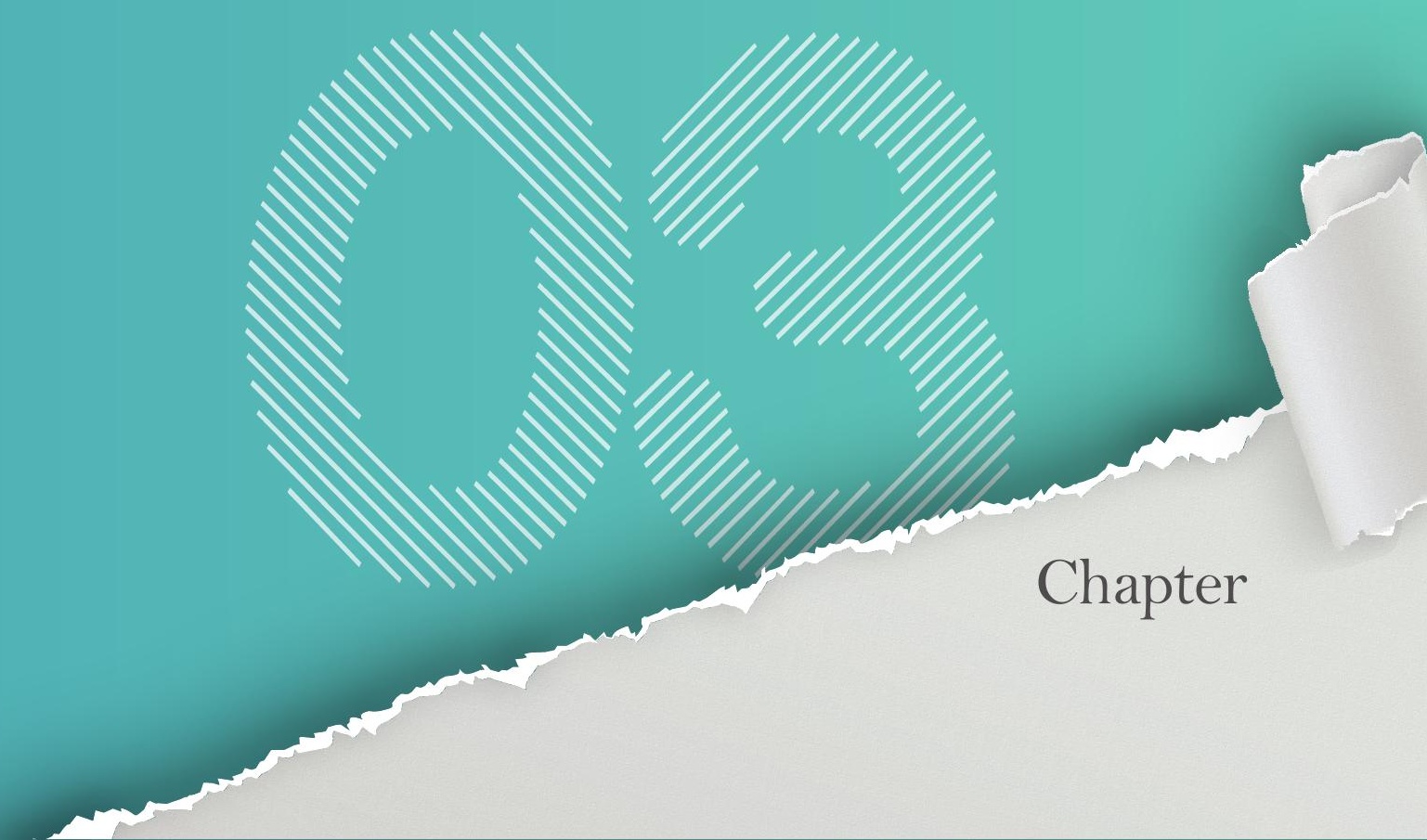




\section{INTRODUCTION}

Acute type $A$ aortic dissection (ATAAD) is a medical emergency that requires immediate surgery to avert fatal outcome. Dissection is commonly precipitated by aneurysm formation, and the risk for ATAAD is known to correlate with the maximal aneurysm diameter(I). This risk is less than $1 \%$ per year in mildly dilated aortas but increases to $6.9 \%$ once the diameter reaches $60 \mathrm{~mm}(2-5)$. To prevent dissection and rupture, prevailing guidelines recommend preventive extirpation of ascending aortic aneurysms $\geq 55 \mathrm{~mm}$ (or $\geq 50 \mathrm{~mm}$ in high-risk patients)(6-II). Patients with smaller aneurysms require serial imaging until the threshold for intervention is reached.

Although indication criteria for prophylactic surgery rely on maximal diameter measurements, the optimal interval for the follow-up of thoracic aortic aneurysms (TAAs) has not been determined. If any, current guidelines propose surveillance protocols that involve (bi)annual computed tomography (CT) or magnetic resonance imaging (MRI) $(6,7)$. However, these proposals are insufficiently backed up by data demonstrating the necessity for such an approach. The current retrospective longitudinal cohort study aims to I. acquire growth rates of TAAs in the context of aortic valve morphology, 2. identify risk factors that predict the need for pre-emptive aortic repair, and 3 . provide patient-specific follow-up intervals. A total of 332 patients with non-syndromic ascending aortic aneurysms were followed
over a median period of 6.7 years. Diameters were assessed using all available imaging techniques (echocardiography, CT and MRI). Growth rates were calculated from the
differences between the first and last examinations. The diagnostic accuracy of follow-up protocols was calculated as the percentage of subjects requiring pre-emptive surgery in whom timely identification would have occurred.

\section{RESULTS}

The mean growth rate in our population was $0.2 \pm 0.4 \mathrm{~mm} /$ year. The highest recorded growth rate was $2.0 \mathrm{~mm} /$ year, while $40.6 \%$ of patients showed no diameter expansion during follow-up. Females exhibited significantly higher growth rates than men $(0.3 \pm 0.5$ vs $0.2 \pm 0.4 \mathrm{~mm} /$ year, $p=0.007$ ). Conversely, a bicuspid aortic valve was not associated with more rapid aortic growth. The optimal imaging protocol comprises triennial imaging of aneurysms $40-49 \mathrm{~mm}$ in diameter and yearly imaging of those measuring $50-54 \mathrm{~mm}$. This strategy is as accurate as annual follow-up, but reduces the number of imaging examinations by $29.9 \%$.

\section{CONCLUSIONS}

In our population of patients with non-syndromic TAAs, we found aneurysm growth rates to be lower than those previously reported. Yearly imaging does not lead to changes in the management of small aneurysms. Thus, lower imaging frequencies might be a good alternative approach.

\section{KEYWORDS}

Aorta; aortic aneurysm; thoracic aortic aneurysm; follow-up; dissection

\section{KEY POINTS}

- Nearly half of ascending aortic aneurysms do not grow over time.

- Female sex and aortic regurgitation predispose to more rapid aortic growth.

- Triennial imaging suffices for aneurysms with diameters between 40-49 mm.

\section{METHODS}

\section{Study population}

We reviewed the clinical database of the Maastricht University Medical Centre (MUMC+) for patients who were referred for TAA evaluation between January 1999 and August 2019. Patients with maximal ascending aortic diameters $>40 \mathrm{~mm}$ at baseline who underwent multiple imaging examinations during follow-up were included. Exclusion criteria comprised prior aortic or valvular surgery and a diagnosis or suspicion of hereditary connective tissue disease. The study protocol was reviewed and approved by the institutional medical ethics committee, who waived the need for informed consent due to the study's retrospective nature.

\section{Data collection and image analysis}

Data collection and image assessment were performed by two readers (B.A., M.R.). Baseline characteristics and medical history were drawn from electronic patient records. Valve morphology and baseline valvular function were determined using transthoracic echocardiography (TTE) and classified according to current guidelines(12, 13).

All TTE, CT angiography, and MRI procedures performed for evaluation of TAA dimensions were assessed to study aortic diameters. Echocardiographic diameters were measured in parasternal long-axis views at end-diastole, using the leading edge-to-leading edge technique. $C T$ and MRI were typically performed using prospective ECG gating with end-diastolic triggering, while measurements were acquired from inner edge to inner edge. For all modalities, care was taken to perform measurements perpendicular to the long axis of the aorta. Mean aneurysm growth rates were calculated by dividing the diameter difference between the first and last imaging examinations by the time interval between the two studies. The primary endpoint was reached when a patient met the indication criterion for pre-emptive surgery. This threshold was set at $\geq 55 \mathrm{~mm}$ (tricuspid aortic valve (TAV) and uncomplicated bicuspid aortic valve (BAV)) or $\geq 50 \mathrm{~mm}$ (BAV with concomitant risk factors (arterial hypertension, aortic coarctation, family history of dissection and/or expansion rate $\geq 3 \mathrm{~mm} /$ year) $)(6,8)$. 


\section{Statistical analysis}

Statistical analyses were performed using SPSS version 24 (IBM SPSS Statistics, Armonk, NY, USA). Continuous variables are presented as mean \pm standard deviation (SD) or median and interquartile range (IQR). The Student $t$-test and Mann-Whitney $U$ test were used for comparison between groups. Categorical variables are given as frequencies and percentages, and were compared using the chi-square test. Logistic regression was performed to identify predictors for reaching the endpoint of prophylactic surgery. For the patients who reached this endpoint, it was calculated - based on mean growth rates - whether a 2-or 3-yearly imaging strategy would have delayed surgery compared to an annual surveillance approach. The diagnostic accuracy of various follow-up protocols was calculated as the percentage of subjects in whom timely identification would have occurred.

\section{RESULTS}

Baseline characteristics

In total, 332 TAA patients (25.3\% female) were included (Table I). Median age was 64.2 years (range 19-86 years). Fifty-seven patients (17.2\%) had BAV. Compared to those with BAV, patients with TAV were older $(65.9$ vs 52.4 years, $p<0.001$ ) and more frequently suffered from hypertension $(76.4 \%$ vs $43.9 \%, p<0.001)$ and hyperlipidaemia $(44.0 \%$ vs $17.5 \%, p<0.001)$. Patients with BAV more often had moderate or severe aortic stenosis at baseline $(28.1 \%$ vs $6.9 \%$, $p<0.00 \mathrm{I})$.

Median follow-up of the entire cohort was 6.7 years (IQR 4.5-10.2 years). During the cumulative follow-up of 2545.4 years, the included patients underwent 2233 imaging examinations (TTE $n=1750, C T n=378$, and MRI $n=105$ ). Mean time between two consecutive measurements was $1.3 \pm 0.7$ years. Of the patients who died during follow-up $(n=23)$, none died of thoracic aortic disease. Two patients suffered dissection and underwent emergency surgery; both had $\mathrm{TAV}$ and diameters $<55 \mathrm{~mm}$ at last follow-up contact (both $<1$ year before dissection onset).

Table I. Baseline characteristics of the study population

\begin{tabular}{|l|l|l|l|}
\hline & $\begin{array}{l}\text { TAV } \\
(\mathrm{n}=275)\end{array}$ & $\begin{array}{l}\text { BAV } \\
(\mathrm{n}=57)\end{array}$ & p-value \\
\hline Age (years) & $65.9(58.4-71.7)$ & $52.4(42.4-59.8)$ & $<\mathbf{0 . 0 0 I}$ \\
\hline Sex (female) & $65(23.6 \%)$ & $19(33.3 \%)$ & 0.125 \\
\hline Height $(\mathbf{c m})$ & $174.8 \pm 8.6$ & $177.2 \pm 9.6$ & 0.07 \\
\hline Weight $(\mathbf{k g})$ & $81.8 \pm 14.8$ & $83.6 \pm 14.8$ & 0.39 \\
\hline BMI $\left(\mathbf{k g} / \mathbf{m}^{2}\right)$ & $26.6 \pm 3.9$ & $26.6 \pm 4.1$ & 0.94 \\
\hline BSA $\left(\mathbf{m}^{2}\right)$ & $2.0 \pm 0.2$ & $2.0 \pm 0.2$ & 0.19 \\
\hline Hypertension & $210(76.4 \%)$ & $25(43.9 \%)$ & $<\mathbf{0 . 0 0 1}$ \\
\hline Dyslipidemia & $121(44.0 \%)$ & $10(17.5 \%)$ & $<\mathbf{0 . 0 0 1}$ \\
\hline Diabetes & $15(5.5 \%)$ & $3(5.3 \%)$ & 0.95 \\
\hline AS $\geq$ moderate & $19(6.9 \%)$ & $16(28.1 \%)$ & $<\mathbf{0 . 0 0 1}$ \\
\hline AR $\geq$ moderate & $27(9.8 \%)$ & $9(15.8 \%)$ & 0.19 \\
\hline
\end{tabular}

Table I. (continued)

\begin{tabular}{l|l|l|l}
\hline CABG & $\begin{array}{l}\text { TAV } \\
(\mathrm{n}=275)\end{array}$ & $\begin{array}{l}\text { BAV } \\
(\mathrm{n}=57)\end{array}$ & -value \\
\hline CVA/TIA & $25(9.1 \%)$ & $\mathrm{I}(1.8 \%)$ & 0.06 \\
\hline Malignancy & $35(12.7 \%)$ & $6(10.5 \%)$ & 0.65 \\
\hline Haemodialysis & $33(12.0 \%)$ & $6(10.5 \%)$ & 0.75 \\
\hline
\end{tabular}

Values are mean $\pm S D$ or median (interquartile range).

BMI: body mass index; BSA: Body Surface Area; AS: aortic stenosis; AR: aortic regurgitation; CABG: coronary artery bypass graft; CVA: cerebrovascular accident; SD: standard deviation: TIA: transient ischemic attack.

\section{Aneurysm growth}

The growth rates of the entire population were $0.14 \mathrm{~mm} /$ year (median) and $0.2 \pm 0.4 \mathrm{~mm} /$ year (mean and SD). The largest observed growth rate was $2.0 \mathrm{~mm} /$ year, while $40.6 \%$ of patients showed no diameter increase between baseline and last follow-up (Figure. I). Mean expansion rates were comparable between TAV and BAV $(0.2 \pm 0.4 \mathrm{~mm} /$ year vs $0.2 \pm 0.3 \mathrm{~mm} /$ year, $p=0.819$ ) (Figure. 2). Women had greater expansion rates than men $(0.3 \pm 0.5 \mathrm{vs} 0.2 \pm 0.4 \mathrm{~mm}$ year, $p=0.007)$. At multivariable regression analysis, female sex and presence of at least moderate aortic regurgitation (AR) at baseline were shown to be independent predictors for more rapid aneurysm expansion (Table 2). In contrast, the presence of a BAV was not associated with higher growth rates.

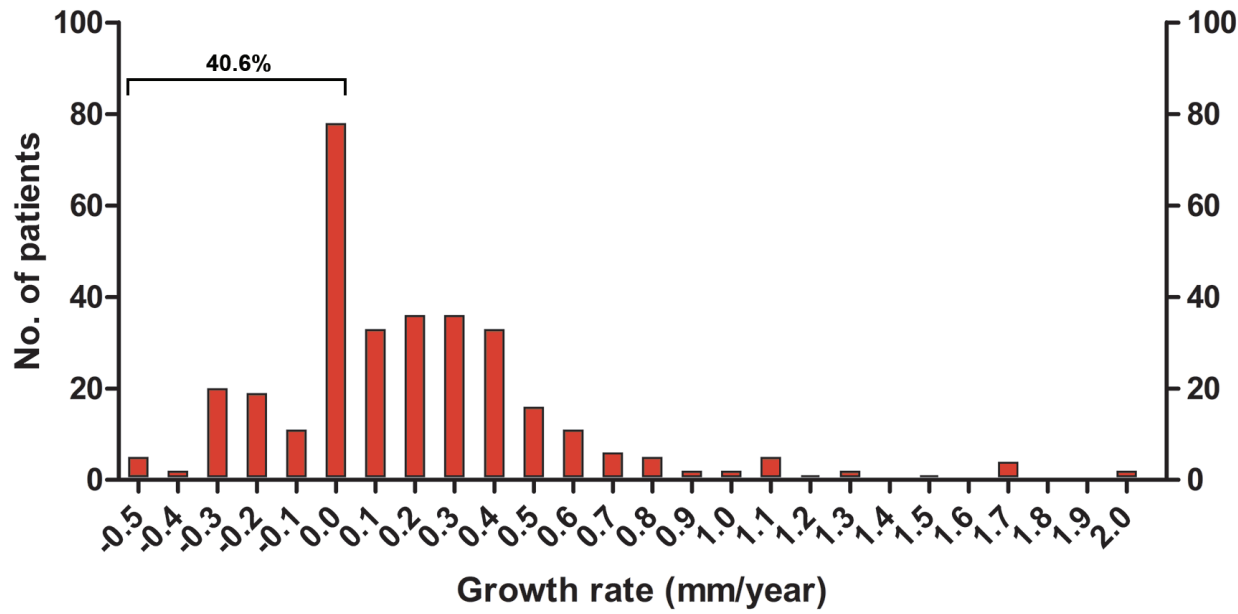

Figure. I Histogram showing the distribution of mean growth rates among patients with thoracic aortic aneurysms. As depicted, the majority of aneurysms remain stable or grow only minimally over time. 


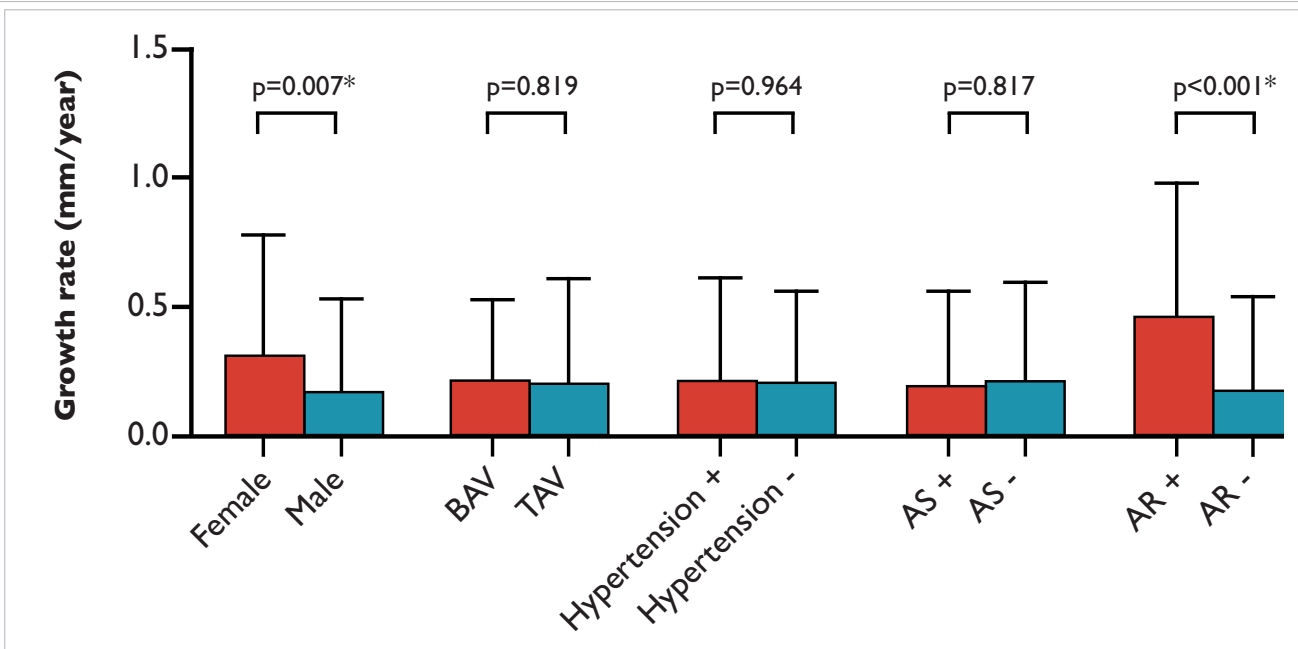

Figure. 2 Bar charts showing mean growth rates of ascending aortic aneurysms as a function of sex, valve type hypertension, and valvular function. Female sex and presence of more than moderate aortic regurgitation (AR) were associated with higher thoracic aortic aneurysm growth rates. AS aortic stenosis, BAV bicuspid aortic valve, TAV tricuspid aortic valve; *statistically significant.

Table 2. Univariable and multivariable regression analysis showing predictors for aortic growth.

\begin{tabular}{|l|l|l|l|l|}
\hline & Univariable & Multivariable & \\
\hline & B & P-value & B & P-value \\
\hline Age (years) & -0.003 & 0.108 & & \\
\hline Sex (female) & 0.134 & $\mathbf{0 . 0 0 7}$ & 2.142 & $\mathbf{0 . 0 3 3}$ \\
\hline Hypertension & 0.002 & 0.964 & & \\
\hline Dyslipidemia & 0.030 & 0.492 & & \\
\hline $\begin{array}{l}\text { Valve morphology } \\
\text { (tricuspid) }\end{array}$ & 0.013 & 0.819 & & \\
\hline AS $\geq$ moderate & -0.016 & 0.817 & & \\
\hline AR $\geq$ moderate & 0.270 & $<\mathbf{0 . 0 0 1}$ & 3.987 & $<\mathbf{0 . 0 0 1}$ \\
\hline Baseline diameter $\mathbf{( m m )}$ & -0.011 & 0.118 & & \\
\hline
\end{tabular}

AR: aortic regurgitation; AS: aortic stenosis.

\section{Surgical repair}

During follow-up, 24 patients (7.2\%) reached the indication criterion for pre-emptive surgery Among those were $9 \mathrm{BAV}$ patients, who all had concomitant risk factors and were referred for aneurysmectomy at a diameter of $\geq 50 \mathrm{~mm}$. Logistic regression revealed baseline diameter growth rate, and the predetermined interventional threshold to be independent predictors of reaching the primary endpoint (Table 3).
Table 3. Univariable and multivariable logistic regression analysis showing predictors for reaching the threshold for prophylactic aortic repair.

\begin{tabular}{|l|l|l|l|l|}
\hline & Univariable & Multivariable \\
\hline Age (years) & B & P-value & B & P-value \\
\hline Sex (male) & -0.031 & $\mathbf{0 . 0 4 6}$ & 0.024 & 0.578 \\
\hline Hypertension & 0.623 & 0.159 & & \\
\hline Dyslipidemia & 0.003 & 0.996 & & \\
\hline AS $\geq$ moderate & -0.089 & 0.839 & & \\
\hline AR $\geq$ moderate & 0.891 & 0.098 & & \\
\hline Surgical threshold $(\mathbf{2 5 5} \mathbf{m m})$ & 1.609 & $\mathbf{0 . 0 0 1}$ & 2.432 & 0.080 \\
\hline Baseline diameter $(\mathbf{m m})$ & 0.302 & $\mathbf{0 . 0 0 9}$ & -5.610 & $\mathbf{0 . 0 0 4}$ \\
\hline Growth rate $(\mathbf{m m} / \mathbf{y e a r})$ & 3.992 & $<\mathbf{0 . 0 0 1}$ & 1.130 & $<\mathbf{0 . 0 0 1}$ \\
\hline
\end{tabular}

AR: aortic regurgitation; AS: aortic stenosis.

Table 4. Diagnostic accuracy of various imaging strategies.

A. Surgical threshold: $\geq 55 \mathrm{~mm}$

\begin{tabular}{|c|c|c|c|c|c|}
\hline & \multicolumn{3}{|c|}{ Current diameter } & \multirow{2}{*}{ Accuracy } & \multirow{2}{*}{$\begin{array}{l}\text { Reduction of } \\
\text { imaging studies* }\end{array}$} \\
\hline & $40-44 \mathrm{~mm}$ & $45-49 \mathrm{~mm}$ & $50-54 \mathrm{~mm}$ & & \\
\hline Protocol I & Two-yearly & Two-yearly & Annually & $100 \%$ & $17.8 \%$ \\
\hline Protocol 2 & Two-yearly & Two-yearly & Two-yearly & $53.3 \%$ & $43.4 \%$ \\
\hline Protocol 3 & Three-yearly & Two-yearly & Annually & $100 \%$ & $20.6 \%$ \\
\hline Protocol 4 & Three-yearly & Three-yearly & Annually & $100 \%$ & $29.9 \%$ \\
\hline
\end{tabular}

B. Surgical threshold: $\geq 50 \mathrm{~mm}$

\begin{tabular}{|l|l|l|l|l|}
\hline & Current diameter & Accuracy & $\begin{array}{l}\text { Reduction of } \\
\text { imaging studies* }\end{array}$ \\
\cline { 2 - 5 } & $40-44 \mathrm{~mm}$ & $45-49 \mathrm{~mm}$ & $100 \%$ & $8.0 \% \%$ \\
\hline Protocol I & Two-yearly & Annually & $33.3 \%$ & $44.4 \%$ \\
\hline Protocol 2 & Two-yearly & Two-yearly & $100 \%$ & $16.0 \%$ \\
\hline
\end{tabular}

*As compared to a once-yearly strategy. 


\section{Optimal imaging interval}

Various imaging protocols were tested for their accuracy in timely identification of the necessity for pre-emptive aortic repair (Table 4). Lowering imaging frequencies to less than once annually causes delay to surgery in patients in whom the current diameter is within $5 \mathrm{~mm}$ of the surgical threshold. However, imaging intervals can be prolonged safely to once every 3 years, as long as the diameter is between 40 and $44 \mathrm{~mm}$ (BAV with risk factors) or 40-49 mm (uncomplicated BAV and TAV). The implementation of such strategies would have reduced the number of imaging examinations in the study population by $16.0 \%$ and $29.9 \%$, respectively.

\section{DISCUSSION}

Cardiovascular guidelines provide comprehensive recommendations on which patients should be selected for preventive aortic repair. However, the management of asymptomatic non-syndromic TAAs with diameters below interventional cut-offs is less well described. Our main conclusions are: (I) the majority of TAAs remain stable or grow minimally over time, (2) the need for prophylactic surgery is determined by baseline diameter, growth rate, and the predetermined interventional threshold, and (3) 3-yearly imaging follow-up suffices for any aneurysm with a diameter $>5 \mathrm{~mm}$ below the surgical indication criterion.

\section{Aortic growth rates}

Thus far, studies that sought to investigate aneurysm growth rates have yielded divergent results. Our findings concur with those of recent investigations, which have shown that ascending aortic aneurysms expand at slightly higher rates than the normal-sized aorta (i.e. $0.2-0.4 \mathrm{~mm} /$ year vs $0.1 \mathrm{~mm} /$ year)(14-17). As such, average TAA growth rates are markedly lower than previously assumed(I8). Pioneer work from the Yale group, whose studies form the basis for many recommendations within current guidelines, demonstrated an average enlargement of $0.7-1.2$ $\mathrm{mm} /$ year(19). Using serial CT, Hirose et al. even documented growth rates as high as $4.2 \mathrm{~mm}$ year(20). However, these early studies included a substantial number of patients with connective tissue disease and chronic dissections, who were followed over a relatively short period (i.e. 6-19 months). Since short follow-up durations can cause small diameter changes and measurement inaccuracies to become translated into disproportionally high annual growth rates, it is conceivable that the expansion rates reported in these studies are somewhat overestimated. In comparison, a growth rate of $\geq 0.7 \mathrm{~mm} /$ year was observed in only $8.1 \%$ of our patient population.

The current study provides more insight into the individual character of TAA progression. Based on reported mean expansion rates, it has long been thought that all aneurysms grow over time $(8,19)$. However, our results reflect that nearly half of non-syndromic TAAs remain stable in size - even at long-term follow-up. In contrast, a small portion of patients exhibit remarkably high growth rates (up to eight times the mean) and are at risk for reaching the diameter threshold for preventive surgery. Moderate or severe AR at baseline was shown to be the most important risk predictor for rapid growth. The pathophysiological mechanism behind this observation can be regarded as a vicious circle, in which AR causes increase of left ventricular stroke volumes and elevated aortic wall stress, and further aortic dilatation leads to aggravation of AR. Importantly, we have shown that presence of BAV does not confer risk for more rapid aneurysm dilatation. This, and the observation that $\mathrm{BAV}$ is not associated with a higher risk of acute aortic events, may question the lower interventional thresholds that apply to this patient $\operatorname{group}(3,2 \mathrm{I})$.

Our data confirm that female sex is associated with more rapid aneurysm growth(22). Moreover outcome studies have demonstrated that female TAA patients have a three-fold higher risk of experiencing dissection, and a $40 \%$ increase in risk of mortality $(19,23)$. Although the magnitude of sex-based growth differences does not merit a more frequent imaging strategy in women, it prompts deliberation as to why the natural history of aneurysms differs between genders. One theory explains the worse outcome in women by their higher vessel wall concentrations of matrix metalloproteinases (MMPs) - enzymes involved in the degradation of extracellular matrix (ECM) content. Interestingly, aneurysms with more pronounced MMP-2 and MMP-9 expression show more extensive ECM remodelling and decreased compliance(24). Future immunohistochemical and biomechanical studies could evince a causal relation between gender-associated structural differences and the more aggressive TAA behaviour in women.

\section{Implications for imaging}

Current guidelines prescribe referral for preventive surgery based on absolute diameter cut-offs. In addition, the ACC/AHA advocates elective operation of patients who exhibit growth rates $>5$ $\mathrm{mm} /$ year. Assessment of these indications requires adequate imaging surveillance, yet only two out of five available guidelines provide appropriateness criteria to this end. Based on the consensus opinion of experts, these recommend yearly or semi-annual CT or $\operatorname{MRI}(6,7)$ Although others cautiously suggest lowering imaging frequencies in the case of stable disease, no previous study systematically investigated the impact of different follow-up protocols. The results of the current study reveal that yearly imaging carries no therapeutic consequences for patients with small aneurysms. On the contrary, it can add unjustifiable costs to health care and unnecessary exposure to radiation and contrast agent administration. Here, we propose a surveillance strategy that consists of 3-yearly imaging of patients with smaller aneurysms and yearly imaging of those who are in close proximity to their respective surgical thresholds. We conclude that this approach is as accurate as annual follow-up and reduces the number of requested imaging examinations by $29.9 \%$ (TAV) and $16.0 \%$ (BAV with risk factors). It is noteworthy that these percentages have been calculated using data of patients who met the endpoint of prophylactic surgery. The proposed strategy could have reduced imaging frequencies by up to two-thirds in patients with stable diameters.

Although current guidelines primarily depend on maximal diameter cut-offs, it is generally known that ATAAD can also occur in aortas that do not meet criteria for pre-emptive surgical repair(25). Recent studies have investigated the predictive potential of aortic length and volume, and found that these may improve the timely identification of patients at risk $(26,27)$. Furthermore, four-dimensional (4D) flow MRI is emerging as a clinically feasible imaging technique that can further improve selection of patients who may benefit from prophylactic surgery $(28,29)$. Future prospective studies are now needed for these novel imaging markers to find their way into clinical guidelines.

\section{Limitations}

Some limitations of the current study need to be addressed. First, our study population is no representative of patients with connective tissue diseases. These are reported to have higher aortic growth rates, and the proposed imaging intervals should not be extrapolated to this patient group(30). Second, we have only looked into growth rates of ascending aortic aneurysms. Descending thoracic and abdominal aneurysms may expand more rapidly and merit more frequent surveillance imaging. Since we included only patients who underwent imaging at $\geq 2$ different time points, we were not able to adequately evaluate the risk of adverse outcomes. Thirc, diameters were assessed using different imaging modalities. Although leading edge-to-leading edge (TTE) and inner edge-to-inner edge (CT and MRI) measurements closely agree, incongruity between methods may have contributed to inaccuracies in calculated growth rates(3I). Fourth, growth rates were calculated assuming a linear TAA growth pattern. According to Laplace's law, 
wall tension is proportional to the vessel radius for a given blood pressure. Therefore, it has been hypothesised that growth rates become higher as the aorta progressively enlarges(32). However, a previous study with standardised imaging intervals could not confirm this hypothesis and found that growth rates remained steady during follow-up(15). Due to the various time points at which our patients were imaged, we were not able to investigate the relationship between aortic size and growth rate in the current study. Finally, this was a single-centre analysis. Future prospective multicentre studies are needed to confirm our results.

\section{CONCLUSIONS}

Non-syndromic ascending aortic aneurysms grow at lower rates than previously assumed. Reduction of imaging frequency to once every 3 years seems reasonable for asymptomatic patients in whom the ascending aorta is only mildly dilated.

\section{REFERENCES}

Farkas EA. Thoracic aortic aneurysm cinically pertinent controversies and uncertainties. J Am Coll Cardiol. 2010;0;5(9):841-57.
Colitions

2. Coady MA, Rizzo JA, Hammond GL, Mandapati D, Dar $\checkmark$, Kopf GS, et al. What is the appropriate size criterion for resection of thoracic aortic aneurysms? I Thorac

. Kim moderately dilated ascending aorta. J Am Colll Cardiol. 2016;68(II):1209-19.

4. Epperlein S, Mohr-Kahaly S, Erbel R, Kearney P, Meyer J. Aorta and aortic valve morphologies predisposing to aortic dissection. an in vivo assessment with transoesophElefteriades JA. Natural history of thoracic aortic aneurysms: indications for surgery, and surgical versus nonsurgical risks. Ann Thorac Surg 2002;74(5):S1877-80 6. Hiratzka LF, Bakris GL, Beckman JA, Bersin RM, Carr VF, Casey DE, et al. 2010 ACCF/AHA/AATS/ACR/ASA/
SCA/SCAISIR/STS/SVM guidelines for the dis. and manarement of patients with tho for the dicososis IAm Coll Cardiol. 2010;55(14):e27-el29.

7. JCS Joint Working Group. Guidelines for diagnosis and treatment of aortic aneurysm and
201I). Circ I. 2013;77(3):789-828

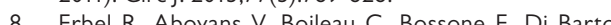
Erbel R, Aboyans V, Boileau C, Bossone E, Di Bartodomeo R, Eggebrecht $H$, et al. 2014 ESC guidelines on the 2014:35(41):2873-926.

9. Boodhwani M, Andelfinger G, Leipsic J, Lindsay T. McMurtry MS, Therrien J, et al. Canadian Cardiovascular Society position statement on the management of
thoracic aortic disease. Can J Cardiol. 2014;30(6):577-89

10. Svensson LG, Adams DH, Bonow RO, Kouchoukos NT. Miller DC, O'Gara PT, et al. Aortic valve and ascending aorta guidelines for management and quality measures. Ann Thorac Surg. 2013;95(6):SI-S66

11. Goldstein SA, Evangelista A, Abbara S, Arai A, Asch FM, Badano $L P$, et al. Multimodality imaging of diseases of the thoracic aorta in adults: from the American Society of Cardiovascular Imaging. endorsed by the Society of Cardiovascular Computed Tomography and Society for Cardiovascular Magnetic Resonance. J Am Soc Echocardiogr. 2015;28(2):!19-82.

2. Zoghbi WA, Adams D, Bonow RO, Enriquez-Sarano M, Foster E, Grayburn PA, et al. Recommendations for report from the American Society of Echocardiography developed in collaboration with the Society for Cardiovascular Magnetic Resonance. J Am Soc Echocardiogr. 2017;30(4):303-71.

13. Baumgartner $\mathrm{H}$, Hung J, Bermejo J, Chambers JB, Edvardsen T, Goldstein S, et al. Recommendations on stenosis; a focused update from the European Association of Cardiovascular Imaging and the American Society of Echocardiography. J Am Soc Echocardiogr. 2017;30(4):372-92.
Park KH, Chung S,

4. Park KH, Chung S, Kim DJ, Kim JS, Lim C. Natural history tions for determining the Cardiothorac Surg. 2017;51(5):959-64.
15. Gagné-Loranger M, Dumont É, Voisine P, Mohammadi S, Dagenais F. Natural history of $40-50 \mathrm{~mm}$ root/ascending . Wolak A, Gransar H, Thomsan LE, Friedman JD, Hachamovitch R, Gutstein A, et al. Aortic size assessment by lits by age, gender, and body surface area. I Am Coll Cardiol Img. 2008; I (2):200-9.

17. Devereux RB, de Simone G, Arnett DK, Best LG, Boerwinkle E, Howard BV, et al. Normal limits in relation to age, body size and gender of two-dimensiona 15 years of a

18. Oladokun D. Patterson B, Sobocinsk I, Karthikest-w ingam A, Loftus I, Thompson M, et al. Systematic review of the growth rates and influencing factors in thoracic aortic aneurysms. Eur I Vasc Endovasc Surg 2016;51(5):674-81.

19. Davies RS, Goldstein LJ, Coady MA, Tittle SL, Rizzo JA thoracic aortic aneurysms: simple prediction based on size. Ann Thorac Surg. 2002;73(1): 17-28.

20. Hirose Y, Hamada S, Takamiya M, Imakita S, Naito H, Nishimura T. Aortic aneurysms: growth rates measured with CT. Radiology. 1992;185(I):249-52.

Toplery Y Suri RM, AD, Mahoney D, Margaryan E. Tons in patients with bicuspid aortic valves, JAMA. 2011;306(10):1104-12.

22. Cheung K, Boodhwani M, Chan KL, Beauchesne L, Dick A, Coutinho T. Thoracic aortic aneurysm growth: role of sex and aneurysm etiology. J Am Heart Assoc.

.

CA, Fattori R, Mehta RH, Richartz BM, Evangelista A, Petzsch M, et al. Gender-related differences in acute
2004:109(24):3014-21.

24. Sokolis DP, lliopoulos DC. Impaired mechanics and 政 Behav Biomed Mater. 2014:34:154-64. Aortic diameter $25.5 \mathrm{~cm}$ is not a (for predictor of Type $A$ aortic dissection observations from the International Registry of Acute Aortic Dissection (RAD). Circulation. 2007, 16(10).1120-7.

Cheriex EC, et al. Aortic elongation part II: the risk $R$,

27. Heuts S, Adriaans BP, Rylski B, Mihl C, Bekkers SC. Olsthoorn JR, et al. Evaluating the diagnostic accuracy of Maximal aortic diameter, length and volume for prediction

of aortic dissection. Heart. 2020;106 (12).892-97.

28. Hope MD, Sigovan M, Wrenn Sj, Saloner D, Dyverfeld artic valve-related aortic disease. I Magn Reson Imaging. 2014;40(I):140-5

29. Markl M, Frydrychowicz A, Kozerke S, Hope M, Wiebe O.4D flow MRI.JMagn Reson Imaging. 2012;36(5):1015-36. friet PM. Mulder BI Aortic rinderman AH, Engelwomen with the Marfan's syndrome. Am J Cardiol. 2005;96(10):1441-4. 
31. Lang RM, Badano LP, Mor-Avi V, Afilalo J, Armstrong A, Ernande $L$, et al. Recommendations for cardiac chamber quantification by echocardiography in adults: an update European Association of Cardiovascular Imaging. Eur Heart J Cardiovasc Imaging. 2015;16(3):233-71.

2. Rizzo JA, Coady MA, Elefteriades JA. Procedures for estimating growth rates in thoracic aortic aneurysms.
J Clin Epidemiol. 1998;5( 9 ):747-54. 


\section{Aortic elongation part I: the normal aortic ageing process}

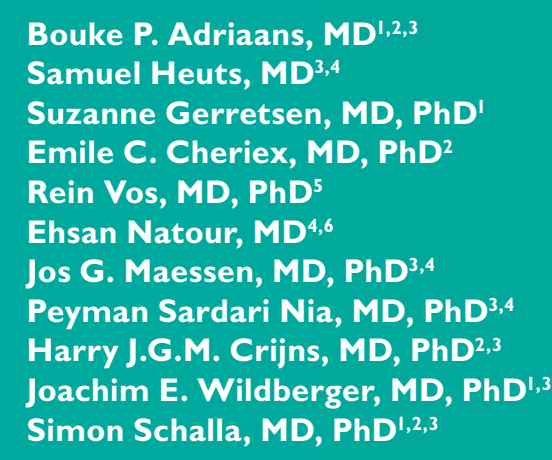

I. Department of Radiology and Nuclear Medicine, Maastricht University Medical Center+, Maastricht, the Netherlands

2. Department of Cardiology, Maastricht University Medical Center+, Maastricht, the Netherlands

3. Cardiovascular Research Institute Maastricht (CARIM), Maastricht University, Maastricht, the Netherlands

4. Department of Cardiothoracic Surgery, Maastricht University Medical Center+, Maastricht, the Netherlands

5. Department of Methodology and Statistics, Maastricht University, Maastricht, the Netherlands 6. Department of Thoracic and Cardiovascular Surgery, Uniklinik RWTH Aachen, Aachen, Germany

Heart 2018 Nov; 104(21):1772-1777

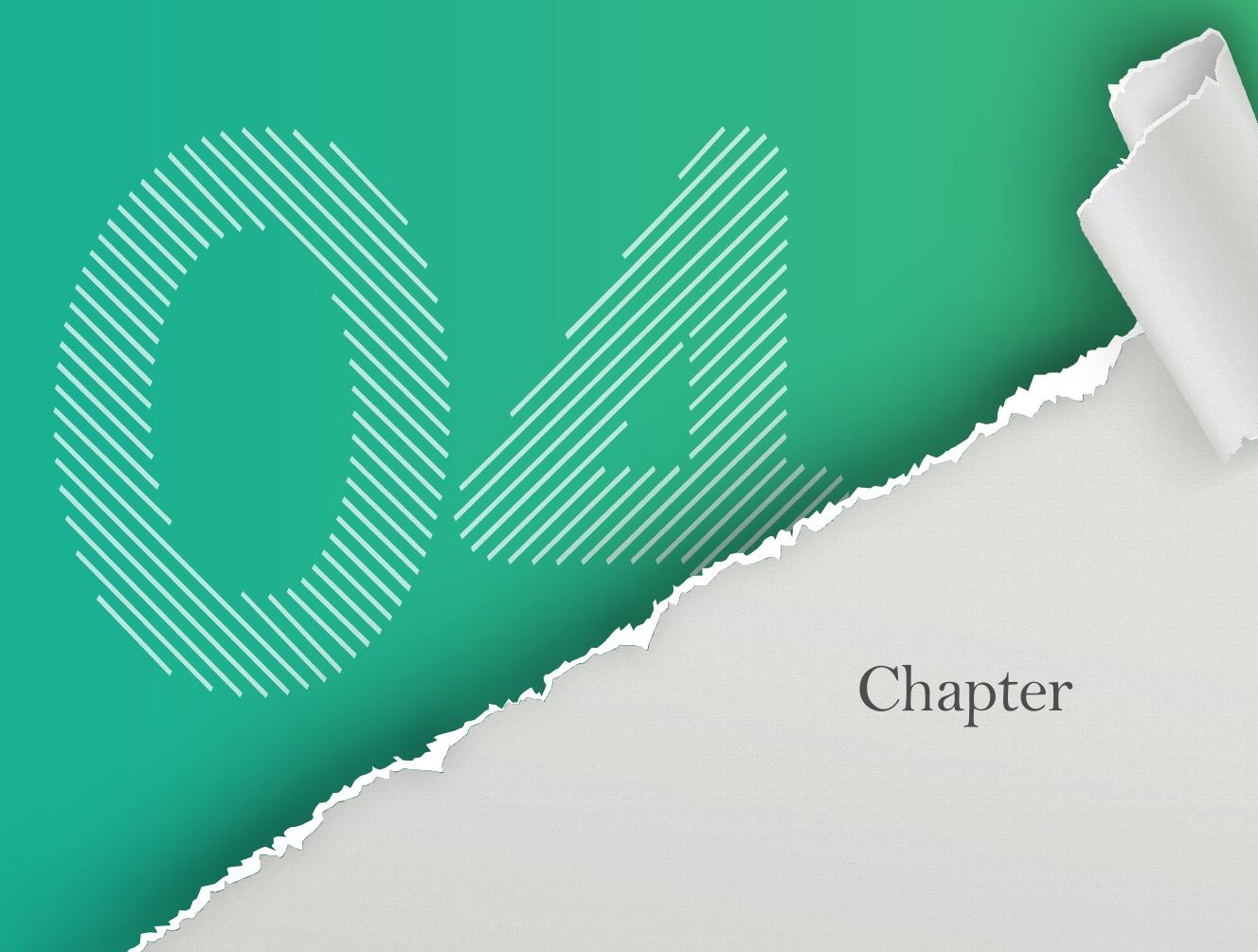




\section{INTRODUCTION}

As the Western population grows increasingly older, physicians will more frequently encounter age-related alterations of the vascular system. It is important to distinguish normal from abnormal aspects of vascular aging, since an accelerated aging process confers risk for future cardiovascular disease (CVD) (I, 2). Prominent structural changes of the aorta include thickening of the intimal vessel wall and gradual luminal dilatation(3-7). The increase of aortic diameters has been studied extensively, given the relation of excessive dilatation with severe complications like dissection and rupture(8). In contrast to its circumferential dimensions, the longitudinal dimensions of the aorta and their evolution over time have not been well studied. It is conceivable that the aorta lengthens during life, since a tortuous deformation or even kinking is frequently observed in elderly patients. This theory was investigated by an autopsy study, which measured aortic length in post mortem specimens (9). However, in vitro measurements may not represent those in vivo due to post mortem contraction and the loss of autonomous nerve innervation $(9,10)$. Since advanced imaging techniques are required to study the complex three-dimensional geometry of the aorta, it was not until recently that non-invasive measurements of aortic length became feasible. One imaging study assessed the relation between age and aortic length and concluded that elongation only occurs in the proximal aorta(II). However, this study measured the length of the ascending aorta as the distance between the sinuses of Valsalva and the apex of the aortic arch. Since the morphology of the aortic arch differs between individuals(12) and may change with increasing age(I3), it is unclear if these findings represent true vessel lengthening. Theoretically, tortuosity and kinking could also result from age-associated changes of thorax configuration (such as spondylosis and increased kyphosis), which may lead to confinement of the aorta in a gradually decreasing intrathoracic volume(14). Using the latest computed tomography (CT) scan techniques, the purpose of the current study is to provide an elaborate description of the evolution of longitudinal aortic dimensions and geometry during life.

pronounced in the proximal descending aorta, which showed an almost 2.5 -fold length increase during life. The lengthening of the thoracic aorta was accompanied by a marked change of its geometry: whereas the aortic apex was located between the branch vessels in younger patients, it shifted to a more distalward position in the elderly.

\section{CONCLUSIONS}

The normal aging process is accompanied by gradual aortic elongation and a notable change of aortic geometry. Part Il of this two-part article investigates the hypothesis that excessive elongation could play a role in the occurrence of acute aortic dissection.

\section{KEYWORDS}

Aortic elongation, vascular aging, aortic aging

\section{KEY POINTS}

- The thoracic aorta gradually elongates with increasing age. The proximal descending aorta is the segment in which greatest longitudinal growth is observed.

- During life, the aorta becomes more tortuous and the apex shifts to a position distal of the left subclavian artery. The length of the proximal descending aorta is the most important predictor of aortic phenotype (i.e., type I or type II).

\section{MATERIALS AND METHODS}

\section{Study population}

Consecutive adult patients who underwent contrast-enhanced chest $C T$ at the Maastricht University Medical Center+ between September 2015 and September 2016 were prospectively enrolled in this single center cross-sectional study. Patients with suspected or known aortic disease and those who previously underwent cardiothoracic surgery were excluded, as were those with any other condition that might cause distortion of aortic shape (such as previous radiotherapy or pneumothorax). All scans that provided for adequate three-dimensional (3D) modeling of the thoracic aorta with automatically detected centerline were studied. Eventually, a total of 210 patients was included. CT examination was performed because of suspicion of pulmonary embolism (50.7\%), pneumonia (7.1\%), evaluation or follow-up of pulmonary nodules (38.9\%) and other (3.3\%). Baseline characteristics were drawn from the medical record. The institutional review board approved the study protocol and waived the need for written patient consent because of the observational character of the study.

\section{Image acquisition}

All CT scans were performed on a third-generation dual-source CT scanner (Somatom Force, Siemens Healthineers, Forchheim, Germany) with $96 \times 0.6$ slice collimation at a rotation time of 0.25 seconds (s). Indications and protocolling were clustered in vascular $(\mathrm{n}=\mathrm{III})$ and oncologica $(n=99)$ workflows without dedicated ECG synchronization of the respective data sets. Tube 
voltage and tube current were individually and semiautomatically adapted in all examinations (CARE kV, CARE Dose4D, Siemens), depending on patient's Body Mass Index (BMI). lopromide (300 mg iodine/mL, Ultravist, Bayer, Berlin, Germany) was used as a contrast medium in all subjects, using an individualized approach (Contrast Dose Management, Certegra, Bayer). Image reconstruction was performed with I $\mathrm{mm}$ slice thickness and a reconstruction increment of maximal 0.7 millimeter $(\mathrm{mm})$ with soft tissue kernels (Siemens Bv36/Br40), using a raw data based iterative reconstruction algorithm (ADMIRE, reconstruction strength 3).

\section{Image evaluation}

Image evaluation was performed by a single observer with 5 years experience in cardiovascular imaging. A 3D reconstruction of the thoracic aorta with fitted centerline was created automatically using dedicated software (Syngo.via, Siemens). The aorta was then manually divided by the observer into multiple anatomical segments following current guidelines (Figure IA)(15-17). The ascending aorta was defined as the part of the aorta between the sinotubular junction (STJ) and the origin of the brachiocephalic trunk. The aortic arch was measured as the distance from the brachiocephalic trunk to the left subclavian artery. The descending aorta was defined as the segment between the left subclavian artery and the diaphragm and subdivided into two parts: a proximal part (from the left subclavian artery to the level of the bifurcation of the pulmonary trunk) and a

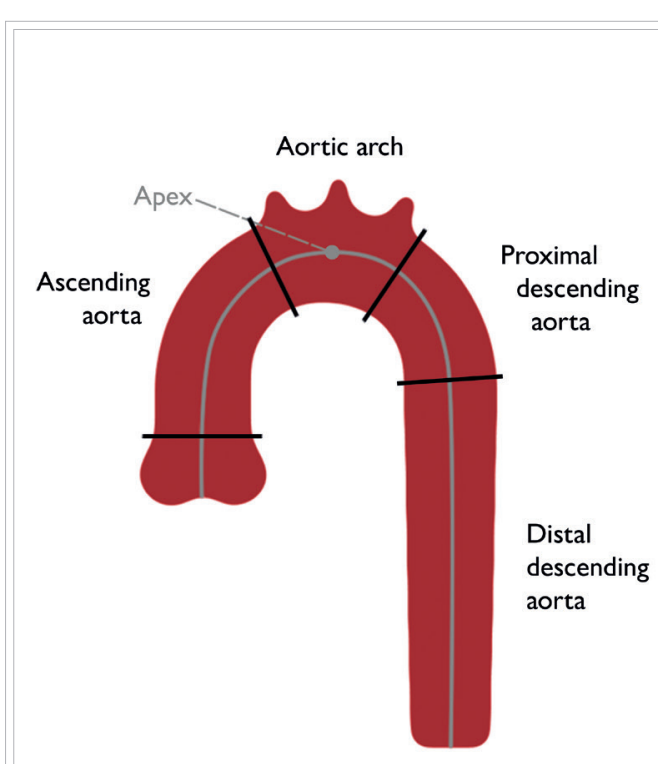

A

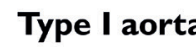

Type I aorta

Figure I: The two distinct aortic types. In type I aorta (A), the apex can be appreciated between the branch vessels (as depicted by the gray dot). Type Il aorta (B) is characterized by a more distal position of the apex, in the segment defined as the proximal descending aorta. Figure IA shows the four individual segments in which the thoracic aorta was divided. Figure IB shows the measurement methods for segment length and torturity: the black line marks the centeline lingth of the ascending aorta, while the dotted line marks the direct liear black line (S) sinotubular junction (STJ) and the brachiocephalic trunk. Segment tortuosity was calculated as the ratio between the centerline and the linear line between these anatomical landmarks. distal part (from the level of the pulmonary trunk bifurcation to the diaphragm). The length of each segment was measured as the centerline distance between two points. Segment tortuosity was calculated as the ratio of the centerline path length to the direct linear distance between centerline endpoints (Figure IB). The position of the aortic apex (i.e. the most cranial position of the centerline) determined the morphology of the aorta. Type I was defined as an aorta in which the apex was located between the branch vessels (i.e. in the segment defined as the aortic arch), while in type II aorta the apex was identified at a position distally of the left subclavian artery (Figure I).

\section{Statistical analysis}

Statistical analyses were performed using commercially available software (IBM SPSS Statistics, version 24, Armonk, New York, USA). The distribution of continuous variables was assessed for normality by the Shapiro-Wilk test and assessed visually by inspection of histograms and standardized normal probability (P-P) plots. Continuous baseline characteristics are presented as mean \pm standard deviation or as median and interquartile range (IQR) in the presence of skewness. Categorical variables are expressed as frequency and percentages. Differences between genders were assessed using the independent samples t-test (or Mann-Whitney $\mathrm{U}$ test, if deemed appropriate) and Chi-square test for categorical variables. Linear regression tested the relationship between age and aortic length. Model assumptions on normality, linearity and homoscedasticity for multiple regression analysis were checked and variance stabilizing measures, such as log transformation and bootstrapping were applied. Check for (curvi)linearity was performed by introducing linear and quadratic terms for the quantitative predictor of age (in years minus the average, to prevent collinearity between the linear and quadratic term)(I8). Logistic regression analysis was performed to obtain predictors for the two distinct aortic types. A p-value $<0.05$ was considered statistically significant.

\section{RESULTS}

\section{Study population}

Subject characteristics are summarized in Table I. The study sample comprised more females than males (61\% vs. $39 \%$, respectively). The median age of the total study sample was 62 years (IQR 52-72, range 23-92) and did not differ between genders. Men were significantly taller and heavier than women and, consequently, had a larger body surface area (BSA). Body mass index (BMI) was comparable between genders. Sixty-eight patients were free of any cardiovascular risk factor. The others were marked as smoker $(n=82)$ and/or suffered from hypertension $(n=69)$, hypercholesterolemia $(n=29)$ or diabetes $(n=19)$. Of the hypertensive subjects, $62(91 \%)$ were treated with antihypertensive medication. 
Table I. Baseline characteristics of the study population.

\begin{tabular}{|l|l|l|l|}
\hline & Males $(\mathrm{N}=82)$ & Females $(\mathrm{N}=128)$ & $\mathrm{p}$-value \\
\hline Age $($ years) & $65[55-73]$ & $61[50-70]$ & 0.072 \\
\hline Length $(\mathbf{c m})$ & $176 \pm 8$ & $165 \pm 8$ & $<\mathbf{0 . 0 0 I}$ \\
\hline Weight $(\mathbf{k g})$ & $82.0[71.0-90.0]$ & $70.9[59.3-81.5]$ & $<\mathbf{0 . 0 0 I}$ \\
\hline BMI & $26.2[23.4-28.6]$ & $25.0[21.7-29.7]$ & 0.58 \\
\hline BSA $\left(\mathbf{m}^{2}\right)$ & $2.0 \pm 0.2$ & $1.8 \pm 0.2^{\dagger}$ & $<\mathbf{0 . 0 0 I}$ \\
\hline Hypertension & $34(41.5 \%)$ & $35(27.3 \%)$ & 0.036 \\
\hline Dyslipidemia & $15(18.3 \%)$ & $14(10.9 \%)$ & 0.47 \\
\hline Diabetes & $13(15.9 \%)$ & $6(4.7 \%)$ & 0.15 \\
\hline (Past) smoker & $35(42.7 \%)$ & $47(36.7 \%)$ & 0.012 \\
\hline
\end{tabular}

BMI: Body Mass Index; BSA: Body Surface Area.

\section{Aortic length}

The entire thoracic aorta and all individual segments were, on average, significantly longer in men than in women. However, after adjustment for BSA, none of these differences persisted, indicating the influence of body proportions on aortic length. The BSA-indexed length of the entire thoracic aorta was positively related to age $(r=0.54, p<0.00 I)$, as were the individual lengths of the ascending aorta $(r=0.55, p<0.001)$ and the aortic arch $(r=0.52, p<0.001$, Figures $2 \mathrm{~A}-\mathrm{C})$. The length of the descending aorta was also correlated with age $(r=0.45, p<0.00 \mathrm{I})$. However, this was solely driven by notable lengthening of its proximal part $(r=0.63, p<0.001$, Figure 2D). No relation was found between the length of the distal descending aorta and age $(r=0.09, p=0.178$, Figure $2 E)$. Between the ages of 20 and 80 years, the total length of the thoracic aorta increased by a mean of $59 \mathrm{~mm}$ (males) and $66 \mathrm{~mm}$ (females), reflecting a relative lifelong growth of approximately $125 \%$. The extent of elongation differed markedly between individual segments: the length of the ascending aorta increased by 142\%, compared to 169\% (aortic arch) and $247 \%$ (proximal descending aorta)

\section{Aortic geometry}

The tortuosity ratios of the ascending aorta, aortic arch, and distal descending aorta were not significantly related to age. The tortuosity of the proximal descending aorta was moderately associated with age $(r=0.38, p=0.004)$ and increased from mean 1.07 (at age 20 years) to I.2I (at age 80 years). During life, the morphology of the thoracic aorta changed markedly: younger patients exhibited a type I aorta $(n=49)$, whereas a type II aorta was mainly observed in the elderly ( $n=|6|$, Figure 3 and 4). Multivariable logistic regression analysis revealed age, proxima descending aortic length, and hypertension to be independent predictors of aortic type (Table 2). The morphology of the aorta was not influenced by BSA, gender or cardiovascular risk factors other than hypertension.
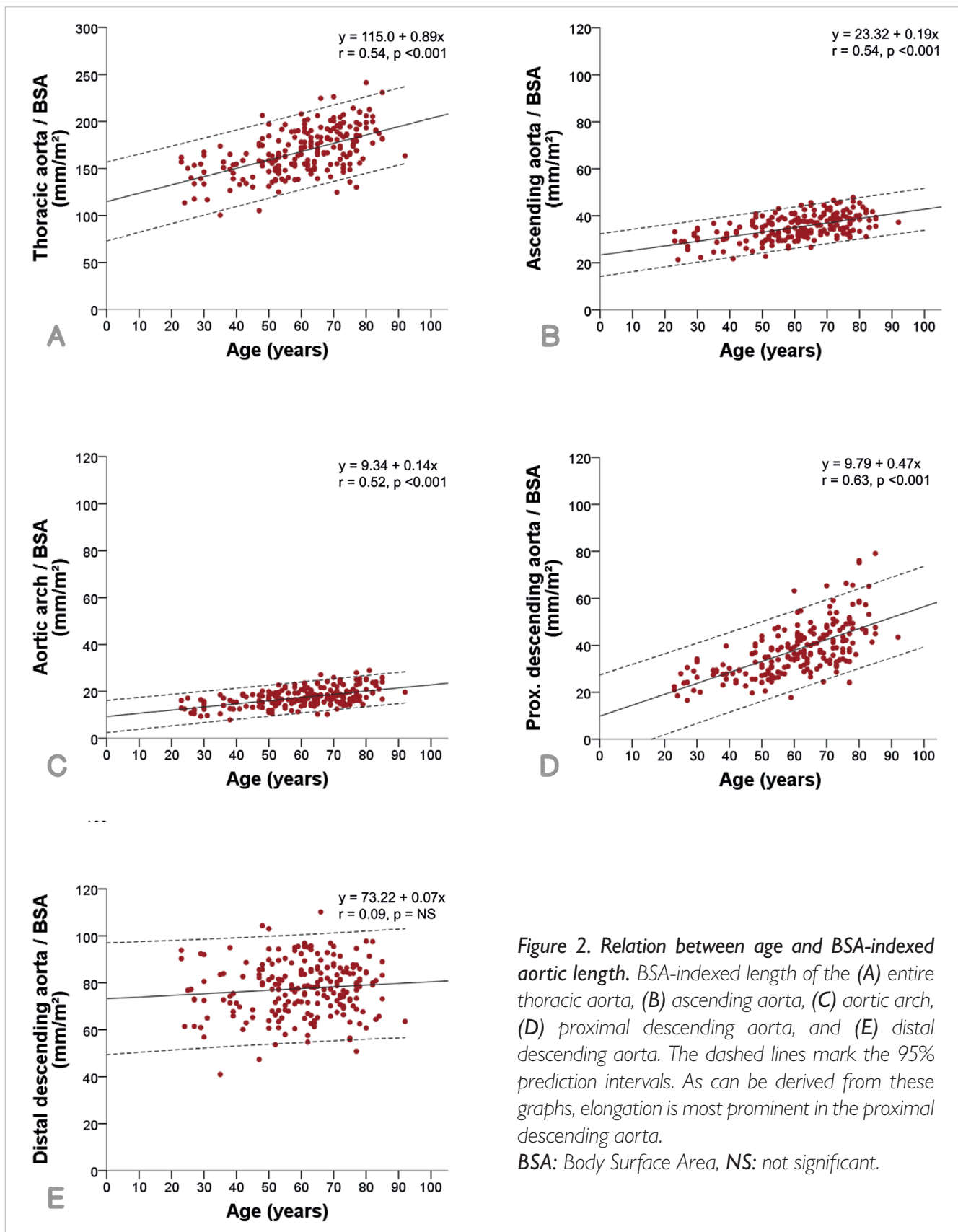

Figure 2. Relation between age and BSA-indexed aortic length. BSA-indexed length of the $(A)$ entire thoracic aorta, (B) ascending aorta, (C) aortic arch (D) proximal descending aorta, and (E) dista descending aorto. The dashed lines mark the 95\% prediction interval. As can be derived from these graphs, elongation is most prominent in the proximal BSA: Body Surface Area, NS: not significant. 


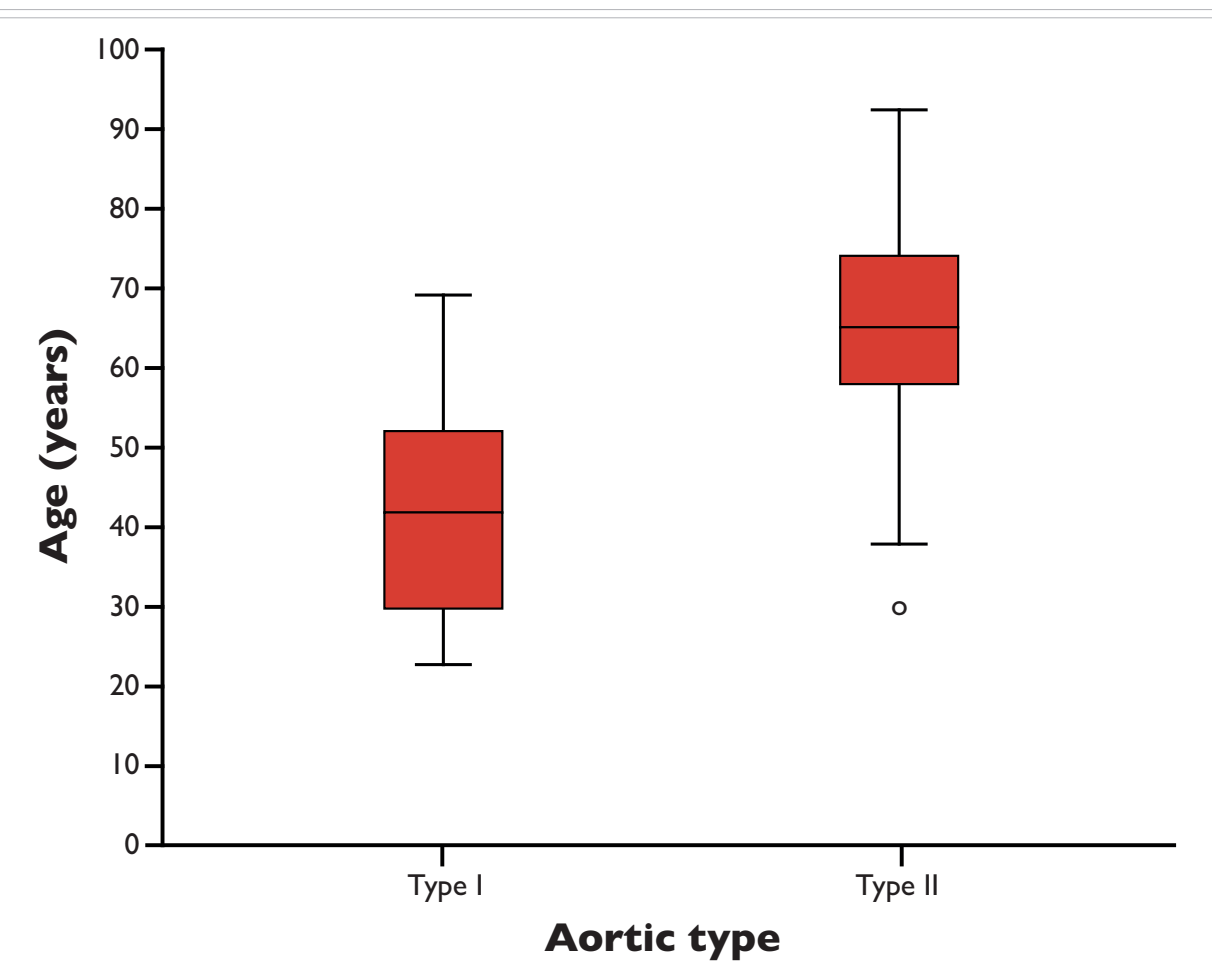

Figure 3. The influence of age on aortic type. Boxplot showing the age differences between aortic types: type is more prevalent in younger individuals, while type II aorta is mainly observed in the elderly.

Table 2. Univariable and multivariable logistic regression analysis showing predictors for aortic morphology.

\begin{tabular}{|c|c|c|c|c|}
\hline & \multicolumn{2}{|c|}{ Univariable } & \multicolumn{2}{|c|}{ Multivariable } \\
\hline & B & $p$-value & B & $p$-value \\
\hline Age (years) & 0.166 & $<0.001$ & 0.212 & $<0.001$ \\
\hline Gender & -0.360 & 0.296 & & \\
\hline BSA $\left(m^{2}\right)$ & -1.899 & 0.011 & -1.000 & 0.547 \\
\hline Hypertension & 1.324 & 0.003 & -1.828 & 0.047 \\
\hline Dyslipidemia & 0.734 & 0.194 & & \\
\hline Diabetes & 0.152 & 0.796 & & \\
\hline (Past) smoker & 0.360 & 0.296 & & \\
\hline Ascending aortic length (mm) & 0.104 & $<0.001$ & -0.079 & 0.151 \\
\hline Aortic arch length $(\mathrm{mm})$ & 0.117 & $<0.001$ & -0.125 & 0.086 \\
\hline Proximal descending aortic length $(\mathrm{mm})$ & 0.227 & $<0.001$ & 0.342 & $<0.001$ \\
\hline
\end{tabular}

BSA: Body Surface Area.

\section{DISCUSSION}

Premature vascular aging plays a major role in the development of CVD, as it forms the basis for specific pathophysiological disease mechanisms to act upon. An extensive body of literature describes the relation between common features of vascular aging, such as reduced vesse compliance and luminal dilatation, and the occurrence of cardiovascular events(|9-2I). Information on aortic length, however, is scarce, since older imaging techniques did not provide for an accurate and three-dimensional visualization of the thoracic aorta. Using latest CT equipment and acquisition protocols, we have assessed the longitudinal dimensions of the aorta in apparently healthy subjects. By implication, we have shown that it is possible to assess aortic length on routinely acquired CT, even if scans were not specifically acquired for a focused visualization of the aorta. The main findings of the current study are that: i) the thoracic aorta and its individual segments lengthen with increasing age, ii) the extent of elongation differs between segments, and iii) the morphology of the thoracic aorta (aortic type) changes over time. As shown, the ascending aorta only grows modestly during life, while the greatest increase in length is observed in the segment distal to the arch branch vessels. This results in a notable change of aortic morphology. Whereas the younger aorta typically looks like a candy cane (type I aorta), the older aorta unfolds and is more 'question mark-shaped' (type II aorta, Figure 4). Few previous studies have addressed the age-related alterations of aortic length. Sugawara et al. investigated aortic length in healthy volunteers, but concluded that elongation occurs in the ascending aorta only(II). However, their study defined the ascending aorta as the distance between the root and the apex of the aorta. As we have shown, the position of the apex changes during life and, therefore, the measurements by Sugawara et al. represent an alteration of aortic morphology rather than lengthening of the tubular ascending aorta. To avoid indistinctness, we would advocate the use of anatomical landmarks in the assessment of aortic length, as supported by current guidelines(15-17). Rylski et al. investigated gender- and age-related differences of aortic diameters and length, which were found to be largest in males(22). BSA-indexed aortic lengths (but not diameters) were comparable between genders and increased in a similar pattern when compared to the current study. We have additionally shown that the geometry of the thoracic aorta changes with increasing age and postulate that these changes could reflect an (un)successful vascular aging process. Future studies are warranted to investigate the prognostic importance of changes of longitudinal aortic dimensions.

The question arises how our results can be explained from a biomechanical point of view. It has been suggested that aortic elongation is part of a gradual remodeling process as a result of 'material fatigue' of the vessel wall(I0, II, 23). The lifelong exposure to pulsatile strain causes fracture and breakdown of elastin fibers, which results in structural remodeling. Besides elongation and dilatation, this theory explains age-related vascular stiffening, as the reduction of elastin content impairs vessel compliance. Two reasons provide a possible explanation for the differences in elongation between various segments. First, elastin content is highest in the aortic arch and proximal descending aorta $(24,25)$. Following the principles of material fatigue, one would expect these segments to be more prone to remodeling, which is in line with the findings of the current study. Second, the distal descending aorta is fixated to the spine by the intercostal arteries and endures only little longitudinal strain(26), whereas the more proximal aortic segments can move relatively freely in the longitudinal direction. Circumferential strain values, however, are comparable throughout the entire thoracic aorta(26). This provides a plausible explanation for the fact that diameter increase is more prominent than length increase in the distal descending aorta, whereas the opposite applies to the more proximal segments of the thoracic aorta(6). 


\section{Clinical perspective}

Our findings evoke several clinical questions. First, future research could address the clinica implications of aortic elongation. It has been postulated that aortic length plays a role in the occurrence of aortic dissection, which is the result of an imbalance between the biological strength of the aorta and forces exerted on its wall(27). To date, the transverse diameter is the only recognized anatomical risk factor for dissection and the sole marker used in the stratification towards prophylactic aortic surgery. However, luminal diameters are considered to be a poor risk predictor for dissection, as the majority of patients (either presenting with Stanford type A or type B dissection) would not have met the threshold for preventative aortic repair(28-30). In part II of this two-part article, we will investigate the hypothesis that excessive aortic elongation could also play a role in the development of aortic dissection.

Furthermore, our findings should be taken into account in the assessment of arterial stiffness. Pulse wave velocity (PWV) is the velocity at which the arterial pulse propagates through the circulatory system and is the gold standard technique for measurements of arterial stiffness. It is measured as PWV = distance (meters) / $\Delta t$ (transit time in seconds), in which $t$ is the time delay between the arrival of two waveforms obtained at different anatomical locations (usually at the level of the carotid and femoral arteries). The distance covered by the waves is usually assimilated to the surface distance between the two recording sites. Our results indicate that this technique only provides approximations of the distance traveled by the pulse waves, as vessel length differs between individuals and changes with increasing age. The use of 3D-imaging methods allows for exact distance measurements between two recording sites and, thus, for more precise calculations of PWV.

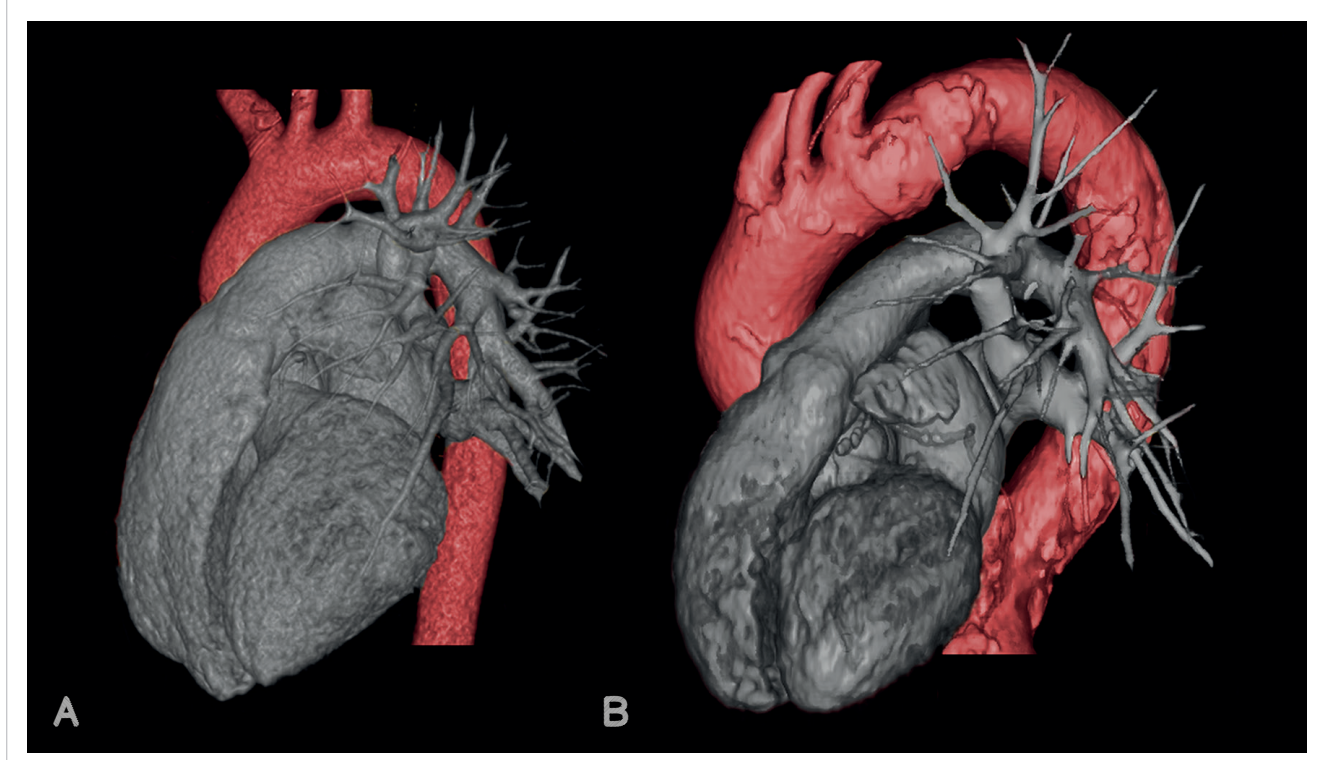

Figure 4. Three-dimensional CT models of the aorta. Three-dimensional modeled CT images of the aorta of a 24-year old female (A) and an 85-year old female (B). In (A), a type I aorta is displayed, as the apex of the arch is located between the branch vessels. (B) depicts a type Il aorta, as the apex has shifted to a position distally of the left subclavian artery.

\section{Study limitations}

A few limitations of the current study should be addressed. First, we used a cross-sectional study design, whereas a longitudinal design could be preferred to investigate an aging process. However, to investigate aortic elongation, one would need to conduct a study with a near lifelong follow-up duration, which carries insuperable constraints for both patient and researcher.

Second, CT examinations were performed for clinical purposes, which implicates that a substantial number of subjects were exposed to cardiovascular risk factors such as hypertension and hyperlipidemia. Our study sample therefore represents a population that is encountered in daily clinical practice, rather than a population of entirely healthy volunteers. As patients aged 50 to 70 years undergo CT more frequently, these are somewhat overrepresented in our study population. The greater variance of aortic length in the elderly should be taken into consideration in the prediction of aortic length.

Third, CT acquisitions were performed without ECG synchronization. Nevertheless, in none of the included scans did we encounter motion artifacts that could hamper the accuracy of length measurements. With the acquisition parameters as described above, the entire thoracic aort can be acquired within one rotation of the scanner tube. With rotation times as short as 250 msec, acquisition time only covers a small fraction of the R-R interval, which explains the absence of motion artifacts. Scans acquired with older scanners (and, thus, longer acquisition times) will more likely benefit from ECG synchronization. 
REFERENCES

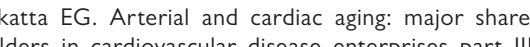
cellular and molecular clues to heart and arterial aging. Circulation. 2003;107(3):490-7.

2. Lakatta $E G$, Levy D. Arterial and cardiac aging: major shareholders in cardiovascular disease enterprises part 1 : aging arteries: a "set up"

3. Virmani R, Avolio A, Mergner W, Robinowitz M, Herderick E, Cornhill J, et al. Effect of aging on aortic morphology in populations with high and low prevalence of hypertension and atherosclerosis. Comparison
between occidental and Chinese communities. Am J between occidental and
Pathol. 1991;139(5): III

4. Wolak A, GransarH, Thomson LE, Friedman JD, Hatemovitch R, Gutstein A, et al. Aortic size assessment by noncontrast cardiac computed tomography: norma limits by age, gender, and body surface area. J Am Coll Cardiol Img. 2008; (2):200-9.

. Campens L, Demulier L, De Groote K, Vandekerckhove echocardiographic assessment of the diameter of the aortic root and ascending aorta spanning all age categories. Am J Cardiol. 2014;/I4(6):914-20.

6. Lin FY, Devereux RB, Roman MJ, MengJ, Jow VM, Jacobs A, et al. Assessment of the thoracic aorta by multidetector computed tomography. age-and sex-specific disease I Cardiovasc Comput Tomogr. 2008:2(5)-298308.

7. Roman MJ, Devereux RB, Kramer-Fox R, O'Loughlin J. Two-dimensional echocardiographic aortic root dimensions in normal children and adults. Am J Cardiol.

8. Goldfinger JZ, Halperin JL, Marin ML, Stewart AS, Eagle KA, Fuster V. Thoracic aortic aneurysm and dissection. Mitchell I, Adams ]. Aortic size and Nichols W, O'Reurcesclerosis. 1977;27(4):437-46. blood flow in arteries: theoretical, experimental and

Sugawaral, HayashiK YokoiT. Tanaka H. Age-associated elongation of the ascending aorta in adults. I Am Coll Cardiol Img. 2008; (6):739-48.

12. Madhwal S, Rajagopal V, Bhatt DL, Bajzer CT, Whitlow P, Kapadia SR. Predictors of difficult carotid stenting as determined by aortic arch angiography. I Invasive

E, Harouni AA, Kachearch geometry: relationship with proximal aortic function and left ventricular mass and remodeling. J An Coll Cardiol. $2011 ; 58(12): 1262-70$.

14. Fon GT, Pitt MJ, Thies Jr A. Thoracic kyphosis: range in

15. Goldstein SA, Evangelista A, Abbara S, Arai A Asch FM. Badano $L$, et al. Multimodality imaging of diseases of the thoracic aorta in adults: from the American Society of Echocardiography and the European Association of Cardiovascular Imaging: endorsed by the Society of Cardiovascular Magnetic Resonance I Am Soc Echocardiogr. 2015;28(2):119-82.
16. Erbel R, Aboyans V, Boileau C, Bossone E, Di Bartothe diagnosis and treatment of aortic diseases. Eur Heart J. 2014:35(41):2873-926.

7. Hiratzka LF, Bakris GL, Beckman JA, Bersin RM, Carr VF, Casey DE, et al. 2010 ACCF/AHA/AATS/ACR/ASA . Am Coll Cardiol. 2010;55(14):e27-el29.

Kleinbaum DG, Klein M, Pryor E. Logistic regression: self-learning text. New York, USA: Springer; 2002.

19. Nagai Y, Metter E,, Earley C], Kemper MK, Becker LC, Lakatta $\in G$, et al. Increased carotid artery intimal-media induced induced myocar 1 1998; 15 ):1504-9.
1998

20. Vlachopoulos C, Aznaouridis K, Stefanadis C. Prediction of cardiovascular events and all-cause mortality with arterial stiffness: a systematic review and meta-analysis.

Am Coll Cardiol. 2010,55(13).1318-27.

Geary DH, Polak KF, Kronmal RA, Manolio TA, Burke thickness as a risk factor for myocardial infarction and stroke in older adults. N Engl] Med. 1999;340(I):14-22.

2. Rylski B, Desjardins B, Moser W, Bavaria]E, Milewski RK. Gender-related changes in aortic geometry throughout lif. EurJ Cardiothorac Surg. 2014,45(5):805-11.

23. sions and Stiffness in Normal Adults J. Aor Coll CimenImg. 2008; (6):749-51.

24. Sokolis DP. Passive mechanical properties and structure of the aorta: segmental analysis. Acta physio

2007:190(4):277-89.
25. Sokolis DP, Boudoulas H, Karayannacos PE. Segmental implications. Hellenic Cardio. 2008:49(3): $145-54$

26. Morrison TM, Choi G, Zarins CK, Taylor CA. Circumferential and longitudinal cyclic strain of the human thoracic aorta: age-related changes. J Vasc Surg. 2009;49(4):1029-36.

27. Kruger T, Oikonomou A, Schibilsky D, Lescan M, Brege dissection: the Tübingen Aortic Pathoanatomy (TAIPAN) project. European Journal of Cardio-Thoracic Surgery. 2017;51(6):1119-26.

28. Trimarchi S, Jonker FH, Hutchison S, Isselbacher EM, Pape LA, Patel H], et al. Descending aortic diameter of type B artic dissection. J Thorac Cardiovasc Surg

Pape LA, Tsai TT, Iss

Evangelista A, et Isselbacher EM, Oh JK, O'Gara PT, ood predictor of Type A a diameterz $5.5 \mathrm{~cm}$ is not a from the International Registry of Acute Aortic

Rylski B, Branchetti E, BavariaJE, Vallabhajosyula P, Szeto

WY, Milewski RK, et al. Modeling of predissection aortic size in acute type A dissection: more than $90 \%$ fail to meet the guidelines for elective ascending replacement. Thorac Cardiovasc Surg 2014;148(3):944-8. 


\section{Aortic elongation part II: the risk of acute type $\mathrm{A}$ aortic dissection}

Samuel Heuts, MD',2

Bouke P. Adriaans, MD2,3,4

Suzanne Gerretsen, MD, PhD ${ }^{4}$

Ehsan Natour, MD 1,5

Rein Vos, MD, PhD'

Emile C. Cheriex, MD, PhD ${ }^{3}$

Harry J.G.M. Crijns, MD, PhD2,3

Joachim E. Wildberger, MD, PhD',4

Jos G. Maessen, MD, PhD',2

Simon Schalla, MD, PhD2,3,4

Peyman Sardari Nia, MD, PhD ${ }^{1,2}$

I. Department of Cardiothoracic Surgery, Maastricht University Medical Center+, Maastricht, the Netherlands

2. Cardiovascular Research Institute Maastricht (CARIM), Maastricht University, Maastricht. the Netherlands

3. Department of Cardiology, Maastricht University Medical Center+, Maastricht, the Netherlands

4. Department of Radiology and Nuclear Medicine, Maastricht University Medical Center+, Maastricht, the Netherlands

5. Department of Thoracic and Cardiovascular Surgery, Uniklinik RWTH Aachen, Aachen, Germany

6. Department of Methodology and Statistics, Maastricht University, Maastricht, the Netherlands

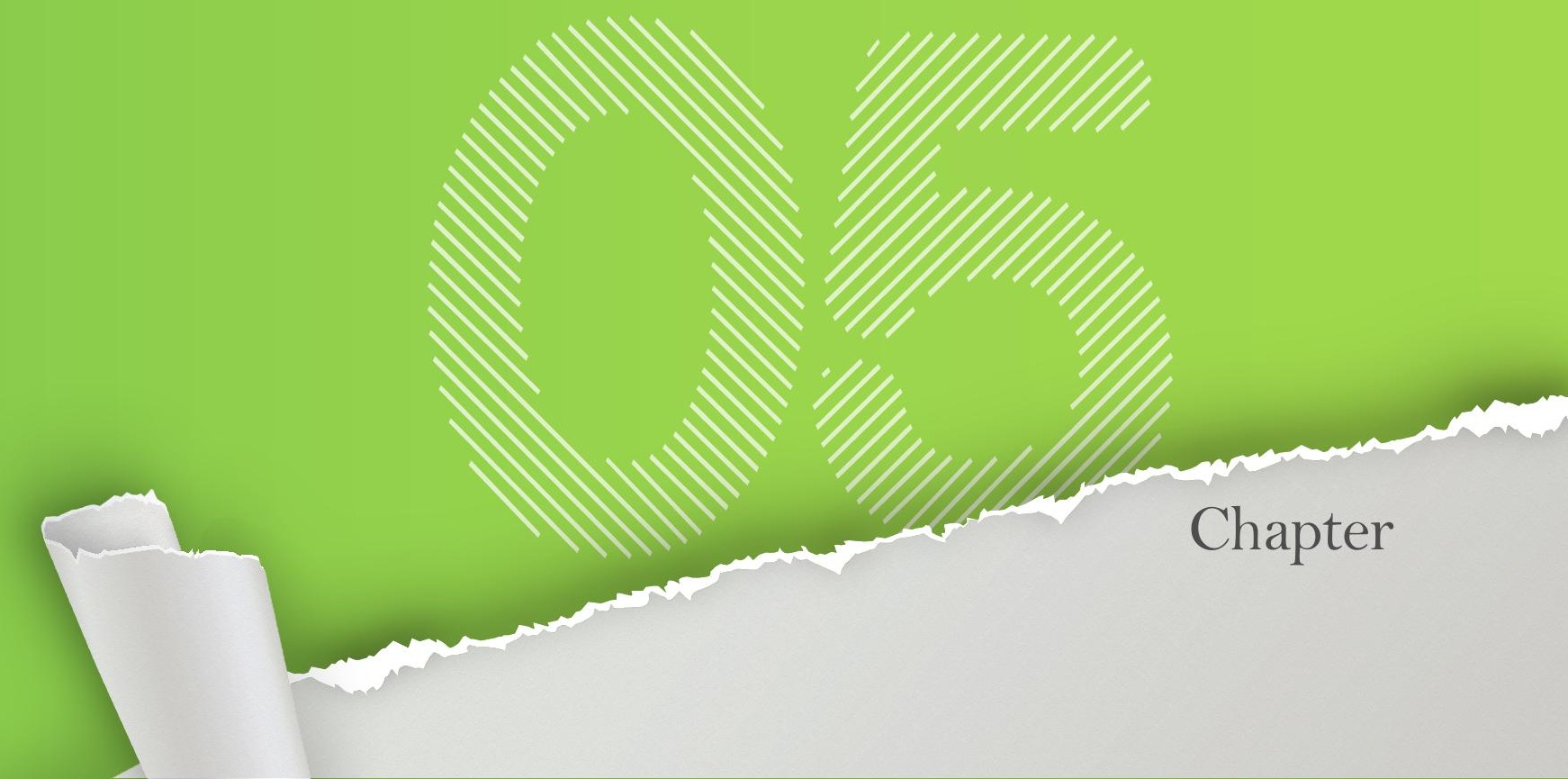




\section{INTRODUCTION}

Acute Type A Aortic Dissection (ATAAD) is a life-threatening cardiovascular disease with an annual incidence of approximately 10 per 100.000 per year $(I, 2)$. Mortality rates are high and range from $27 \%$ in surgically treated patients to $56 \%$ in those who undergo conservative therapy(3). Aortic dilatation is the only recognized anatomical risk factor for development of ATAAD and ascending aortic replacement is considered in patients with aortic aneurysms to prevent the occurrence of dissection and rupture(4). Current guidelines recommend preventative surgical intervention in aneurysms $\geq 55$ millimeters $(\mathrm{mm})$, as these carry an annual complication risk that exceeds the current surgical mortality rates $(5,6,7)$. However, the sole use of aortic diameters in the risk prediction for ATAAD is questionable, since multiple studies have shown that the majority of dissected aortas exhibit diameters below this cut-off $(8,9)$. Modeling of dissected aortas to pre-dissection dimensions even demonstrated that $97 \%$ of ATAAD patients would fail to meet the criterion for preventative aortic repair(I0). Therefore, the identification of additional risk factors is warranted in order to reduce the incidence of ATAAD. We hypothesize that excessive aortic elongation, like dilatation, could carry the risk of dissection. In part I of this two-part article, we have investigated the normal aging process of the thoracic aorta and shown that its length gradually increases with age. In daily clinical practice, the dissected aorta often appears abnormally elongated and tortuous in its course. Moreover, a transverse intimal entry tear is often observed upon inspection of the vessel wall, whereas a longitudinal burst would be expected as a consequence of severe aortic dilatation(II, I2). In our hypothesis, the transverse entry tear reflects disruptive stretch in the longitudinal direction, which may result from excessive aortic lengthening. Aim of the current study was to evaluate the potential role of elongation in the occurrence of ATAAD using three-dimensional (3-D) modeled computed tomography (CT) and to compare the aortic lengths of ATAAD patients with those of propensity-matched healthy controls.

Two-hundred and fifty patients were included in the study (ATAAD $n=40$, healthy controls $\mathrm{n}=210$ ). Ascending aortic length and diameter proved to be independent predictors for ATAAD $(O R=5.3 \mathrm{Cl} 2.5-11.4, p<0.001, O R=8.6 \mathrm{Cl} 2.4-31.0, p=0.001$, respectively). Eighty patients were matched based on propensity scores (ATAAD $n=40$, controls $n=40$ ). The ascending aorta was longer and more dilated in ATAAD patients when compared to matched healthy controls $(78.6 \pm 8.8 \mathrm{~mm}$ vs. $68.9 \pm 7.2 \mathrm{~mm}, \mathrm{p}<0.00 \mathrm{I}$ $34.4 \mathrm{~mm} \pm 0.32$. vs. $39.4 \mathrm{~mm} \pm 0.77, \mathrm{p}<0.00 \mathrm{I}$, respectively). No differences were found in the lengths of the aortic arch and descending aorta.

\section{CONCLUSIONS}

Ascending aortic length could serve as an independent predictor for ATAAD. Future studies that investigate indications for prophylactic aortic surgery should also focus aortic length.

\section{KEYWORDS}

Aortic elongation, aortic dissection, ascending aorta

\section{KEY POINTS}

- The length of the ascending aorta is increased in patients with type A dissection compared to propensity-matched controls.

- Ascending aortic length and diameter are both independent predictors for occurrence of acute type A dissection

\section{MATERIALS AND METHODS}

\section{Study population}

We retrospectively evaluated all consecutive adult patients who were diagnosed with ATAAD at the Maastricht University Medical Center+ between January 2010 and December 2016 and who underwent contrast-enhanced CT angiography (CTA). Exclusion criteria were prior aortic surgery, iatrogenic dissection, connective tissue disease (Marfan's disease, Loeys-Dietz syndrome, or Ehlers-Danlos syndrome), bicuspid aortic valve and familial thoracic aneurysm and dissection (TAAD). Results were compared with those of an apparently healthy control group, which was presented in part I of this two-part article. In brief, the control group consisted of apparently healthy adult patients who were referred for contrast-enhanced chest CT between December 2015 and December 2016. The study protocol was reviewed and approved by the local ethics committee. The need for written patient consent was waived because of the observational character of this study.

\section{Image acquisition}

The CT protocol for control patients was described in part I of this study. In the ATAAD group, scans were performed on a second-generation dual source CT scanner (Somatom Flash, Siemen Healthineers, Forchheim, Germany) with $128 \times 0.6$ slice collimation at a rotation time of 0.28 . The scan protocol consisted of a non-contrast enhanced CT of the aorta, a retrospective ECG-triggered helical CTA of the aortic root and ascending aorta followed by a high-pitch spiral 
CTA from the aortic arch to the femoral bifurcation. Tube voltage and tube current were semiautomatically adapted in all examinations (CARE kV, CARE Dose4D, Siemens) based on patient habitus. lopromide (300 mg iodine/mL, Ultravist, Bayer, Berlin, Germany) was used as a contrast medium in all subjects, using an individualized approach (Contrast Dose Management, Certegra, Bayer). Image reconstruction was performed to achieve the same reconstruction parameters (slice thickness and increment) as in the control group.

Image analysis and modeling of aortic dimensions

Image analysis of ATAAD patients was performed by a single observer. After image acquisition, CT datasets were loaded onto a workstation for post processing (Syngo.via, Siemens). A three-dimensional model of the thoracic aorta was created and divided into three anatomical segments following current guidelines (Figure I)(I3). The ascending aorta was measured as the centerline distance between the sinotubular junction (STJ) and the origin of the brachiocephalic trunk. The aortic arch was defined as the segment that comprised the three branch vessels. The descending aorta was defined as the part of the aorta from the left subclavian artery to the aortic hiatus in the diaphragm. Luminal diameters were measured using the inner edge to inner edge approach at different levels of the aorta (ST], halfway the ascending aorta and maximal diameter). to the automatically-detected vessel centerline.

To evaluate aortic diameter and length as a potential risk factor for ATAAD, we performed retrospective modeling of the aorta to obtain adjusted pre-dissection dimensions. Rylski et al. demonstrated the dimensions of the ascending aorta to increase on average with $30 \%$ (diameter) and 10\% (length) after the occurrence of dissection, while the lengths of the aortic arch and descending aorta did not increase(14). Like in their study, we modeled the aorta of ATAAD patients to pre-dissection dimensions by deducting $30 \%$ and $10 \%$ of the measured aortic diameter and length, respectively $(10)$

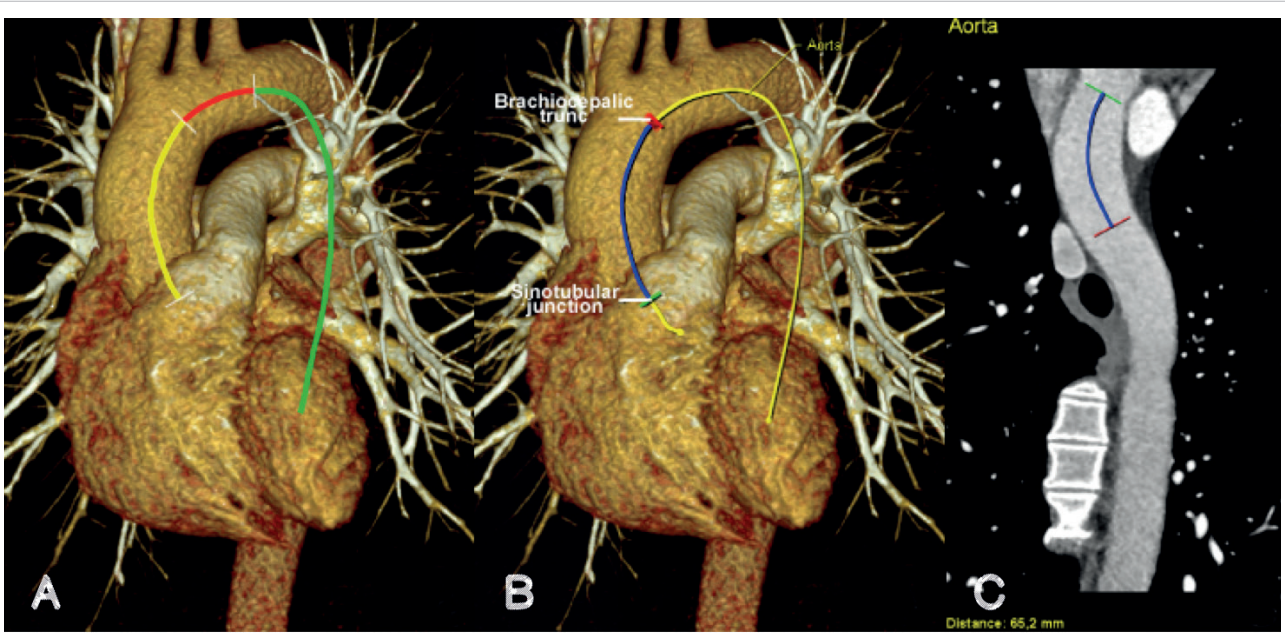

Figure I. Length measurements of different aortic segments. Length measurements of different aortic segments. A: segmental division of the aorta (yellow: ascending aorta, red: aortic arch, green: descending aorta), B: Three-dimensional length measurement of the ascending aorta; C: Multiplanar reformatted image of the thoracic aorta.

\section{Statistical analysis}

The distribution of continuous variables was assessed for normality using the Shapiro-Wilk test and assessed visually by inspection of histograms and standardized normal probability (P-P) plots. Continuous variables are presented as mean \pm standard deviation or median and interquartile range (IQR) in the presence of skewness. Categorical variables are presented as frequencies and percentages. Differences between groups were assessed using the Students t-test or the Mann-Whitney U-test (for continuous variables) or the Chi-square test (categorical variables). Binary logistic regression was performed to assess independent predictors for occurrence of ATAAD.

Covariates for aortic length, used for calculation of propensity scores, were identified using multivariable regression analysis. Variables with $p$-value $<0.20$ were considered to be important covariates and were used to calculate propensity scores. Differences in baseline characteristics were added to this model for balancing purposes. Propensity scores where matched using nearest neighbor matching on a I:I ratio. Replacement was not allowed. Caliper distance was set at 0.10 . Baseline characteristics were presented both before and after propensity-score matching. All statistical analyses were performed using commercially available software (SPSS version 24 IBM, Armonk, New York, USA and R Statistics, the R Foundation, Vienna, Austria).

\section{RESULTS}

Study population

As described in part I of this two-part article, 210 patients were included in the control group. Between January 2010 and December 2016 , a total of 48 patients were diagnosed with ATAAD at our institution based on findings at CT examination. Two patients were excluded because of the iatrogenic origin of their dissection. Six patients were excluded because of concomitant diagnosis of connective tissue disease or bicuspid aortic valve. The remaining 40 patients were included in the study group. Baseline characteristics of both groups before propensity score matching are presented in the supplementary data (Supplementary Data I). The ATAAD group comprised significantly more males than the control group ( $63 \%$ vs. $39 \%, p=0.01)$. Furthermore, ATAAD patients had a larger Body Surface Area (BSA) and were more likely to suffer from hypertension (both $\mathrm{p}<0.0 \mathrm{l}$ ).

Aortic length and diameters

As shown in part I, the length of the ascending aorta was significantly related to age in norma controls and increased by a mean of $3 \mathrm{~mm} /$ decade. Figure 2 depicts the adjusted pre-dissection length of the ascending aorta of ATAAD patients when plotted against the aortic length of the healthy control group. Adjusted and non-adjusted ascending aortic diameters were presented in Table I. Binary logistic regression analysis was performed for evaluation of predictors for ATAAD. All variables with $p<0.20$ in univariable analysis were included in the multivariable model to assess independent predictors (Table 2). Both ascending aortic length and diameter proved to be independently related to the occurrence of ATAAD (OR 5.3, Cl 2.5-II.4, $\mathrm{p}<0.00$ I and $\mathrm{OR}$ 8.6, $\mathrm{Cl}$ 2.3-31.0, $\mathrm{p}=0.001$, respectively). 


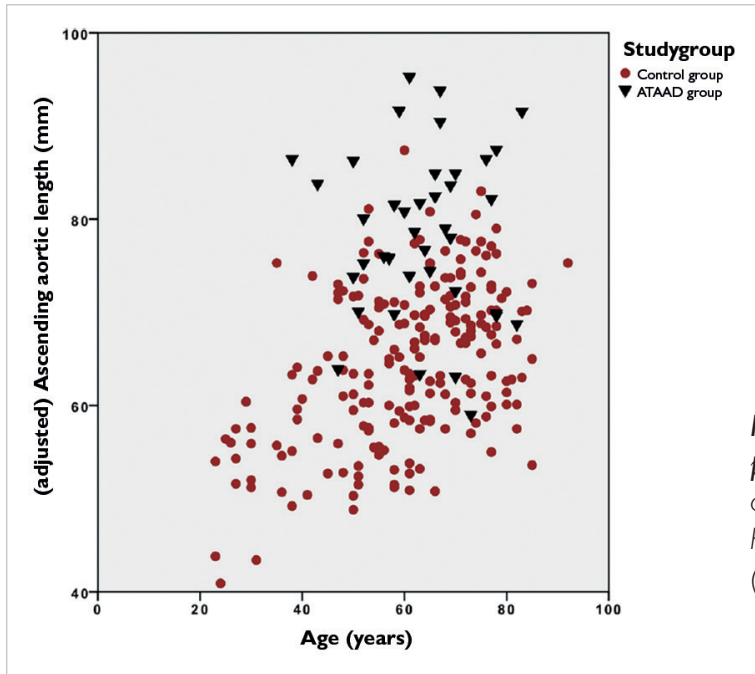

Figure 2. Ascending aortic length of ATAAD patients and healthy controls. Scatter plot pepicting the length of the ascending arto n althy controls (red) and ATAAD patints (black). ATAAD: Acute Type A Aortic Dissection.

Table I: Ascending aortic diameters in ATAAD patients.

\begin{tabular}{l|l|l|}
\hline Mean max. diameter $(\mathrm{mm}, \pm \mathrm{SD})$ & Non-adjusted diameters & Adjusted diameters \\
\hline Stratified max. diameter & $51.2 \pm 0.75$ & $39.4 \pm 0.57$ \\
\hline$<50 \mathrm{~mm}$ & & \\
\hline $50-55 \mathrm{~mm}$ & $17(43 \%)$ & $39(97 \%)$ \\
\hline$>55 \mathrm{~mm}$ & $10(25 \%)$ & $\mathrm{I}(3 \%)$ \\
\hline & $13(32 \%)$ & 0 \\
\hline
\end{tabular}

ATAAD: Acute Type A Aortic Dissection; mm: millimeter; SD: Standard Deviation.

Table 2: Binary logistic regression analysis for occurrence of ATAAD.

\begin{tabular}{|l|c|l|l|l|l|l|}
\hline & \multicolumn{3}{|c}{ Univariable } & \multicolumn{4}{c|}{ Multivariable } \\
\cline { 2 - 8 } & $\mathrm{OR}$ & $\mathrm{Cl}$ & $\mathrm{p}$-value & $\mathrm{OR}$ & $\mathrm{Cl}$ & $\mathrm{P}$-value \\
\hline Age & $\mathrm{I} .0$ & $0.9-1.1$ & 0.21 & & & \\
\hline Gender & 0.4 & $0.2-0.8$ & 0.01 & 1.9 & $0.6-6.0$ & 0.25 \\
\hline BSA & 9.0 & $1.9-44.2$ & 0.01 & 1.2 & $0.1-14.5$ & 0.89 \\
\hline Hypertension & 3.4 & $1.7-6.8$ & $<0.001$ & 1.3 & $0.5-3.5$ & 0.56 \\
\hline Diabetes & 0.3 & $0.0-2.0$ & 0.19 & 0.5 & $0.1-4.8$ & 0.54 \\
\hline Adjusted ascending aortic diameter $\mathbf{( c m )}$ & 7.8 & $4.1-14.6$ & $<0.001$ & 8.6 & $2.4-31.0$ & 0.001 \\
\hline Adjusted ascending aortic length $\mathbf{( c m )}$ & 31.8 & $11.1-90.9$ & $<0.001$ & 5.3 & $2.5-1 I .4$ & $<0.001$ \\
\hline
\end{tabular}

ATAAD: Acute Type A Aortic Dissection; BSA: Body Surface Area; OR: Odds Ratio; Cl: Confidence Intervals.
Propensity score matching

For covariate assessment, multivariable linear regression analysis was conducted in the contro group with ascending aortic length as dependent variable. Age, gender and BSA showed to be independent predictors for ascending aortic length (Table 3). These variables were therefore included in the model for calculation of propensity scores. Hypertension was also added to the model for balancing purposes. The propensity scores pre- and post-matching and their distribution are presented in the supplementary data (Supplementary Data 2). Eventually, 40 pairs were matched. After matching, there were no persisting differences in baseline characteristics between the two groups (Table 4).

Table 3: Univariable and multivariable linear regression analyses for assessment of covariates for aortic length in healthy controls.

\begin{tabular}{l|l|l|l|l|l|l|}
\hline & \multicolumn{3}{|c}{ Univariable } & \multicolumn{4}{c|}{ Multivariable } \\
& $\mathrm{R}$ & $\mathrm{P}$-value & $\mathrm{B}$ & $\beta$ & $\mathrm{Cl}$ & $\mathrm{P}$-value \\
\hline Age & 0.47 & $<\mathbf{0 . 0 0 I}$ & 0.25 & 0.46 & $0.18-0.32$ & $<\mathbf{0 . 0 0 I}$ \\
\hline Gender & 0.44 & $<\mathbf{0 . 0 0 I}$ & -4.63 & -0.30 & $-6.72--2.55$ & $<\mathbf{0 . 0 0 I}$ \\
\hline BSA & 0.29 & $<\mathbf{0 . 0 0 I}$ & 9.22 & 0.25 & $4.62-13.83<<0.001$ \\
\hline Hypertension & 0.33 & $<\mathbf{0 . 0 0 1}$ & 1.09 & 0.08 & $-0.77-3.52$ & 0.21 \\
\hline Diabetes & 0.06 & 0.35 & 1.60 & -0.05 & $-4.62-1.69$ & 0.36 \\
\hline
\end{tabular}

BSA: Body Surface Area; R: correlation coefficient; B: unstandardized regression coefficient; $\beta$ : standardized regression coefficient; Cl: Confidence Intervals.

Table 4: Post-matching baseline characteristics.

\begin{tabular}{|c|c|c|c|}
\hline & Control group $(n=40)$ & ATAAD group $(n=40)$ & P-value \\
\hline Age (years) & $65 \pm 13$ & $63 \pm 11$ & 0.65 \\
\hline Gender (male) & $24(60 \%)$ & $25(63 \%)$ & 1.00 \\
\hline BSA $\left(\mathbf{m}^{2}\right)$ & $1.95 \pm 0.20$ & $1.97 \pm 0.18$ & 0.80 \\
\hline Hypertension & $26(65 \%)$ & $25(63 \%)$ & 1.00 \\
\hline Diabetes & I (3\%) & I (3\%) & 1.00 \\
\hline \multicolumn{4}{|l|}{ Medication } \\
\hline Betablockers & II (28\%) & $10(25 \%)$ & 1.00 \\
\hline ACE-inhibitors & $14(35 \%)$ & $10(25 \%)$ & 0.46 \\
\hline Calciumblockers & $10(25 \%)$ & $3(8 \%)$ & 0.07 \\
\hline Diuretics & $9(23 \%)$ & $7(18 \%)$ & 1.00 \\
\hline
\end{tabular}

ATAAD: Acute Type A Aortic Dissection; SD: Standard Deviation, BSA: Body Surface Area; ACE: Angiotensine Converting Enzyme. 


\section{Aortic dimensions in dissection patients}

The adjusted length of the ascending aorta was significantly increased in the ATAAD group when compared to their propensity-matched healthy peers $(78.6 \pm 8.8$ vs. $68.9 \pm 7.2$ respectively, $\mathrm{p}<0.00 \mathrm{I})$. Adjusted maximum ascending aortic diameter was significantly increased as well $(39.4 \pm 0.57$ vs $34.4 \pm 0.32, p<0.001)$. Aortic arch length $(36.2 \pm 7.0$ vs. $34.3 \pm 11.9, p=0.39)$ and descending aortic length $(219.4 \pm 23.3$ vs. $210.4 \pm 28.1, p=0.13)$ did not differ significantly between the two matched groups (Table 5).

Table 5: Dimensions per segment.

\begin{tabular}{|l|l|l|l|}
\hline & $\begin{array}{l}\text { Control } \\
\text { group } \\
(\mathbf{n}=40)\end{array}$ & $\begin{array}{l}\text { ATAAD } \\
\text { group } \\
(\mathbf{n}=40)\end{array}$ & P-value \\
\hline Adjusted ascending aortic length $\mathbf{( m m )}$ & $68.9 \pm 7.2$ & $78.6 \pm 8.8$ & $<0.001$ \\
\hline Adjusted max. ascending aortic diameter $\mathbf{( m m})$ & $34.4 \pm 0.32$ & $39.4 \pm 0.57$ & $<0.001$ \\
\hline Aortic arch length $(\mathbf{m m})$ & $34.3 \pm 7.0$ & $36.2 \pm 11.9$ & 0.39 \\
\hline Descending aortic length $\mathbf{( m m )}$ & $219.4 \pm 23.3$ & $210.4 \pm 28.1$ & 0.13 \\
\hline
\end{tabular}

ATAAD: Acute Type A Aortic Dissection; SD: Standard Deviation

\section{DISCUSSION}

Acute type $\mathrm{A}$ aortic dissection is a catastrophic cardiovascular disease that carries high morbidity and mortality rates(16). Although aortic dilatation is a well-known risk factor for dissection, it can also occur in normal-sized aortas. Only $32 \%$ of dissection patients in the current study exhibited diameters on post-dissection scans that would qualify for prophylactic surgery, which is in accordance with previous studies that stated that the sole use of aortic diameters is insufficient for adequate risk prediction for $\operatorname{ATAAD}(8,9,14)$. In fact, when the acute diameter expansion after dissection onset is taken into account, $97 \%$ of patients would fail to meet the indication criterion of $<55 \mathrm{~mm}$, which is also in line with previously reported findings $(10)$. We hypothesized that, like dilatation, aortic elongation could also carry risk for dissection and use 3-D modeled CT to show that the adjusted ascending aorta of ATAAD patients is significantly longer than would have been expected based on age, gender and body posture. Our conclusions concur with those of Krüger et al., who were the first to investigate aortic length and diameters in dissected aortas and proposed a new risk scoring system based on these two anatomical variables $(17,18)$. However, in their study, the normal age-related changes of longitudinal aortic dimensions were not accounted for, and non ECG-gated scans were used for length and diameter measurements. Besides the differences in aortic dimensions between ATAAD patients and healthy controls, we additionally investigated the role of ascending aortic length and diameter in the occurrence of ATAAD using a regression model. This model also included predisposing factors like age, BSA, diabetes and hypertension. Length and diameter increase both proved to be significantly associated with an increased risk for ATAAD (with every centimeter increase of ascending aortic length carrying a 5 -fold risk of ATAAD occurrence). A similar significant increase in risk was demonstrated for diameter expansion. We therefore endorse the vision of Krüger et al. for a multifactorial risk scoring system for the prediction of ATAAD, which would include both aortic length and diameter(I8). Ideally, also factors like aortic curvature(19), genetic predisposition(20), and hemodynamics(2l) would be included in this model.

Of note, the aortic arch and descending aorta were not elongated in ATAAD patients. In healthy controls however, elongation and tortuosity of these segments is not uncommon. The question arises if the etiology of aortic elongation, like aneurysm formation, differs per anatomical segment. It has been well-described that aneurysm disease divides itself into two entities, one involving the ascending aorta and one involving the descending aorta(22). The distinct embryological origin of the aorta's smooth muscle cells (the smooth muscle cells of the ascending aorta derive from the neural crest, while those of the descending aorta derive from somatic mesoderm) are thought to attribute to this segmental predisposition of aneurysm formation(23). Likewise, and in accordance with the findings of the current study, it is conceivable that the extent of aortic elongation varies per segment and concentrates solely in the ascending aorta in patients suffering from ATAAD.

\section{Limitations}

Some limitations of the current study should be addressed. First, we used a cross-sectional study design. To evince a clear causal relationship between aortic elongation and dissection, a prospective and longitudinal study design should be conducted. However, given the low incidence rate of ATAAD and the time span that is required to investigate an aging process like aortic elongation it would be challenging to perform such a study. We therefore consider our study design combined with modeling of dimensions to be the best achievable alternative.

Second, we measured aortic diameters in the healthy control group using non-ECG gated CT. The accuracy of diameter measurements in the control group could benefit from ECG-gating on CT(24). However, reference values for aortic diameters are mostly based on non-triggered scans and in daily practice, the majority of diameter and circumferential measurements are performed on non-ECG-gated images $(6,25)$.

Finally, aortic modeling was performed using a generalized algorithm in all patients. However, the actual increase in diameter and length after dissection onset may differ between patients.

\section{CONCLUSION}

Ascending aortic diameter is an insufficient stand-alone predictor for the occurrence of ATAAD. The current study demonstrated ascending aortic diameter and length to contribute equally to the occurrence of dissection. Furthermore, we have shown that the ascending aorta of ATAAD patients is significantly longer compared to their propensity matched counterparts. No difference was found between the lengths of the aortic arch and descending aorta, implying ATAAD to have a specific pathophysiological origin in the ascending aorta. 


\section{REFERENCES} based study of incidence and outcome of acute aortic
dissection and premorbid risk factor control: 10 -year results from the Oxford Vascular Study. Circulation 2013;127:2031-7.

2 Olsson C, Thelin S, Stahle E, et al. Thoracic aortic aneurysm and dissection: increasing prevalence and population-based study of more than 14,000 cases from 1987 to 2002. Circulation 2006; ;14:2611-8.

3 Mehta RH, Suzuki T, Hagan PG, et al. Predicting death in patients with acute type a aortic dissection. Circulation

Parish LM, Gorman JH, 3rd, Kahn S, et al. Aortic size in acute type A dissection: implications for preventive
ascending aortic replacement. Eur $\mid$ Cardiothorac Surg 2009;35:941-5; discussion 5-6.

5 Erbel R, Aboyans V, Boileau C, et al. 2014 ESC Guidelines on the diagnosis and treatment of aortic diseases: Document covering acute and chronic aortic diseases of Force for the Diagnosis and Treatment of Aortic Diseases of the European Society of Cardiology (ESC). Eur Heart 2 2014;35:2873-926.

6 Hiratzka LF, Bakris GL, Beckman JA, et al. 2010 ACCF/ AHA/AATS/ACR/ASA/SCA/SCAI/SIR/STS/SVM guidelines for the diagnosis and management of patients College of Cardiology Foundation/American Heart Association Task Force on Practice Guidelines. American Association for Thoracic Surgery, American College of Radiology, American Stroke Association, Society of Cardiovascular Anesthesiologists, Society for Cardiovascular Angiography and Interventions, Society of 2010;121:e266-369.

7 Davies RR, Goldstein LI, Coady MA, et al. Yearly rupture or dissection rates for thoracic aortic aneurysms: simple prediction based on size. Ann Thorac Surg 2002; 73:17-27,
discussion -8.

Pape LA Tsai

A, Tsai TT, Isselbacher EM, et al. Aortic diameter $>$ or $=5.5 \mathrm{~cm}$ is not a good predictor of type A aortic of Acute Aortic Dissection (IRAD). Circulation 2007;116:1120-7.

Kim EK, Choi SH, Sung K, et al. Aortic diameter predicts acute type $\mathrm{A}$ aortic dissection in patients with Marfan J Thorac Cardiovasc Surg 2014;147:1505-10.

10 Rylski B, Branchetti E, Bavaria JE, et al. Modeling of predissection aortic size in acute type $\mathrm{A}$ dissection: more than $90 \%$ fail to meet the guidelines for elective ascending replacement. The Journal of thoracic and Hirst AE, Jr Johns VJ, Jr. Kime SW.

Jime SW, Jr. Dissecting (Baltimore) 1958;37:217-79.

12 O'Rourke M, Farnsworth A, O'Rourke J. Aortic dimensions and stiffness in normal adults. JACC Cardiovas

Goldstein SA, Evangelista A, Abbara S, et al. Multimofrom the American Society of Echocardiography and the
European Association of Cardiovascular Imaging: dorsed by the Society of Cardiovascular Computed Resonance. I Am Soc Echocardiogr 2015:28:119-82.

Rylski B, Blanke P, Beyersdorf F, et al. How does the ascending aorta geometry change when it dissects? J Am

changes in aortic geometry throughout life. Eur J Cardiothorac Surg 2014;45:805-11.

16 Tsai TT, Trimarchi S, Nienaber CA. Acute aortic

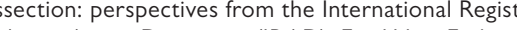
Acute Aortic Dissection Kuner T, Forkasets O, $V$

the Veseli K, et al. Ascending aortic Surg 2016;50:241-7.

18 Kruger T, Oikonomou A, Schibilsky D, et al. Aortic Angation and the risk for dissection: the Tubn Cardic

Poullis MP, Warwick R, Oo A, et al. Ascending aortic and ascending aortic aneurysm formation: a mathematica model. Eur J Cardiothorac Surg 2008:33:995-1001.

20 Elefteriades JA, Pomianowski P. Practical genetics of thoracic aortic ancurysm. Prog Cardovasc D

in diagnosis, Eagle KA. Aortic dissection: new frontiers diagnostic strategies. Circulation 2003;108:628-35.

22 Coady MA, Davies RR, Roberts M, et al. Familial pattern of thoracic aortic aneurysms. Arch Surg 1999;134:361-7.

of human vascular smooth muscle subtypes pration Insight into embryologicat origin-dopendent disease susceptibility. Nat Biotechnol 2012;30:165-73.

24 Morrison TM, Choi G, Zarins CK, et al. Circumferential Mo longitudinal cyclic strain of the human thoracic aorta. age-related changes.J Vasc Surg 2009,49.1029-36. Diameters of the thoracic aorta thrord $U$, et al. measured with helical computed tomography I Thorac Cardiovasc Surg 2002;123:1060-6. 
Age-dependent aortic elongation: a new predictor for type A aortic dissection?

Ibrahim Akin ${ }^{1,2}$

Christoph A. Nienaber ${ }^{3}$

I. Department of Cardiology, Universitätsmedizin Mannheim, Mannheim, Germany

2. Deutsches Zentrum für Herzkreislaufforschung, Mannheim, Germany

3. Cardiology and Aortic Centre, Royal Brompton Hospital and Harefield Trust, London, United

Kingdom

Heart 2018 Nov;104(21):1729-1730. 
Aortic dissection is a relatively rare condition with catastrophic outcomes if left untreated. The classification of this pathology is essentially based on its anatomical location or acuity. Data from the International Registry for Acute Aortic Dissection (IRAD) revealed that in the absence of immediate surgical repair, acute type A aortic dissection (ATAAD) is associated with a $24 \%$ mortality in the first 24 hours, $29 \%$ at 48 hours, $44 \%$ at day 7 and $50 \%$ after 2 weeks. Despite major advances in diagnostic yield, the early clinical diagnosis of aortic dissection remains elusive in up to $38 \%$ of patients. Furthermore, in $28 \%$ of cases the correct diagnosis was ascertained only after postmortem examination(I). The most common risk factor associated with aortic dissection is systemic hypertension, with up to $72 \%$. Particularly in the

elderly, other major risk factors include atherosclerosis, prior cardiac surgery and known aortic aneurysms. With younger age ( $<40$ years), hereditary conditions of aortopathology (eg. Marfan syndrome and other genetic factors) constitute a significant fraction of cases of aortic dissection(I). Despite recent advances in identifying structural and biomechanical properties of the aorta in vivo, a variety of determinants for the evolution to an aortic dissection are still unclear. The common denominator is a weakening of the aortic tunica media, which predisposes to dissection by splitting the cohesive layers of the aortic wall. This weakening of the tunica media could be due to either a derangement or possibly a loss of structural elements in the media layer, including elastin, collagen, non-fibrous matrix and smooth muscle cells. Aortic diameter is currently the best-evaluated predictor for aortic dissection with specific 'hinge points' at which rupture or dissection is increasingly likely to occur. These hinge points are set a around $6 \mathrm{~cm}$ for the ascending aorta and $7 \mathrm{~cm}$ for the descending aorta(2), with current recommendations for preventive treatment when the diameter exceeds $5.5 \mathrm{~cm}$ regardless of location. For patients with Marfan syndrome or other hereditary conditions, bicuspid aortic valve or family history of aortic dissection, the threshold is set lower at $4.5 \mathrm{~cm}^{2}$ or $5.0 \mathrm{~cm}^{3}$. Interestingly, a substantial number of patients dissect at an aortic diameter less than $5.5 \mathrm{~cm}$. The IRAD registry showed nearly $60 \%$ of patients with type A dissection had an aortic diameter $<5.5$ $\mathrm{cm}$ and almost $40 \%$ had diameters $<5.0 \mathrm{~cm}(4)$, suggesting that aortic diameter alone is an insufficient marker to predict the risk of dissection, and highlighting the need for better predictors. A detailed discussion on aortic dimensions and geometry in healthy individuals and in patients with ATAAD was presented in the Heart paper. The first article evaluated the aortic length of 210 consecutive routine non-dissected patients with contemporary CT. The length of the thoracic aorta was significantly related to age $(r=0.54 ; p<0.001)$, with an increase of $59 \mathrm{~mm}$ in men and $66 \mathrm{~mm}$ in women noticed between the ages of 20 and 80 years, reflecting a longitudinal growth to approximately $125 \%$. Such correlation was found for the ascending aorta, arch and proximal part of the descending aorta, while the distal part of the descending thoracic aorta failed to show such a relationship between age and length $(p=0.178)$. Elongation was most prominent in the proximal part of the descending thoracic aorta (247\%), followed by the arch $(169 \%)$ and the ascending thoracic aorta (142\%). Additionally, a change in geometry was notice by a distalward shift in the aortic apex from type I to type II aorta(5). A separate back-to-back publication compared the control group with 40 patients with ATAAD and adjusted the data to predissection dimensions. Elongation of the ascending aorta and diameter proved both to be independent predictors of dissection (OR=5.3, $\mathrm{Cl} 2.5$ to II.4, $\mathrm{p}<0.00 \mathrm{I}$; $\mathrm{OR}=8.6, \mathrm{Cl} 2.4$ to 31.0 $p=0.001$, respectively). The ascending aorta was longer and more dilated in patients with ATAAD compared with healthy controls $(78.6 \pm 8.8 \mathrm{~mm}$ vs $68.9 \pm 7.2 \mathrm{~mm}, \mathrm{p}<0.001 ; 34.4 \pm 3.2 \mathrm{~mm}$ v $39.4 \pm 5.7 \mathrm{~mm}, \mathrm{p}<0.00 \mathrm{I}$, respectively). Meanwhile, longitudinal elongation in both the aortic arch and the descending aorta was not predictive(6). Current guidelines regarding replacement of ascending aorta are based on diameters only. Interestingly, of the 343 patients who had undergone $\mathrm{CT}$ angiography $<2$ years before and within 12 hours after aortic dissection onset,
334 (97\%) patients had an ascending aorta diameter of $<5.5 \mathrm{~cm}$ and $315(92 \%)$ patients had a diameter $<5 \mathrm{~cm}$ before dissection(7). Similar to the IRAD experience(4), more than $60 \%$ of women and $70 \%$ of men had a non-dilated ascending aorta before the onset of a type $A$ dissection(8), corroborating a need for more powerful aortic event predictors. This could be elongation of the ascending aorta as suggested and emphasized by the Maastricht group. It is generally believed that the aorta and large elastic arteries become tortuous with ageing. In this regard, the cross-sectional, propensity-matched study of non-cardiovascular patients was helpfu in evaluating the geometric change during the ageing process dominated by lifelong exposure to pulsatile strain resulting in fracture and breakdown of elastin. Besides elongation and dilatation, this theory explains the age-related vascular stiffening as the reduction of elastin content impairs vessel compliance. Elastin content is highest in the aortic arch and proximal descending aorta. Furthermore, the mobile proximal aortic segments can move relatively free in the longitudinal direction as compared with the fixed distal parts. As circumferential strain values are comparable throughout the entire thoracic aorta, this provides a plausible explanation for an increasing diameter in the distal aorta but more elongation in the proximal aorta and arch. This observation is supported by independent finite element stress analysis with peak wall stress present both above the sinotubular junction, and distal to the left subclavian artery, thereby setting a local

stage for aortic dissection(9). Progressive ascending aortic growth in women, and the observation that both genders have similar absolute diameters at an older age, could provide the basis for the observation that aortic dissection is more predominant among men at younger age than women, while this difference between genders evens out with older age $(I 0)$. Thus both the dynamic diameter and the length of the aorta play an important role in the pathophysiology of aortic dissection. Nevertheless, it should be emphasised that aortic dissection is triggered by multiple other factors. Previous guidelines recommended treatment based on hinge points in aortic diameter as a sole criterion, which however is insufficient. While the group in Maastricht effectively examined the influence of aortic elongation by geometric analysis as one new risk predictor, even the development of some global risk score with cut-off values is unlikely to cover all aspects of this disease entity. In addition to the classical comorbidities, haemodynamic and anatomical conditions, genetics, traumatic, iatrogenic and inflammatory factors certainly play an important role and should eventually be taken into consideration in the future. 


\section{REFERENCES}

(Isselbacher EM, et al. The Interinsights into an old disease. JAMA 2000;283:897-903. . Elefteriades JA, Farkas EA. Thoracic aortic aneurysm clinically pertinent controversies and uncertainties. J Am Coll Cardiol 2010;55:841-57.

rel $\mathrm{d}$, Aboyans V, Bolleau C, et al. 2014 ESC GuideDocument covering acute and chronic aortic diseases of the thoracic and abdominal aorta of the adult. The task force for the diagnosis and treatment of aortic diseases of the European Society of Cardiology (ESC). Eur Heart

Pape LA, Tsai TT, Isselbacher EM, et al. Aortic diameter Por $=5.5 \mathrm{~cm}$ is not a good predictor of type $A$ aortic
dissection: observations from the international Registry of Acute Aortic Dissection (IRAD). Circulation

2007; 116:1120-7.

5. Adriaans $B P$, Heuts $S$, Gerretsen $S$, et al. Aortic elongation part l: the normal aortic ageing process. Heart
Published Online First: 28 March 2018 . doi: 10.1136/ heartjnl-2017-312866.

6. Heuts S, Adriaans BP, Gerretsen S, et al. Aorticelongation part II: the risk of acute type $\mathrm{A}$ aortic dissection.
Heart Published Online First: 28 March 2018. doi: Heart Published Online First: 28 March 2018. doi
10.1136/heartinl-2017-312867.

10.1136/heartinl-2017-312867.
Rylski B, Blanke P, Beyersdorf F, et al. How does the ascending aorta geometry change when it dissects?] Am
Coll Cardiol 2014;63:1311-9.

Rylski B, Branchetti E, Bavaria JE, et al. Modeling of predissection aortic size in acute type $A$ dissection. mor replacement. J Thorac Cardiovasc Surg 2014; 148:944-8. acute aortic dissection: a finite element stress analysis. Ann Thorac Surg 2011;99: :458-63. Rylski B, Desjardins B, Moser W, et al. Gender-related
changes in aortic geometry throughout life. Eur J Cardiothorac Surg 2014;45:805-11. 
Supplementary data I: Baseline characteristics before propensity score matching.

\begin{tabular}{|c|c|c|c|}
\hline & $\begin{array}{l}\text { Control group } \\
(n=40)\end{array}$ & $\begin{array}{l}\text { ATAAD group } \\
(n=40)\end{array}$ & $\mathrm{P}$-value \\
\hline Age (years) & $62.0[23-92]$ & 63.5 [38-83] & 0.39 \\
\hline Gender (male) & $82(39 \%)$ & 25 (63\%) & 0.01 \\
\hline BSA $\left(m^{2}\right)$ & $1.86 \pm 0.22$ & $1.97 \pm 0.18$ & $<0.001$ \\
\hline Hypertension & 69 (33\%) & $25(63 \%)$ & $<0.001$ \\
\hline Diabetes & $19(9 \%)$ & I (2\%) & 0.21 \\
\hline $\begin{array}{l}\text { Medication } \\
\text { Betablockers } \\
\text { ACE-inhibitors } \\
\text { Calciumblockers } \\
\text { Diuretics }\end{array}$ & $\begin{array}{l}41(20 \%) \\
39(19 \%) \\
23(11 \%) \\
35(17 \%)\end{array}$ & $\begin{array}{l}10(25 \%) \\
10(25 \%) \\
3(8 \%) \\
7(18 \%)\end{array}$ & $\begin{array}{l}0.52 \\
0.39 \\
0.78 \\
1.00\end{array}$ \\
\hline
\end{tabular}

\section{SUPPLEMENTARY DATA}

Supplementary data 2: Distribution of propensity scores pre and post matching.
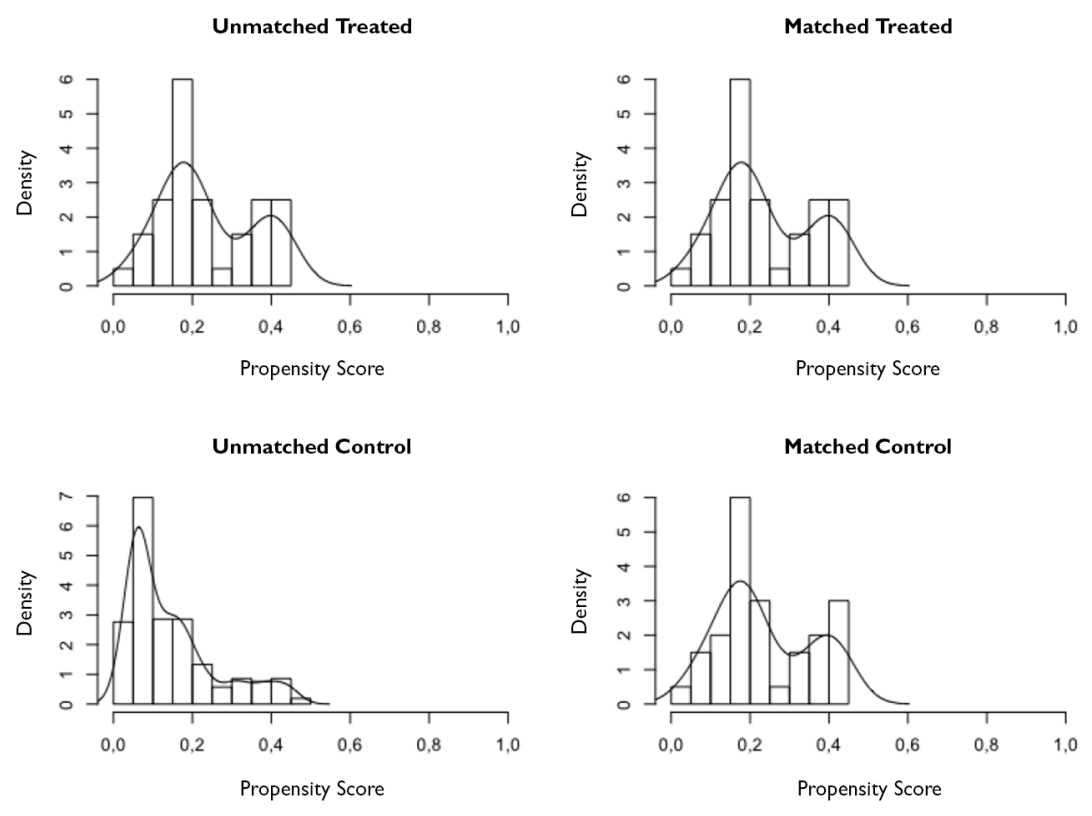
Bouke P. Adriaans, MD',2,3*

Samuel Heuts, MD, PhD ${ }^{3,4 *}$

Bartosz Rylski, MD ${ }^{5}$

Casper Mihl, MD, PhD ${ }^{1,3}$

Sebastiaan C.A.M. Bekkers, MD, PhD ${ }^{2,3}$

Jules R. Olsthoorn, MD

Ehsan Natour, MD 4,7

Heleen J. Bouman, MD, PhD

Mikolaj Berezowski, MD

Kinga Kosiorowska, MD

Harry J.G.M. Crijns, MD, PhD ${ }^{2,3}$

Jos G. Maessen, MD, PhD ${ }^{3,4}$

oachim E. Wildberger, MD, PhD

Simon Schalla, MD, PhD $D^{1,2,3}$

Peyman Sardari Nia, MD, $\mathrm{PhD}^{3,4}$

* Both authors contributed equally

I. Department of Radiology and Nuclear Medicine, Maastricht University Medical Center+ Maastricht, the Netherlands

2. Department of Cardiology, Maastricht University Medical Center+, Maastricht, the Netherlands

3. Cardiovascular Research Institute Maastricht (CARIM), Maastricht University, Maastricht, the Netherlands

4. Department of Cardiothoracic Surgery, Maastricht University Medical Center+, Maastricht, the Netherlands

5. Department of Cardiovascular Surgery, Heart Centre Freiburg University, Faculty of Medicine, University of Freiburg, Freiburg, Germany

6. Department of Cardiothoracic Surgery, Catharina Hospital, Eindhoven, the Netherlands

7. Department of Thoracic and Cardiovascular Surgery, Uniklinik RWTH Aachen, Aachen, Germany

8. Department of Internal Medicine, Maastricht University Medical Center+, Maastricht, the Netherlands

9. Department of Cardiac Surgery, Wroclaw Medical University, Wroclaw, Poland

\section{Evaluating the diagnostic accuracy of maximal aortic diameter, length and volume for prediction of aortic dissection}




\section{OBJECTIVE}

Management of thoracic aortic aneurysms (TAAs) comprises regular diameter follow-up until the indication criterion for prophylactic surgery is reached. However, this approach is unable to predict the majority of acute type $A$ a artic dissections (ATAADs). The current study aims to evaluate the diagnostic accuracy of ascending aortic diameter, current study aims to evaluate the diagnostic
length and volume for occurrence of ATAAD.

\section{METHODS}

This two-center observational cohort study retrospectively screened 477 consecutive patients who presented with ATAAD between 2009 and 2018. Of those, 25 (5.2\%) underwent computed tomography angiography (CTA) within two years before dissection onset. Aortic diameter, length and volume of these patients ('pre-ATAAD') were compared with those of TAA controls $(n=75)$. Receiver operating curve $(R O C)$ analysis

\section{RESULTS}

$96 \%$ of pre-ATAAD patients did not meet the surgical diameter threshold of $55 \mathrm{~mm}$ before dissection onset. Maximal aortic diameters (45 [40-49] mm vs. 46 [44-49] mm, $\mathrm{p}=0.075)$ and volume $\left(126[95-157] \mathrm{cm}^{3}\right.$ vs. $\left.124[102-136] \mathrm{cm}^{3}, \mathrm{p}=0.909\right)$ were comparable between pre-ATAAD patients and TAA controls. Conversely, ascending aortic length $(84 \pm 9 \mathrm{~mm}$ vs. $90 \pm 16 \mathrm{~mm}, p=0.031)$ was significantly larger in pre-ATAAD patients. All three parameters had an area under the curve of $>0.800$. At the $55 \mathrm{~mm}$ cut-off point, the maximal diameter yielded a positive predictive value (PPV) of $20 \%$. While maintaining same specificity levels, measurements of aortic volume and length showed superior diagnostic accuracy (PPV 55\% and 70\%, respectively).

\section{CONCLUSION}

Measurements of aortic volume and length have superior diagnostic accuracy compared to the maximal diameter and could improve the timely identification of patients at risk for ATAAD.

\section{KEYWORDS}

Aortic dissection, aortic diameter, aortic elongation, $\mathrm{CT}$, risk prediction

\section{KEY POINTS}

- Large registries have demonstrated that more than half of dissection patients present with diameters below the threshold for prophylactic surgery.

- Ascending aortic length is significantly increased in dissection patients compared to TAA controls. Measurements of aortic length and volume have superior diagnostic accuracy over diameters for prediction of dissection.

- Clinical implementation of aortic length and volume measurements might improve the selection of patients who benefit from preventive aneurysmectomy.

\section{NTRODUCTION}

Acute type A aortic dissection (ATAAD) is a medical emergency that carries high morbidity and mortality rates. Only half of patients survive until arrival at the hospital for emergency surgery, and another $20 \%$ of these die perioperatively due to severe disease complications (such as end-organ malperfusion)(I-3). To date, the maximal aortic diameter is the only recognized anatomic predictor for dissection and rupture. It has been shown that the probability for these to occur increases substantially when cross-sectional dimensions exceed 60 millimeters $(\mathrm{mm})(4)$ Since the disruption risk inherent to smaller thoracic aortic aneurysms (TAAs) is low, it does not outweigh the risks of pre-emptive surgery. Therefore, current guidelines recommend referring patients for aneurysm extirpation when the maximal diameter grows beyond $55 \mathrm{~mm}(5-7)$ Despite their low risk, the relatively large number of patients with small TAAs cause more than $50 \%$ of dissections to develop in aortas below this size criterion - the so-called 'aortic size paradox'(7-9). Since lowering interventional thresholds would not necessarily imply a net mortality benefit (i.e., it would expose a large low-risk population to the considerable risk of surgery) recent studies have debated the clinical value of maximal diameter measurements and focused on the identification of new predictors in an attempt to enhance individualized risk assessment.

Arguably the most important limitation of maximal diameter measurements is the observation that these do not adequately represent the three-dimensional process of aortic growth. Elongation and cylindrical deformation (i.e., diameter growth proximally or distally from the widest portion of the aneurysm sac) are two scenarios of aortic remodeling that have shown to occur regardless of maximal diameter increase $(10,1 \mathrm{I})$. Therefore, measurements of aortic volume and length could provide additional information over diameters with regard to the detection of aneurysm progression. Whereas the predictive value of aortic volumetry has not yet been investigated, several studies have evaluated the potential role of excessive vessel lengthening in the pathophysiology of dissection(12-14). Although all of these studies reported that ATAAD patients had elongated ascending aortas when compared to healthy controls, these reports mainly included post-dissection measurements. This approach is debatable, since it has been shown that the aorta acutely dilates and elongates when it dissects(15). In the current retrospective cohort study, we have identified a group of patients who - for various indications had undergone computed tomography angiography (CTA) within two years from ATAAD onset. Using this cohort, we were able to assess the geometry of the aorta shortly prior to dissection. By comparing findings with those of TAA controls, his study aimed to evaluate the diagnostic accuracy of ascending aortic diameter, length, and volume for the occurrence of acute type A aortic dissection.

\section{MATERIALS AND METHODS}

\section{Study population}

We retrospectively reviewed the clinical databases of the Maastricht University Medical Center+ and Heart Centre Freiburg University between January 2009 and December 2018 for patients who were diagnosed with ATAAD and underwent CTA within two years before dissection onset. Patients with a history of cardiothoracic surgery, connective tissue disease (such as Marfan's syndrome, Loeys-Dietz, or Ehlers-Danlos) or bicuspid aortic valve (BAV) were excluded. The remaining patients were included to form the study population ('pre-ATAAD').

Consecutive patients who underwent CTA at the Maastricht University Medical Center+ between January 2018 and December 2018 were included in the control groups. Exclusion criteria comprised (suspected) acute aortic syndrome, prior cardiothoracic or aortic surgery, 
known BAV, and presence of any medical condition that might distort aortic shape (such as pulmonary malignancy or pneumothorax). The enrolled patients were subdivided into a group of apparently healthy controls (maximal ascending aortic diameter $<40 \mathrm{~mm}$ ), and a group of TAA patients (maximal diameter $\geq 40 \mathrm{~mm}$ ). The local ethical committees approved the study protocol and waived the need for informed consent due to the observational character of the study.

\section{Patient and public involvement}

This research was done without patient involvement.

Image acquisition and analysis

All patients underwent contrast-enhanced CT on a second-generation (Maastricht and Freiburg) or third-generation (Maastricht) dual-source scanner (SOMATOM Definition Flash and SOMATOM Force, Siemens Healthineers, Forchheim, Germany, respectively). Pre-ATAAD and TAA patients typically underwent a dedicated aortic scan protocol that comprised a native CT of the entire aorta, a retrospective ECG-gated helical CT angiography (CTA) of the ascending aorta in caudocranial direction, and a non-ECG-triggered high-pitch scan (flash) from the aortic arch to the femoral bifurcation. Scans of the ascending aorta were acquired at slice thickness 0.6 $\mathrm{mm}$ using automated dose modulation (CARE kV, CareDose 4DTM, Siemens Healthineers). They were reconstructed at an increment of $0.4 \mathrm{~mm}$ using raw-data based iterative reconstruction algorithms (Sinogram Affirmed Iterative Reconstruction [SAFIRE] or Advanced Modelled Iterative Reconstruction [ADMIRE], strength 3, dependent on scanner type). Comprehensive overviews of the various scan parameters per scanner are provided in Supplementary Tables and 2. Scans of healthy controls were performed using oncological or vascular workflows, without ECG synchronization of the respective datasets. Monomeric, non-ionic, low-osmolar iodinated contrast medium $(300 \mathrm{mgl} / \mathrm{ml}$; lopromide; Bayer Healthcare, Berlin, Germany) was prewarmed to standardized $37^{\circ} \mathrm{C}$ before injection in the antecubital vein using catheter sizes between 18-22G. The injection parameters were monitored by a data acquisition system Certegra $^{\text {TM }}$ Informatics Solution, Bayer Healthcare).

Images were analyzed by a single observer who was blinded for patient history (B.A., five years of experience in cardiovascular imaging), using a commercially available software package (Syngo.via ${ }^{\mathrm{TM}}$, Siemens Healthineers). Maximal diameters were measured orthogonal to the vessel centerline using the inner edge to inner edge technique (Figure IA and ID). Measurements of length and volume were performed on a $3 \mathrm{D}$ reconstruction of the thoracic aorta with automatically fitted centerline (Figure IB-C and IE-F). The ascending aorta was defined as the part between the sinotubular junction (STJ) and the origin of the brachiocephalic trunk. Segment ength was measured as the centerline distance between the mentioned anatomic landmarks. The luminal volume was calculated using the adaptive region growing tool provided by the software. Clicking into the vessel initiated a region growing algorithm by segmenting connected voxels of a similar enhancement. Contours were corrected manually in the axial slices when required. Eventually, the volume of the segmentation was calculated automatically by multiplying reconstruction increment. Measurements were repeated in a random sample of 20 patients by the same observer and also carried out by a second observer (S.H., three years of experience) in order to test intra- and interobserver variability.

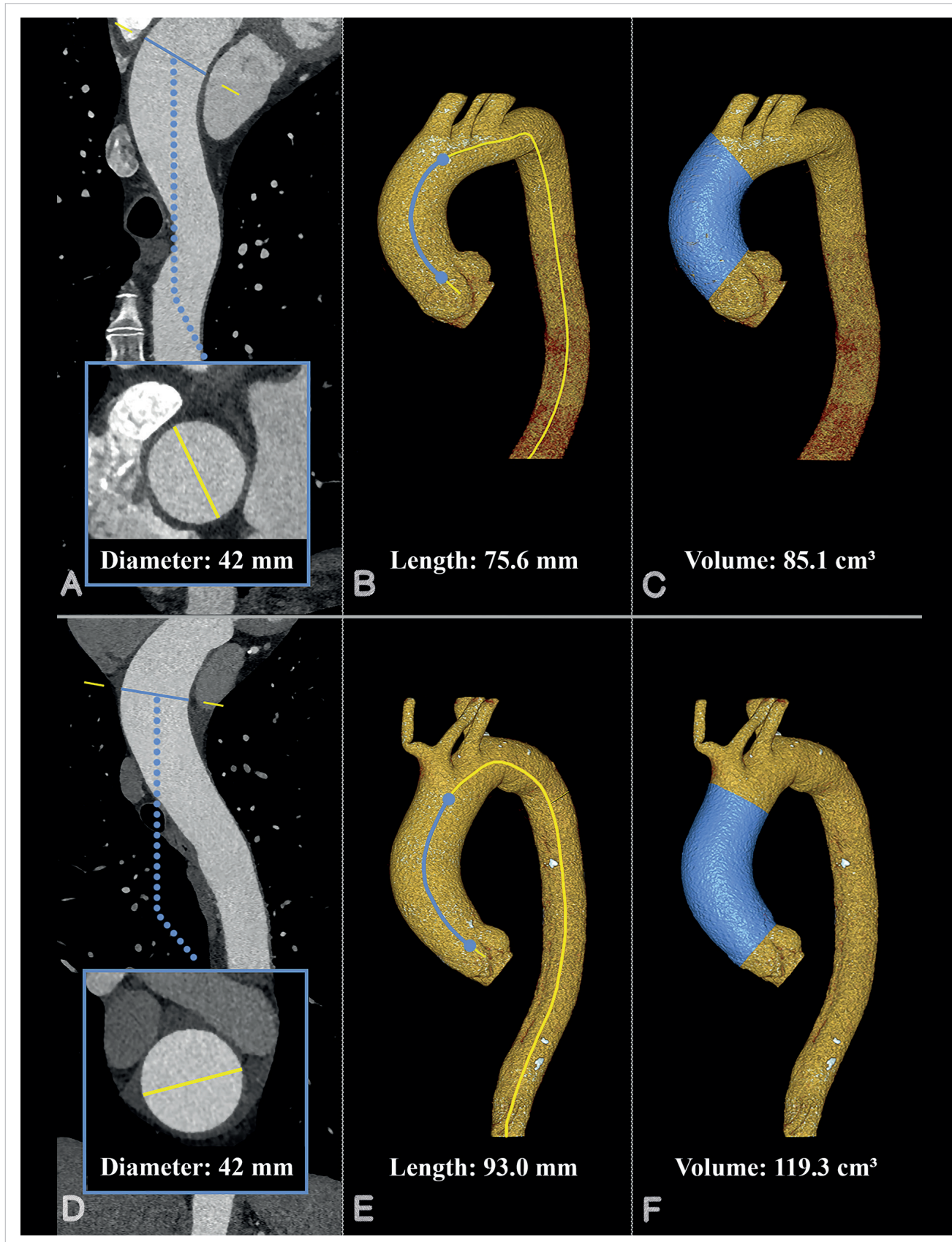

Figure I. Methodology of the three different aortic measurements in a TAA patient and a pre-ATAAD patient. A-C demonstrate aortic measurements in a TAA patient. Panel A depicts a stretched view of the curved planar $C$ reconstruction with diameter measurement perpendicular to the centerline. The two right panels display a 3D CT mode with measurements of ascending aortic length (B) and volume (C). D-F demonstrate similar measurements in a pre-ATAAD patient. Despite equal diameters, the pre-ATAAD patient exhibits a notably longer and larger ascending aorta. PD: three-dimensiona CT: computed tomography: TAA: thoracic aortic aneurysm: ATAAD: acute type A oortic dissection. 


\section{Statistical analysis}

Statistical analysis of the data was performed using commercially or freely available software (SPSS version 24, IBM, Armonk, New York, USA; or R Statistics, the R Foundation, Vienna, Austria). Continuous data are presented as mean \pm standard deviation (SD) (or median and interquartile range [IQR] in the presence of skewedness) and were compared using the student $t$-test or Mann-Whitney $U$-test. Categorical data are expressed as frequencies and percentages and were compared using the Chi-square test. A p-value $<0.05$ was considered statistically significant.

Receiver operating characteristic (ROC) analysis was applied to measure the predictive accuracy of the three measurements, with the calculated area under the curve (AUC) representing the quality of discrimination. The specificity of the current surgical diameter cut-off $(55 \mathrm{~mm})$ was calculated with corresponding sensitivity and used as reference to determine the sensitivities of aortic length and volume at that specificity level. McNemar's test was used to compare sensitivities between groups (DTComPair, R Statistics)(16, 17). In terms of diagnostic accuracy, positive predictive value (PPV) and negative predictive value (NPV) were reported along with $95 \%$ confidence intervals $(\mathrm{Cl})$.

Finally, intra- and interobserver agreement was analyzed using intraclass correlation coefficient (ICC) and normalized Bland-Altman analysis.

\section{RESULTS}

The demographic data of the different patient groups are presented in Table I. Between anuary 2010 and December 2018, a total of 477 patients were diagnosed with ATAAD at the participating institutions. Of those, 25 (5.2\%) had undergone CTA within two years before dissection onset. The median time interval between the pre-ATAAD scan and the actual dissection was 124 days [IQR 34-543 days].

In total, 258 healthy controls and 75 TAA patients were enrolled in the control groups. scan indications for healthy controls ranged from evaluation of pulmonary nodules $(45.3 \%)$ to suspicion of pulmonary embolism (45.0\%), pneumonia (5.8\%), and other (3.9\%). All TAA patients underwent $\mathrm{CT}$ for periodical diameter surveillance.

Table I. Baseline characteristics.

\begin{tabular}{|l|l|l|l|l|}
\hline & Healthy controls & \multicolumn{2}{|c}{ Aortopathy } & p-value* \\
& $(\mathrm{n}=258)$ & $\begin{array}{l}\text { TAA controls } \\
(\mathrm{n}=75)\end{array}$ & $\begin{array}{l}\text { Pre-ATAAD } \\
(\mathrm{n}=25)\end{array}$ & \\
\hline Age (years) & $64[53-73]$ & $69[61-75]$ & $69[63-78]$ & 0.668 \\
\hline Gender $(\mathbf{m a l e})$ & $114(44 \%)$ & $50(67 \%)$ & $15(60 \%)$ & 0.457 \\
\hline Height $(\mathbf{c m})$ & $170 \pm 9$ & $174 \pm 7$ & $174 \pm 7$ & 0.767 \\
\hline Weight $\mathbf{( k g )}$ & $73[64-85]$ & $80[72-90]$ & $78[70-87]$ & 0.347 \\
\hline BMI $\left(\mathbf{k g} / \mathbf{m}^{2}\right)$ & $25.5[22.3-28.8]$ & $27.1[24.5-29.6]$ & $25.6[23.4-27.7]$ & 0.141 \\
\hline BSA $\left(\mathbf{m}^{2}\right)$ & $1.9 \pm 0.2$ & $2.0 \pm 0.2$ & $1.9 \pm 0.2$ & 0.496 \\
\hline Hypertension & $93(36 \%)$ & $56(75 \%)$ & $18(72 \%)$ & 0.710 \\
\hline Smoking & $83(32 \%)$ & $19(25 \%)$ & $4(16 \%)$ & 0.530 \\
\hline
\end{tabular}

Table I. (continued)

\begin{tabular}{|c|c|c|c|c|}
\hline & \multirow{2}{*}{$\begin{array}{l}\text { Healthy controls } \\
(n=258)\end{array}$} & \multicolumn{2}{|c|}{ Aortopathy } & \multirow[t]{2}{*}{$\mathrm{p}$-value* } \\
\hline & & $\begin{array}{l}\text { TAA controls } \\
(n=75)\end{array}$ & $\begin{array}{l}\text { Pre-ATAAD } \\
(\mathrm{n}=25)\end{array}$ & \\
\hline Dyslipidemia & $42(16 \%)$ & 31 (4l\%) & $8(32 \%)$ & 0.485 \\
\hline Diabetes & $29(11 \%)$ & $3(4 \%)$ & 0 & 1.000 \\
\hline
\end{tabular}

*p-values are given for comparison between TAA controls and pre-ATAAD patients.

Aortic dimensions and ROC-curve analysis

In the pre-ATAAD group, 24 of 25 subjects (96\%) had maximal ascending aortic diameters below the interventional threshold of $55 \mathrm{~mm}$. While diameters and volume were comparable, these patients had significantly longer ascending aortas than those with TAA but no dissection (90 \pm $16 \mathrm{~mm}$ vs. $84 \pm 9 \mathrm{~mm}, \mathrm{p}=0.03 \mathrm{I})$ (Table 2 ).

Table 2. Aortic dimensions of the different patient groups.

\begin{tabular}{|l|l|l|l|l|}
\hline & Healthy controls & \multicolumn{2}{|c}{ Aortopathy } & P-value* \\
\cline { 3 - 4 } & $(\mathrm{n}=258)$ & $\begin{array}{l}\text { TAA controls } \\
(\mathrm{n}=75)\end{array}$ & $\begin{array}{l}\text { Pre-ATAAD } \\
(\mathrm{n}=25)\end{array}$ & \\
\hline Diameter $(\mathbf{m m})$ & $33[30-36]$ & $46[44-49]$ & $45[40-49]$ & 0.075 \\
\hline Length $(\mathbf{m m})$ & $66 \pm 9$ & $84 \pm 9$ & $90 \pm 16$ & 0.031 \\
\hline Volume $\left(\mathbf{c m}^{3}\right)$ & $56[45-67]$ & $124[102-136]$ & $126[95-157]$ & 0.909 \\
\hline
\end{tabular}

*p-values are given for comparison between TAA controls and pre-ATAAD patients.

All 358 patients were included in the ROC model (dissection $n=25$, control $n=333$ ). Within the entire clinical cohort, all three parameters had an AUC $>0.800$ for prediction of dissection (diameter: 0.810 ; length 0.842 ; volume 0.854 , all $p<0.001$. See Figure $2 A$ ). The current surgical threshold of $55 \mathrm{~mm}$ showed to yield an excellent specificity of $98.8 \%$ (NPV: 93\%, Cl 90-96\%). However, the corresponding sensitivity showed to be no more than 4\% (PPV 20\%, Cl 0-55\%). At same specificity levels (98.8\%, Figure $2 B$ ), aortic volume (cut-off: $161 \mathrm{~cm}^{3}$, sensitivity $20 \%$, $\mathrm{p}=0.045$ ) and length (cut-off: $98 \mathrm{~mm}$, sensitivity $28 \%, \mathrm{p}=0.014$ ) demonstrated five- and sevenfold higher sensitivity for ATAAD detection. Also, PPV of these parameters was markedly higher than that of the maximal diameter (PPV volume: $55 \%, \mathrm{Cl} 23-88 \%$ and PPV length: $70 \%, \mathrm{Cl}$ 23-88\%), with similar NPV's (volume $94 \%$, length $95 \%$ ). No statistical significance was reached when comparing the sensitivities of aortic length and volume $(p=0.414)$. Combining the different measurements did not further improve diagnostic performance compared to measurements of aortic length alone. 


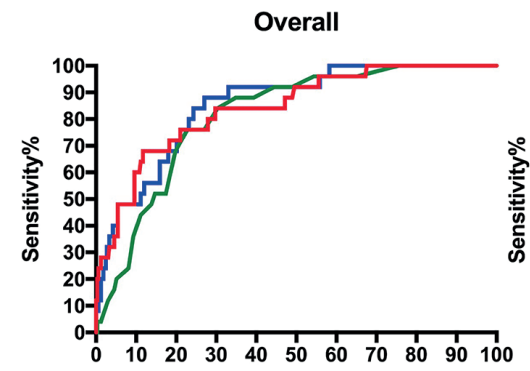

$100 \%$ - Specificity $\%$
High specificity range

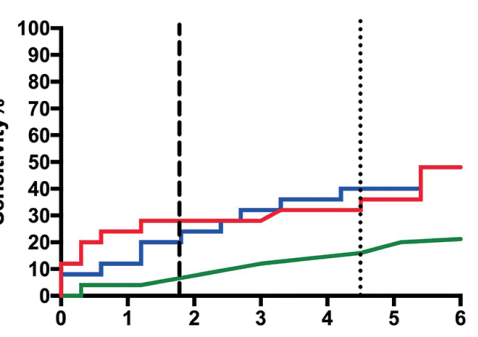

$100 \%$ - Specificity $\%$
- Length

- Volume

: 50 minm diameter reference

$55 \mathrm{~mm}$ diameter reference
Iine
Figure 2. Receiver-operating curves (ROC). (A) ROC curves comparing the overall ability of different anatomic predictors to identify patients at risk for acute type A aortic dissection. (B) Diameter cut-offs of $50 \mathrm{~mm}$ and 55 $\mathrm{mm}$ yield excellent specificity and preclude unnecessary surgical intervention (dashed lines). At same specificity levels, measurements of aortic length and volume showed significantly higher sensitivities. ROC: receiver-operating curves.

\section{Intra- and interobserver variability}

Intra-observer agreement was excellent for all three parameters (ICC 0.94, 0.97, and 0.99 for aortic diameter, length, and volume, respectively). With ICCs of 0.95 (diameter), 0.94 (length) and 0.99 (volume), inter-observer agreement was also excellent. Bland-Altman plots are displayed in Figure 3.

\section{DISCUSSION}

Research into the natural risk of TAAs is constrained by multiple methodological issues, one of which is the observation that the dimensions of the aorta change when dissection occurs(I5). In the current work, we have overcome this limitation by assessing the morphology of the aorta shortly before dissection onset. We found that i) $96 \%$ of ATAAD patients fail to meet criteria for prophylactic surgery prior to dissection, ii) aortic length is significantly larger in pre-ATAAD patients when compared to TAA controls, and iii) the sensitivities of aortic volume and length for prediction of dissection are five- and sevenfold higher than the sensitivity of the maximal diameter.

Guidelines for the preventative management of aortic disease depend solely on measurements of maximal cross-sectional dimensions and have long remained unchanged $(5,6)$. They have largely been based on early work from Davies et al., who longitudinally studied a cohort of TAA patient and found that the aortic diameter is strongly related to the risk of natural complications $(4,18)$. Even though the cut-off of $55 \mathrm{~mm}$ provides excellent specificity and precludes exposure to unnecessary intervention, it has been well recognized that the current surgical approach is unable to prevent the majority of dissections $(8,9,19)$. Our findings confirm estimates by Rylski et al., who modeled post-dissection aortas to pre-dissection dimensions and postulated that $>90 \%$ of ATAAD patients would not have qualified for prophylactic surgery before dissection onset(20). As such, they emphasize the need for deciphering additional parameters that can improve patient selection for pre-emptive surgery.
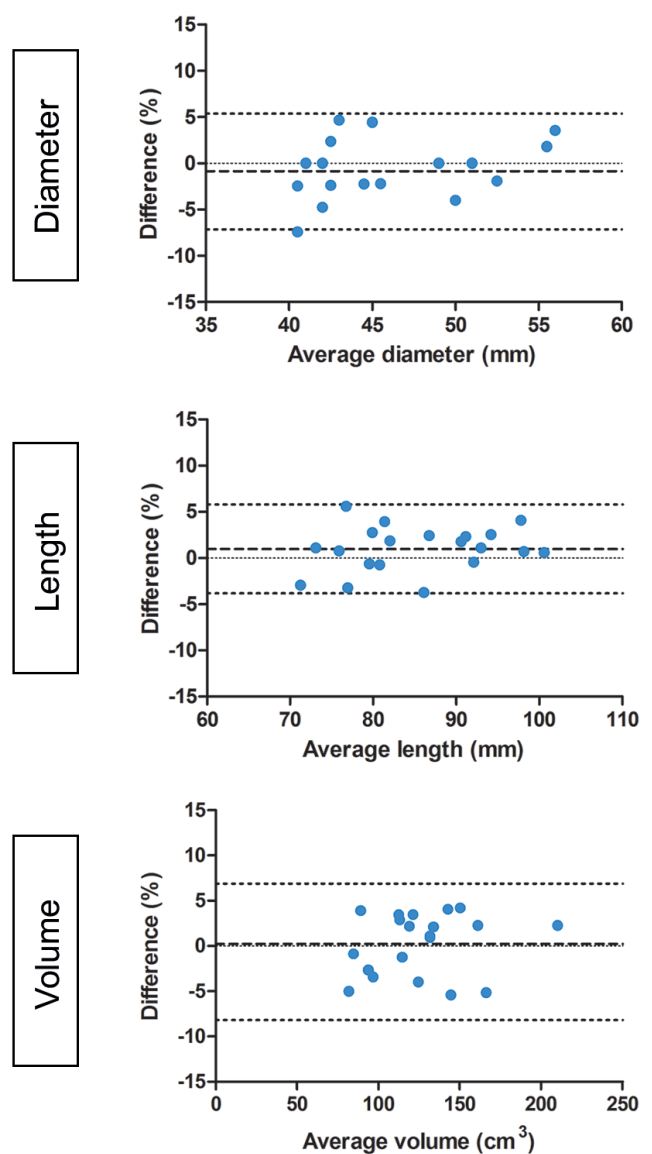
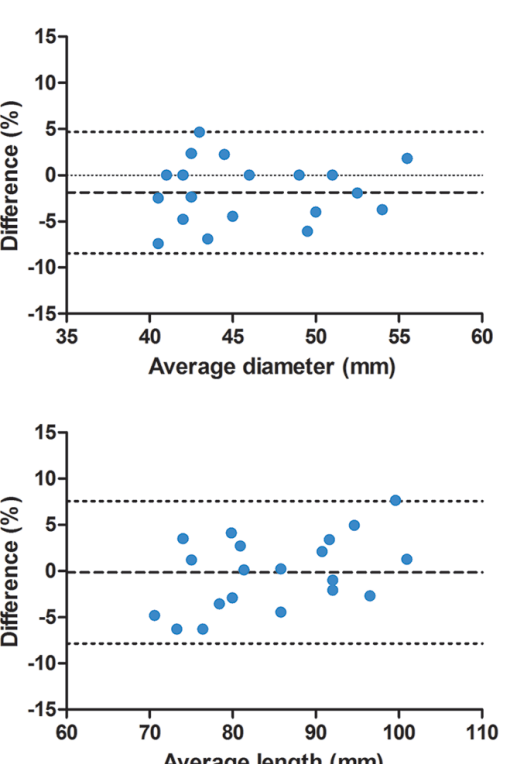

Average length $(\mathrm{mm})$

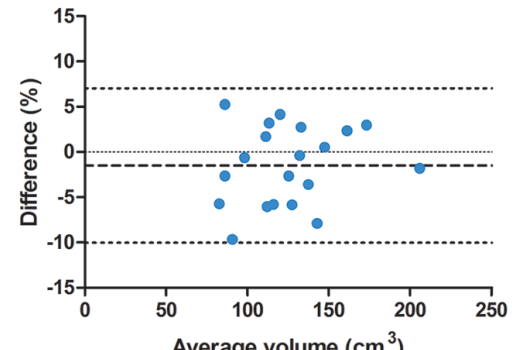

Average volume $\left(\mathrm{cm}^{3}\right)$
Figure 3. Bland Altman plots showing intra- and interobserver agreement. Bland Altman plots showing the normalized bias (dashed line) and $95 \%$ limits of agreement (dotted lines) for measurements of maximal aortic diameter, aortic length and aortic volume.

Over the past decade, technological advances have facilitated the acquisition of high-resolution isotropic multi-slice spiral CT and magnetic resonance imaging (MRI) datasets. Whereas earlier techniques (such as ultrasound and spiral CT) only provided for two-dimensional (2D) images and measurements, modern acquisitions afford a detailed three-dimensional (3D) visualization of the human arterial system. This evolution has paved the way for more comprehensive radiological measurements, such as those of aortic length and volume shown here. Previous studies investigating vessel length have demonstrated that the healthy aorta gradually elongates with age and that the dissected aorta is notably longer than would have been expected based on age, gender, and body surface area (BSA)(I2-14, 2I-23). The current work adds to this knowledge by revealing that aortic length also serves as more discriminative ATAAD predictor than the maxima transverse diameter. Although the observed sensitivity of $28 \%$ may not seem earth shattering at 
first glance, it means substantial and readily available improvement in the diseases' detection rate, with no trade-off in terms of specificity. Before the start of the study, we expected aortic volume to evolve into an even better indicator of future adverse events. However, our data has proven otherwise. Whereas the sensitivity of aortic volume was significantly higher than that of the maximal transverse diameter, we found no additional diagnostic value over measurements of aortic length. Yet, in line with previous studies, aortic volume did show excellent reproducibility, which could serve as important argument in favor of its use in clinical TAA follow-up(24). Aortic length and volume now require longitudinal and prospective validation as the next step towards their implementation into clinical practice guidelines.

It should be noted that current surgical indications are based on imaging data collected in the 1980s and 1990s, a time when measurements were performed mainly on axial images. Since then, and along with the transition to 3D imaging, the semiautomated centerline method has become routinely available. Multiple previous studies have reported that axial measurements significantly overestimate diameters when compared to centerline methods, especially in more tortuous aortic segments $(25,26)$. Based on these observations, it has been argued that current guidelines are not adapted to the use of centerline measurements, and that the surgical threshold should be shifted to smaller TAA sizes(27). Although we concur that this hypothesis deserves further attention, our data indicate that the diagnostic performance of the maximal diameter - even at lower cut-offs - remains lower than that of aortic volume and length (Figure 2B). As expected, lowering the threshold to 50 $\mathrm{mm}$ would increase diameter sensitivity (from $4 \%$ to $17 \%$ ). Concurrently, however, the sensitivities of aortic volume (from $20 \%$ to $38 \%$ ) and length (from $28 \%$ to $33 \%$ ) would also increase.

\section{Future directions}

Prospective research into the pathophysiology of dissection is challenging due to the diseases' low incidence and the (life)long follow-up duration required for the condition to develop. The design of the current study has afforded an alternative way to evaluate the anatomy of the aorta prior to dissection onset. Our findings could lead to a paradigm shift in the preventative management of aortic disease, enabling the more timely identification of patients at risk. Emerging techniques like four-dimensional (4D) flow MRI and positron emission tomography (PET) permit imaging of the hemodynamic and inflammatory processes that potentially underlie aneurysm progression, and could further improve the detection rate of patients who are susceptible to dissection(28,30).

\section{Limitations}

Some limitations of the current study should be addressed. First, a cross-sectional study design was used. Therefore, it is possible that any of the control patients will develop dissection on short terms. Future longitudinal studies are needed to evince a true causal relationship between the various anatomic measurements and the risk of unfavorable outcomes.

Second, the study population is relatively small and not representative of subjects with BAV or connective tissue disease. As the latter are known to suffer dissection at larger aortic diameters, our results are not generalizable to this patient population(9). Studies focusin specifically on genetically triggered aneurysms should investigate whether aortic volume and length measurements are of additional value in these patient entities.

\section{CONCLUSIONS}

The aortic diameter is incapable of predicting the vast majority of dissections. Measurements of aortic volume and length have superior diagnostic accuracy over maximal diameters and could improve the timely identification of patients at risk for ATAAD.

\section{REFERENCES} patients with acute type $A$ aortic dissection. Circulation. 2002;105(2):200-206.

Tanaka Y, Sakata K, Sakurai Y, et al. Prevalence of type A acute artic dissection in patients with out-of-hospital cardioReutersbers $B$. AmJ Cardiol. 2016;:17(1):1826-1830. Hospital Incidence and In-Hospital Mortality of Surgi cally and Interventionally Treated Aortic Dissections: Secondary Data Analysis of the Nationwide German Diagnosis-Related Group Statistics From 2006 to 2014. Am Heart Assoc. 2019;8(8):e011402.

Davies RR, Goldstein L), Coady MA, et al. Yearly rupture 政 2002;73(1):17-28.

5. Hiratzka LF, Bakris GL, Beckman JA, et al. 2010 ACCF/ AHA/AATS/ACR/ASA/SCA/SCAI/SIR/STS/SVM guidelines for the diagnosis and management of patients with thoracic aortic dsease. J Am Coll Cardio

6rbel R, Aboyans V, Boileau C, et al. 2014 ESC Guidelines on the diagnosis and treatment

. Kim JB, Spotnitz M, Lindsay ME, MacGillivray TE, sselbacher EM, Sundt TM. Risk of aortic dissection in the moderately dilated ascending aorta. J Am Coll Cardiol.

Pape LA Tsai TT, Isse

. $5.5 \mathrm{~cm}$ is not a goocher EM, et al. Aortic diameter dissection observations from the International Registry of Acute Aortic Dissection (IRAD). Circulation. 2007;:116(10):II20-1127.

Kim EK, Choi SH, Sung K, et al. Aortic diameter predicts Kict J Thorac Cardiovasc Surg. 2014;:147(5):1505-1510.

10. Lilieqvist ML, Hultgren R, Gasser TC, Royj. Volume growth of abdominal aortic aneurysms correlates with baseline volume and increasing finite element analysis-derive

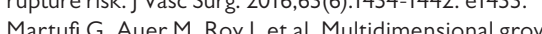

measurements of Royj, et al. Multidimensional growth Surg. 2013:58(3):748-755.

12. Adriaans BP, Heuts S, Gerretsen S, et al. Aortic elongation part I: the normal aortic ageing process. Heart. 2018;104(21)::1172-1177.

13. Heuts S, Adriaans BP, Gerretsen S, et al. Aortic elongation part II: the risk of acute type A aortic dissection. Heart. Krüger T, Oikonomou

mou A, Schibilsky D, et al. Aortic elongation and the risk for dissection: the Tübingen A thorac Surg. 2017;51(6):1119-1126,

15. Rylski B, Blanke P, Beyersdorf $F$, et al. How does the Coll Cardiol. 2014;63(13):1311-1319.
Col

16. Stock C, Hielscher T. DTComPair: Comparison of Binary Diagnostic Tests in a Paired Study Design v. I. . . 3. R Statistics. 2014.

17. McNemar Q. Note on the sampling error of the difference metween correlated propor
18. Coady MA, Rizzo JA, Hammond GL, et al. What is the appropriate size criterion for resection of thoracic aortic Trimarchi S, Jonker FH, Hutchison S, et al Descending artic diameter of $5.5 \mathrm{~cm}$ or greater is not an accurate predictor of acute type B aortic dissection. I Thorac

Rylski B. Sang 201t, $E$, Bavaria IE, et a

(B) Modeling of predissection aortic size in acute type $A$ dissection ascending replacement. I Thorac Cardiovasc Surg. 2014;148(3):944-948. e941.

1. Sugawara], Hayashi K, Yokoi T, Tanaka H. Age-associate Cardiol Img. 2008:I (6):739-748.

22. Krüger T, Forkavets $O$, Veseli $K$, et al. Ascending aor elongation and the risk of dissection. Eur ] Cardiothorac Surg. 2016;50(2):241-247.

23. Ryskki B, Desjardins B, Moser W, Bavaria E, Milewski RK. Gender-related changes in aortic geometry throughout life.

Renapurkar RD, Setser RM, O'Donnell TP,

Renapurkar RD, Setser RM, O'Donnell TP, et al. Aortic with untreated infrarenal abdominal aneurysm. Eur Radiol. 2012;81 (2):e87-e93.

. Mendoza DD, Kochar M, Devereux RB, et al. Impact of mage analysis methodology on diagnostic and surgic Ann Thorac Surg. 2011:92(3):904-912. Variation in maximum diameter measurements of descending thoracic aortic aneurysms using unformatte planes versus images corrected to aortic centerline. Eur

. Zasc Endovase Surg. 2014,47(1).19-26.

Zgsenhin BA, Zafar MA, Elefteriades JA. Descending time for a "left-shift" in guidelines? J Thorac Cardiovas Surg. 2019;157(1):37-42.

28. Forsythe RO, Dweck MR, McBride OMB, et al. (I8) Anodium Fluoride Uptake in Abdominal Aortio 2018.71(5):513-523.

Guzzardi DG, Barker AJ, Van Ooij P, et al. Valve-related nsights from wall shear stress mapping. I Am Col Cardiol. 2015;66(8):892-900

30. Markl M, Frydrychowicz A, Kozerke S, Hope M, Wieben O. 4D flow MRI. J Magn Reson Imaging 


\section{Prediction of aortic dissection}

\section{Ibrahim Akin ,}

Christoph A. Nienaber

I. Department of Cardiology, Universitätsmedizin Mannheim, Mannheim, Germany

2. Deutsches Zentrum für Herzkreislaufforschung, Mannheim, Germany

3. Cardiology and Aortic Centre, Royal Brompton Hospital and Harefield Trust, London, United Kingdom

Heart. Jun;|06(|2):870-87| 
Aortic dissection is a low-incidence, high-impact and potentially catastrophic condition if not treated adequately and in time. Acute aortic dissection is diagnosed within 2 weeks of onset of symptoms, which is the high-mortality period. Patients surviving 2 weeks are considered to have subacute disease, and chronic aortic dissection is diagnosed after 8 weeks. The anatomical classification is based on the involvement of ascending aorta (type A according to Stanford) or not (type B)(I). Historical data for untreated type $A$ aortic dissection show a mortality rate of $1 \%-2 \%$ per hour within the first 24 hours, resulting in a mortality rate of up to $50 \%-74 \%$ during the acute phase(2). Uncomplicated acute type B dissection is less frequently lethal, with survival rates for medically treated patients of $84 \%$ at I year. Within the risk factors, arterial hypertension is dominating. It affects arterial wall composition, causing intimal thickening, fibrosis, and calcification and extracellular fatty acid deposition. The extracellular matrix also undergoes accelerated degradation, apoptosis and elastolysis with hyalinisation of collagen. Other risk factors in the elderly are atherosclerosis, prior cardiac surgery and known aortic aneurysms. On the contrary, hereditary conditions of aortopathology (eg, Marfan syndrome and other genetic factors) are the main cause of dissection in younger patients. The pathophysiological denominator is a weakened aortic tunica media, which predisposes to dissection by splitting the cohesive layers of aortic wall. This weakening of the tunica media could be due to either a derangement or possibly a loss of structural elements in the media layer, including elastin, collagen, non-fibrous matrix and smooth muscle cells. The anatomical criterion based on aortic diameter, which is the only criterion in the latest guideline, is currently the best-evaluated predictor for aortic dissection and rupture with specific 'hinge points' $(6 \mathrm{~cm}$ for the ascending aort and $7 \mathrm{~cm}$ for the descending aorta)(3) However, the majority of patients dissect at an aortic diameter ess than these hinge points, which was shown in the International Registry of Aortic Dissection (IRAD) registry, in which nearly two-thirds of type A dissection patients had an aortic diameter of $<5.5 \mathrm{~cm}$ (4). Similarly. Rylski et al reported that of the 343 patients who had undergone CT angiography $<2$ years before and within 12 hours after aortic dissection onset, 334 (97\%) patients had an ascendin aorta diameter of $<5.5 \mathrm{~cm}$, and $315(92 \%)$ patients had a diameter of $<5 \mathrm{~cm}$ before dissection(5), which underlines the need for more powerful aortic event predictor tools.

An elegantly work about diameter, volume and length of the aorta in predissection phase was presented by the Maastricht group in the current issue of Heart. They compared in a two-centre matched cohort 25 patients suffering from acute type $A$ aortic dissection (ATAAD) and undergoing CT within 2 years before dissection with 258 healthy subjects and 75 patients with thoracic aortic aneurysm using a propensity score matching strategy(6). More strongly accentuated than in IRAD registry, 96\% did not meet the guideline-defined threshold of $5.5 \mathrm{~cm}$ in diameter. They could confirm a larger length and volume without any differences in diameter of ascending aorta in patients with ATAAD in the predissection phase as compared with propensity-matched controls with superio diagnostic accuracy. Similarly, the aortic length was significantly larger in patients with pre-ATAAD when compared with controls.

The same Maastricht group identified in a previous publication an age-depending elongation of the aorta in healthy subjects and in patients with ATAAD. The length of the thoracic aorta increased by 59 and $66 \mathrm{~mm}$ in healthy men and women, respectively, between the ages of 20 and 80 years with a predominance on the ascending aorta (142\%), the aortic arch (169\%) and the proximal part of the descending aorta (247\%)(7). A comparison of the ATAAD and control groups with adjustment to predissection dimensions revealed that elongation of the ascending aorta and diameter proved both to be independent predictors of dissection. Thus, the ascending aorta was longer and more dilated in patients with ATAAD compared with healthy controls, whereas longitudinal elongation in both the aortic arch and the descending aorta was not predictive(8). The aorta and the large elastic arteries become tortuous, and there is an elongation with increasing age. Similarly, there is vascular stiffening as the reduction of elastin content, which is highest in the aortic arch and the descending aorta,
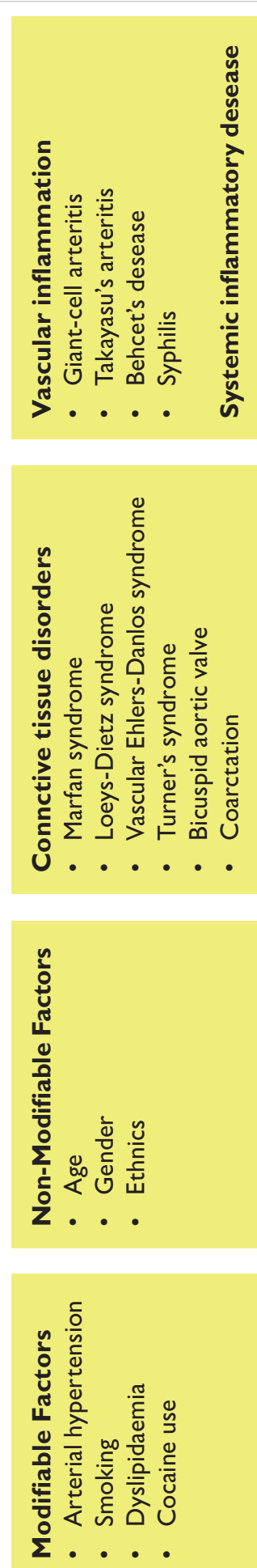
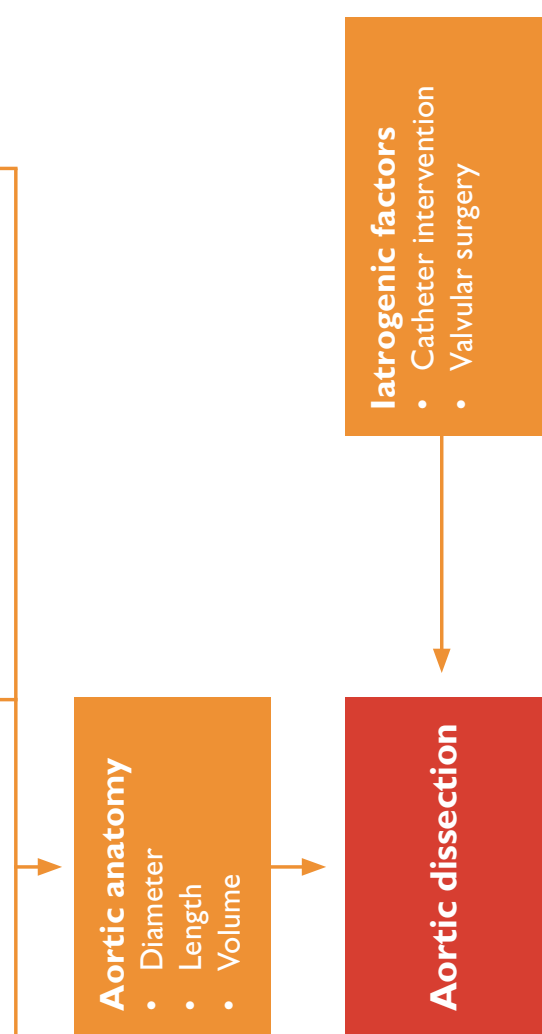
impairs vessel compliance. Despite the fact that current guidelines try to define a user-friendly solution by restricting the prediction to diameter, this may not be sufficient. Dimensional anatomica parameters such as diameter, length and volume are certainly factors to be considered in the predictive analysis of aortic dissection. However, these parameters often represent the result of long-lasting influences of hypertension or connective tissue disorders, and a prediction tool based on anatomy only would leave many aspects unconsidered (Figure I). Even the Aortic Dissection Detection risk score, which summarises baseline conditions with pain features, exam features and D-dimer values, is only an approximation of the multifactorial genesis of the disease. In addition to the classical cardiovascular risk factors, haemodynamic and anatomical conditions, genetics, traumatic, atrogenic and inflammatory factors certainly play a role and should be taken into consideration, perhaps in a complex algorithm employing artificial intelligence brought to the bedside. For the time being and without access to such a tool yet, the need for an individual patient-specific management plan designed by a multidisciplinary aortic team is unchallenged.

\section{REFERENCES}

on the diagnosis $V$, Boileau C, et al. 2014 ESC guidelines document covering acute and chronic aortic diseases of the thoracic and abdominal aorta of the adult. The task force for the diagnosis and treatment of aortic diseases of the European Society of Candology (ESC). Eur Heart

. Hagan PG, Nienaber CA, Isselbacher EM, et al. The new insights into an old disease. JAMA 2000;283:897-903.

3. Elefteriades JA, Farkas EA. Thoracic aortic aneurysm clinically pertinent controversies and uncertainties. JAm Coll Cardiol 2010,55.841-57.

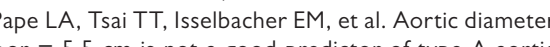
dissection: observations from the International Registry of Acute Aortic Dissection (IRAD). Circulation 2007;116:1120-7.

5. Rylski B, Branchetti E, Bavaria JE, et al. Modeling of predissection aortic size in acute type A dissection:
More than $90 \%$ fail to meet the guidelines for elective ascending 2014:148:944-8

6. Heuts S, Adriaans BP, Rylski B, et al. Evaluating the diagnostic accuracy of maximal aortic diameter, length and volume for prediction of aortic dissection. Heart 2020. Doil. $0.1136 /$ heartin Adriaans BP, Heut

S, Gerretsen S, et al. Aortic Heart 2018;104:1772-7.

8. Heuts S, Adriaans BP, Gerretsen S, et al. Aortic elongation Part II: the risk of acute type $\mathrm{A}$ aortic 
Supplementary Table I. Scan parameters for Siemens SOMATOM Flash.

\begin{tabular}{l|l|l|l|}
\hline Protocol & Native & Ascending aorta & Aorta (flash) \\
\hline Mode & Spiral & Spiral & High pitch \\
\hline Collimation $(\mathbf{m m})$ & 0.6 & 0.6 & 0.6 \\
\hline Acquisition $\mathbf{( m m})$ & $128 * 0.6$ & $128 * 0.6$ & $128 * 0.6$ \\
\hline Tube voltage $\mathbf{( k \mathbf { V } )}$ & 120 & 100 & 100 \\
\hline Dose modulation & on & on & on \\
\hline mAs ref & 100 & 330 & 150 \\
\hline Rot.Time (s) & 0.5 & 0.28 & 0.28 \\
\hline Pitch & 0.9 & 0.17 & 2.65 \\
\hline Delay (s) & n.a. & Test bolus technique & Test bolus technique \\
\hline Direction & Cranio-caudal & Caudo-cranial & Cranio-caudal \\
\hline
\end{tabular}

Reconstruction I

$\begin{array}{llll}\text { Slice thickness }(\mathbf{m m}) & 2 & 0.6 & 1.5 \\ \text { Increment }(\mathbf{m m}) & 1.5 & 0.4 & 1.0 \\ \text { Kernel } & 130 \mathrm{f} & 126 \mathrm{f} & 131 \mathrm{f}\end{array}$

$k V$ p: peak kilovoltage; $m$ As: milliampere-seconds.

Supplementary Table 2. Scan parameters for Siemens SOMATOM Force.

\begin{tabular}{|c|c|c|c|}
\hline Protocol & Native & Ascending aorta & Aorta (flash) \\
\hline Mode & Spiral & Spiral & High pitch \\
\hline Collimation (mm) & 0.6 & 0.6 & 0.6 \\
\hline Acquisition (mm) & $192 * 0.6$ & $192 * 0.6$ & $192 * 0.6$ \\
\hline Tube voltage (kVp) & 120 & 100 & 80 \\
\hline Dose modulation & on & on & on \\
\hline $\mathrm{mAs}_{\text {ref }}$ & 80 & 330 & 174 \\
\hline Rot.Time (s) & 0.5 & 0.25 & 0.25 \\
\hline Pitch & 0.9 & 0.15 & 1.9 \\
\hline Delay (s) & n.a. & Test bolus technique & Test bolus technique \\
\hline Direction & Cranio-caudal & Caudo-cranial & Cranio-caudal \\
\hline \multicolumn{4}{|l|}{ Reconstruction I } \\
\hline Slice thickness (mm) & 2 & 0.6 & 1.5 \\
\hline Increment (mm) & 1.5 & 0.4 & 1.0 \\
\hline Kernel & $\mathrm{Br} 40$ & Bv40 & Bv40 \\
\hline
\end{tabular}

$k V p$ : peak kilovoltage; $m$ As: milliampere-seconds. 
Supplementary Table 3. Pre-matching baseline characteristics.

\begin{tabular}{|l|l|l|}
\hline Controls & $\begin{array}{l}\text { Pre-ATAAD } \\
(\mathrm{n}=25)\end{array}$ \\
\hline Age (years) & $67 \pm 11$ & $69 \pm 9$ \\
\hline Gender $($ male) & $50(67 \%)$ & $15(63 \%)$ \\
\hline BSA $\left(\mathbf{m}^{2}\right)$ & $1.9 \pm 0.2$ & $1.9 \pm 0.1$ \\
\hline Hypertension & $56(75 \%)$ & $15(63 \%)$ \\
\hline
\end{tabular}

ATAAD: acute type A aortic dissection; BSA: body surface area. 


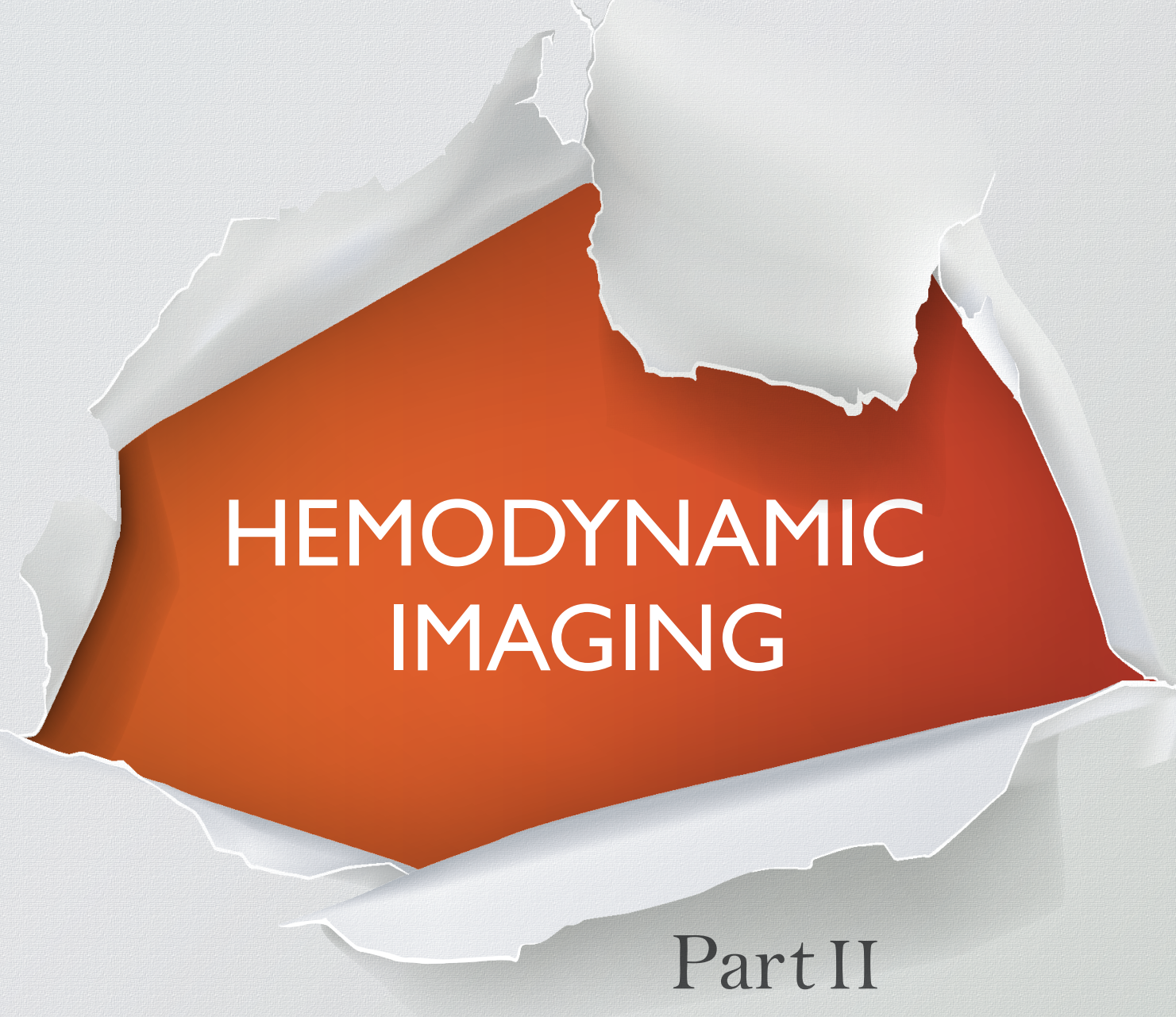




\section{Clinical assessment of aortic valve stenosis: comparison between 4D flow MRI and transthoracic echocardiography}

Bouke P. Adriaans, MD',2,3

Jos J. Westenberg, $\mathrm{PhD}^{4}$

Yvonne J.M. Van Cauteren, MD',2,3

Suzanne Gerretsen, MD, PhD'

Mohammed S.M. Elbaz, PhD 5

Sebastiaan C.A.M. Bekkers, MD, PhD $D^{1,2,3}$

Leo F. Veenstra, MD2

Harry J.G.M. Crijns, MD, PhD ${ }^{2,3}$

Joachim E. Wildberger, MD, PhD

Simon Schalla, MD, PhD',2,3

I. Department of Radiology and Nuclear Medicine, Maastricht University Medical Center+, Maastricht, the Netherlands

2. Department of Cardiology, Maastricht University Medical Center+, Maastricht, the Netherlands 3. Cardiovascular Research Institute Maastricht (CARIM), Maastricht University, Maastricht, the Netherlands

4. Department of Radiology, Leiden University Medical Center, Leiden, the Netherlands

5. Department of Radiology, Feinberg School of Medicine, Northwestern University, Chicago, USA

J Magn Reson Imaging 2020 Feb;5I(2):472-480 


\section{$\Delta$ \\ BACKGROUND}

The prevalence of valvular aortic stenosis (AS) increases as the population ages. Echocardiographic measurements of peak jet velocity $(\mathrm{V})$, mean pressure gradient $\left(\mathrm{P}_{\mathrm{P}}\right)$ and aortic valve area (AVA) determine AS severity and play a pivotal role in the stratification towards valvular replacement. A multimodality imaging approach might be needed in cases of uncertainty about the actual severity of the stenosis.

\section{PURPOSE}

To compare four-dimensional phase-contrast magnetic resonance (4D PC-MR), two-dimensional (2D) PC-MR and transthoracic echocardiography (TTE) for quantification of AS.

\section{STUDY TYPE}

Prospective.

\section{POPULATION}

20 patients with various degrees of AS (69.3 \pm 5.0 years).

\section{FIELD STRENGTH/SEQUENCES}

4D PC-MR and 2D PC-MR at 3T.

\section{ASSESSMENT}

We compared $V_{\text {peak }}, P_{\text {mean }}$ and AVA between TTE, 4D PC-MR and 2D PC-MR. Flow eccentricity was quantified by means of normalized flow displacement, and its influence on the accuracy of TTE measurements was investigated.

\section{STATISTICAL TESTS}

Pearson's correlation, Bland-Altman analysis, paired t-test, and intraclass correlation coefficient.

\section{RESULTS}

Four-dimensional PC-MR measured higher $\mathrm{V}_{\text {peak }}(r=0.95$, mean difference $+16.4 \pm$ $10.7 \%, p<0.001)$ and $P_{\text {mean }}(r=0.92$, mean difference $+14.9 \pm 16.0 \%, p=0.013)$, but a less critical AVA $(r=0.80$, mean difference $+19.9 \pm 20.6 \%, p=0.002)$ than TTE. In contrast, unidirectional 2D PC-MR substantially underestimated AS severity when compared to TTE. Differences in $\mathrm{V}_{\text {peak }}$ between 4D PC-MR and TTE showed to be strongly correlated to the eccentricity of the flow jet $(r=0.89$, p $<0.00 \mathrm{I})$. Use of 4D
PC-MR improved the concordance between $\mathrm{V}_{\text {peak }}$ and $\mathrm{AVA}$ (from 0.68 to 0.87 ), and between $P G_{\text {mean }}$ and $A V A$ (from 0.68 to 0.86 ).

\section{DATA CONCLUSION}

4D PC-MR improves the concordance between the different AS parameters and could serve as additional imaging technique next to TTE. Future studies should address the potential value of 4D PC-MR in patients with discordant echocardiographic parameters.

\section{KEYWORDS}

Aortic stenosis, valvular disease, 4D flow MRI

\section{KEY POINTS}

- 4D flow MRI measures significantly higher flow velocities in aortic stenosis (AS) patients compared to transthoracic echocardiography (TTE).

- Difference between peak velocities as measured by 4D flow MRI and TTE is highly correlated to the eccentricity of the flow jet.

- 4D flow MRI increases concordance between the parameters that determine AS severity (peak velocity, mean transvalvular pressure gradient and aortic valve area). 


\section{INTRODUCTION}

Calcific aortic stenosis (AS) is the most common valvular heart disease in developed countries, affecting up to $12.4 \%$ of elderly patients (I, 2). Since the Western population grows progressively older, AS will put an increasing burden on public health and health resources over the coming decades. Transthoracic echocardiography (TTE) is the key diagnostic tool for evaluation of stenosis severity, and main parameters recommended to be recorded include peak jet velocity $\left(V_{\text {peak }}\right)$, mean transvalvular pressure gradient $\left(P_{\text {mean }}\right)$ and aortic valve area $(A V A)(3)$. However certain pitfalls apply to the echocardiographic assessment of AS, which should be avoided in order to ascertain the accuracy of measurements(4). First, image quality is operator-dependent and can be hampered by poor acoustic windows. Second, Doppler measurements rely on a parallel alignment between the ultrasound beam and the direction of blood flow, and violation of tition results in underestimation of flow velocities and is calculated using the continuity equation, a formula that includes the cross-sectional area of the left ventricular outflow tract (LVOT). This area is typically computed from the LVOT diameter implicating the outflow tract to have a circular shape. In fact, the LVOT is elliptical in the majority of patients, and this approach has been reported to result in a considerable underestimation of AVA $(6,7)$. In a subgroup of patients, in whom image quality is insufficient or there is discordance between the TTE-derived AS parameters, clinical-decision making may benefit from alternative non-invasive imaging techniques.

Phase-contrast magnetic resonance imaging (PC-MR) has evolved as a reliable tool for non-invasive flow and velocity measurements and has been validated in vitro and multiple patien groups(8-10). The technique is usually performed using a prospectively planned two-dimensiona (2D) acquisition with a unidirectional through-plane velocity-encoding. However, this method is only capable of quantifying flow velocities in the direction oriented perpendicular to the imaging slice. Moreover, the exact location of peak jet velocity (the so-called vena contracta) cannot be visualized prior to planning of the acquisition plane, which further reduces the accuracy of measurements. For these reasons, 2D PC-MR has shown significant underestimation of flow rates and velocities when compared to TTE(II-|3). Over recent years, three-directional three-dimensional PC-MR (better known as four-dimensional [4D] flow MR or 4D PC-MR) has emerged as a promising in-vivo flow imaging technique that enables visualization and quantification of complex flow patterns in the heart and large vessels(14-16). In contrast to unidirectional 2D PC-MR, 4D PC-MR provides for velocity-encoding in all three spatial directions. Furthermore, the entire acquired volume can be analyzed in search for the highest flow jet velocity. In healthy volunteers and patients with normally functioning valves, 4D PC-MR has shown improved flow quantification relative to echo(17, 18). We hypothesized that in AS patients, who often exhibit eccentric and dynamic flow jets, the technical features of 4D PC-MR could be even more advantageous(19). Hence, the purpose of the current study is to assess the performance of TTE and PC-MR in a cohort of AS patients, and to investigate the influence of flow eccentricity on the accuracy of measurements.

\section{MATERIALS AND METHODS}

\section{Study population}

Consecutive adult patients who visited our outpatient clinic for the echocardiographic follow-up of AS between June 2017 and December 2018 were invited for participation in this prospective single-center study. Exclusion criteria comprised prior aortic valve replacement, heart failure (NYHA class $\geq 3$ ), renal failure (estimated glomerular filtration rate $<30 \mathrm{ml} / \mathrm{min} / 1.73 \mathrm{~m}^{2}$ ), and the regular exclusion criteria for MR (such as metallic implants and claustrophobia). Furthermore, patients with atrial fibrillation were excluded, since beat-to-beat flow variability caused by irregular heart rhythms might limit the accuracy of PC-MR measurements. Eventually, a total of 20 patients were included. Our local ethical review board approved the study protocol, and all participants provided written informed consent.

\section{Transthoracic echocardiography}

Echocardiograms were performed according to clinical guidelines using a Philips iE33 ultrasound system (Philips Medical Systems, Andover, MA, USA)(3, 20). Recordings were made from the subcostal, parasternal and apical windows with patients lying in supine or left lateral decubitus position. All images were obtained by experienced echocardiographers and reviewed by a single certified cardiologist with $>15$ years of experience in cardiac ultrasound (S.S.). Aortic $\mathrm{V}_{\text {peak }}$ was measured using continuous-wave Doppler ultrasound; the highest velocity recorded from any acoustic window was used for analyses. Transvalvular pressure gradients were calculated from velocity information through the modified Bernoulli equation $\left(P=4 * v^{2}\right)$, with $P_{\text {mean }}$ being the average gradient over the cardiac systole. AVA was computed using the continuity-equation as $\mathrm{AVA}=\mathrm{Area}_{\text {LVOT }} * \mathrm{VTI}_{\text {LVOT }} \mathrm{VTI}_{\text {Aorta }}$. In this equation, $\mathrm{VTI}_{\text {LVOT }}$ and $\mathrm{VTI}_{\text {Aorta }}$ are the velocity-time integrals of the LVOT and aorta as obtained by pulsed-wave Doppler and continuous-wave Doppler, respectively. The area of the LVOT was computed using the LVOT diameter as measured on a parasternal long-axis view: Area $_{\text {LVOT }}=\pi *(\text { Diameter LVOT2 })^{2}$

MR acquisition

All scans were performed on a 3T scanner (Ingenia CX. Philips Healthcare, the Netherlands) equipped with a 32-channel torso coil for signal reception. A steady-state free precession sequence was used to obtain ECG-gated cine images in 2- and 4-chamber long-axis views and in two orthogonal LVOT planes. Unidirectional 2D PC-MR was performed in end-expiratory breath-hold at the level of the LVOT and in two adjacent slices ranging from the aortic valve tips towards the sinotubular junction (Figure IA). Typical PC-MR acquisition parameters are summarized in Table I. Cine LVOT views were used to position imaging planes perpendicular to the aortic valve and aorta. Velocity-encoding (VENC) was individually adapted by repetition of acquisitions with decreasing VENC until the lowest value, at which no aliasing occurred, was reached.

Table I. CMR acquisition parameters.

\begin{tabular}{|l|l|l|}
\hline FOV $(\mathbf{m m} \times \mathbf{~ m m} \times \mathbf{~ m m})$ & 2D PC-MR & 4D PC-MR \\
\hline Acquired voxel size $\mathbf{( m m} \times \mathbf{~ m m})$ & $350 \times 300$ & $350 \times 280 \times 75$ \\
\hline Slice thickness $(\mathbf{m m})$ & $2.5 \times 2.5$ & $2.5 \times 2.5 \times 2.5$ \\
\hline Reconstructed voxel size $(\mathbf{m m})$ & 8.0 & - \\
\hline Flip angle $\left(^{\circ}\right)$ & $1.22 \times 1.22$ & $1.46 \times 1.46 \times 2.5$ \\
\hline TE $(\mathbf{m s})$ & 10 & 10 \\
\hline TR $(\mathbf{m s})$ & 2.4 & 2.3 \\
\hline TFE factor & 4.0 & 4.2 \\
\hline SENSE factor & 6 & 2 \\
\hline & 2 & $2.5(\mathrm{P}) \times 1.5(\mathrm{~S})$ \\
\hline
\end{tabular}




\begin{tabular}{|l|l|l|}
\hline VENC $(\mathbf{c m} / \mathbf{s})$ & 2D PC-MR & 4D PC-MR \\
\hline Shot duration $(\mathbf{m s})$ & $210-600$ & $210-600$ \\
\hline (Reconstructed) cardiac phases & 48 & 33 \\
\hline
\end{tabular}

*Depending on cardiac frequency. FOV: field-of-view; P: phase-encoding direction; S: slice direction; TE: echo time; TR: repetition time; VENC: velocity-encoding

Four-dimensional PC-MR acquisition was initiated immediately after manual administration of a low-dose $(0.1 \mathrm{mmol} / \mathrm{kg}$ body weight) bolus of gadobutrol (Gadovist, Bayer Healthcare, Berlin, Germany). A 3D volume with full coverage of the thoracic aorta was acquired in a sagitta oblique orientation, using a retrospectively ECG-gated and respiratory navigated spoiled turbo-field echo sequence (Figure IB). Velocity-encoding for the three spatial directions was set to same values as in 2D PC-MR. Gradient correction and local phase correction were performed from standard available scanner software. Acquisition lasted $17.2 \pm 5.5$ minutes, depending on heart and respiratory rate.

\section{MR analysis}

MR datasets were reviewed by a single observer (B.A., 5 years of experience in cardiac MR), who was blinded for echocardiographic findings. Two-dimensional PC-MR was analyzed semiautomatically (CAAS MR Flow 2.I, PieMedical Imaging B.V., Maastricht, The Netherlands).

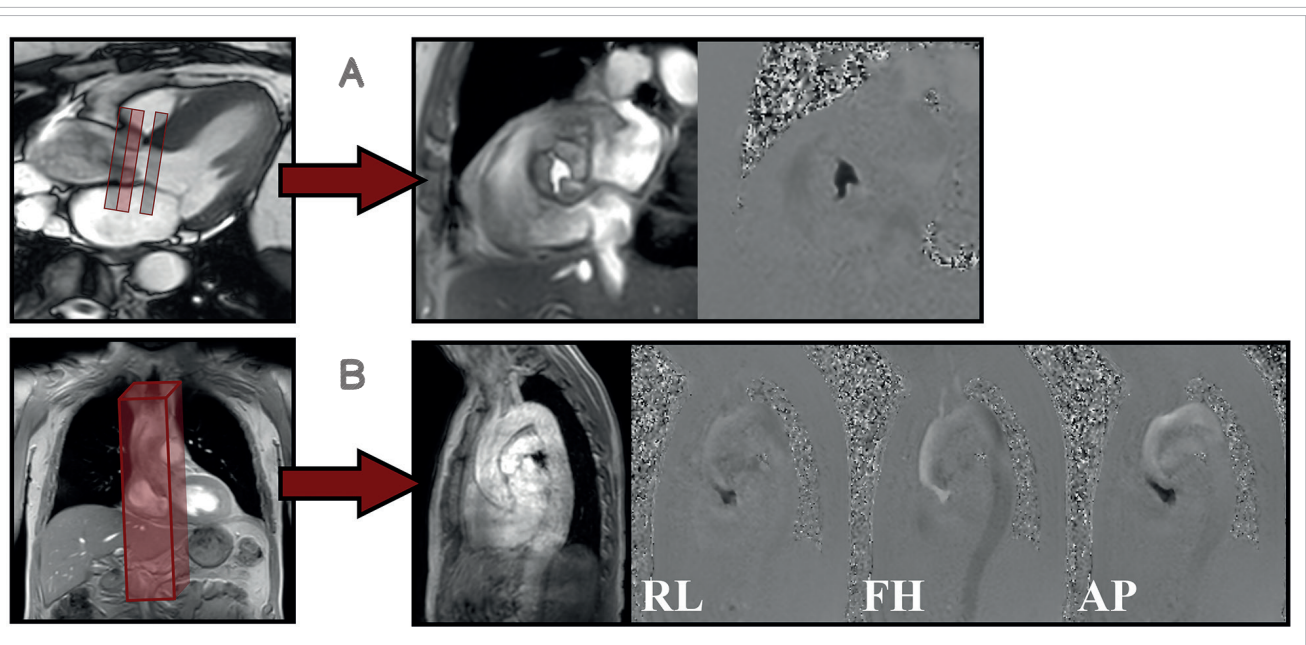

Figure I. Methodology for 2D and 4D PC-MR acquisition. (A) Through-plane 2D PC-MR was performed at the level of the LVOT and in two adjacent planes covering the aortic valve and aortic root. Magnitude and velocity images are provided for the imaging slice depicted in red. (B) In 4D PC-MR, a 3D volume covering the thoracic aorta was acquired. Velocity maps for the three spatial directions are shown bottom right. LVOT: left ventricular outflow tract; PC-MR: phase contrast magnetic resonance.
Regions of interest drawn by the software were checked for their adequacy across all time frames and manually corrected if deemed necessary. Flow rates and velocities were exported for each phase, and the aortic imaging slice that yielded highest $V_{\text {peak }}$ was used for analyses. Planimetric LVOT area was obtained from magnitude images at peak systole. Velocity-time integrals were manually calculated by the observer as the area under the velocity-time curve and used for calculation of AVA using the continuity equation.

Four-dimensional PC-MR data were imported into a commercially available software package (CAAS 4D Flow 2.0, PieMedical Imaging B.V.), and additional phase offset correction and anti-aliasing was performed. Delimiter points were manually placed in the LVOT and descending aorta on weighted speed image and marked the borders of the volume of interest (i.e., the thoracic aorta). This volume was then automatically segmented for the peak systolic phase. The adaptation tool provided by the software was used for manual correction of vessel lumen delineation in case of incorrectness of the automatic segmentation. After completion of the segmentation, analysis planes were placed just below the lowest insertion point of the aortic valve cusps (LVOT), and in the aortic region in which $V_{\text {peak }}$ was identified. Calculations of pressure gradients and AVA were performed similarly as in 2D PC-MR. LVOT area was obtained by planimetry on magnitude images. Peak systolic flow displacement in the aortic plane was computed as the linear distance between the luminal center and the center of velocity, which represents the average position of pixels weighted by velocity information (see also Figure 4A)(2I). Analysis of 4D PC-MR data of 10 randomly selected patients was repeated by the primary observer and also carried out by a second observer (Y.C., 4 years of experience) in order to assess intra- and interobserver variability

\section{Statistical analysis}

Statistical analysis was performed using dedicated software (IBM SPSS Statistics, version 24 Armonk, NY, USA). Continuous data were tested for normality using the Shapiro-Wilk test. Baseline characteristics are presented as mean \pm standard deviation or as frequency and percentages. Pearson's correlation and Bland-Altman analysis were performed to assess the agreement between the TTE- and PC-MR-derived AS parameters, while the paired samples t-test was used to determine whether there was a significant mean difference between both modalities. Intra- and interobserver variability for 4D PC-MR measurements were calculated using the intraclass correlation coefficient (ICC). A p-value $<0.05$ was considered significant.

\section{RESULTS}

\section{Study population}

Twenty patients were included and underwent consecutive TTE and MR. Mean time interval between both examinations was $17.2 \pm 7.2$ days. Pronounced respiratory motion artifacts were encountered in the 4D PC-MR dataset of one patient, who was therefore excluded from further analysis. Baseline characteristics are summarized in Table 2. Based on an echocardiographic AVA $<1.0 \mathrm{~cm}^{2}, 5$ patients were diagnosed with severe AS. The others suffered from moderate (AVA between 1.0 and $1.5 \mathrm{~cm}^{2}, \mathrm{n}=8$ ) or mild (AVA $>1.5 \mathrm{~cm}^{2}, \mathrm{n}=6$ ) valvular stenosis. The aortic valve was bicuspid in 4 patients ( 1 severe and 3 moderate AS, all with raphes between the left- and right-coronary cusps). Of the 5 subjects with severe aortic stenosis, 4 underwent aortic valve replacement and experienced improvement of echocardiographic peak velocities (from mean $4.75 \pm 0.43 \mathrm{~m} / \mathrm{s}$ to $2.49 \pm 0.25 \mathrm{~m} / \mathrm{s}$ ) and mean pressure gradients (from mean $50.8 \pm 8.0 \mathrm{mmHg}$ to $13.3 \pm 2.5 \mathrm{mmHg}$. 
Table 2. Baseline characteristics of the study population.

\begin{tabular}{|c|c|c|}
\hline & $N=19$ & Range \\
\hline Male & $13(68,4 \%)$ & \\
\hline Age (years) & $69.3 \pm 5.0$ & $57-77$ \\
\hline Height (cm) & $168.9 \pm 7.3$ & $|50-| 8 \mid$ \\
\hline Weight (kg) & $75.7 \pm 9.4$ & $61-93$ \\
\hline BMI $\left(\mathrm{kg} / \mathrm{m}^{2}\right)$ & $26.5 \pm 2.4$ & $21.1-29.8$ \\
\hline BSA $\left(m^{2}\right)$ & $1.9 \pm 0.14$ & $1.6-2.1$ \\
\hline Hypertension & $16(84.2 \%)$ & \\
\hline Dyslipidemia & II (57.9\%) & \\
\hline Diabetes & I (5.3\%) & \\
\hline Smoker & $3(15.8 \%)$ & \\
\hline eGFR & $70.7 \pm 14.9$ & $44-90$ \\
\hline \multicolumn{3}{|c|}{ NYHA classification } \\
\hline 1 & $15(78.9 \%)$ & \\
\hline$\|$ & $4(21.1 \%)$ & \\
\hline \multicolumn{3}{|c|}{ Valve morphology } \\
\hline Bicuspid & $4(21.1 \%)$ & \\
\hline Tricuspid & $15(78.9 \%)$ & \\
\hline \multicolumn{3}{|l|}{ TTE findings } \\
\hline LVEF (\%) & $63.0 \pm 5.5$ & $50-70$ \\
\hline LV mass (g) & $162.3 \pm 49.0$ & $91-247$ \\
\hline LVEDD (mm) & $47.1 \pm 5.1$ & $39-59$ \\
\hline LVESD (mm) & $31.1 \pm 4.7$ & $24-41$ \\
\hline
\end{tabular}

BMI: body mass index; BSA: body surface area; eGFR: estimated glomerular filtration rate; LV: left ventricle LVEF: left ventricular ejection fraction; LVEDD: left ventricular end-diastolic diameter; LVESD: left ventricular end-systolic diameter; NYHA: New York Heart Association.

\section{Peak jet velocity, mean pressure gradient and aortic valve area}

Measurements of $\mathrm{V}_{\text {peak }}$ obtained by 2D PC-MR and 4D PC-MR were strongly correlated with those derived from TTE (Table 3, and Figures 2 and 3). However, there was a notable systematic difference between the three imaging techniques. Compared to TTE, 2D PC-MR underestimated $\mathrm{V}_{\text {peak }}$ by a mean difference of $-11.2 \pm 10.2 \%(p<0.001)$, whereas 4D PC-MR yielded a significantly higher peak jet velocity (mean difference from TTE: $+16.6 \pm 10.5 \%, p<0.001$ ). A similar pattern was found for $P_{\text {mean }}$ : correlations between modalities were excellent, with pressure gradients from 4D PC-MR being significantly larger than those obtained by TTE or 2D PC-MR (4D PC-MR vs. TTE: +13.8 \pm $16.3 \%, P=0.017$, and 2D PC-MR vs. TTE: $-30.2 \pm 17.6 \%, p<0.001$ ). Scatter diagrams revealed arger underestimation of peak velocities and pressure gradients by 2D PC-MR in more severe cases of AS, whereas 4D PC-MR and TTE maintained relatively good agreement (Figures 2 and 3).
Although higher $\mathrm{V}$ and $\mathrm{P}$ would suggest more critical stenosis, AVA was larger when calculated from 4D PC-MR (mean difference from TTE: $+19.5 \pm 20.1 \%, p=0.00 I$ ). Since the dimensionless index (i.e. the ratio between $\mathrm{VTI}_{\text {LVOT }}$ and $\mathrm{VTI}_{\text {Aorta }}$ ) was comparable between techniques $(p=0.76)$, the higher AVA obtained by 4D PC-MR can be explained only by differences in LVOT area measurements. Indeed, planimetric LVOT area (4D PC-MR) was significantly larger than the same area that was computed from the echocardiographically obtained LVOT diameter $\left(4.7 \pm 0.57 \mathrm{~cm}^{2}\right.$ vs. $\left.3.9 \pm 0.54 \mathrm{~cm}^{2}, \mathrm{p}<0.001\right)$.

Table 3. Mean and percentage differences between TTE and PC-MR

\begin{tabular}{|l|l|l|l|l|l|l|l|l|}
\hline & \multicolumn{4}{|c|}{ 4D PC-MR vs. TTE } & \multicolumn{4}{c|}{ 2D PC-MR vs. TTE } \\
\cline { 2 - 9 } & $\mathrm{r}$ & $\Delta$ (mean) & $\Delta$ (perc.) & $\mathrm{P}$ & $\mathrm{r}$ & $\Delta$ (mean) & $\Delta$ (perc.) & $\mathrm{P}$ \\
\hline $\mathrm{V}_{\text {peak }}(\mathrm{m} / \mathrm{s})$ & 0.95 & $+0.5 \pm 0.4$ & $+16.6 \pm 10.5$ & $<0.001$ & 0.95 & $-0.4 \pm 0.4$ & $-11.2 \pm 10.2$ & $<0.001$ \\
\hline $\mathrm{P}_{\text {mean }}(\mathrm{mmHg})$ & 0.92 & $+4.3 \pm 7.2$ & $+13.8 \pm 16.3$ & 0.017 & 0.92 & $-8.9 \pm 7.7$ & $-30.2 \pm 17.6$ & $<0.001$ \\
\hline AVA $\left(\mathrm{cm}^{2}\right)$ & 0.80 & $+0.3 \pm 0.3$ & $+19.5 \pm 20.1$ & 0.001 & 0.80 & $+0.6 \pm 0.4$ & $+38.2 \pm 25.4$ & $<0.001$ \\
\hline
\end{tabular}

AVA: aortic valve area; $P_{\text {mean }}$ : mean transvalvular pressure gradient; PC-MR: phase contrast magnetic resonance; perc: percentage; $V_{\text {peak }}$ : : meak jet velocity.

\section{Flow displacement}

Flow displacement in the ascending aorta differed highly between individuals (range 0.02-0.15 for patients with tricuspid valves, range 0.07-0.15 for those with bicuspid valves). There was no significant relationship between the severity of AS and the eccentricity of the flow jet $(r=0.23$ for the association between flow displacement and $\mathrm{V}_{\text {peak }}, \mathrm{P}=0.35$ ). However, a strong correlation $(r=0.89, \mathrm{p}<0.00 \mathrm{I})$ was found between flow displacement and the extent to which $\mathrm{V}_{\text {peak }}$ differed between 4D PC-MR and TTE, indicating the influence of flow eccentricity on the accuracy of ultrasound measurements (Figure 4B).

\section{Concordance between AS parameters}

Regression analysis showed excellent correlation between TTE-derived $\mathrm{V}_{\text {peak }}$ and $\mathrm{P}_{\text {mean }}(r=0.97$ Figure 5A). In contrast, correlations between $\mathrm{V}_{\text {peak }}$ and AVA and between $\mathrm{P}_{\text {mean }}$ and AVA were only moderate $(r=0.68$ for both). Use of 4D PC-MR markedly improved these correlations, to $r=0.87$ and $r=0.86$, respectively (Figure $5 B$ ). 


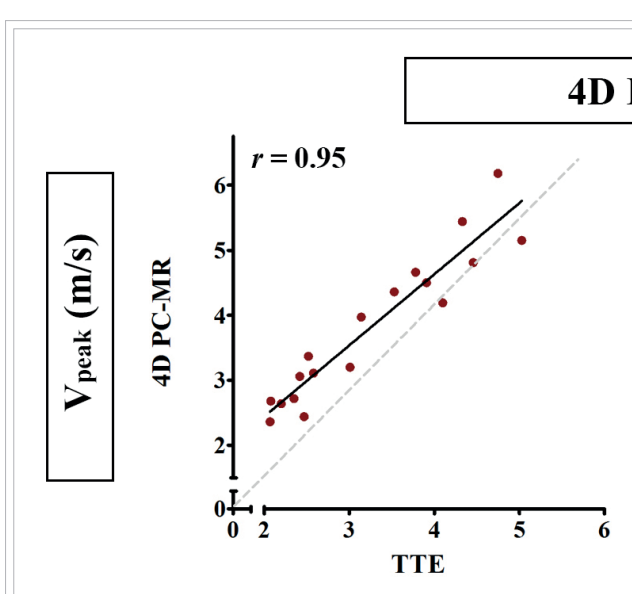

\section{D PC-MR vs. TTE}
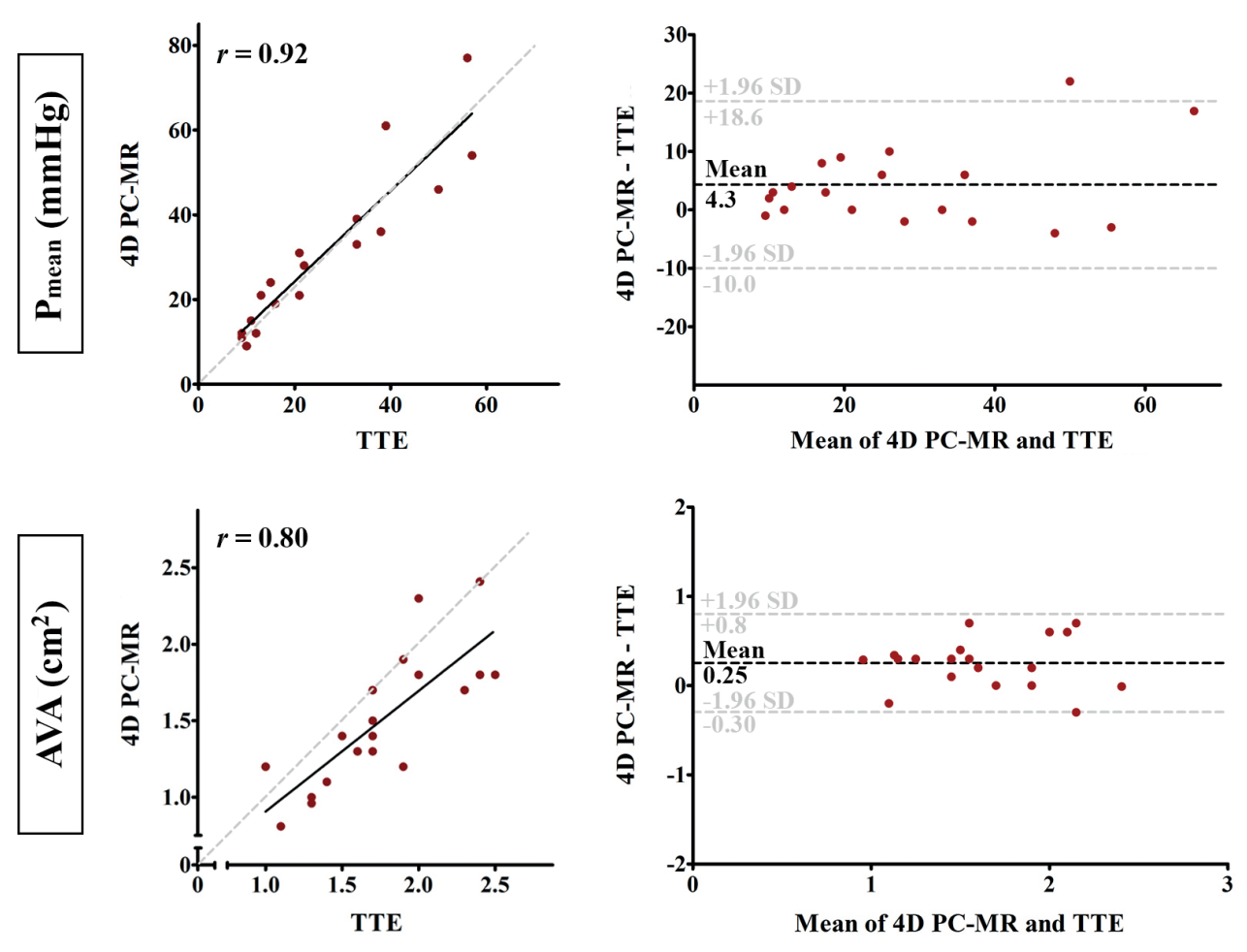

Figure 2. Agreement between 4D PC-MR and TTE. Regression lines and Bland-Altman plots showing the agreement between TTE and 4D PC-MR for measurements of Vpeak, Pmean and AVA. Despite strong correlations between both techniques, 4D PC-MR systematically yielded higher velocities and pressure gradients when compared to TTE. AVA: aortic valve area; Pmean: mean transvalvular pressure gradient; PC-MR: phase-contrast magnetic resonance; TTE: transthoracic echocardiography; Vpeak: peak jet velocity

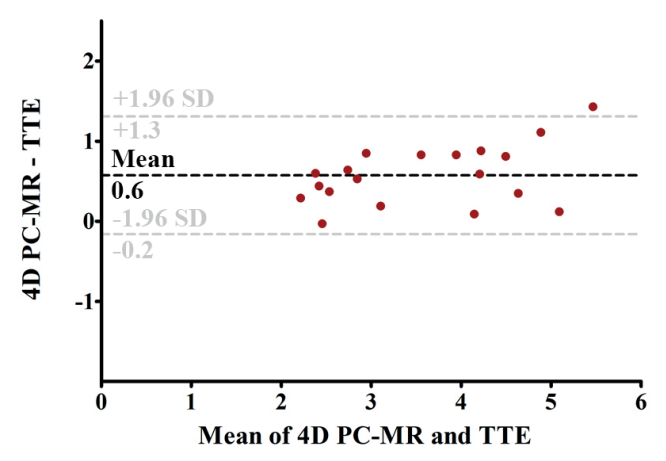

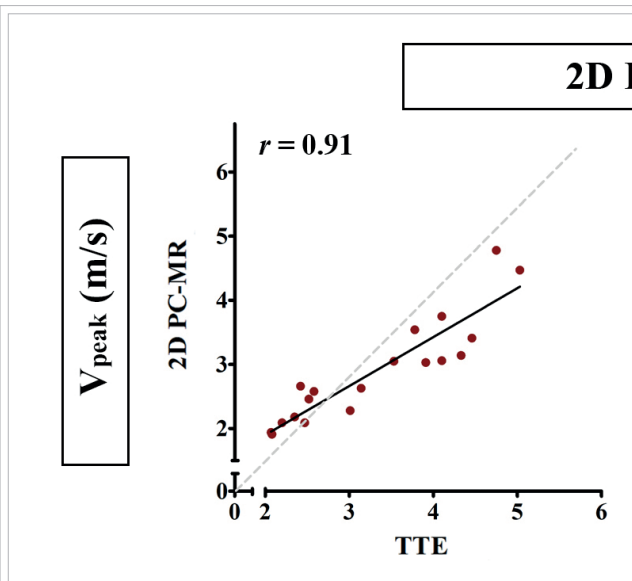

2D PC-MR vs. TTE
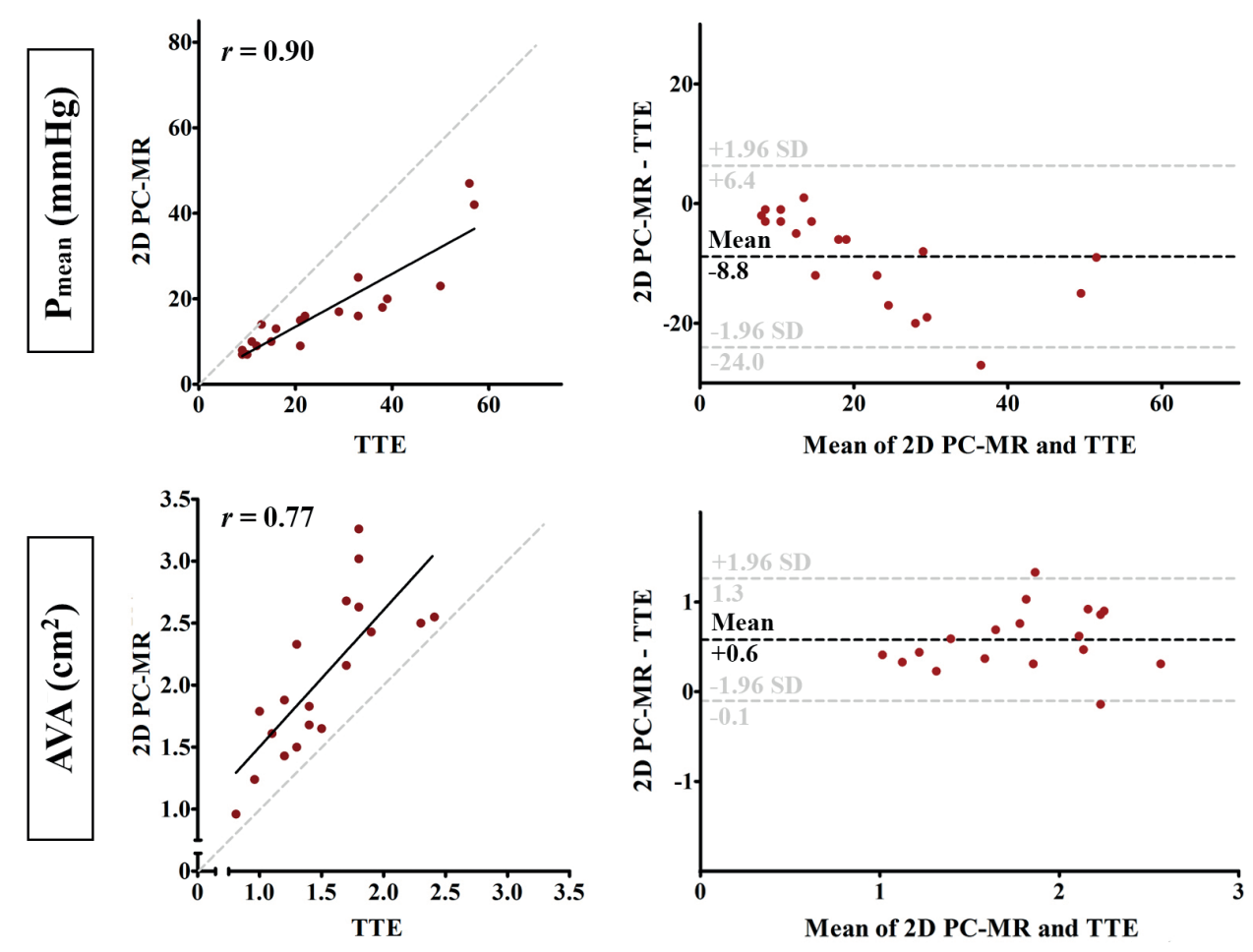

Figure 3. Agreement between 2D PC-MR and TTE. Regression lines and Bland-Altman plots showing agreement between TTE and 2D PC-MR for measurements of Vpeak, Pmean and AVA. As demonstrated, the underestimation of velocities and pressure gradients by 2D PC-MR becomes more pronounced in more critical cases of AS. AVA: aortic valve area; Pmean: mean transvalvular pressure gradient; PC-MR: phase-contrast magnetic resonance; TTE: transthoracic echocardiography; Vpeak: peak jet velocity 

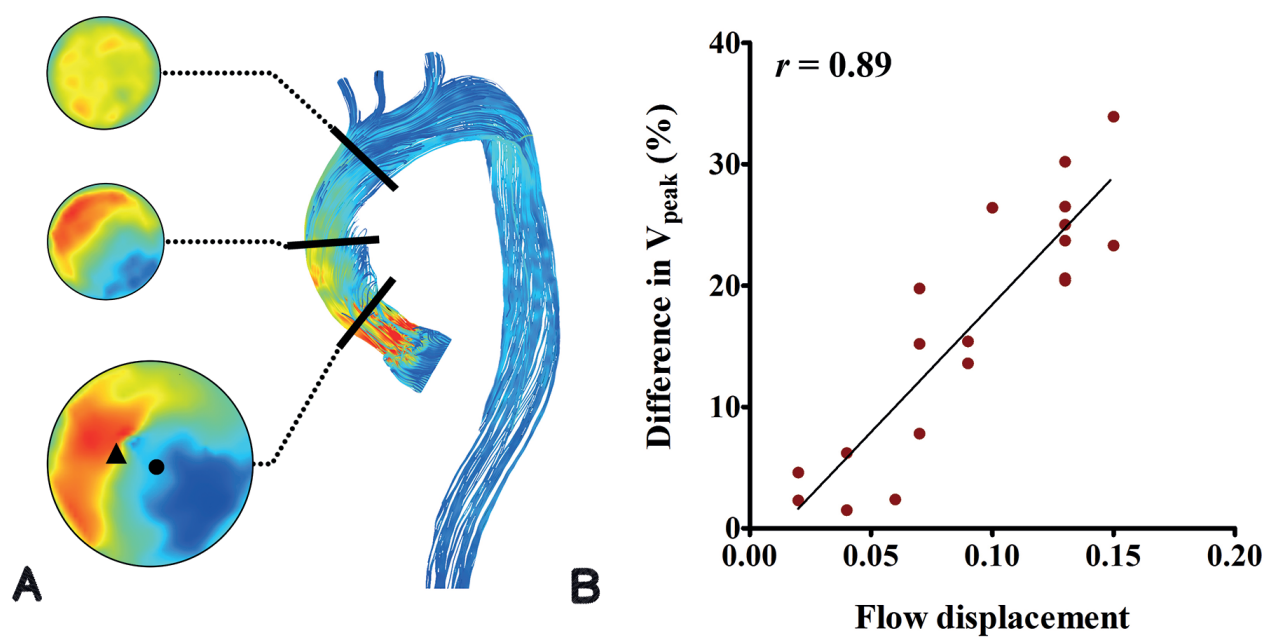

Figure 4. Influence of flow eccentricity on peak jet velocity measurements. (A) 4D PC-MR streamline visualization of the thoracic aorta in a patient with severe aortic stenosis. Velocity profiles (left panel) show marked eccentric flow from the aortic valve until halfway the ascending aorta. Flow displacement (bottom left) is defined as the linear distance between the center of the vessel lumen (marked by the black dot) and the center of velocity (triangle), normalized for vessel lumen diameter. (B) Association between flow displacement and the extent to which peak jet velocity is underestimated by TTE. PC-MR: phase-contrast magnetic resonance; TTE: transthoracic echocardiography.

\section{Intra- and interobserver variability}

Intra-observer agreement was excellent for 4D PC-MR measurements of $\mathrm{V}_{\text {peak }}$ (ICC I.00), $\mathrm{P}$. (ICC 0.99), and AVA (ICC 0.94). Also, interobserver agreement was excellent (ICC 0.97 for $V_{\text {pest }}$ ICC 0.96 for $P_{\text {mean }}$, and ICC 0.90 for AVA).

\section{DISCUSSION}

Transthoracic echocardiography is the imaging modality of first choice for the evaluation of AS, given its practicality, portability and cost-effectiveness. Furthermore, current thresholds for valve replacement are based on echocardiographic studies that investigated the association between various AS parameters and adverse outcomes(22-24). However, TTE should be performed with care, as its potential pitfalls may result in either under- or overestimation of stenosis severity $(3,4)$ In the current study, we investigated whether 4D PC-MR can overcome certain limitations that apply to TTE. Our main findings are: I) 4D PC-MR measures higher $V_{\text {peak }}$ and $\mathrm{P}_{\text {mean }}$ in AS patients when compared to TTE, 2) 2D PC-MR substantially underestimates AS severity when compared to TTE, 3) pronounced flow eccentricity is associated with greater differences in $V_{\text {eer }}$ between TTE and 4D PC-MR, and 4) 4D PC-MR improves concordance between the parameters that define AS severity. To date, logistic constraints (such as long acquisition times and the need for advanced MR hardware and post-processing tools) have impeded the widespread use of 4D PC-MR. Nevertheless, it affords a uniquely detailed assessment of flow patterns in the heart and aorta. Validation studies have compared 4D PC-MR with echocardiography in healthy volunteers and in patients without valvular disease (i.e., subjects with laminar flow patterns), and found good agreement between
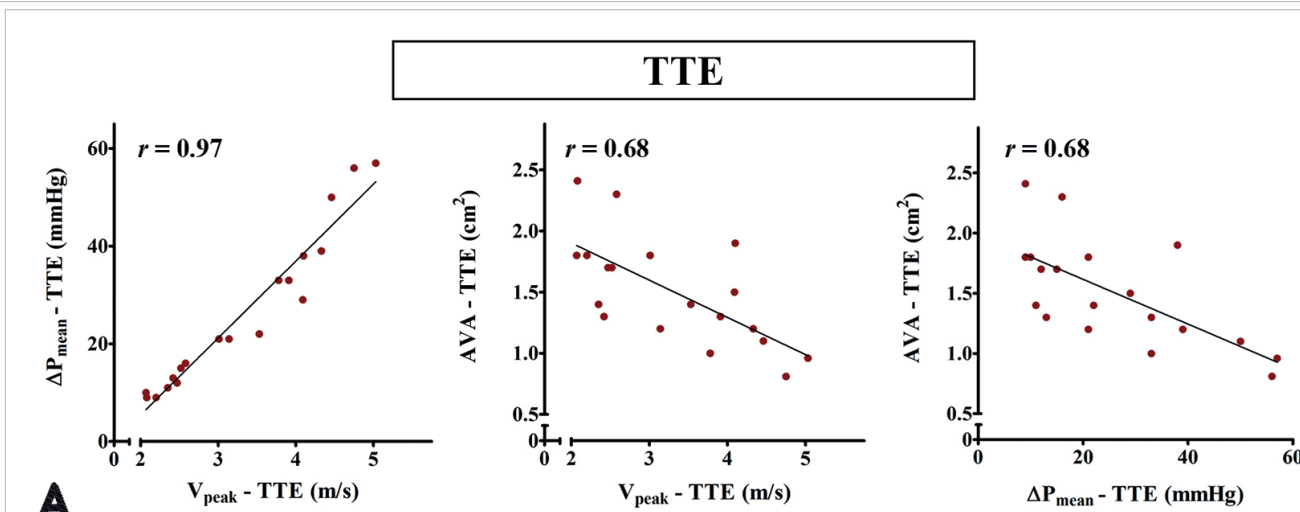

.

4D PC-MR

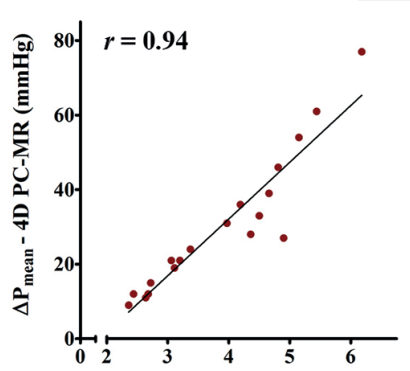

$8 V_{\text {peak }}-4 \mathrm{D}$ PC-MR $(\mathrm{m} / \mathrm{s})$
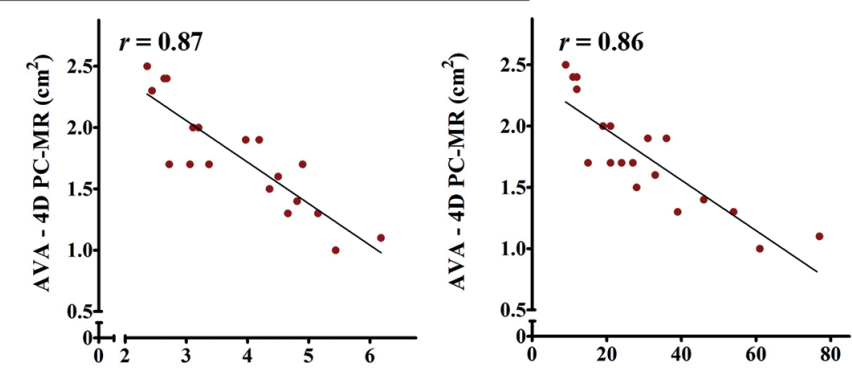

$V_{\text {peak }}$ - 4D PC-MR $(\mathrm{m} / \mathrm{s})$

Figure 5. Concordance between the different parameters used for AS grading. Regression lines showing concordance between Vpeak, Pmean and AVA from (A) transthoracic echocardiography and (B) 4D PC-MR. As depicted, the correlation coefficients between Vpeak and AVA, and between Pmean and AVA improved through the use of 4D PC-MR (from $r=0.68$ to $r=0.87$ and from $r=0.68$ to $r=0.86$, respectively). AS: aortic stenosis; AVA: aortic valve area; Pmean: mean transvalvular pressure gradient; PC-MR: phase-contrast magnetic resonance; TTE: transthoracic echocardiography; Vpeak: peak jet velocity

both modalities (17, 18). However, as previously reported by others, we found that systolic flow jets in AS patients are often eccentric $(19,25)$. Four-dimensional PC-MR is not hindered by flow eccentricity, since its multidirectional velocity-encoding provides for quantification of velocities regardless of the spatial orientation of the flow jet. In TTE, however, abnormal flow patterns confer risk for misalignment of the ultrasound beam with the AS jet. Therefore, it is conceivable that TTE underestimates $V_{\text {peak }}$ and $P_{\text {mean }}$ in AS patients, which is in line with the findings of the current study. The excellent correlation that was found between flow displacement and the extent to which TTE underestimated $\mathrm{V}_{\text {peak }}$ serves as internal validation for this hypothesis.

Of note, use of unidirectional 2D PC-MR led to substantial underestimation of velocities and pressure gradients, especially in patients with more critical valvular stenosis. Recently, Da Silveir et al. have evaluated a 2D PC-MR sequence with three-directional velocity-encoding and demonstrated the importance of multidirectional flow imaging in AS patients(I2). Their sequence, which they were able to acquire within one breath hold, showed improved correlations with TTEformostAS parameters. Rose et al. performed 4DPC-MR in a pediatric cohort of non-stenotic $B A V$ patients and calculated the underestimation of peak velocities by unidirectional methods to 
be $6.6 \%(26)$. Our study adds to this knowledge by showing that the benefits of 4D PC-MR are more pronounced in AS patients with higher peak velocities and in those with highly eccentric flows. Furthermore, and in contrast to 2D PC-MR, 4D PC-MR facilitates visualization of aortic flow patterns and estimation of secondary flow-related metrics (such as wall shear stress), which is of potential interest in the pathophysiology of valve-related aortopathy $(15,27,28)$.

$\mathrm{AVA}$ is, in theory, the ideal parameter to reflect AS severity, albeit the most challenging one to assess. It has been well-described that AVA shows considerable variability depending on measurement method (anatomical vs. functional) and imaging modality(29). Two-dimensional echocardiography usually underestimates AVA in comparison to other imaging techniques, because it measures the anteroposterior (i.e., minor) axis of the LVOT for calculation of its cross-sectional area $(6,7)$. Our results confirm that the TTE-derived LVOT area is approximately $20 \%$ smaller than its planimetric equivalent from 4D PC-MR(30). Hence, AVA differs to the same extent. Since current thresholds for valve replacement are based on echocardiographic studies that showed AVA $\leq 1.0 \mathrm{~cm}^{2}$ to be associated with increased mortality risk, the higher AVA from 4D PC-MR would require definition of new, modality-specific, cut-offs for AS grading. Nevertheless, the technique has potential to develop into a useful tool for the hemodynamic assessment of stenosis severity, as it is the first imaging modality that showed ability to improve correlations between different AS parameters(7). Whereas this might not be of added value for patients with symptomatic high-gradient AS (since these already qualify for valve intervention), it can be particularly useful for the assessment of patients with discordant echocardiographic grading patterns. Such patterns are observed in up to $35 \%$ of patients with severe AS and typically involve cases of low-gradient AS (i.e., presence of a small valve orifice [AVA $\left.\leq 1.0 \mathrm{~cm}^{2}\right]$ accompanied by a relatively low transvalvular pressure gradient $\left.\left[\mathrm{P}_{\text {mean }}<40 \mathrm{mmHg}\right]\right)(3 \mathrm{l}, 32)$. Although, depending on flow status and LV ejection fraction, several subtypes of low-gradient AS have been acknowledged, the first step in their encountering should be to exclude any measurement errors from TTE. Future studies should investigate whether 4D PC-MR has the potential to distinguish between actual low-gradient severe AS and overestimated moderate AS, and if the technique can play a role in determining the need and timing of aortic valve replacement in this specific patient group.

Several limitations of the current study and the 4D PC-MR imaging technique should be addressed. First, there exists no gold standard for velocity measurements in AS patients against which our findings could be compared.

Second, in vitro studies have demonstrated that phase-contrast techniques tend to underestimate flow rates in stenotic flows, and that measurement errors increase with higher velocities and longer TE(33). Although 4D PC-MR revealed higher flow velocities than TTE in the current study, patients with severe AS were relatively underrepresented. Future studies that include a larger number of patients with highly accelerated flows are required to investigate the potential impact of the limited temporal resolution of 4D PC-MR on the accuracy of flow and velocity measurements in more detail.

Third, even though our results indicate that 4D PC-MR is a feasible imaging modality that can be performed using clinically available hardware and software platforms, shortening of scan duration is a prerequisite in order for the technique to find its way into clinical practice guidelines. Several technical advances (such as compressed SENSE, parallel imaging and novel reconstruction algorithms) hold promise to significantly reduce the long scan time of 4D PC-MR.

Finally, based on our results on improved concordance between $V_{\text {peak }}, P_{\text {mean }}$ and AVA using 4D PC-MR, future studies should address the potential value of 4D PC-MR for the assessment of AS patients with discordant echocardiographic parameters.
In conclusion, 4D PC-MR can be performed with high intra- and interobserver accuracy in patients with AS. Pronounced flow eccentricity is associated with greater differences in $V_{\text {pex }}$ between TTE and 4D PC-MR. Use of 4D PC-MR increases concordance between $V_{\text {peak }}, P_{\text {mean }}$ and AVA. Based on these findings, future studies should address the potential value of $4 D P C-M R$ for the assessment of patients with discordant echocardiographic AS grading. 


\section{REFERENCES}

Frequency by decades of unicuspid, bicuspid, and tricuspid aortic valves in adults having isolated aortic valve replacement for aortic stenosis,
with or without associated artic restartion. Circulation. 2005; III (7):920-5.

2. Osnabrugge RL, Mylotte D, Head SJ, Van Mieghem NM, Nkomo VT, LeReun CM, et al. Aortic stenosis in the transcatheter aortic valve replacement: a meta-analysis and modeling study.JAm Coll Cardiol. 2013;62 (II): 1002-12. Baumgartner H, Falk V, Bax J], De Bonis M, Hamm C, Holm PJ, et al. 2017 ESC/EACTS Guidelines for the management of valvular heart disease. Eur Heart $J$

Baumgartner H, Hung J, Bermejo J, Chambers JB,
Edvardsen T, Goldstein S, et al. Recommendations the echocardiographic assessment of aortic valve stenosis: a focused update from the European Association of Cardiovascular Imaging and the American Society of Echocardiography. J Am Soc Echocardiogr.

, Aelelis F, Binda C. Bohbot $Y$, et al. Prospective assessment of the frequency
of low gradient severe aortic stenosis with preserved left ventricular ejection fraction: Critical impact of aortic flow misalignment and pressure recovery pher

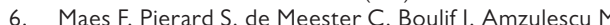
Vancraeynest $D$, et a Minpact of left ventricular out flow tract ellipticity on the grading of aortic stenosis in patients with normal eje
Magn Reson. 2017:19(1):37.

7. Clavel M-A, Malouf J, Messika-Zeitoun D, Araoz PA, Michelena $\mathrm{HI}$, Enriquez-Sarano M. Aortic valve are diography. Am Coll Cardiol Img. 2015:8(3).248-57.

8. Pelc NJ, Herfkens RJ, Shimakawa A, Enzmann DR. Phase contrast cine magnetic resonance imaging. Magn Res Quart. 1991;7(4):229-54.

. Pelc NJ, Sommer F, Li K, Brosnan TJ, Herfkens RJ. Enzmann DR. Quantilative magnetic resonance flow

PG, Yoganathan AP, Pettigrew RI. Evaluation of the precision of magnetic resonance phase velocity mapping for blood flow measurements. Cardiovasc Magn Reson. 2001;3(I):II-9.

I. Defrance C, Bollache E, Kachenoura N, Perdrix L, Hrynchyshyn N, Bruguière E, et al. Evaluation of Aortic Comparison of an Original Semi-Autometic Resonance Phase-Contrast-CMR with Doppler Echocardiography. Circ-Cardiovasc lmag. 2012,5(5).604/12.

12. da Silveira JS, Smyke M, Rich AV, Liu Y, Jin N, Scandling D. et al. Quantification of aortic stenosis diagnostic paramphase contrast CMR and transthoracic echocardiog raphy. J Cardiovasc Magn Reson. 2017;19(I):35.

13. Søndergaard L, Hildebrandt P, Lindvig K, Thomsen $C$. Stáahlberg $F$, Kassis $E$, et al. Valve area and cardiac outpu in aortic stenosis: quantification by magnetic reson
velocity mapping. Am Heart |. 1993;126(5): II I56-64.

4. Markl M, Frydrychowicz A, Kozerke S, Hope M, Wieben O.4D flowMRI.JMagn Resonlmaging. 2012;36(5):I015-36.
15. Dyverfeldt P, Bissell M, Barker AJ, Bolger AF, Carlhäll C-J a consensus st.
2015; $17(1): 72$.

16. Westenberg JJ, Roes SD, Ajmone Marsan N, Binnendij NM, Doornbos J, Bax JJ, et al. Mitral valve and tricuspid 作 tracking. Radiology. 2008;249(3):792-800.

17. Gabbour M, Schnell S, Jarvis K, Robinson JD, MarkI M, Rigsby CK. 4-D flow magnetic resonance imaging: blood low quantification compared to 2-D phase-contrast magnetic resonance imaging and Doppler echocardiog-

Wehrum T, Guenther F, Fuchs A, Sc

Schuchardt $F$ and aortic blood flow velocities in stroke patients: comparison of 4D flow MRI and echocardiography. Int Cardiovasc Imaging. 2018:I-8.

19. von Knobelsdorff-Brenkenhoff F, Karunaharamoorthy Evaluation of Aortic Blood Flow and Wall Shear Stress in Aortic Stenosis and Its Association With Left Ventricular Remodeling. Circ-Cardiovasc Imag. 2016;9(3):e004038.

20. Nishimura RA, Otto CM, Bonow RO, Carabello BA, Erwin JP, Guyton RA, et al. 2014 AHA/ACC guideline for the manage American Heart Association Task Force on Practic Guidelines. J Am Coll Cardiol. 2014;63(22):e57-el85.

21. Sigovan M, Hope MD, Dyverfeldt P, Saloner D. Comparison of four-dimensional flow parameters for quantification of flow eccentricity in the ascending aorta. Magn Reson Imaging. 201,34(J).1226-30.

Lang I, Christ $G$ Schemper M, et al. Predictors of outcome in severe, asymp-

23. Otto CM, Burwash IG, Legget ME, Munt BI, Fujioka M. Healy $\mathrm{NL}$, etal. Prospective study of asymp tomatic valvular aortic stenosis: clinical, echocardiographic, and exercise

24. Stewart RA, Ker AJ, Whally GA, Lesge ME, Z

Williams MI, et al. Left ventricular systolic and diastolic function assessed by tissue Doppler imaging and outcome in asymptomatic aortic stenosis. Eur Heart 1 .

2010;31(18):2216-22.
25. van Ooij P, Markl M, Collins JD, Carr JC, Rigsby C, Bonow
RO et al Aortic Valve Stenosis Alters Expression of Regional Aortic Wall Shear Stress: New Insights From 4-Dimensional Flow Magnetic Resonance Imaging Study of 57l Subjects. I Am Heart Assoc. 2017;6(9):e005959.

26. Rose MJ, Jarvis K, Chowdhary V, Barker AJ, Allen BD, Robinson JD, et al. Efficient method for volumetric assessment of peak blood flow velocity using 4D flow MRI. Magn Reson Imaging. 2016;44(6).1673-82.

Doij P, Malaisrie SC Puthumana Jj, Belke DD, et al. Valve-related hemodynamics mediate human bicuspid aortopathy: insights
from wall shear stress mapping. I Am Coll Cardiol. 2015;66(8):892-900.

28. Hope MD, Hope TA, Crook SE, Ordovas KG, Urbania related ascending aortic disease. J Am Coll Cardiol Ims 2011;:4(7):781-7.
29. Garcia D, Kadem L. What do you mean by aortic valve area: geometric orifice area, effective orifice area, o Delgado V Ns AC van de Veire NR, van der Schuijf JD, Tops $L F$, et al. Transcatheter aortic valve
implantation: role of multi-detector row computed tomography to evaluate prosthesis positioning and deployment in relation to valve function. Eur Heart $J$. 2010,31(9).114-23.

Z Dumesnil JG, Bogaty P, Pibarot P. Paradoxical low-flow, low-gradient severe aortic (lojection fraction is as

32. Berthelot-Richer M, Pibarot P. Capoulade R, Dumesn Berthelot-Richer M, Pibarot P, Capoulade R, Dumesn JG, Dahou A, Thebault C, et al. Discordant grading of survival benefit associated with aortic cralve replacement. J Am Coll Cardiol Img. 2016;9(7):797-805.

33. O'Brien KR, Cowan BR, Jain M, Stewart RA, Kerr A], Young AA. MRI phase contrast velocity and flow errors in .2008;28(I):210-8 


\section{Characterization of ascending aortic flow in patients with degenerative aneurysms: a 4D flow magnetic resonance study}

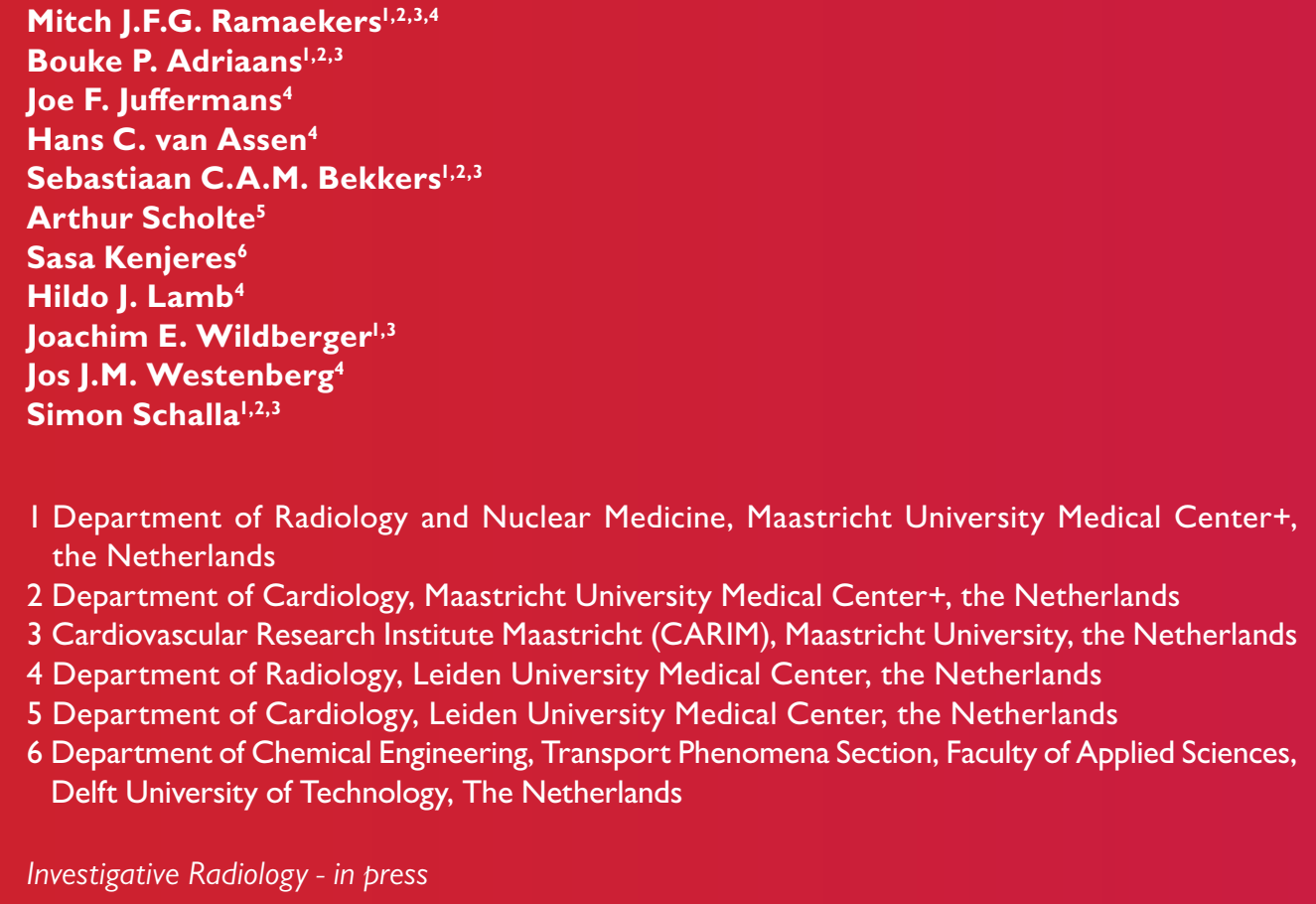

I Department of Radiology and Nuclear Medicine, Maastricht University Medical Centert, the Netherlands

2 Department of Cardiology, Maastricht University Medical Center+, the Netherlands

3 Cardiovascular Research Institute Maastricht (CARIM), Maastricht University, the Netherlands

4 Department of Radiology, Leiden University Medical Center, the Netherlands

5 Department of Cardiology, Leiden University Medical Center, the Netherlands

6 Department of Chemical Engineering, Transport Phenomena Section, Faculty of Applied Sciences,

Delft University of Technology, The Netherlands

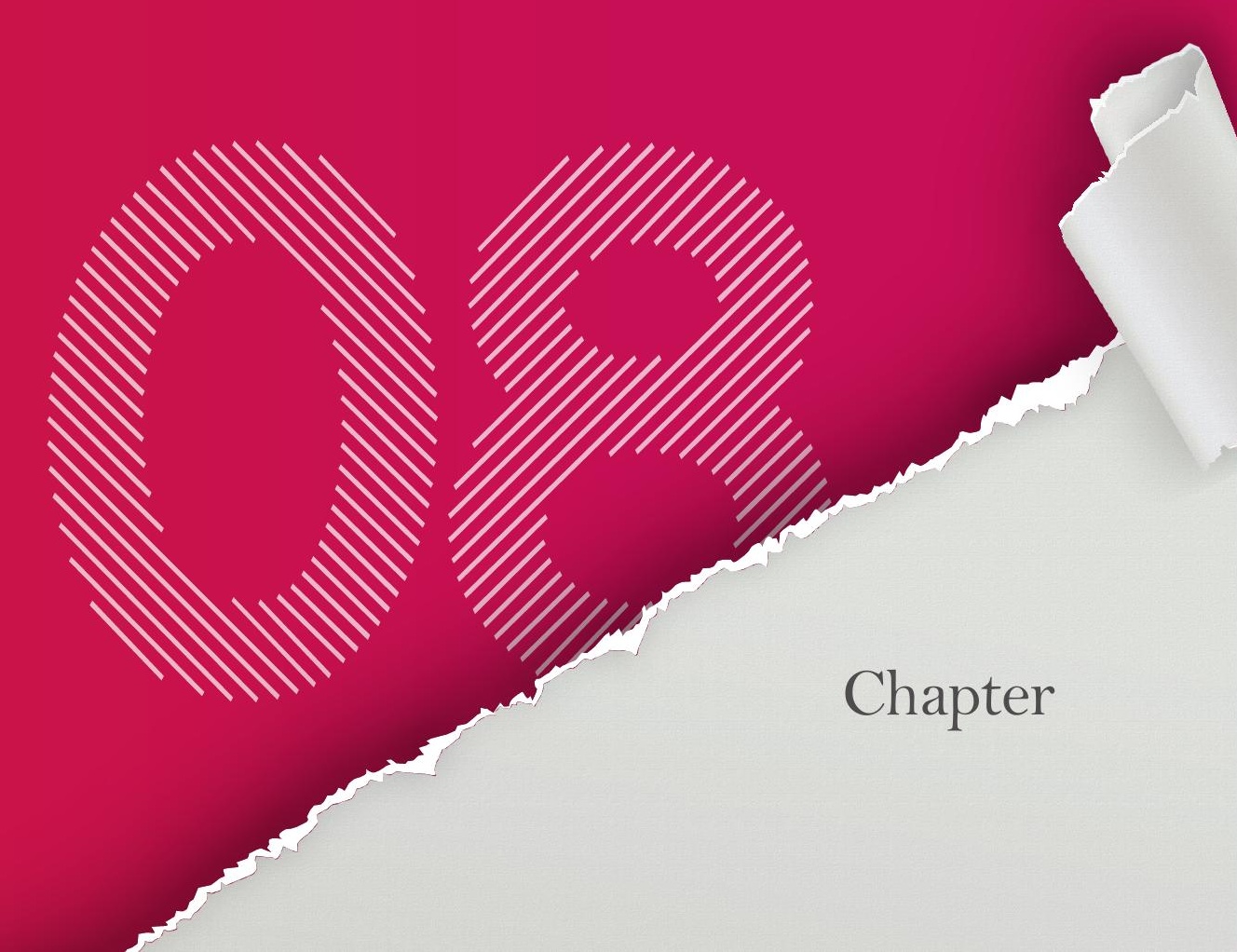




\section{OBJECTIVES}

Degenerative thoracic aortic aneurysm (TAA) patients are known to be at risk of life-threatening acute aortic events. Guidelines recommend pre-emptive surgery at diameters of $>55 \mathrm{~mm}$, although many patients with small aneurysms show only mild growth rates and more than half of complications occur in aneurysms below this threshold. Thus, assessment of hemodynamics using 4D flow magnetic resonance has been of interest to obtain more insights in aneurysm development. Nonetheless, the role of aberrant flow patterns in TAA patients is not yet fully understood.

\section{MATERIALS AND METHODS}

A total of 25 TAA patients and 22 controls underwent time-resolved 3D phase contrast MR imaging with 3-directional velocity encoding (i.e., 4D flow MRI). Hemodynamic parameters such as vorticity, helicity and wall shear stress (WSS) were calculated from velocity data in three anatomical segments of the ascending aorta (root, proximal and distal). Regional WSS distribution was assessed for the full cardiac cycle.

\section{RESULTS}

Flow vorticity and helicity were significantly lower for TAA patients in all segments. The proximal ascending aorta showed a significant increase in peak WSS in the outer curvature in TAA patients, whereas WSS values at the inner curvature were significantly lower as compared to controls. Furthermore, positive WSS gradients from sinotubular junction to mid-ascending aorta were most prominent in the outer curvature, whereas from mid-ascending aorta to brachiocephalic trunk the outer curvature showed negative WSS gradients in the TAA group. Controls solely showed a positive gradient at the inner curvature for both segments.

\section{CONCLUSION}

Degenerative TAA patients show a decrease in flow vorticity and helicity which is likely to cause perturbations in physiological flow patterns. The subsequent differing distribution of WSS might be a contributor to vessel wall remodeling and aneurysm formation.

\section{KEYWORDS}

Aorta, aneurysm, 4D flow MRI, dissection

\section{KEY POINTS}

- Degenerative thoracic aortic aneurysm (TAA) leads to disturbed intra-aortic flow with decreased flow helicity and vorticity.

- Patients with TAA have asymmetrically distributed aortic wall shear stress (WSS), with elevated WSS values along the outer curvature.

\section{INTRODUCTION}

Thoracic aortic aneurysm (TAA) is defined as a local enlargement of the thoracic aorta to more than $150 \%$ of the expected diameter $(I)$. Despite its asymptomatic character, TAA predisposes for occurrence of life-threatening aortic events (such as dissection or rupture). The risk of natural complications is correlated to the maximal aortic diameter and increases sharply at diameters $>60 \mathrm{~mm}(2,3)$. Hence, current clinical guidelines recommend pre-emptive surgical extirpation of degenerative aneurysms $\geq 55 \mathrm{~mm}$ (or smaller if concomitant risk factors are present)(4-6). However, more than half of type A dissections occur at diameters below the cut-offs for prophylactic intervention(7-9). Therefore, there is a need for additional predictors of TAA progression, dissection, and rupture(I0).

Since dissection and rupture are commonly associated with hypertension there is a developing interest in the role of hemodynamics in the pathophysiology of aortic disease. Four-dimensional flow magnetic resonance imaging ( $4 \mathrm{D}$ flow $\mathrm{MRI}$ ) is an emerging non-invasive imaging modality that provides comprehensive insight into aortic hemodynamics(II-I3). The technique facilitates acquisition of time-resolved three-dimensional three-directionally encoded velocity data and allows for visualization and quantification of flow patterns and flow-derived hemodynamic markers(14). To date, abnormal hemodynamics (such as elevated wall shear stress [WSS], flow eccentricity, and flow vorticity) have been linked to different expressions of aortopathy in patients with Marfan's syndrome and bicuspid aortic valve (BAV)(15-18). Previous research has described that flow deviations predominantly occur in an aneurysmatic region and that these flow patterns normalize once the aortic diameter normalize distal from the aneurysmatic area(|9-2|). However, flow patterns in patients with degenerative TAA have not quantitatively been characterized and the potential impact of hemodynamics on development and progression of degenerative aneurysms is not fully understood. The current prospective observational two-center study aims to characterize regional hemodynamics in the ascending aorta of patients with degenerative TAA and compare findings with those of healthy controls.

\section{MATERIALS AND METHODS}

\section{Study population}

Patients with degenerative TAA $\geq 40 \mathrm{~mm}$ who visited the outpatient clinic of the Maastricht and Leiden University Medical Centers were prospectively recruited. Exclusion criteria comprised prior aortic or cardiac surgery and the presence of connective tissue disorder, BAV or genera contraindications for MR imaging. Patients with atrial fibrillation were excluded to ascertain the accuracy of MR flow measurements. A population of volunteers without aortic or valvular disease was included as control group. The study protocol was approved by the local medical ethical committee and all subjects provided written informed consent.

\section{MR acquisition}

Patients underwent MR examinations on 3T MR systems (Philips Ingenia, Philips Healthcare, Best, the Netherlands). The acquisition protocol included a 4D flow sequence with full volumetric coverage of the left ventricular outflow tract (LVOT) and thoracic aorta. Both medical centers used the same 4D flow sequence (Table I). Data was acquired using retrospective ECG gating and navigator respiratory gating based on diaphragm excursion. Velocity encoding (VENC) was typically set at $150 \mathrm{~cm} / \mathrm{s}$.

\section{Data analysis}

mage analysis was performed by a single reader (M.R.) using commercially available software (CAAS MR Solutions 5.I, Pie Medical Imaging Maastricht, the Netherlands). First, the lumen of 
the aorta was segmented from the magnitude images of the 4D flow dataset in peak systole. The segmented mesh was then copied over the entire cardiac cycle for analysis of additional heart phases. Cross-sectional planes were placed at four different locations: I. aortic valve, 2. sinotubula junction (STJ), 3. mid ascending aorta, and 4. proximal to the origin of brachiocephalic trunk. The cross-sectional planes divided the aorta into three segments: aortic root (R), proximal ascending aorta (PAsc), and distal ascending aorta (DAsc) (Figure I). The resulting three aortic segments were each divided into four anatomical regions (anterior and posterior inner curvature and anterior and posterior outer curvature). Wall shear stress (WSS) was defined as the tangential viscous force acting on the endothelial surface as a result of blood flow and calculated as previously described(22). Mean WSS values were calculated for each anatomic region per plane. Flow vorticity $(\omega)$ was defined as the vector that describes the flow rotation and calculated as follows:

$$
\omega=\nabla \times v
$$

where $v$ is the velocity vector and $\nabla$ is Nabla, the differential operator. Nabla in combination with the cross product $(x)$ is called the rotation operator, or curl. Flow helicity $(H)$ was defined as the dot-product of vorticity with the 3D flow vector and calculated as:

$H=v \cdot \nabla \times v$

Flow vorticity magnitude and helicity were both normalized for aortic volume per segment $(\mathrm{mL})$ and corrected for stroke volume $(\mathrm{mL})$

Table I: Four dimensional flow MR acquisition parameters.

\begin{tabular}{|l|l|}
\hline & $4 D$ Phase Contrast MRI \\
\hline FOV $(\mathbf{m m} \times \mathbf{m m} \times \mathbf{m m})$ & $350 \times 280 \times 75$ \\
\hline Acquired voxel size $(\mathbf{m m} \times \mathbf{m m} \times \mathbf{~ m m})$ & $2.5 \times 2.5 \times 2.5$ \\
\hline Reconstructed voxel size $(\mathbf{m m} \times \mathbf{~ m m} \times \mathbf{~ m m})$ & $1.46 \times 1.46 \times 2.5$ \\
\hline Flip angle $\left({ }^{\circ}\right)$ & 10 \\
\hline TE $(\mathbf{m s})$ & 2.3 \\
\hline TR $(\mathbf{m s})$ & 4.2 \\
\hline TFE factor & 2 \\
\hline SENSE factor & $2.5(\mathrm{P}) \times 1.5(\mathrm{~S})$ \\
\hline VENC $(\mathbf{c m} / \mathbf{s})$ & $150-200$ \\
\hline Shot duration $(\mathbf{m s})$ & 33 \\
\hline (Reconstructed) Cardiac phases & $24-43$ \\
\hline
\end{tabular}

FOV: field of view; TE: Echo time; TR: repetition time; VENC: velocity encoding.

\section{Statistical analysis}

Statistical analyses were performed using SPSS Statistics 25 (IBM, Armonk, USA). Normality distribution of the data was tested using the Shapiro-Wilk test. Continuous demographics are expressed as mean \pm standard deviation (or as median and interquartile range in the presence of data skewness). Differences between groups were assessed using student's t-test (or Mann-Whitney $U$ test, if deemed appropriate).

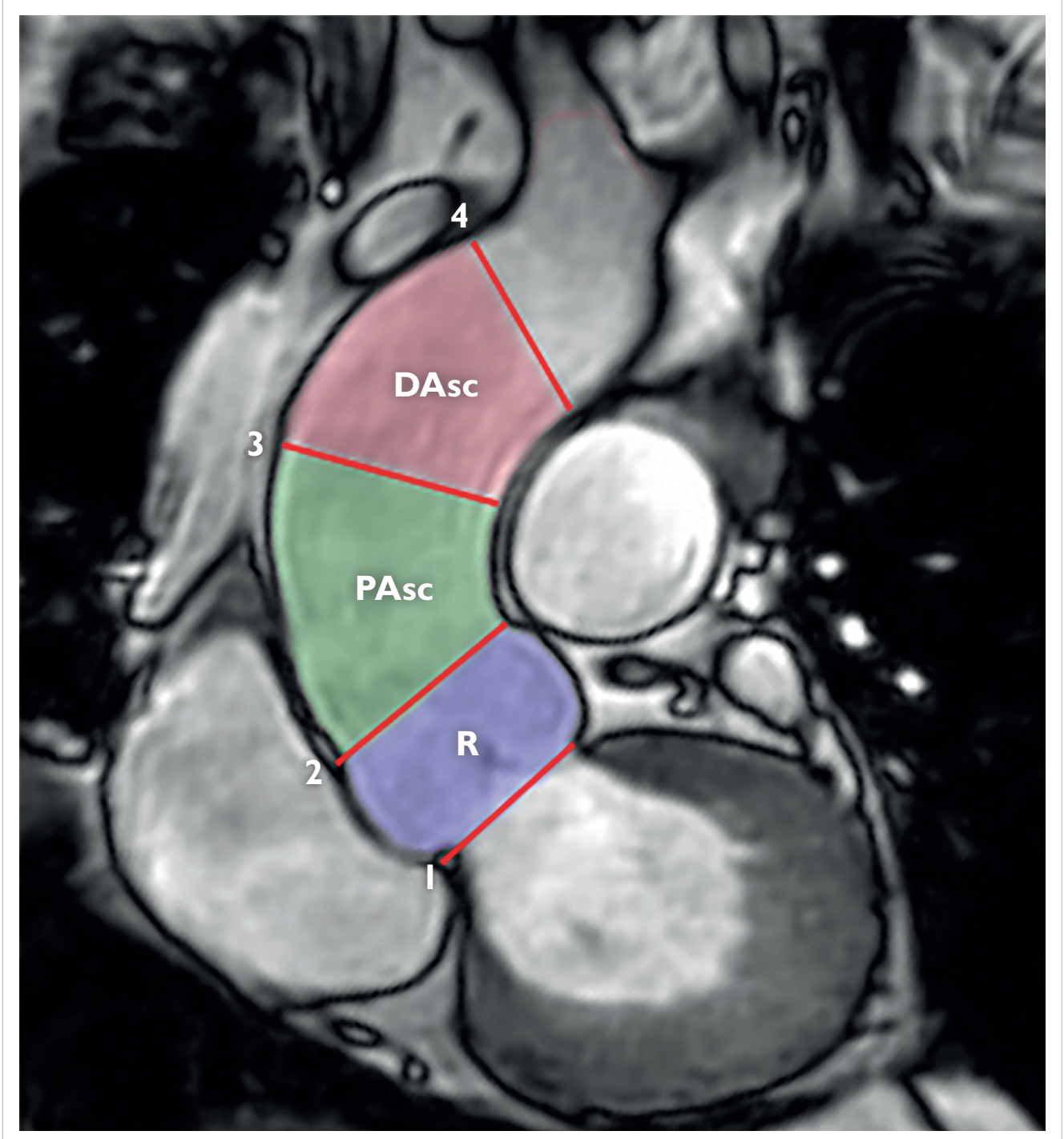

Figure I: Aortic plane placement and division of segments. R: aortic root; PAsc: proximal ascending aorta; DAsc: distal ascending aorta.

Categorical variables are presented as frequencies and percentages and were evaluated using Chi-square test or Fisher's exact test. Correlations between parameters were tested using Spearman's $\mathrm{R}$ or Pearson's correlation coefficient. Gradients were analyzed using a Wilcoxon signed-rank test considering the presence of skewness. A p-value of $<0.05$ was considered statistically significant.

\section{RESULTS}

A total of 25 TAA patients and 22 controls were included. Patients with TAA were more likely to suffer from hypertension ( $48.0 \%$ vs. $4.3 \%, \mathrm{p}<0.00 \mathrm{l}$ ) and to use antihypertensive medication (Table 2). Additiona demographics - such as age, gender, and body size - did not differ significantly between groups. 
Aortic diameters were significantly larger in TAA patients at all levels of the ascending aorta (plane 2: $41.7 \mathrm{~mm}$ vs. $34.4 \mathrm{~mm}, \mathrm{p}<0.00 \mathrm{l}$; plane $3: 42.7 \mathrm{~mm}$ vs. $32.5 \mathrm{~mm}, \mathrm{p}<0.00 \mathrm{l}$; plane 4 : $41.4 \mathrm{~mm}$ vs. $31.5 \mathrm{~mm}, \mathrm{p}<0.00 \mathrm{I})$

Table 2: Baseline characteristics of the study population.

\begin{tabular}{|l|l|l|l|}
\hline & Controls & TAA & p-value \\
\hline N & 22 & 25 & - \\
\hline Age (years) & $63.5[57.0-67.3]$ & $64.5[50.8-72.3]$ & 0.790 \\
\hline Men & $12(54.5 \%)$ & $15(60.0 \%)$ & 0.807 \\
\hline BMI (kg/m2) & $25.5[22.5-28.7]$ & $26.4[23.7-28.7]$ & 0.565 \\
\hline BSA (m2) & $1.90( \pm 0.26)$ & $1.98( \pm 0.16)$ & $0.28 \mid$ \\
\hline Hypertension & $I(4.5 \%)$ & $12(48 \%)$ & $0.00 I^{*}$ \\
\hline Hypercholesteraemia & $2(9.1 \%)$ & $8(32.0 \%)$ & 0.079 \\
\hline Diabetes & $2(9.1 \%)$ & $3(12.0 \%)$ & 1.000 \\
\hline Current smoker & $4(18.2 \%)$ & $4(16.0 \%)$ & 1.000 \\
\hline Past smoker & $7(31.8 \%)$ & $8(32.0 \%)$ & 0.989 \\
\hline Medication & & & \\
\hline Beta blocker & $\mathrm{I}(4.5 \%)$ & $8(32.0 \%)$ & $0.025^{*}$ \\
\hline ACE-inhibitor & $\mathrm{I}(4.5 \%)$ & $12(48.0 \%)$ & $0.00 I^{*}$ \\
\hline Calcium antagonist & $0(0 \%)$ & $5(20.0 \%)$ & 0.052 \\
\hline Nitrate & $0(0 \%)$ & $0(0 \%)$ & - \\
\hline Statin & $2(9.1 \%)$ & $8(32.0 \%)$ & 0.079 \\
\hline
\end{tabular}

BMI: body mass index; BSA: body surface area. * = statistically significant.

Table 3: Maximal aortic diameters measured at three levels of the ascending aorta.

\begin{tabular}{|l|l|l|l|}
\hline & Controls $(\mathrm{n}=22)$ & TAA $(\mathrm{n}=25)$ & P-value \\
\hline Maximal diameter root $(\mathbf{m m})$ & $34.3( \pm 4.5)$ & $41.7( \pm 6.0)$ & $<0.00 I^{*}$ \\
\hline Maximal diameter Pas $(\mathbf{m m})$ & $32.5( \pm 4.1)$ & $42.7( \pm 4.5)$ & $<0.00 I^{*}$ \\
\hline Maximal diameter DAsc $(\mathbf{m m})$ & $31.5( \pm 4.2)$ & $41.4( \pm 4.2)$ & $<0.00 I^{*}$ \\
\hline Centerline length root $(\mathbf{m m})$ & $15.7( \pm 3.4)$ & $17.2( \pm 3.6)$ & 0.151 \\
\hline Centerline length PAsc $(\mathbf{m m})$ & $28.5( \pm 4.7)$ & $33.3( \pm 9.3)$ & $0.031^{*}$ \\
\hline Centerline length DAsc $(\mathbf{m m})$ & $30.3( \pm 5.2)$ & $41.0( \pm 9.73)$ & $<0.001^{*}$
\end{tabular}

Ascending aortic dimensions. Maximal aortic diameters (in $\mathrm{mm}$ ) of the study population are measured at three levels of the ascending aorta. Centerline length (in $\mathrm{mm}$ ) is measured in all three segments of the ascending aorta. PAsc = proximal ascending aorta, DAsc = distal ascending aorta. * = statistically significant.
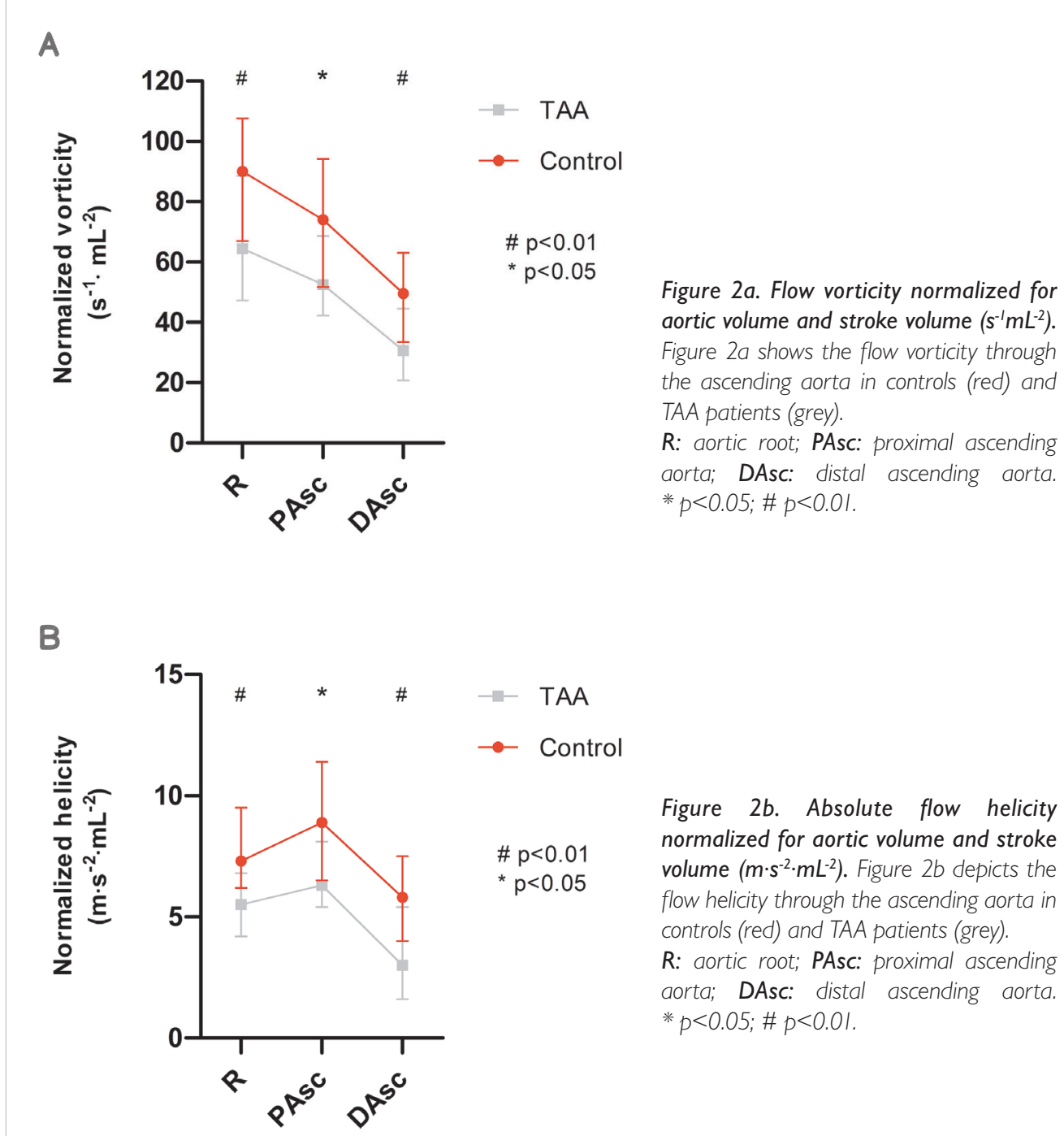

Figure 2b. Absolute flow helicity normalized for aortic volume and stroke volume $\left(m \cdot s^{-2} \cdot \mathrm{mL}^{-2}\right)$. Figure $2 b$ depicts the flow helicity through the ascending aorta in controls (red) and TAA patients (grey) R: aortic root; PAsc: proximal ascending orta; DAsc: distal ascending aorta $* p<0.05 ; \# p<0.01$

Peak normalized vorticity was significantly lower in the aortic root of TAA patients (64.4 $\left.\mathrm{s}^{-1} \mathrm{~mL}^{-2} \mathrm{vs} .90 .0 \mathrm{~s}^{-1} \mathrm{~mL}^{-2}, \mathrm{p}=0.00 \mathrm{I}\right)$, as well as in the proximal and distal ascending aorta $\left(52.6 \mathrm{~s}^{-1} \mathrm{~mL}^{-2}\right.$ vs. 74.1 s $\mathrm{mL}^{-2}, \mathrm{p}=0.013$, and $30.6 \mathrm{~s}^{-1} \mathrm{~mL}^{-2} \mathrm{vs} .49 .5 \mathrm{~s}^{-1} \mathrm{~mL}^{-2}, \mathrm{p}=0.005$, respectively) (Figure 2a). Peak absolute normalized helicity was significantly lower in TAA patients at the level of the aortic root $\left(5.5 \mathrm{~m} \cdot \mathrm{s}^{-2} \cdot \mathrm{mL}^{-2} \mathrm{vs} .7 .3 \mathrm{~m} \cdot \mathrm{s}^{-2} \cdot \mathrm{mL}^{-2}, \mathrm{p}=0.00 \mathrm{I}\right)$, proximal ascending aorta $\left(6.3 \mathrm{~m} \cdot \mathrm{s}^{-2} \cdot \mathrm{mL}^{-2} \mathrm{vs} .8 .9 \mathrm{~m} \cdot \mathrm{s}^{-2} \cdot \mathrm{mL}^{-2}\right.$, $\mathrm{p}=0.013)$ and distal ascending aorta $\left(3.0 \mathrm{~m} \cdot \mathrm{s}^{-2} \cdot \mathrm{mL}^{-2} \mathrm{vs} .5 .8 \mathrm{~m} \cdot \mathrm{s}^{-2} \cdot \mathrm{mL}^{-2}, \mathrm{p}=0.003\right)$ (Figure 2b). Besides total values being significantly lower, partial derivatives show distinct differences, whereas areas of high vorticity in controls are mostly located at the inner curvature, whilst TAA patients show a less uniform distribution throughout the lumen (Figures 3 and 4). 


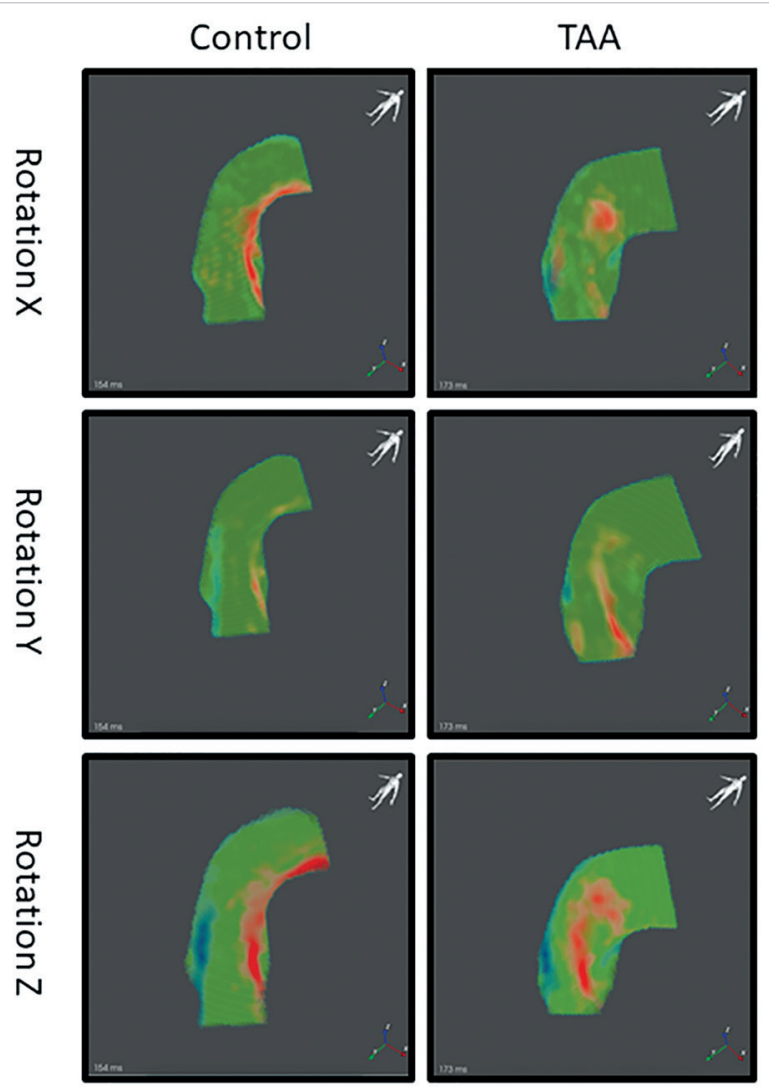

Figure 3. Separate components of rotation in vorticity calculation. Images depict values of a central vertica plane of a single representative subject per group. Red and blue are positive and negative values, respectively.

Dynamics of WSS over the cardiac cycle for different planes and different regions of the ascending aorta are depicted in Figure 4. In general as compared to controls, peak WSS in TAA patients was lower at the sinuses of Valsalva, while it was higher at the outer curvature and lower at the inner curvature at the proximal ascending aorta and returning to lower values at the distal ascending aorta. Peak WSS was significantly lower at the level of the sinuses of Valsalva in TAA patients at the posterior part of the inner curvature $(729 \mathrm{mPa}$ vs. $955 \mathrm{mPa}$, $p=0.026)$, the anterior part of the inner curvature $(652 \mathrm{mPa}$ vs. $874 \mathrm{mPa}, \mathrm{p}=0.036)$ and the posterior part of the outer curvature $(769 \mathrm{mPa}$ vs. $979 \mathrm{mPa}, \mathrm{p}=0.049)$. Peak WSS was significantly lower at the anterior part of the inner curvature of the proximal ascending aorta in TAA patients (734 mPa vs. $864 \mathrm{mPa}, \mathrm{p}=0.026$ ), whereas it turned out to be significantly higher at the anterior part of the outer curvature $(1285 \mathrm{mPa}$ vs. $963 \mathrm{mPa}, \mathrm{p}=0.007)$. The distal ascending aorta showed significantly lower peak WSS values in TAA patients at the anterior area of the inner curvature $(773 \mathrm{mPa}$ vs. $986 \mathrm{mPa}, \mathrm{p}=0.006)$, the posterior area of the inner curvature $(936 \mathrm{mPa}$ vs. $1306 \mathrm{mPa}, \mathrm{p}<0.00 \mathrm{I})$ and the posterior area of the outer curvature (707 mPa vs. $947 \mathrm{mPa}, \mathrm{p}=0.00 \mathrm{I}$ ). Peak WSS did not differ significantly at other regions.

Of note, positive peak WSS gradients were observed between the STJ and PAsc in TAA patients at the outer curvature posterior $(769 \mathrm{mPa}$ to $1 / 19 \mathrm{mPa}, \mathrm{p}=0.007)$, at the outer curvature

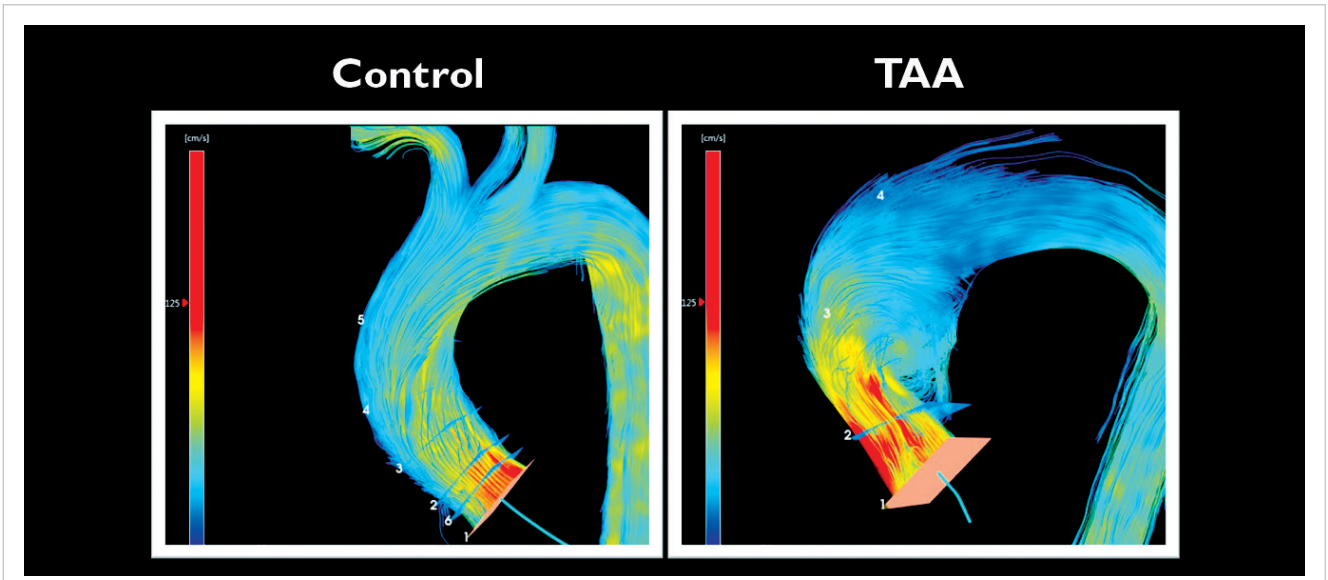

Figure 4. Visualization of ascending aortic flow velocities and flow directions in the systolic heart phase with most pronounced flow perturbations of a TAA patient and a healthy control. Blue and red indicate low and high velocity respectively. Full videos of flow patterns in these subjects are available as Supplemental Digital Content (See videos Supplemental Digital Content I and 2, showing ascending aortic flow patterns.

anterior $(839 \mathrm{mPa}$ to $1285 \mathrm{mPa}, \mathrm{p}<0.00 \mathrm{I})$ and at the inner curvature posterior $(729 \mathrm{mPa}$ to 938 $\mathrm{mPa}, \mathrm{p}=0.004)$, whereas controls only showed a significant positive gradient at the inne curvature posterior from ST] to PAsc ( $955 \mathrm{mPa}$ to $1138 \mathrm{mPa}, \mathrm{p}=0.027$ ). From PAsc to DAsc a negative gradient is seen in TAA patients at the outer curvature posterior and anterior (III) mPa to $707 \mathrm{mPa}, \mathrm{p}<0.001$ and $1285 \mathrm{mPa}$ to $964 \mathrm{mPa}, \mathrm{p}=0.002$, respectively). Controls showed a positive gradient between PAsc and DAsc for the inner curvature posterior and anterior (II38 $\mathrm{mPa}$ to $1306 \mathrm{mPa}, \mathrm{p}=0.003$ and $864 \mathrm{mPa}$ to $992 \mathrm{mPa}, \mathrm{p}=0.008$, respectively) (Figure 5).

\section{DISCUSSION}

In the current study we assessed hemodynamic parameters in the ascending aortas of patients with degenerative TAA and compared them to those in healthy controls. We found that TAA patients i) have decreased normalized aortic flow vorticity and helicity, ii) show more asymmetrically distributed peak WSS values with elevated WSS at the outer curvature and decreased WSS at the inner curvature, and iii) show a positive WSS gradient from the sinotubular junction to the proximal ascending aorta.

\section{Aberrant flow pattern}

Physiological vorticity and helicity play a role in maintaining stable flow through the aorta(19, 23). According to Poiseuille's law of flow in a U-bend shape, such as the thoracic aorta, centripeta forces in the proximal part cause a shift of the parabolic peak velocity from the center of aorta to the inner curvature, where distally in the U-bend, centrifugal forces dominate and cause shift towards the outer curvature. The secondary flow patterns that occur as a consequence, consisting of two counter rotating in-plane vortices, are needed to maintain stable flow and mass transportation. In the current study, these secondary flow patterns were clearly seen in controls when taking a look at the rotation components of the flow vorticity, whereas the pattern in TAA patients was found to be different (Figures 3 and 4). These secondary flow patterns in the healthy aorta have been demonstrated to compensate 

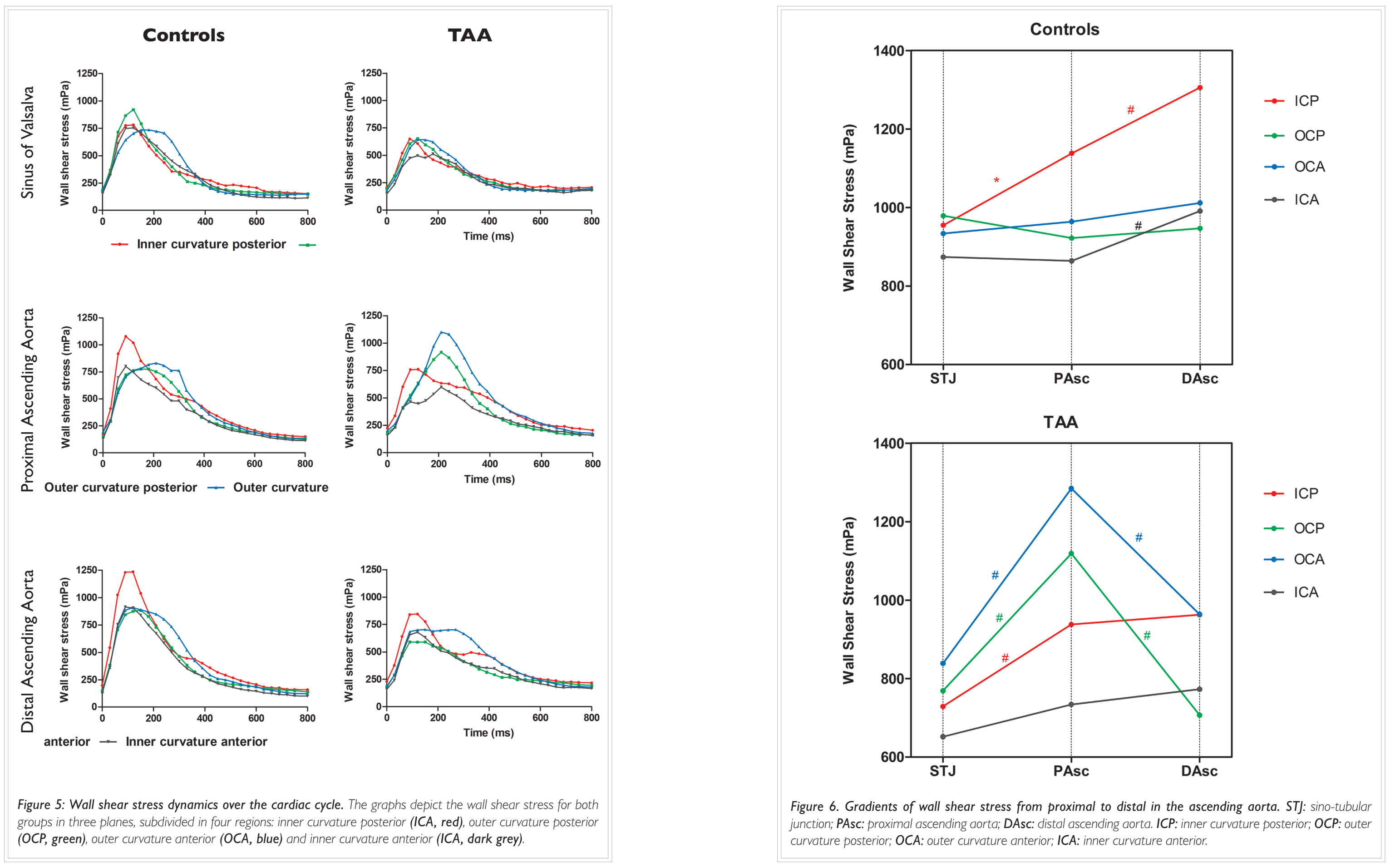
for the adverse effects of the aortic curvature on blood flow, hence sparing the ascending aorta and arch from low-density lipoprotein (LDL) deposition and atherogenesis(24). The normal aortic ageing process involves luminal dilatation and elongation, which occur in association with decreased flow helicity and vorticity $(23,25,26)$. Changes in blood flow have been of increasing interest in patients with aortic disease. Recent 4D flow MR studies reported pronounced helical and vortical flow patterns in patients with TAA, connective tissue disease and $\operatorname{BAV}(17,19,27)$ However, most of these studies used qualitative observations using stream- or path-line analysis, which are prone for bias and difficult to analyse regarding the secondary in-plane flow patterns. Only one previous study quantified flow vorticity in the ascending aorta in patients with BAV, showing increased vorticity as compared to healthy controls(28). Yet, given that substantial part of the included BAV population had dysfunctional valves with concomitant high peak flow velocities, this result could be foreseen when looking at the formula to calculate vorticity. Compared to healthy controls and as opposed to BAV, we found a decrease in flow vorticity and helicity in degenerative ascending aortic aneurysms. We hypothesize that the transformations of aortic dimensions with increasing age lead to substantial perturbations in the in-plane vorticity, with abnormal flow patterns as a consequence. Moreover, subsequently to the need of vorticity and helicity to stabilize flow, declining vorticity and helicity increases the risk of flow abnormalities such as flow separation. Flow separation might occur with diminishing secondary in-plane vortices and are a possible cause of large 'slow' vortices in TAA patients. It is proposed that this could lead to unequal distribution of WSS, with more risk of LDL transportation along the side of the vessel wall that experiences low WSS(24).

\section{Wall Shear Stress}

Wall shear stress is an important parameter when describing the mechano-transduction of flow stresses on the vessel wall. Both, low and high WSS play a role in the pathophysiology of aortic disease. Results from in vitro studies indicate that elevated WSS contributes to aortic dilatation, while low WSS is associated with atherosclerotic plaque formation(29, 30). High WSS and positive WSS gradients have been shown to result in adapted gene expression in endothelial cells which initiates endothelial proliferation, extracellular matrix degradation and aneurysm formation (30). Mahedevia et al. used 4D flow MRI and found a relationship between different BAV fusion patterns and the location of peak ascending aortic WSS, which might be part of the link between BAV and the associated aortopathy(17). Moreover, a high ratio of circumferentia to total WSS has been described as a cause of poststenotic aortic dilatation (i.e., aneurysm formation distal to a stenotic aortic valve)(3l).

Contrary to studies that have observed an association between elevated WSS and vesse dilatation, there is evidence that rupture of aneurysms occurs at regions of low WSS. It is hypothesized that low WSS and thrombus deposition predominates at regions of flow recirculation, which results in adventitial degeneration and subsequent aneurysm rupture(32). One previous 4D flow MR study concluded that TAA patients exhibit significantly lower WSS in all aortic segments and regions during peak systole(19). Our results do not support this conclusion. First, we found that WSS is asymmetrically distributed around the vessel wall. Although the averaged WSS per segment may be lower in TAA, we have demonstrated that peak WSS in the outer aortic curvature was significantly higher as compared to controls. Second, due to aberrant flow patterns, awareness for looking beyond peak systole rises, since these flow patterns occur more toward end-systole(33). A discrepancy between peak systole and peak WSS might be a plausible cause for deviating results as compared to the earlier study(19). Along with the positive WSS gradient, this elevated peak WSS could promote aortic dilation in this region.
Mechano-sensing of wall shear stress and other mechanical stresses in the arterial wall is of great importance(34). The exact influence of aberrant flow and deviated WSS on mechanotransduction deserves further evaluation, considering a previously described association of aortic stiffness with aortic disease progression(35). An interesting goal for future studies would thus be to evaluate MR methods that combine flow analysis and markers of vessel wall stiffness such as pulse wave velocity and MR elastography(36-38).

\section{Study limitations}

Some limitations of the current study need to be addressed. First, the accuracy of WS estimations by 4D flow MR is limited by the technique's inherent spatial and temporal resolution. Consequently, WSS estimations are consistently lower than those derived from model-based computational fluid dynamics (CFD) simulations (which have arbitrary high spatial and tempora resolution)(39). However, the MR acquisition protocol was similar for all study subjects, which allows for reliable WSS comparison between patient groups.

Second, we created a static 3D geometry during peak systole and used this to calculate WSS, vorticity and helicity over the cardiac cycle. This approach neglects potential cyclic movement and distensibility of the ascending aorta. However, segmentation was performed on velocity data, making it infeasible to create accurate geometric models in phases with low flow velocities (especially diastole).

We found a decrease of flow vorticity and helicity and an unequal distribution of WSS with higher peak WSS in TAA patients. The decrease of helicity and vorticity are a possible cause of aberrant flow in degenerative thoracic aortic aneurysms, which is likely to induce the unequal distribution of wall shear stress. These variations in peak wall shear stress and wall shear stress gradients are potential contributors to vessel wall remodeling and thus could promote further aortic dilation 


\section{REFERENCES} . Multimodality imaging of diseases of the thoracic aorta in adults: from the American Society of ovascular Imaging: endorsed by the Society of Cardiovascular Computed Tomography and Society fo diogr. 2015;28(2): $119-82$

2. Davies RR, Goldstein LI, Coady MA, Tittle SL, Rizzo JA, Kopf GS, et al. Yearly rupture or dissection rates for thoracic aortic aneurysms: simple prediction based on size. The Annals of thoracic surgery. 2002;73(I):17-27. Coady MA, Rizzo JA, Hammond GL, Mandapati D, Dar for resection of thoracic aortic aneurysms? I Thoo Cardiovasc Surg. |997; || 3(3):476-91; discussion 89-9I.

4. Coady MA, Rizzo JA, Hammond GL, Kopf GS, Elefteriades JA. Surgical intervention criteria for thoracic aortic aneurysms: a study of growth rates and complications.

Ann Thorac Surg. of ,67(6). 1922-6, discussion 53-8.

RD, Eggebrecht $\mathrm{H}$, et al 2014 ESC Guidelines on the diagnosis and treatment of aortic diseases: Document covering acute and chronic aortic diseases of the thoracic and abdominal aorta of the adult. The Task Force for the Diagnosis and Treatment of Aortic Diseases of the
European Society of Cardiology (ESC). Eur Heart J.

Casey DE, Ir. et al. 2010 man JA, Bersin RM, Carr VF, ASA/SCA/SCAI/SIR/STS/SVM Guidelines for the diagnosis and management of patients with thoracic

aortic disease. J Am Coll Cardiol. 2010;55(14):e27-el29.

Pape LA, Tsai TT, Isselbacher EM, Oh JK, O Gara P T. a good predictor of type $A$ aortic dissection. observations from the International Registry of Acute Aortic Dissection (IRAD). Circulation. 2007; I16(10):I120-7.

8. Heuts S, Adriaans BP, Gerretsen S, Natour E, Vos R, Cheriex EC, et al. Aortic elongation part II: the risk of Heuts S, Adrians BP. Rylski B, Mihl C B B Olsthoorn JR, et al. Evaluating the diagnostic accuracy of maximal aortic diameter, length and volume for prediction of aortic dissection. Heart. 2020;106(12):892-7. 10. Adriaans BP, Wildberger JE, Westenberg JJM, Lamb H. Schalla S. Predictive maging forthoracic aortic dissection and rupture: moving beyond diameters. Eur Radiol.

Ebbers $T$, et al, 4D flor AJ, Bolger AF, Carlhäll CJ. resonance consensus statement. I Cardiovasc Magn Reson. 2015;17(1):72.

12. Frydrychowicz A, Markl M, Hirtler D, Harloff A, pathensak $C$, Geiger J, et al. Aortic hemodynamics in vivo analysis by $4 \mathrm{D}$ flow-sensitive magnetic imaging. Invest Radiol. 201।;46(5):317-25,

13. Catapano F, Pambianchi G, Cundari G, Rebelo J, Cilia F. Carbone l, et al. 4D flow imaging of the thoracic aorta: is there an added clinical valuel Ca thovasc Dign ther.

O.4DflowMRI.JMagn Resonlmag
15. Geiger J, Hirtler D, Gottfried K, Rahman O, Bollache E, Garker Al. et al Gongitudinat Evaluation of Aortic 4D Flow Cardiourtan Syndrone Year Follow-Up Study. I Cardiovasc Magn Reson.

16. Barker AJ, Markl M, Bürk J, Lorenz R, Bock J, Bauer S, et Bear stress in the ascending aorta. Circ Cardiovasc Imaging. 2012;5(4):457-66.

17. Mahadevia R, Barker A], Schnell S, Entezari P, Kansal P, edak PW, et al. Bicuspid aortic cusp fusion morphology

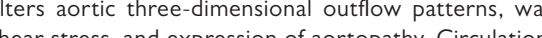

Bissell MM, Hess AT, Biasiolli L, Glaze S1, Loudon M, Picher $A$, et al. Aortic dilation in bicuspid aortic valve Wease. low pattern is a major contributor and differs We

9. Burk J, Blanke P, Stankovic Z, Barker A, Russe M, Geige

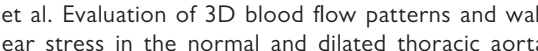
using flow-sensitive 4D CMR. J Cardiovasc Magn Reson. 2012;14:84.

20. Hope TA, Markl M, Wigström L, Alley MT, Miller DC Herfkens RJ. Comparison of flow patterns in ascending magnetic resonance velocity mapping. I Magn Reso maging. 2007;26(6): $1471-9$.

21. Kilner P], Yang GZ, Mohiaddin RH, Firmin DN, Longmore DB. Helical and retrograde secondary flow patterns he aortic arch studied by three-directional magnetic Pt I) 2235-47.

Stalder AF, Russe MF, Frydrychowicz A, BockJ, Hennig J. optimized analysis of blood flow and vessel wall param eters. Magn Reson Med. 2008;60(5):I218-31.

Figrree $G$, M, Bannon P, Barin E, Celemajer D, Jeremy R, dynamics in healthy adult aortas: A $4 \mathrm{D}$ flow MRI study Magn Reson Imaging. 2019:49(1):90-100

24. Liu X, Pu F, Fan Y, Deng X, Li D, Li S. A numerical study on the flow of blood and the transport of LDL in the human aorta: the physiological significance of the helical 2009:297(1) H16 70 . Am J Physio Heart Circ

25. Adriaans BP, Heuts S, Gerretsen S, Cheriex EC, Vos R, ortic ageing process. Heart 2018:104(21): 1772-7.

26. Wolak A, Gransar H, Thomson LE, Friedman JD, Hacha movitch R, Gutstein A, et al. Aortic size assessment by oncontrast cardiac computed tomography: norm Cons by age, gender, and body surface ar

M], van Ooii P, et al. Altered aortic $3 \mathrm{D}$ hemodynamics and geometry in pediatric Marfan syndrome patients.

28. Elbaz MSM, Scott MB, Barker AJ, McCarthy P, Malaisrie C vasive Assessment of Intra-artic Hemodynamicsin Bicuspid Aortic Valve Disease. Radiology. 2019:293(3):54I-50.
29. Cheng C, Tempel D, van Haperen R, van der Baan A, Grosveld F, Daemen MJ, et al. Atherosclerotic lesion size shear stress. Circulation. 2006:113(23):2744-53. 30. Dolan JM, Kolega J, Meng H. High wall shear stress and
spatial gradients in vascular pathology: a review. Ann Biomed Eng. 2013;41(7):1411-27.

31. Kauhanen SP, Hedman M, Kariniemi E, Jaakkola P, Vanninen $R$, Saari $P$, et al. Aortic dilatation associates with flow
displacement and increased circumferential wall shear stress in patients without aortic stenosis: A prospective clinical study. J Magn Reson Imaging. 2019;50(I):136-45.

32. Boyd AJ, Kuhn DC, Lozowy RJ, Kulbisky GP. Low wall shear stress predominates at sites of abdominal aortic aneurysm rupture. J Vasc Surg. 2016;63(6):1613-9.
von Spiczak J. Crelier G Giese D, Kozerke S Manis

3. von Spiczak J, Creler G, Glese D, Kozerke S, Maintz D, in the Thoracic Aorta Using 4D Phase Contrast MRI. PLoS One. 2015; 10(9):e0139025.

34. Humphrey JD, Schwartz MA, Tellides G, Milewicz DM. Role of mechanotransduction in vascular biology: focus on thoracic aortic aneurysms and dissections. Circ Res.

35. Boczar KE, Boodhwani M, Beauchesne L, Dennie C, Chan KL, Wells GA, et al. Aortic Stiffness, Central Blood Thoracic Aortic Aneurysm Expansion. Hypertension. 2021;77(I)::126-34.

6. Shahzad R, Shankar A, Amier R, Nijveldt R, Westenberg JJM, de Roos A, et al. Quantification of aortic pulse wave method. J Cardiovasc Magn Reson. 2019:21/(1):27.

37. Dong H, Russell DS, Litsky AS, Joseph ME, Mo X, White RD, et al. In Vivo Aortic Magnetic Resonance Elastogaphy in Abdominal Aortic Aneurysm. A Validation in an

38. Schaafs LA, Tzschätzsch H, Reshetnik A, van der Giet $M$, Elastography of the Aorta: Effect of Age and Hypertension on Aortic Stiffness. Invest Radiol. 2019;54(II):675-80.

39. Szajer J,Ho-Shon K. A comparison of 4 D flow MRI-derived wall shear stress with computational fluid dynamics

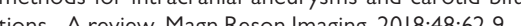


Summary

General discussion

Future outlook

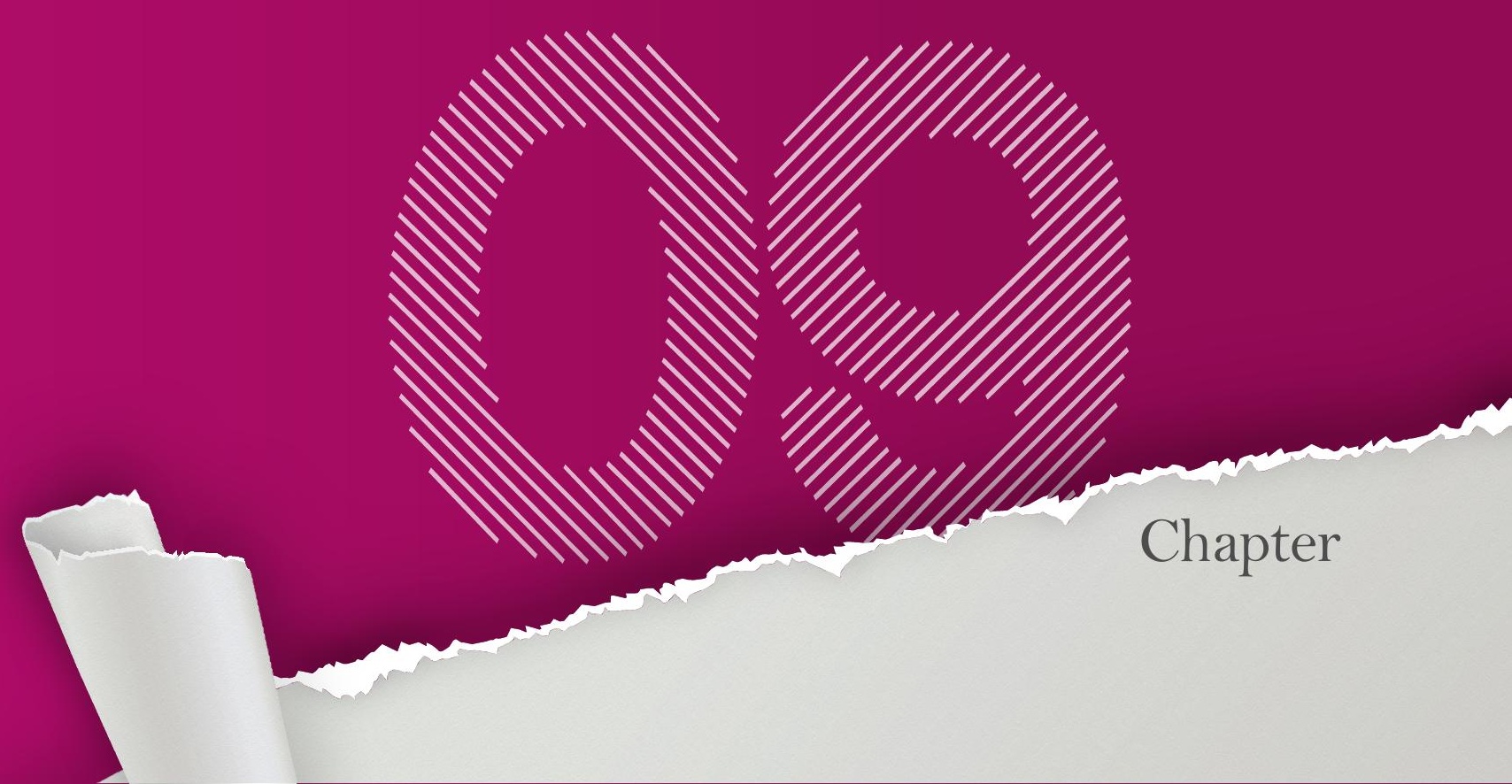


The preventive management of ascending thoracic aortic aneurysm (TAA) comprises stringent control of risk factors and periodic imaging for assessment of aortic valve function and aneurysm size(I-3). Using state-of-the-art acquisition and post-processing techniques, we have evaluated the timing and clinical value of aortic diameter measurements for prediction of acute aortic syndromes (AAS). Furthermore, we aimed to identify novel imaging markers that improve the identification of patients at risk. The current chapter discusses the presented studies in light of their clinical and scientific relevance and provides an outlook for future research.

\section{PART I - ANATOMIC IMAGING}

\section{Aneurysm surveillance intervals}

The indication for pre-emptive surgical extirpation of TAA relies on a maximal aortic diameter $\geq 55 \mathrm{~mm}$. This cut-off is based on studies conducted between 1985 and 1996, which revealed sharp 'hinge points' in the size at which AAS occur(4-6). Despite the indispensable role of imaging in TAA management, no standardized timing intervals for diameter surveillance have been defined. Consequently, follow-up frequencies vary between patients and are primarily determined by the insights and preferences of the treating physician. In Chapter 3, we calculated yearly expansion rates of non-syndromic TAA and used these to propose diameter-specific intervals for imaging

\section{Optimal timing for TAA imaging}

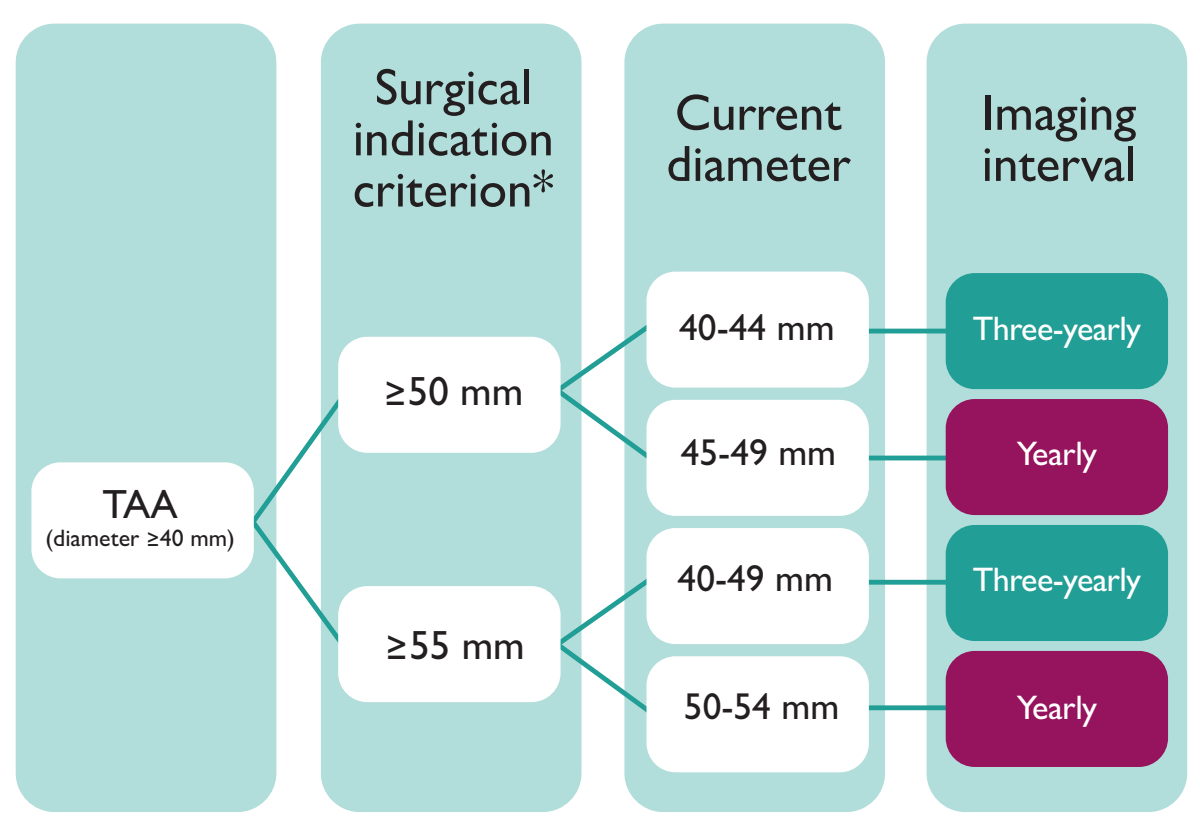

* $\geq 50 \mathrm{~mm}$ : BAV with risk factors; $\geq 55 \mathrm{~mm}: \mathrm{TAV}$ and uncomplicated BAV

Figure I. Flow chart depicting the optimal imaging intervals of non-syndromic ascending aortic aneurysms. BAV: bicuspid aortic valve; TAA: thoracic aortic aneurysm; TAV: tricuspid aortic valve. follow-up. Contrary to the prevailing view that all aneurysms gradually enlarge(7) we found that nearly half of all TAA remain stable over time. Moreover, we showed that (semi-)annual imaging - which is recommended by some current guidelines $(2,8)$ - carries no therapeutic consequences for patients with small aneurysms (diameter $<50 \mathrm{~mm}$ ). The proposed imaging protocols prescribe triennial imaging of TAA that are $>5 \mathrm{~mm}$ away from the predetermined surgical threshold and showed to be as accurate as yearly imaging with regard to the timing of intervention (Figure I).

The study presented in Chapter $\mathbf{3}$ has several strengths compared to existing literature that reports on the natural evolution of TAA. Previous studies included heterogeneous populations (including patients with connective tissue disease and chronic dissections)(4, 9-II), while other did not distinguish between aneurysms at different anatomic locations of the aorta(I0, I2). In a recent systematic review, the presence of Marfan syndrome and a distal aneurysm location (i.e. in the descending or thoracoabdominal aorta) were identified as the main factors predisposing to rapid TAA growth(I3). Since we used different imaging modalities to evaluate aortic diameters, one should consider the limitations that relate to the potential measurement bias between these techniques(14). Moreover, imaging intervals were inconsistent, for which it was unable to asses exact yearly growth. The latter is not irrelevant since American guidelines also recommend prophylactic surgery in patients with TAA expansion $>5 \mathrm{~mm} /$ year(2). Future (randomized) studies using standardized follow-up intervals are needed to prospectively validate the safety and cost-effectiveness of less frequent imaging strategies.

\section{The aortic diameter - a poor man's surrogate}

Chapter 2 discusses the clinical value of aortic diameter measurements. On the one hand, current surgical thresholds have near 100\% specificity for prediction of dissection. Thus, they accurately select those with highest relative risk and preclude unnecessary surgical intervention. On the other hand, it has become increasingly clear that most dissections occur in aortas with diameters below interventional cut-offs $(15,16)$. The International Registry of Acute Aortic Dissection (IRAD) reported that $59 \%$ of enrolled patients $(n=591)$ had diameters $<55 \mathrm{~mm}$ at the time of presentation(17), which is comparable to the findings in our database (Chapter 5). The explanation for this paradoxical observation lies in the right-skewed distribution of aneurysm sizes, with $97.6 \%$ of TAA patients having aortic diameters between 40 and $50 \mathrm{~mm}(18)$. One suggestion to increase the sensitivity of diameter measurements is to lower surgical cut-offs, favoring prophylactic intervention at smaller ascending aortic sizes(19). Three arguments substantiate this claim:

- Current surgical thresholds are based on post-dissection imaging studies and neglect the sudden increase in aortic size at the moment of dissection onset. Recent data has shown that post-dissection diameters are approximately $30 \%$ larger than pre-dissection dimensions(20-22). This finding indicates that dissection develops at smaller aortic sizes than previously thought. - Current cut-offs are based on older imaging techniques. Along with the advent of three-dimensional (3D) imaging, centerline diameter measurements found their way into clinical practice(23). Compared to axial measurements, these have improved intra- and interobserver agreement(24). However, multiple studies reported that centerline diameter are consistently smaller than those obtained by traditional measurement methods(23-26). Therefore, surgical cut-offs require adaptation to the use of state-of-the-art imaging methods. - Outcomes of TAA patients have improved as a result of optimization of surgical techniques and centralization of aortic care into specialized centers (27). Over the last decades, the perioperative mortality rate for elective procedures has declined from $4.3 \%$ to $1.3 \%-2.3 \%(28,29)$. Moreover stent grafting of the ascending aorta is emerging as a safe therapeutic option in those with favorable anatomy and may further improve surgical outcomes(30). For these reasons, the balance between the risks and benefits of surgery deserves re-evaluation(3I). 
In Chapter 6, we used pre-dissection computed tomography (CT) to study the geometry of the aorta at the moment of impending dissection, and confirmed that $96 \%$ of observed dissections occurred at diameters $<55 \mathrm{~mm}(22)$. As expected, the sensitivity of the maximal diameter for prediction of dissection would increase (from $4 \%$ to $17 \%$ ) when the surgical cut-off is shifted to $\geq 50 \mathrm{~mm}$, while specificity remains high (95.5\%). Ongoing studies will further evaluate the optimal surgical indication criterion and could lead to guideline changes in the near future.

In addition to the considerations above, this thesis shows that other anatomic markers can improve prediction of AAS. In Chapters $\mathbf{5}$ and $\mathbf{6}$, we focused on elongation of the ascending aorta and found that aortic length more accurately predicts dissection as compared to the maximal diameter. This finding was validated in a recent longitudinal study by a group from Yale(32), whose previous work formed the basis of many recommendations within current guidelines. However, in their study, Elefteriades et al. referred to aortic length as the "neglected dimension'. We do not entirely agree with this statement, since the assessment of longitudina aortic dimensions requires high-resolution electrocardiographically (ECG)-gated isotropic datasets and advanced post-processing software packages (Figure 2). Therefore, rather than neglected, we think that it was not until recently that measurements of aortic length became feasible. Now that 3D imaging has become common in daily practice, it is time to maximally exploit its possibilities and embrace the novel predictors that these techniques afford.

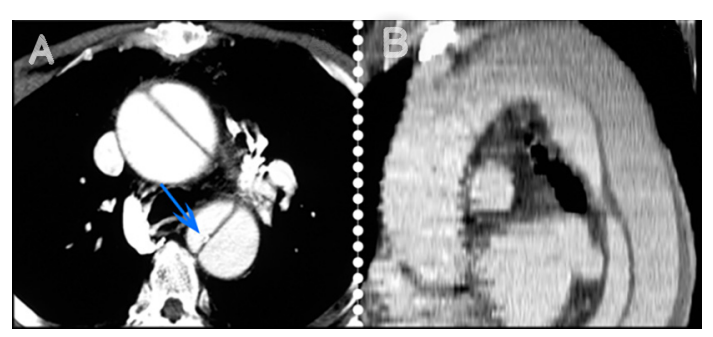

Figure 2. Non ECG-gated CT angiography of a patient with a chronic type A dissection, performed on a single-slice CT-scanner with a rotation time of $1.0 \mathrm{~s}$, slice thickness of $5 \mathrm{~mm}$ and a reconstruction increment of $4 \mathrm{~mm}$. Th transwersal slice (A) shows clear dissection membranes in both the ascending and descending thoracic oorta, and a calification in the dissection membrane of the descending oorta (arow). The lock of cardic gating can prono cinced star-step antiocs in the sagitta ronounced stair-step artifacts in the sagittal oblique multiplanar reconstruction (B) with complete dissemination of the dissection membrane in the ascending aorta and aortic arch.

\section{Aortic elongation and volumetry}

'Aortic unfolding' is a term commonly used in chest X-ray reports and is generally thought to represent age-associated aortic dilatation. However, the aortic diameter increases by only $3 \%$ per decade, which seems out of proportion to the degree of unfolding observed in X-ray studies(33-35). In Chapter 4, we described the age-related evolution of longitudinal aortic dimensions and showed that the thoracic aorta elongates by $7 \%$ (ascending aorta), 12\% (arch) and $25 \%$ (proximal descending aorta) per decade of life. Also, we found that the aortic apex gradually shifts away from the branch vessels to a more distal position. Therefore, it is likely that aortic unfolding depicts the process of aortic lengthening rather than dilatation.

There are several reasons to assume that aortic elongation plays a role in the pathogenesis of dissection. First, biomechanical studies have shown that the forces acting on the aortic wall increase when a vessel becomes more tortuous(36). Second, the intimal entry tear runs in the circumferential direction in $84 \%$ of dissection cases(37), suggesting stretch in the longitudina direction. In Chapter $\mathbf{5}$, we modeled the ascending aortas of dissection patients to pre-dissection dimensions and showed that these were significantly longer than those of propensity-matched healthy controls. The previously mentioned Yale study confirmed our results by investigating ascending aortic length (AAL) in a prospective cohort of TAA patients. They showed that $A A L$ $\geq 13 \mathrm{~cm}$ was associated with a five-fold higher risk of adverse events compared to $A A L<9 \mathrm{~cm}(32)$. The authors also assessed the accuracy of the 'aortic height index' (AHI), which they defined as the sum of the aortic diameter and length normalized for patient height. The AHI showed to be a more powerful predictor for dissection and rupture than any other anatomic parameter (diameter, normalized diameter, AAL, normalized AAL) alone. This index is close to our idea that aortic volume should be added to the measurement parameters derived from aortic $C T$ or MR. As presented in Chapter 6, we found that aortic volumetry holds added value over measurements of aortic diameters alone, and that it increases the positive predictive value (PPV) for dissection from $20 \%$ to $55 \%$. The concept of normalizing aortic volume measurements to patient body size is interesting and deserves further attention.

\section{PART II - HEMODYNAMIC IMAGING}

In Part I of this thesis we have demonstrated that aortic length and volume superiorly predict dissection as compared to the maximal diameter. Nevertheless, even in the best possible scenario, the sensitivity of anatomic measurements did not outreach $28 \%$. Since aortic disease is a biomechanical process that commonly occurs in association with hypertension, hemodynamic imaging may further improve the selection of those at risk for AAS(38-40).

\section{D flow MR imaging}

Flow imaging with phase-contrast magnetic resonance (PC-MR) is conventionally performed in two dimensions (2D). The technique is based on the feature of hydrogen atoms to accumulate an MR phase shift proportional to the speed at which they move along a magnetic gradient field. Two-dimensional PC-MR acquires unidirectionally-encoded velocity data that is directed either through or parallel to a prescribed imaging plane ('through-plane' or 'in-plane', respectively). It is routinely used for the evaluation of a broad spectrum of cardiovascular conditions, including valvular regurgitation and shunts. Over the past decade, technical advances have facilitated the development of 4D PC-MR (or 4D flow MR). This technique captures three-directionally encoded velocity data in a 3D volume with time (i.e., synchronization to the cardiac cycle) as the fourth dimension(4I-43). 4D flow MR offers several advantages as compared to 2D PC-MR. First, three-directional velocity-encoding has shown improved flow and velocity quantification as compared to unidirectionally-encoded methods(44-5I). Second, 4D flow MR allows post-hoc analysis and reduces operator-dependency(52). Third, the technique offers the ability to evaluat novel intravascular hemodynamic markers such as flow helicity and wall shear stress (WSS) However, these advantages come at the cost of prolonged scan times and susceptibility to motion artifacts (due to the inability to perform acquisition during breath-holding). In our institution, the acquisition of a respiratory-compensated 4D flow MR dataset takes between 15-20 minutes depending on heart rate and respiratory gating.

Flow patterns from 4D flow MR datasets can be analyzed using stream- or pathline visualization. Streamlines follow velocity vectors of each acquired voxel at an instantaneous time point. Pathlines display the temporal evolution of flow over the entire cardiac cycle. The color-coding of stream- and pathlines represents flow velocity and allows identification of regions with flow acceleration (such as in aortic stenosis and coarctation). 
4d flow MR for assessment of aortic valve disease

Transthoracic echocardiography (TTE) is the clinical gold standard for assessment of aortic stenosis (AS). Chapter $\mathbf{7}$ investigates the diagnostic accuracy of 4D flow MR for AS classification by comparing measurements against 2D flow MR and TTE. Using streamline visualization, we found that post-stenotic systolic flow in the ascending aorta is mostly eccentric. Under this condition, and in contrast to 2D PC-MR, 4D flow MR benefits from its three-directional velocityencoding. Moreover, streamline analysis allows optimized positioning of analysis planes in the region of highest flow velocity. Compared to TTE, 4D flow MR increased the congruity between the parameters used for AS grading. This finding is of interest since discordant echocardiographic AS grading patterns (which are observed in $28.7 \%$ of AS patients) pose a challenge to clinicians in determining AS severity(53-55). Future studies that specifically focus on discordant AS are needed to assess the potential added value of $4 \mathrm{D}$ flow MR in this patient group.

As a future outlook, additional to basic flow metrics, recent studies have presented 4D flow MR-derived energy measurements that reflect aortic stenosis severity. In echocardiography, the modified Bernoulli equation $\left(\Delta \mathrm{P}=4 v^{2}\right)$ is used to calculate pressure gradients from Dopplerderived velocity measurements. However, this formula assumes laminar flow and neglect important boundary conditions (such as the flow velocity in the left ventricular outflow tract [LVOT] and LVOT shape)(56). MR-derived turbulent kinetic energy (TKE) is defined as energy loss caused by flow turbulence and has been proposed as a marker that better reflects the increased workload placed on the left ventricle. Recent 4D flow MR-studies found that TKE highly depends on aortic valve morphology and function, and is significantly elevated in patients with $\mathrm{AS}(57)$. Although its clinical significance and relation with prognosis have yet to be established, there is growing evidence that flow energetics can characterize aortic valve disease complementary to traditional flow measurements $(58,59)$.

\section{4d flow MR in thoracic aortic aneurysm}

Normal aortic flow is laminar and follows a right-handed helical outflow pattern through the aortic arch. Age-related aortic stiffening causes a change in helix direction and increases flow velocities and WSS(60-62). To date, most 4D flow MR studies in the setting of aneurysmal disease have been performed in patients with bicuspid aortic valve (BAV). Since medial degeneration is also present above normally functioning bicuspid valves, it has long been thought that the aortopathy in BAV patients results from a systemic connective tissue disorder $(63,64)$. However 4D flow MR studies have revealed that aortic flow patterns are highly affected by valvular abnormalities, causing pronounced helical flow patterns and elevated regions of WSS along the outer aortic curvature(65-68). Of note, this region is typically the site of the asymmetric dilatation observed in BAV and has shown to be especially prone to histologic medial degeneration $(69,70)$.

It is estimated that $0.5 \%$ of the population has been diagnosed with TAA(7I). Although most previous $4 \mathrm{D}$ flow MR studies pointed their attention to Marfan syndrome or BAV, these are the underlying causes of only $21.5 \%$ of TAA(72). The remainder (i.e., 69.800 cases in the Netherlands(73)) are labeled as degenerative. In Chapter 8, we have evaluated flow patterns in patients with degenerative TAA and non-stenotic tricuspid valves. In our population, we found decreased flow helicity and vorticity as compared to healthy controls. Also, we observed large systolic vortex rings in the distal ascending aorta, which can be explained by the central (laminar) flow jet encountering a sudden increase in aortic diameter. This is completely different from flow patterns in BAV. In BAV, the outflow through the bicuspid valve is intrinsically eccentric and causes impingement of a high-velocity flow jet on the aortic vessel wall. Therefore, and in contrast to BAV, we postulate that the aberrant flow patterns in degenerative TAA are the result of aortic dilatation rather than its primary cause. Nevertheless, both flow mechanisms result in supraphysiologic WSS at the outer curvature of the ascending aorta, aggravating endothelial proliferation, extracellular matrix degradation, and smooth muscle cell apoptosis $(38,42,74)$.

There is great future potential of $4 \mathrm{D}$ flow $M R$ in the sense that it adds a functional dimension to the classical anatomical display. However, some limitations need to be overcome for the technique to find its place in clinical practice. First, advanced acceleration methods are required to achieve shorter scan times. Second, image acquisition remains challenging and currently limits implementation to hospitals with state-of-the-art MR platforms and devoted physicists. Third, as always in imaging, it is mandatory to prove a causation between $4 \mathrm{D}$ flow MR and outcome. As yet, only one study has longitudinally assessed the correlation between flow imaging markers and TAA expansion. In a small study population (median follow-up duration: 4 years), this study found flow eccentricity $(r=0.65)$ and maximal WSS $(r=0.5)$ to be significantly associated with aneurysm growth(75). Another study collected tissue samples from patients undergoing elective aortic replacement and found pronounced medial degeneration in regions with elevated WSS(76). In summary, further research that improves 4D flow MR acquisition and proves its clinical relevance is needed.

\section{Future outlook}

For decades, the maximal aortic diameter has been the key parameter to monitor TAA. This thesis describes the limitations of 'straightforward' aortic size measurements and demonstrates the need for more advanced imaging parameters to guide clinical decision-making. Severa ongoing studies aim to further improve the diagnostic accuracy of aortic imaging. The aortic valve is the door to the aorta, and should not be forgotten when assessing TAA risk. Our efforts to implement 4D flow MR at the Maastricht University Medical Center+ have led to our participation in the RADAR-study ('earlier Recognition of Aortic Dissection and Aneurysm Rupture', CVON 2017/08 RADAR). This multicenter project aims to develop an integrated MR approach to improve the predictive value of both anatomic and hemodynamic imaging markers. Initiatives like these, and those of others who have made impressive progress in the fields of genetics and biomarkers, will jointly bring us closer towards the overarching objective: to reduce the incidence and mortality of aortic disease. Let us walk further towards this ultimate goal, and move beyond diameters. 


\section{REFERENCES}

Erbel R, Aboyans V, Boileau C, Bossone E, Di Bartothe diagnosis and treatment of aortic diseases. Eur Heart J. 2014:35(41):2873-926.

2. Hiratzka LF, Bakris GL, Beckman JA, Bersin RM, Carr VF Casey DE, et al. 2010 ACCF/AHA/AATS/ACR/ASA SCA DCA/SI/STS and management of patients with thoracic
J Am Coll Cardiol. 2010;55(14):e27-el29.

3. Svensson LG, Adams DH, Bonow RO, Kouchoukos NT, Miller DC, O'Gara PT, et al. Aortic valve and ascending aorta guidelines for management and quality measures.

4. Davies RR, Goldstein LJ, Coady MA, Tittle SL, Rizzo JA, Kopf GS, et al. Yearly rupture or dissection rates for thoracic aortic aneurysms: simple predize
size. Ann Thorac Surg. 2002;73(I): 17-28

5. Davies RR, Kaple RK, Mandapati D, Gallo A, Botta DM, Jr., Elefteriades JA, et al. Natural history of ascending aortic aneurysms in the setting of an unreplaced bicus

6oady MA, Rizzo JA, Hammond GL, Kopf GS, Elefteriades JA. Surgical intervention criteria for thoracic aortic aneurysms: a study of growth rates and complications. Ann Thorac Surg. 1999;67(6):1922-6,

Elefteriades JA, Farkas EA. Thoracic aortic aneurysm clinically pertinent controversies and uncertainties. J Am

JCS Joint Working Group. Guidelines for diagnosis and treatment of aortic aneurysm and

Bonser R, Pagano D, Lewis M, Rooney S, Guest P, Davie $P$, et al. Clinical and patho-anatomical factors affecting expansion of thoracic aortic aneurysms. Heart

CK, Richard Aa, et JD, Sadeghi AM, Lansman SL, Mezrow aneurysms.JThorac Cardiovasc Surg. 1994:107(5): 1 1323-33 Detaint D, Michelena HI, Nkomo VT, Vahanian A Jondeau G, Sarano ME. Aortic dilatation patterns and sudy with Marfon solidrome asd a comparative study with Marfan syndrome a
aortopathy. Heart. 2014;100(2):126-34.

12. Hirose Y, Hamada S, Takamiya M, Imakita S, Naito H, Nishimura T. Aortic aneurysms: growth rates measured with CT. Radiology. 1992;185(1):249-52.

3. Oladokun D, Patterson B, Sobocinski j, Karthikesalingam A, Loftus I, Thompson M, et al. Systematic review of the growth rates and influencing factors in thoracic aortic

14. Bons LR, Duijnhouwer AL, Boccalini S, van den Hoven AT, van der Vlugt MJ, Chelu RG, et al. Intermodality variation
of aortic dimensions: How, where and when to measure the ascending aorta. Int J Cardiol. 2019;276:230-5.

15. Trimarchi S, Jonker FH, Hutchison S, Isselbacher EM. $5.5 \mathrm{~cm}$ or greater is not an accurate predictor of acute type B aortic dissection. I Thorac Cardiovasc Sur 2011; I I2(3):el01-7.

16. Kim EK, Choi SH, Sung K, Kim WS, Choe YH, Oh JK, et al. Aortic diameter predicts acute type A aortic patients without Marfan syndrome. J Thorac Cardiovasc Surg. 2014: $147(5): 1505-10$.
17. Pape LA, Tsai TT, Isselbacher EM, On JK, O'Gara PT, Evangelista A, et al. Aortic diameter $25.5 \mathrm{~cm}$ is not ood predictor of Type A aortic dissection observation from the International Registry of Acute Aortic

18. Kim JB, Spotnitz M, Lindsay ME, MacGillivray TE, Isselbacher EM, Sundt TM. Risk of aortic dissection in the moderately dilated ascending aorta. J Am Coll Cardiol.

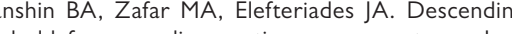
Z Surg. 2019;157(I):37-42.
Serter.

20. Rylski B, Blanke P, Beyersdorf F, Desai ND, MIlewski RK, Siepe M, et al. How does the ascending aorta geometry change when it dissects? I Am Coll Cardiol. 2014;63(13):1311-9.

21. Mansour AM, Peterss S, Zafar MA, Rizzo JA, Fang $\mathrm{H}$ Charilaou $P$, et al. Prevention of aortic dissection suggests a diameter. Phifto a lower aortic size threshold

22. Rylski B, Branchetti E, Bavarial E, Vallabhajosyula P. Szeto WY, Milewski RK, et al Modeling of predissection aortic size in acute type A dissection: more than $90 \%$ fail to meet the guidelines for elective ascending replacement. Thorac Cardiovasc Surg. 2014; I48(3):944-8. el.

23. Rengier F, Weber TF, Giesel FL, Böckler D, Kauczo CT angiographic examinations: benefits and limitations. Am J Roentgenol. 2009;192(5):W255-W63.

24. Rudarakanchana $\mathrm{N}$, Bicknell C, Cheshire N, Burfitt $\mathrm{N}$, Chapman A, Hamady M, et al. Variation in maximum diameter measurements of descending thoracic aortic aneurysms using unformatted planes versus images 2014:47(I):19-26.

25. Han SM, Elsayed RS, Ham SW, Mahajan A, Fleischman F, Rowe VL, et al. Comparison of intravascular ultrasound and centerline computed tomography-determine artic diameters during thoracic endover .

M, Geisbüsch P, Liao W. ments using centerline analysis applications? Objective ground truth evaluation reveals software-specific centerline characteristics.J Endovasc Ther. 2017;24(4):584-94.

. Hughes GC, Zhao Y, Rankin JS, Scarborough JE, O'Brien , Bavaria JE, et al. Effects of institutional volumes o North America. The fournal of thoracic and cardiovascular surgery. 2013;145(I):166-70.

28. Kallenbach K, Karck M, Pak D, Salcher R, Khaladj N, Leyh R, etal. Decade of aortic valve sparing remplantation: are we - pushing the limits too far? Circulation. 2005, I1 (29):-1-253-1-9, after thoracic aortic surgery: a population-based study J Thorac Cardiovasc Surg 2014:148(1):47-52. of endovascular repair of ascending aortic dissection in patients unsuitable for direct surgical repair. J Am Coll Cardiol. 2016,68(18).1944-54.

in the setting of bicuspic aortic valve: how big? How much? J Thorac Cardiovase
Surg. 2015;149(2): 56 -S9.
32. Wu J, Zafar MA, Li Y, Saeyeldin A, Huang Y, Zhao R, et al. Ascending aortic length and risk of aortic adverse events: the neglected

33. Roman MJ, Devereux RB, Kramer-Fox R, O'Loughlin Two-dimensional echocardiographic aortic root dimensions in normal children and adults. Am J Cardiol. 1989;64(8):507-12

Wolak A, Gransar H, Thomson LE, Friedman JD, Hachamovitch R, Gutstein A, et al. Aortic size assessment by noncontrast cardiac computed tomography: normal Cardiol Img. 2008:1 (2):200-9.

35. Devereux RB, de Simone G, Arnett DK, Best LG, Boerwinkle E, Howard BV, et al. Normal limits in relation to age, body size and gender of two-dimensiona 15 years of age. Am J Cardiol. 2012;110(8): $1189-94$.
.

36. Poullis MP, Warwick R, Oo A, Poole R. Ascending aortic curvature as an independent risk factor fortype $A$ dissection. and ascending aortic aneurysm formation: a mathematica model. Eur) Cardiothorac Surg. 2008,33(6).995-1001.

37. Hirst AE, Johns VJ, Kime SW. Dissecting aneurysm of the

3. Dolan JM, Kolega I. Mens $\mathrm{H}$. High wall shear stress and spatial gradients in vascular pathology: a review. Ann Biomed Eng. 2013;41(7):1411-27.

39. Dolan JM, Meng H, Sim FJ, Kolega J. Differential gene expression by endothelial cells under positive and negative streamwise gradients of high wall shear stress.

Cecchi E, Giglioli C, Valente S, Lazzeri C, Gensini $G$, Abbate R, et al. Role of hemodynamic shear stress in cardiovascular disease. Atherosclerosis. 2011;214(2):249-56. 4. Dyverfeldt P, Bissell M, Barker AJ, Bolger AF, Carlhäll C-J, Ebbers $T$, et al. 4D flow cardiovascular magnetic resonance

Consensusstatement.j CardiovascMagn Reson. 2015; I7(1):72. TH, Alley MT, et al. 4D flow CMR in assessment of valverelated ascending aortic disease. J Am Coll Cardiol Img. 2011;4(7):781-7.

43. Markl M, Frydrychowicz A, Kozerke S, Hope M, Wieben O.4D flow MRi.JMagn Resonlmaging. 2012;36(5):1015-36. 44. Stalder AF, Russe M, Frydrychowicz A, Bock J, Hennig J,
Markl M. Quantitative 2D and 3D phase contrast MRI optimized analysis of eters. Magn Reson Med. 2008;60(5):|1218-31.

45. Hanneman K, Sivagnanam M, Nguyen ET, Wald R, Greiser A, Crean AM, et al. Magnetic resonance assessment of pulmonary (QP) to systemic (QS) flows using 4D phasethrough-plane $2 \mathrm{D}$ phase-contrast imaging Acd radiology. 2014;21(8):1002-8.

46. Gabbour M, Schnell S, Jarvis K, Robinson JD, MarkI M Rigsby CK. 4-D flow magnetic resonance imaging: blood low quantication compared to 2-D phase-contras magnetic resonance imaging and Doppler echocardiog-

2 Frydrychowicz A, Wieben O, Niespodzany E, Reeder B, Johnson KM, François CJ. Quantification of thoracic with radial velocity encodic magnetic resonance imaging radiol. 2013:48(12):819-25.

48. Brix L, Ringerard S, Rasmuseon A, Soressen TS, Kin WY Three dimensignal the com, Sonensen TS, Kan cardiovascular magnetic resonance velocity mapping: comparison of flow measurements from $3 \mathrm{D}$ and $2 \mathrm{D}$ acquisitions.J Cardiovasc Magn Reson. 2009; II (I):3.

Vas cation with time-resolved volumetric phase-contrast MRI. Ped radiol. 201I;41(6):71I-20.

50. Meckel S, Leitner L, Bonati LH, Santini F, Schubert Stalder AF, et al. Intracranial artery velocity measurement (a) 2013:55(4):389-98.

Nordmeyer S, Riesenkampff E, Crelier G, Khasheei A,
Schnackenburg B, Berger F, et al. Flow-sensitive fourdimensional cine magnetic resonance imaging for offline blood flow quantification in multiple vessels. a validation Kilner PJ, Gateson Imaging. 2010,32(3).677-83. by magnetic resonance: a unique asset wor
J Cardiovasc Magn Reson. 2007;9(4):723-8,

53. Berthelot-Richer M, Pibarot P, Capoulade R, Dumes G, Dahou A, Thebault C, et al. Discordant grading of (tic stenosis severity. echocardiographic predictors of survival benefit associated with aortic valve

assessing low-gradient severe aortic stenosis. J Am Co Cardiol Img. 2017;10(2):185-202.

55. Clavel M-A, Messika-Zeitoun D, Pibarot P, Aggarwal SR, Malouf J, Araoz PA, et al. The complex nature of discordant severe calcified aortic valve disease grading
new insights from combined Doppler echocardiographic and computed tomographic study I Am Coll Cardiol. 2013;62(24):2329-38.

56. Oshinski JN, Parks W], Markou CP, Bergman HL, Larson $\mathrm{BE}, \mathrm{Ku} \mathrm{DN}$, et al. Improved measurement of pressure gradients in aorte coarctation by magnetic resonance

Binter C Gotschy A Sündermann SH. Frank M Ta

FC, Lüscher TF, eta, Turbuentkin, Frank M, Tanne multipoint 4-dimensional flow magnetic resonance imaging provides additional information relative to echocardiography for the determination of aortic stenosis

58. Tyszk IM, Ladlaw DH, Asa. IW S Silve).e0 JMe. Thre

Tyszka JM, Laidlaw DH, Asa JW, Silverman JM. Three
dimensional, time-resolved (4D) relative using magnetic resonance imaging. J Magn Reson Imag.

Bock J, Frydrychowicz A, Lorenz R, Hirtler D, Barker A Johnson $K M$, et al. In vivo noninvasive $4 D$ pressure diference mapping in the human aorta. phantom comparison and application in healthy volunters
patients. Magn Reson Med. 2011;66(4):1079-88.

60. Bogren HG, Buonocore MH. 4D magnetic resonance velocity mapping of blood flow patterns in the aorta in young vs. elderly normal subjects. J Magn Reson Imaging

61. Frydrychowicz A, Berger A, Del Rio AM, Russe MF, Bock secondary flow patterns, geometry, and age antlysed by 4-dimensional phase contrast magnetic resonance imaging at 3 Tesla. Eur radiol. 2012;22(5): $1122-30$.

62. Van Ooij P, Garcia], Potters WV, Malaisrie SC, Collins JD, Carr JC, et al. Age-related changes in aortic 3D blood flow velocities and wall shear stress. in lications for the identivalve disease J Magn Reson Imaging 2016:43(5):1239-49. 
63. Nistri S, Sorbo M, Marin M, Palisi M, Scognamiglio R, Thiene G. Aortic root dilatation in young men with 1999;82(I):19-22.
normalling artic valves. Heart.

64. Michelena HI, Desjardins VA, Avierinos J-F, Russo A, Nkomo VT, Sundt TM, et al. Natural history of asymptomatic patients with normally functioning or minimally
dysfunctional bicuspid aortic valve in the community. Circulation. 2008;:17(21):2776-84.

65. Barker AJ, Markl M, Bürk J, Lorenz R, BockJ, Bauer S, et al. Bicuspid aortic valve is associated with altered wall
shear stress in the ascending aorta. Circ: Cardiovasc Imag. 2012:5(4):457-66.

66. Bissell MM, Hess AT, Biasiolli L, Glaze S), Loudon M, Pitcher $\mathrm{A}$, et al. Aortic dilation in bicuspid aortic valve disease. flow pattern is a major contributor and differs 2013;6(4):499-507.

67. Mahadevia R, Barker AJ, Schnell S, Entezari P, Kansal P, Fedak PW, et al. Bicuspid aortic cusp fusion morphology alters aortic three-dimensional outflow patterns, wall shear stress, and expression of aortopathy. Circulation.

68. van Ooij P, Markl M, Collins JD, Carr JC, Rigsby C, Bonow RO, et al. Aortic valve stenosis alters expression 4-dimensional flow magnetic resonance imaging study of 571 subjects. J Am Heart Assoc. 2017;6(9):e005959. 9. Della Corte A, Quarto C, Bancone C, Castaldo C, D Meglio F, Nurzynska D, et al. Spatiotemporal patterns of with bicuspid and tricuspid aortic valve stenosis: focus on cell-matrix signaling. I Thorac Cardiovasc Surg. 2008;135(I):8-18. e2.

70. Nataatmadja M, West M, West J, Summers K, Walker P. Nagata M, et al. Abnormal extracellular matrix protein transport associated with increased apoptosis of bicuspid aortic valve thoracic aortic aneurysm. Circulation. 2003;108(10 suppl I):|I-329-II-34

71. Olsson C, Franco-Cereceda A. Health-related quality of life in thoracic aortic disease. Aorta. 2013; (03):I53-61. 72. Howard DP, Banerjee A, Fairhead JF, Perkins J, Silver LE,
Rothwell PM. Population-based study of incidence and outcome of acute aortic dissection and pre-morbid riskfactor control: 10-year results from the Oxford Vascular Study. Circulation. 2013;21 (127(2)):2031-7.

73. Centraal Bureau voor de Statistiek - Bevolkingspiramide (via https://www.cbs.nl/nl-nl/visualisaties/ bevolkingspiramide).

P. MRI hemodyna, Wrenn SJ, Saloner D, Dyverfeld P. MRI hemodynamic markers of progressive bicuspic
aortic valve-related aortic disease. J Magn Reson Imaging. 2014;40(I): $140-5$.

75. Hope MD, Wrenn J, Sigovan M, Foster E, Tseng EE, Saloner $D$. Imaging biomarkers of aortic disease increased growth rates with eccentric systolic flow. J Am

76. Guzzardi DG, Barker AJ, Van Ooij P, Malaisrie SC,
Puthumana II, Belke DD, et al. Valve-related hemodynamics mediate human bicuspid aortopathy: insights from wall shear stress mapping. J Am Coll Cardiol. 2015;66(8):892-900. 
Glossary of terms

Scientific and societal impact

Nederlandse samenvatting

Dankwoord

About the author

List of publications

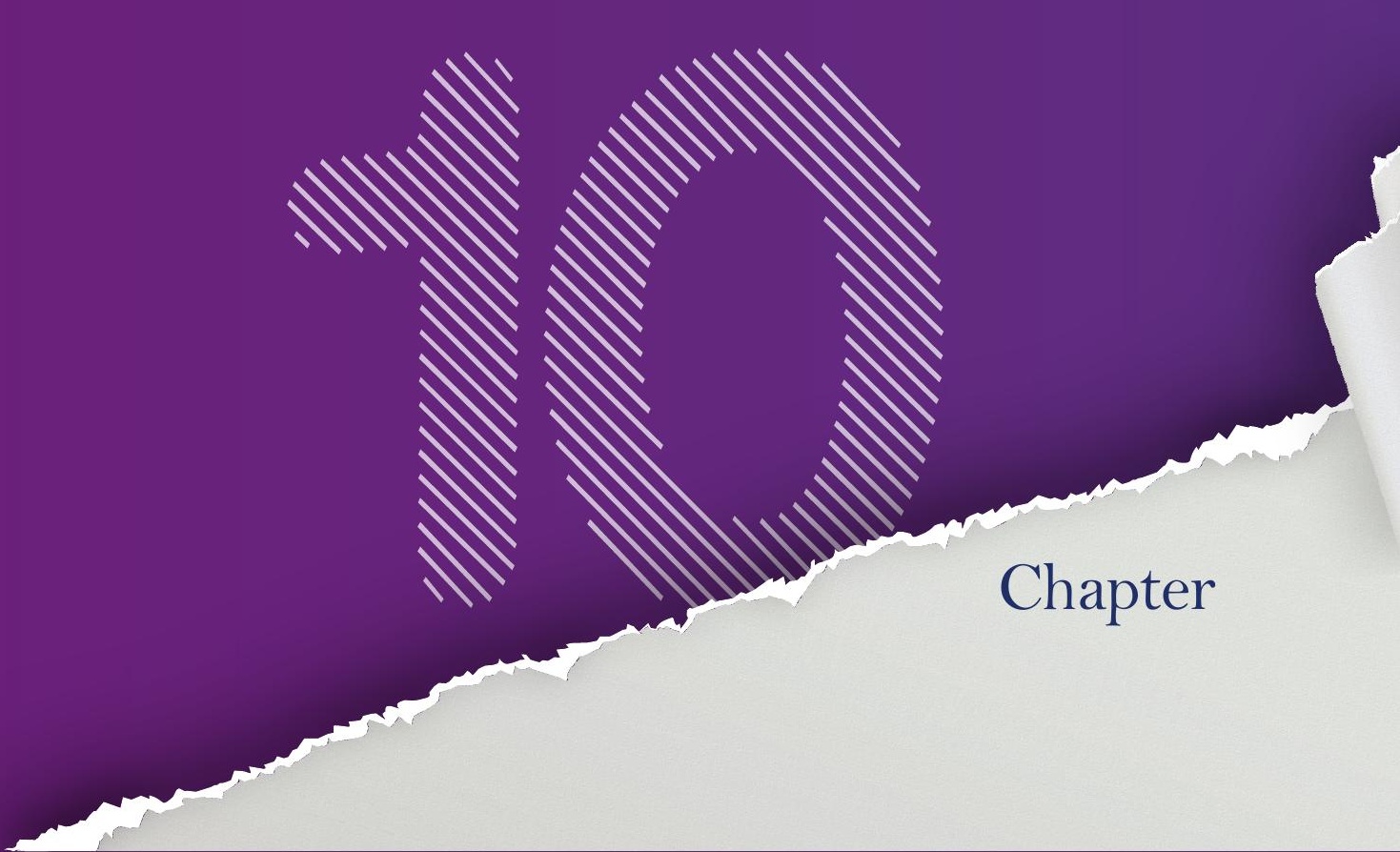




\section{GLOSSARY OF TERMS}

Acute aortic syndrome (AAS)

A spectrum of aortic conditions that have similar presentations but distinct demographic and pathophysiological characteristics. Major AAS entities include aortic dissection, intramural hematoma, penetrating ulcer and unstable aortic aneurysm.

\section{Aortic aneurysm}

A permanent focal dilatation of the aorta having a $\geq 50 \%$ increase in diameter as compared to the expected diameter (based on age, gender, and body size).

\section{Aortic dissection}

A disastrous condition in which the inner lining of the aortic vessel wall is torn, allowing blood to enter into the wall and create a false lumen.

\section{Aortic elongation}

The process in which the aorta lengthens and eventually becomes more tortuous.

\section{Aortic size paradox}

The paradoxical observation that most acute aortic syndromes occur in patients with aortic diameters below surgical interventional criteria.

\section{Aortic valve stenosis}

Congenital, degenerative or rheumatic narrowing of the aortic valve, causing a transvalvular pressure gradient. Hemodynamically important aortic valve stenosis will lead to heart failure and mortality if left untreated.

\section{Bicuspid aortic valve (BAV)}

The most common congenital form of valvular heart disease (prevalence: $0.5-2 \%$ ), which is characterized by presence of two unequal-sized aortic valve leaflets (instead of three normal leaflets.)

\section{Thoracic aortic aneurysm (TAA)}

An aortic aneurysm located within the thoracic cavity. Thoracic aortic aneurysm (TAA) encompasses a wide range of locations (aortic root, ascending aorta, aortic arch, descending thoracic aorta) and etiologies. For the purpose of this thesis TAA indicates an aneurysm of the aortic root or ascending aorta.

\section{Wall shear stress}

The frictional force exerted on the vessel wall by the blood flow, and which depends on blood viscosity and flow profile. 
Diseases of the aorta, the largest artery of the human body, occur relatively infrequent as compared to other forms of heart and vessel disease. However, the aorta serves a vital function in the human body, rendering any aortic disease to be life-threatening. The death rate of aortic diseases in the Netherlands exceeds 150.000 annually. Two-thirds of all acute aortic syndromes (AAS) occur in patients that are less than 65 years old. Timely recognition of patients at risk is potentially life-saving and, thus, has great socio-economic impact. This thesis focuses on the role of imaging for prediction of AAS, ranging from timing of imaging follow-up to the application of novel anatomic and hemodynamic imaging markers. One of the most important conclusions from our work is that these novel markers can superiorly predict AAS as compared to simply measuring the maximal aortic diameter. Ever since publication, our findings have been validated by other research groups, raising hope that they can improve patient care in the near future. The Dutch Heart Foundation has acknowledged the high potential of advanced imaging by providing funds for the RADAR-study ('earlier Recognition of Aortic Dissection and Aneurysm Rupture') In this multi-institutional CVON (Cardiovasculair Onderzoek Nederland)-project, we combine forces with researchers from Leiden University Medical Center (LUMC) and Delft University of Technology (TU Delft) to develop an integrated magnetic resonance (MR) imaging platform that can further improve identification of patients at increased risk. Although the development and clinical evaluation of new imaging methods will take many years, the results from projects like the RADAR-study might revolutionize the future preventive management of aortic disease.

Although advanced imaging techniques enhance the ability to predict and monitor disease, they are a major contributor to health care expenditure. Therefore, they should be used in a cost-effective and expedient way. The results presented in this thesis reveal that a substantia part of currently performed annual routine imaging does not lead to changes in patient management, resulting in an important source of waste. The (cost-)efficacy of aortic imaging is one of the prioritized researched questions in the 2019 knowledge agenda of the Dutch Society of Cardiology (Nederlandse Vereniging voor Cardiologie, NVVC) and will receive further attention in coming years.

The results presented in this thesis are relevant to all patients with aortic disease. Aortic disease can be a worrisome diagnosis, and new follow-up strategies may impact quality of life, stress and anxiety levels. On the other hand, development of more sensitive imaging methods may also be reassuring. Obtaining information about these aspects is crucial for successfu implementation of new surveillance approaches. For a better focus on patients' view, research funders increasingly stimulate involvement of patients with experience of the condition in health care research. In our ongoing projects, we appreciate the valuable input from the 'Contactgroep Marfan Nederland', which is the national interest group of patients with Marfan syndrome. Their Marfan Nederland', which is the national interest group of patients with Marfan syndrome. Their
knowledge and experience has proven complementary to that of our research group and will enhance dissemination of research results in the future. 


\section{NEDERLANDSE SAMENVATTING}

De grote lichaamsslagader (ook wel aorta) transporteert zuurstofrijk bloed van het hart naar organen, spieren en weefsels. Gezien haar belangrijke functie is een aandoening van de aorta potentieel levensbedreigend. In Nederland zijn naar schatting 200.000 patiënten met een verwijding (aneurysma) van de aorta. Bij ongeveer 87.500 bevindt betreft dit het gedeelte van het bloedvat in de borstholte. Patiënten met een aneurysma hebben een verhoogd risico op het ontwikkelen van een acuut aorta syndroom (AAS; zoals een scheur in de vaatwand). Een complete scheur van de aorta in de borstholte is vaak fataal. Bij een scheur in de binnenste laag van de vaatwand (een zogenaamde dissectie) is een spoedoperatie nodig om het aangedane deel te vervangen. Desondanks heeft ook een dissectie een hoog mortaliteitsrisico (circa 70\%). Om het optreden van ruptuur of dissectie te voorkomen wordt een preventieve chirurgische aorta-vervanging verricht bij patiënten met een aorta-diameter $\geq 55 \mathrm{~mm}$. Patiënten met een bijkomende klep- of bindweefselziekte hebben een verhoogd risico op AAS, bij hen is de grenswaarde voor operatie daarom $\geq 50 \mathrm{~mm}$. In dit proefschrift is de voorspellende waarde van diameter-metingen voor het optreden van AAS onderzocht. Tevens is gezocht naar nieuwe anatomische en hemodynamische metingen die het optreden van AAS nauwkeuriger kunnen voorspellen.

In Hoofdstuk I wordt het onderwerp van dit proefschrift geïntroduceerd en worden de doelen van het onderzoek beschreven. Hoofdstuk $\mathbf{2}$ is een beschouwing van bestaande wetenschappelijke literatuur, waarin de voorspellende waarde van diameter-metingen nader besproken wordt. pelijke literatuur, waarin de voorspellende waarde van diameter-metingen nader besproken wordt.
In eerdere onderzoeken wordt gesteld dat $97 \%$ van alle AAS-patiënten een aortadiameter heeft die kleiner is dan de afkapwaarde voor profylactische chirurgie. Dus, zelfs als deze patiënten adequaat werden opgevolgd, zouden ze niet in aanmerking zijn gekomen voor preventief chirurgisch ingrijpen Hoofdstuk 2 beschrijft ook de potentieel toegevoegde waarde van nieuwe, veelbelovende beeldvormende technieken (zoals 4D flow MRI en PET-CT) waarmee het in de toekomst wellicht mogelijk wordt om patiënten met verhoogd risico op AAS in een vroeger stadium te herkennen.

Het is tot op heden onduidelijk hoe vaak de aorta-diameter moet worden gemeten bij patiënten met een thoracaal aneurysma van de aorta (TAA). In Hoofdstuk 3 is dit onderzocht. De belangrijkste conclusies van dit hoofdstuk zijn dat de aorta niet zo snel groeit (gemiddeld slechts I mm per 5 jaar), en dat driejaarlijkse follow-up derhalve volstaat voor patiënten met een TAA $<50 \mathrm{~mm}$. Pas indien de diameter tussen 50 en $55 \mathrm{~mm}$ is, is jaarlijkse opvolging nodig om tijdige verwijzing voor preventief chirurgisch ingrijpen te garanderen.

Hoofdstukken 4, 5 en $\mathbf{6}$ bekijken de diagnostische waarde van metingen van aortalengte en -volume. In hoofdstuk $\mathbf{4}$ is beschreven hoe de aortalengte met de leeftijd verandert en welke invloeden hierin een rol spelen. Gedurende het leven wordt de aorta ongeveer $25 \%$ langer. Hoge bloeddruk versnelt dit verouderingsproces. Op basis van de aortalengte kan $28 \%$ van alle dissecties vroegtijdig worden herkend. Deze parameter is daarmee een stuk gevoeliger dan de aortadiameter (4\%). De verwachting was dat metingen van aortavolume (zijnde een afspiegeling van zowel diameter als lengte) nog gevoeliger zouden zijn, maar dit bleek niet het geval (sensitiviteit: 20\%). Aangezien er geavanceerde beeldvormende (verwerkings-)technieken nodig zijn om de lengte van de aorta te kunnen meten, was dit tot voor kort nog geen klinische routine. Met huidige CT- en MRI-technieken kunnen deze metingen wel routinematig verkregen worden. Op basis van onze bevindingen, en die van andere onderzoekers die soortgelijke resultaten hebben gepubliceerd, is de verwachting dat de aortalengte in de toekomst een belangrijkere rol gaat spelen in de beeldvormende follow-up van TAA-patiënten.

Hoewel de aortalengte in vergelijking met de diameter meer AAS tijdig herkent, is de voorspellende waarde nog niet optimaal. Bijna alle AAS-patiënten hebben hypertensie. Derhalve ontstaat er de latste jaren steeds meer interesse in beeldvormende technieken die in stat zin om de hemodynamiek in de aorta af te beelden. Eén van de technieken die het verst is ontwikkeld, 
is een 4-dimensionale MRI-scan (zogenaamde 4D flow MRI). Hiermee kunnen anatomische en hemodynamische metingen worden gecombineerd, en kunnen afwijkende bloedstroomprofielen (en de gevolgen hiervan op de vaatwand) in kaart worden gebracht. In Hoofdstuk $\mathbf{7}$ hebben we de nauwkeurigheid van deze techniek onderzocht bij patiënten met aortaklepstenose, door de gemeten bloedstroomsnelheden te vergelijken met die van Doppler echo-onderzoek. Uit dit onderzoek blijkt dat de metingen die met 4D flow MRI worden gedaan betrouwbaar zijn, ook bij bekeken hoe de bloedstroom bij aneurysma-patiënten verschilt van die van gezonde vrijwilligers. In dit hoofdstuk is met name gekeken naar de wandschuifspanning (de kracht van de wrijving van de bloedstroom langs de vaatwand). Bij gezonde vrijwilligers blijkt deze wall shear stress gelijk verdeeld over de omtrek van de vaatwand. Echter, bij aneurysma-patiënten is deze krachtsverdeling asymmetrisch, met een hoge piek op de wand van de buitenste curvatuur van de aorta. De hypothese is dat deze verhoogde schuifspanning er in de loop van de tijd voor zorgt dat de aorta verder verwijdt (zoals een rivierbedding uitdijt onder invloed van het stromende water). Door patiënten in de komende jaren op te volgen hopen we dit causaal verband in de toekomst te kunnen bevestigen. 


\section{DANKWOORD}

Dan het belangrijkste en misschien wel meest gelezen hoofdstuk van elk proefschrift: het dankwoord. Ik kijk met heel veel plezier terug op de tijd die ik aan dit onderzoek heb mogen besteden. Hoewel ik niet te betrappen ben op enig artistiek talent, beschouw ik mijn proefschrift als een soort van kunstwerk dat langzaam maar zeker steeds verder vorm begon te krijgen. Hoewel dit proces me overwegend enthousiasmeerde, kon het ook stressvol en/of frustrerend zijn. Inclusie-aantallen, beeldkwaliteit en artefacten, deadlines, etc.; het heeft me (soms letterlijk) wakker gehouden. Des te groter waren echter de ontladingen wanneer er een mooi resultaat geboekt werd, en des te trotser ben ik op het eindresultaat. Ik ben ontzettend blij en dankbaar dat ik in deze periode van mijn leven heb mogen rekenen op het enthousiasme en de toewijding van alle mensen die me - in en buiten het ziekenhuis - hebben gesteund, en zonder wie het voltooien van dit proefschrift nooit was gelukt:

Beste professor Wildberger, beste Joachim, ik ben je ontzettend dankbaar voor de kansen die je me hebt geboden (en nog steeds biedt). Buiten je deskundige inhoudelijke input heb ik me altijd enorm gewaardeerd gevoeld bij je. Je hebt een fantastische infrastructuur voor wetenschappelijk onderzoek opgebouwd waar ik dankbaar gebruik van heb mogen maken. De manier hoe je onderzoek ondersteunt is bijzonder en bood me alle kansen om een succesvol traject neer te zetten. Bedankt voor de vele besprekingen die we in je kantoor hebben gehad. Ik hoop dat we onze samenwerking zo kunnen voortzetten en de komende jaren nog veel mooie projecten kunnen uitwerken.

Beste professor Crijns, beste Harry, je passie voor onderzoek heeft me altijd enorm geïnspireerd. Dankzij je brede interesse en kennis heb je me in de afgelopen jaren veel interessante deeën en invalshoeken geboden. I ben blij dat ik ook nog een aantal jaren van jou als opleider heb mogen leren. Je waarderende knipoog in de ochtendoverdracht zal worden gemist. Geniet van de toekomst met minder administratieve lasten en afspraken!

Beste dr. Schalla, beste Simon, ik heb tot nu toe in mijn opleiding/carrière maar één keer echt
Be toekomst met minder administratieve lasten en afspraken! gesolliciteerd. Dat was in 2012 voor de WESP-stage waarin jij me begeleidde. Je hebt me sindsdien onder je vleugels genomen, een goed woordje voor me gedaan bij de opleiders voor een ANIOS- (en later AIOS)-aanstelling, en uiteindelijk ben ik ook op jouw voorspraak aangenomen als promovendus. Je hebt me in de afgelopen jaren op een hele fijne en persoonlijke manier begeleid, en ik ben me steeds meer gaan realiseren hoe uniek dat is. Je gaf me een stukje manier begeleid, en ik ben me steeds meer gaan realiseren hoe uniek dat is. Je gaf me een stukje
zelfstandigheid om mijn 'kunstwerk' (zie boven) vorm te geven, en stuurde bij waar nodig of gevraagd. Als ik een schouderklopje of bemoedigend woordje nodig had, wist je me dat altijd precies op het juiste moment te geven. Je hebt in Mitch een enthousiaste opvolger gevonden en ik hoop je nog lang te mogen helpen bij zijn begeleiding.

Voorzitter en leden van de beoordelingscommissie, prof. dr. G.W.H. Schurink, prof. dr. M. Das, prof. dr. M.W. de Haan, prof. dr. A.W.J. van 't Hof en prof. dr. J.W. Roos-Hesselink, hartelijk dank voor de deskundige beoordeling van mijn proefschrift.

Gezien het multidisciplinaire onderwerp was mijn proefschrift nooit tot stand gekomen zonder de samenwerking met en deskundige hulp van verschillende specialismen:

Beste dr. ir. Westenberg, beste Jos, het heeft je heel wat moeite en bezoekjes gekost om de 4D flow sequentie in Maastricht aan de praat te krijgen. Heel erg bedankt voor al je inspanningen en de fijne samenwerking.

Aan de afdeling radiologie MUMC+, in het bijzonder Suzanne Gerretsen en Casper Mihl, heel erg bedankt voor jullie kennis, het meedenken over de beste aanpak van verschillende metingen, en jullie logistieke hulp bij onze gezamenlijke projecten. 
Aan alle onderzoekers van het Weijerhorst-project: hartelijk dank voor de samenwerking. Het was fijn om gebruik te mogen maken van de brede kennis binnen dit team.

Beste dr. Bekkers, beste Bas, naast je deskundige input op mijn onderzoeksprojecten heb je me in de afgelopen jaren veel geleerd over CMR. Je kunt fantastisch onderwijs geven en de rol van (mede-)opleider past je dan ook als gegoten. Bedankt voor alle tijd die je in me hebt geïnvesteerd; ik kijk er naar uit om me de komende jaren verder te verdiepen in de non-invasieve beeldvorming.

Beste dr. Cheriex, beste Miel, hoofdstuk 4 van mijn proefschrift is gebaseerd op één van jouw stokpaardjes: de ouder wordende mens. Bedankt voor de kansen die je me als opleider hebt geboden. Ik beloof dat er in de komende jaren nog een publicatie komt over het sigmoïd septum.

Ook een woord van dank aan de andere cardiologen van het MUMC+ voor het benaderen van potentiële studiepatiënten en voor alles wat ik in de afgelopen jaren van jullie heb mogen leren.

Ik wil ook graag de cardiothoracaal chirurgen bedanken voor de fijne samenwerking. Beste

dr. Sardari Nia, bedankt voor je waardevolle begeleiding bij onze gezamenlijke projecten, waar een belangrijk deel van mijn proefschrift op is gebaseerd.

Beste prof. dr. Vos, beste Rein, bedankt voor je hulp bij de statistische analyses, dit heeft tot twee mooie publicaties geleid.

Beste prof. Lamb, beste Hildo, hartelijk dank dat ik vanaf de Maastricht-zijde betrokken ma zijn bij de RADAR-studie. Ik weet zeker dat de komende jaren vanuit dit project nog veel mooie publicaties zullen volgen

Inmiddels werk ik al bijna een jaar met veel plezier in Venlo. Aan de vakgroep cardiologie VieCuri, jullie hebben een heel prettig opleidingsklimaat gecreëerd en het is heel bijzonder hoeveel prioriteit jullie aan de opleiding geven. Heel erg bedankt voor jullie inspanningen om mi te leren katheteriseren en echoën

Dan een aantal mensen aan wie ik veel dank verschuldigd ben voor de ondersteuning die ze me in de afgelopen jaren hebben geboden:

Beste Monique, *74912 stond onder de sneltoetsen op mijn telefoontoestel. Ik heb je in de afgelopen jaren heel vaak lastig mogen vallen met vragen of verzoekjes, en altijd was alles binnen de kortste keren geregeld. Heel erg bedankt voor al je hulp.

Ilse, Liesbeth, Luydmyla en Shahla: heel erg bedankt voor alle mooie scans en de vele gezellige uren achter de scanner. Roland, ik heb je vast een paar grijze haren bezorgd met alle MRIaanvragen. Qua planning was altijd alles perfect in orde: bedankt.

Thea, jij verdient eigenlijk een apart hoofdstuk in mijn proefschrift, want je was nog mee begaan met de 4D flow dan ikzelf. We hebben een hele goede band opgebouwd gedurende de vele uren bij $\mathrm{VH} 4$. Het was voor mij ontzettend fijn om iemand te hebben die zich zo proactief inzette voor mijn onderzoek, die ik alles kon vragen, en die ik blindelings in alles kon vertrouwen. Ik vind het ontzettend erg dat jij en John momenteel zo'n moeilijke periode moeten doormaken en hoop van harte dat jullie hier samen goed doorheen komen.

Mahboobeh en Maryam, dank voor de mooie lay-out van mijn proefschrift en al het werk dat jullie hierin hebben verzet. Het allereerste ontwerp van de cover ('de scheur') kwam voor mil als een hele positieve verrassing en sprak me meteen aan. Ik ben dan ook heel erg blij met het eindresultaat.

k ben blij dat ik mijn proefschrift mag gaan verdedigen met twee fantastische paranimfen aan mijn zijde:

Yvonne, mijn PhD-buddy, klaagmuur en goede-koffie-maatje. Het was heel fijn om iemand te hebben die - op een andere manier - in hetzelfde PhD-schuitje zat. Wat er ook gebeurde of voorviel, ik kon altijd bij je terecht. Het was fijn je weer te zien opfleuren na start van de
Pleiding, want de laatste maanden van je onderzoeks-tijd waren niet altijd even gemakkelijk. Uiteindelijk gaat ook jouw proefschrift er komen; daar twijfel ik niet aan!

Sam, onze samenwerking lag misschien niet direct voor de hand, maar we bleken elkaar perfect aan te vullen. Onze eerste kennismaking (en tevens eerste brainstormsessie) was na een ROC-avond in de binnentuin van de Petit Bonheur. Nu, een paar jaar later, blijkt dat de basis te zijn geweest van een groot deel van mijn proefschrift. Bedankt voor al je geduld, telkens als ik weer een stuk voor de zoveelste keer begon te herschrijven. Ik weet zeker dat er de komende jaren nog vele mooie papers zullen volgen!

Dan een hele batterij aan lieve PhD-collega's met wie ik in de loop der jaren de onderzoekskamer heb mogen delen. In bijna geheel alfabetische volgorde:

Als eerste mijn opvolger: Mitch. Je hebt als WESP-student laten zien over veel enthousiasme en talent voor onderzoek te beschikken. We hoefden dan ook niet lang na te denken toen er een mogelijkheid tot promotieonderzoek ontstond. Met je rustige uitstraling en droge humor heb je snel je plekje op de onderzoekskamer weten te vinden. Ik hoop dat je deze lijn kunt doortrekken, dan zul je jouw deel van de RADAR-studie zeker tot een succes maken.

Anne, voor zover ik me kan herinneren ben jii de eerste vrouw die zich staande heeft weten te houden tussen al die mannen van het DCM-team. Volgens mij begint je proefschrift al aardig vorm te krijgen. Bedankt dat ik betrokken mag zijn bij een aantal van je projecten.

Arantxa, jouw proefschrift ligt hier naast me op mijn bureau. Superknap dat je zo veel werk hebt weten te verzetten met twee kleintjes thuis. Succes met het latste deel van de opleiding!

Casper, jij was mijn overbuurman op nivo 4. Ik kwam laatst de Trivers-Willard-hypothese tegen (Kanazawa, Reprod Sci 20II). Kortweg komt het er op neer dat aantrekkelijke ouders meer kans hebben om dochters te krijgen. Just sayin'... Mooi dat je je plekje gevonden hebt in Roermond, veel succes daar!

Elton, ik heb vanuit mijn hoekje in de kamer altijd heerlijk kunnen genieten van je scherpe reacties en sarcastische opmerkingen richting alles om je heen. Dankzij jou is er een hele nieuwe 'muziek'-wereld voor me opengegaan. Mijn leven was niet compleet geweest zonder Ben en Ruurd, Manita en Marlous; bedankt!

Floor, één van de dapperen die het - zonder ervaring - aandurfde om mee op skireis te gaan en ook nog eens over veel talent bleek te beschikken. Succes met het afronden van je promotie en de opleiding.

Frederique, jii was het onbetwiste organisatietalent van de kamer. Bedankt voor de ski-uitjes die ik samen met jou heb mogen organiseren. Ik dacht al een paar dubieuze plaatsen in de wereld te hebben gezien, maar Gerlos was absolute buitencategorie. Heel veel succes in je B-jaar, ik weet zeker dat je het naar je zin gaat hebben in Venlo.

Jerremy, kortstondig nog even mijn buurman op de vierde verdieping. Als ik Strava mag geloven heb je Zwift deze winter bijna uitgespeeld. Cycle Paris wordt dus een makkie voor je.

Job, het rustige element binnen het verder tamelijk luidruchtige DCM-team. Ik ga je nog steeds een keer verslaan met squashen. Veel succes met je opleiding bij de genetica.

Jort, het liefdevolle logeeradres voor ons konijn tijdens onze vakanties. Inmiddels een beetje van de radar verdwenen, maar in je onderzoeks-tijd altijd duidelijk aanwezig en altijd in voor een slechte grap. Het ga je goed.

Luuk, ondanks dat je gehuisvest bent aan de andere kant van de brug wel altijd aanwezig bij de PhD-uitjes. Ik heb nog mooie filmpjes van je gevonden van de workshop breakdance. Jouw promotiefilmpje komt t.z.t. wel af

Manouk, ik moest aan je denken toen de kappers afgelopen winter in lockdown gingen. 
Knap dat je zo'n mooi en ambitieus pad voor jezelf hebt weten uit te stippelen, waarin je de huisartsenopleiding combineert met je promotieonderzoek. Je gaat zonder twijfel een hele betrokken huisarts worden.

Mark, het werd niet rustiger op de kamer toen jij een postdoc beurs kreeg. Wel mooier. Bedankt voor alle mooie etentjes, borrels en dartpartijtjes. Ook dank voor de samenwerking op wetenschappelijk vlak; de eerste papers gaan binnenkort landen, en ik hoop dat er de komende jaren nog vele volgen.

Martijn, je hebt met de CARMENTA één van de mooiste (en ook logistiek uitdagendste) studies in het MUMC+ succesvol weten af te ronden. Ik ben stiekem wel een beetje jaloers op je promotie-cadeau. Binnenkort weer een rondje?

Michiel, duidelijk het ochtendmens van de kamer. Ondanks dat je vrij snel verhuisde naar 'de overkant' heb je altijd aansluiting gehouden met de rest van de groep. Succes met het afronden van je promotie.

Nick, jij was misschien wel de drukst bezette op de kamer met alle (klinische) taken die je op je bordje kreeg. Toch had je nog voldoende tijd om de kamer (en toiletten) te versieren me mooie Photoshop-creaties. We komen elkaar binnenkort weer tegen als jij ook aan je B-jaar in Venlo begint.

Nikki, jij hebt Elton opgevolgd op de ACWAS-studie en kopt de ene na de andere jaloersmakende publicatie binnen. Soms maakte ik me wel een beetje zorgen om je, want je werkte wel heel erg hard. Veel succes met je opleiding vanaf april!

Ömer, mijn carpool-buddy naar Venlo. Held in thermo-legging. Je eerste ski-middag en je duikvlucht richting de zijmuur van de skilift staan nog steeds op mijn netvlies. Je bent een ontzettend fijne collega, ik ben blij dat ik mijn tijd in VieCuri samen met je mag doorbrengen.

Zoals mijn copromotor vaker zei: 'promoveren is het leren omgaan met frustraties'. Hoewel de hoeveelheid frustraties (achteraf) best meeviel, was het af en toe heerlijk om buiten het ziekenhuis even stoom af te blazen.

Wesley, Gijs en Neal, ik weet niet eens meer hoe onze uitjes een traditie zijn geworden Weekenden waar je al weken naar uitkijkt kunnen soms een beetje tegenvallen, maar die met jullie zijn altijd nog briljanter dan ik me vooraf had voorgesteld. Ik hoop dat we snel weer op pad kunnen. Madame Koo, miss Renate, Liv, de mensen-hatende barman van de Newton, en iedereen die ik nog vergeet; jullie ook bedankt voor jullie aandeel aan deze weekenden.

Victor, de drijvende kracht achter de weekendjes in Valkenburg. ledere keer weer een heerlijke uitlaatklep: stukje fietsen, Kippie-pan, een paar flügels in 't Hoekje, maar vooral even weg van huis en werk. Ik hoop dat we deze traditie nog lang in stand gaan houden.

Bart, bedankt voor de vele rondjes op de fiets die ons naar de mooiste plekjes van Zuid-Limburg en de Voerstreek hebben gebracht. Zodra onze huishoudens het weer toestaan ga ik graag weer eens naar de Vogezen.

Arnout, met jullie terugkeer naar Maastricht is er ook een nieuwe sociale impuls gekomen. Dank voor de mooie etentjes en avonden die je op touw hebt gezet. Ook bedankt voor de kennismaking met jullie spelletjeskast; met 'Saboteur' vliegt menig avond in deze lockdown voorbij.

Last but not least, mijn familie:

Lieve Bart en Femke, toen ik jullie leerde kennen zaten jullie midden in de babytijd. Door he spelen met jullie lieve (toen nog kleine) kindjes begon het bij mij ook een beetje te kriebelen. Nu kruipen wij zelf langzaam uit die tropenjaren en kijk ik stiekem weer naar jullie als voorbeeld voo de komende jaren: een heerlijk huis gekocht, weer wat meer tijd voor leuke dingen en sport, en nieuwe uitdagingen op het werk. Jullie hebben het goed voor elkaar samen. Tot snel weer.
Lieve Heleen en Ruud, tot de winter van 2012 moest ik niets hebben van wintersport (koud, sneeuw etc.). Dankzij jullie enthousiasme (en wat schnaps van Gert-Jan) heb ik me toch de piste op gewaagd voor de lessen van Ruud. Ik was snel verkocht, en nu is de wintersport misschien we hetgeen ik in corona-tijd het meeste mis. Bedankt voor alles dat jullie door de jaren heen voor de familie hebben georganiseerd, met jullie bruiloft in Oostenrijk als absolute hoogtepunt!

Lieve Jaap en Mieke, ik kom inmiddels al bijna II jaar bij jullie over de vloer en heb me vanaf het begin heel welkom gevoeld. Jullie genieten volop van jullie pensioen met heerlijke vakanties en veel activiteiten. Om de week maken jullie bovendien de reis naar Maastricht om op onze kindjes te passen. Ik zou willen dat ik vroeger zo'n goede band met mijn opa en oma had gehad. Heel erg bedankt voor jullie steun en interesse in de afgelopen jaren.

Lieve Gieltje, mijn zussie, onze leventjes zijn van jongs af aan heel verschillend geweest. Waar ik inmiddels al 17 jaar in Maastricht woon, heb jij de hele wereld rond gereisd en ben je uiteindelijk met Marc neergestreken in Londen. Ondanks onze verschillen vind ik het ontzettend knap wat je allemaal doet en hoe fanatiek je je voor je werk en idealen inzet. Ik hoop dat de komende jaren jullie veel moois gaan brengen. Op het moment dat Marc begint met rijlessen weten wij genoeg :)

Lieve pap, iij was mijn allereerste proefpersoon voor de 4D flow MRI. De scan verliep toen nog niet zo soepel, met als gevolg dat je twee uur en een kwartier in de scanner hebt gelegen. Er zijn volgens mij ook maar weinig ouders die zichzelf contrastvloeistof laten toedienen voor het promotieonderzoek van hun zoon (dat vond ik overigens wel even spannend...). Het is gelukkig niet voor niks geweest. Heel erg bedankt voor de steun en alle momenten waarop je/jullie in de afgelopen jaren zijn bijgesprongen. Ik vind het erg knap hoe je je nu staande houdt na het overlijden van mama, ondanks dat ik weet dat dat niet altijd meevalt. Weet dat we er graag voor je zijn als het nodig is.

Aan mijn lieve meisjes: Imme, ik was 1.5 maand bezig met mijn promotieonderzoek toen ji werd geboren. Trots als ik was zat ik 's ochtends in een roze trui in de ochtendoverdracht. Inmiddels heb je je ontwikkeld tot een lieve en leergierige meid, die heel bedachtzaam de wereld aan het ontdekken is. Fiene, hoewel we je af en toe wel achter het behang zouden willen plakken, kunnen we ook heel erg genieten van hoe ondeugend, vrolijk en creatief jij je door het leven beweegt. Jullie zijn twee schatjes, en ik zie er heel erg naar uit om jullie verder te zien opgroeien.

Allerliefste Marian, eigenlijk is dit voor een belangrijk deel ook jouw proefschrift. We zijn nu meer dan II jaar samen en je hebt me altijd gesteund in alles wat ik deed. Je kwam terug vanuit Den Haag voor mijn opleiding, zodat we in Maastricht samen ons leventje konden gaan opbouwen. Ondanks dat jij ook last moet hebben gehad van de stress die mijn onderzoek me soms bezorgde, heb je me altijd aangemoedigd in de keuzes die ik maakte. We hebben de afgelopen jaren hard gewerkt om alle ballen in de lucht te houden, en ondanks dat het soms pittig was is dat heel aardig gelukt. Nu mijn promotie (bijna) is afgerond en de kindjes ouder worden, krijgen we langzaam ook weer wat meer tijd voor ons tweetjes. En daar heb ik ontzettend veel zin in. Ik hou van je!

Er zal tijdens mijn verdediging helaas een stoeltje leeg blijven op de eerste rij van de Mindersbroedersberg. Lieve mama, jouw ziek zijn en overlijden bracht veel verdriet gedurende mijn onderzoeks-jaren. Toch was de laatste tijd samen, waarin we elkaar veel hebben gezien, enorm fijn en waardevol. Ik had je graag nog een keer trots gemaakt. We missen je. 


\section{ABOUT THE AUTHOR}

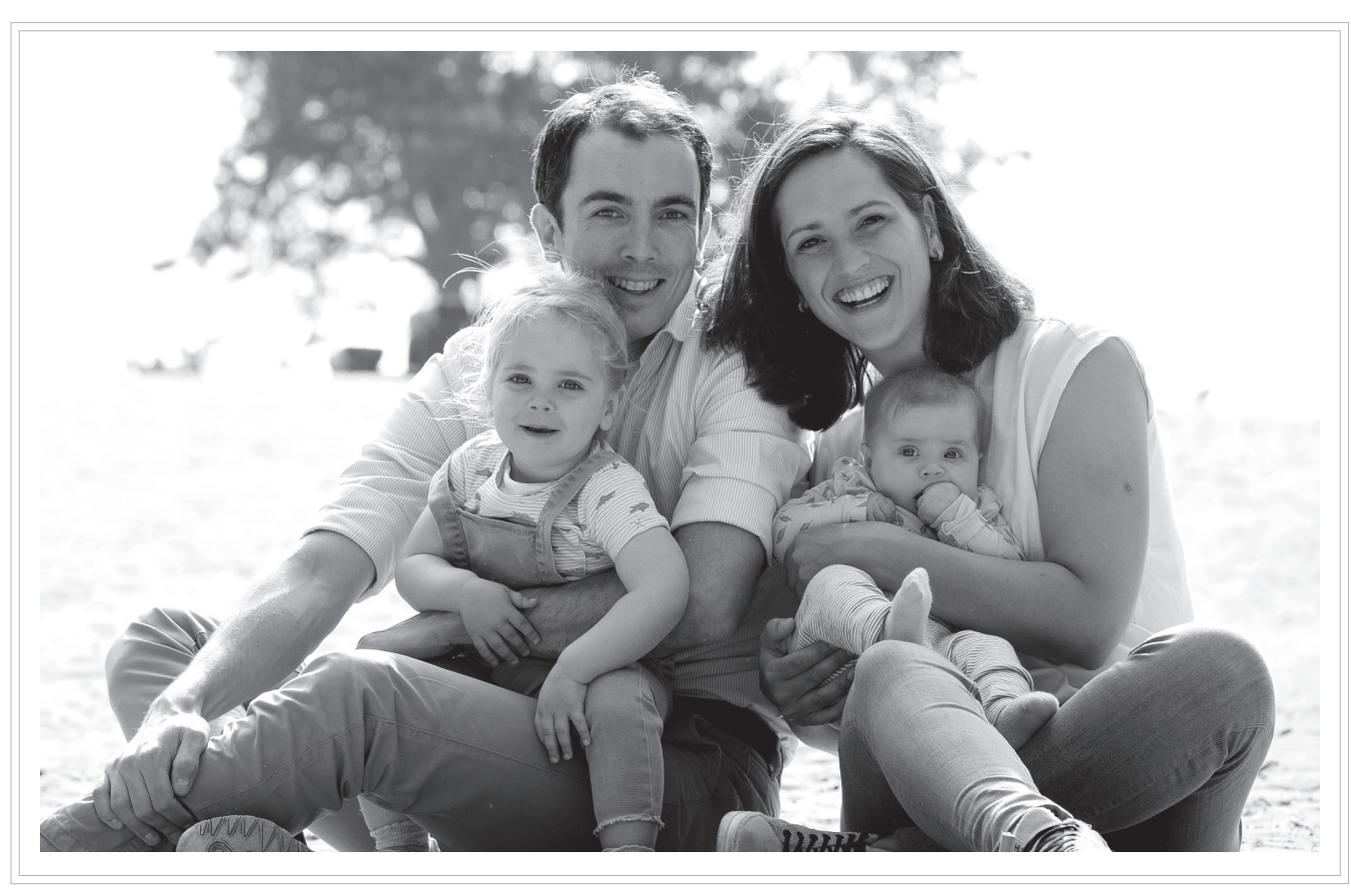

Bouke Piet Adriaans was born on December $28^{\text {th }} 1986$ in Eindhoven, the Netherlands. In 2004 he graduated from secondary school at the Van Maerlant Lyceum in Eindhoven and moved to Netherlands). He followed his medical training at the same institution from 2006 onwards. In the final year of medical school, he participated in a research internship at the department of cardiology under supervision of Dr. S. Schalla. He graduated in 2013 and subsequently started his clinical training in cardiology at the Maastricht University Medical Center+ (supervision: Prof. dr. H.J.G.M. Crijns). In 2016, he was offered a position as PhD-candidate in cardiovascular imaging at the department of radiology and nuclear medicine (supervision: Prof. dr. J.E. Wildberger, Prof. dr. H.J.G.M. Crijns and Dr. S. Schalla). His main research topic was imaging of the aortic valve and thoracic aorta, with focus on prediction of acute aortic syndromes. The results of this research are presented in this thesis. He has resumed his clinical training in 2020 at the VieCuri Medical Center (Venlo, the Netherlands), while holding a part-time research position at the Cardiovascular Research Institute Maastricht (CARIM). He expects to finish his registration as cardiologist mid-2024. 


\section{LIST OF PUBLICATIONS}

Adriaans BP, Samarska IV, de Vries B, Bekkers SCAM.

A patient with progressive dyspnea.

Neth Heart J 2015 Jul;23(7-8):399-401.

Adriaans BP, Heuts S, Gerretsen S, Cheriex EC, Vos R, Natour E, Maessen JG, Sardari Nia P, Crijns HJGM, Wildberger JE, Schalla $S$.

Aortic elongation part I: the normal aortic ageing process.

Heart 2018 Nov;104(21):1772-1777

Heuts S, Adriaans BP, Gerretsen S, Natour E, Vos R, Cheriex EC, Crijns HJGM, Wildberger JE, Maessen JG, Schalla S, Sardari Nia P.

Aortic elongation part II: the risk of acute type A aortic dissection

Heart 2018 Nov;104(21):1778-1782.

Adriaans BP, Wildberger JE, Westenberg JJM, Lamb HJ, Schalla S.

Predictive imaging for thoracic aortic dissection and rupture: moving beyond diameters. Eur Radiol 2019 Dec; 29(I2):6396-6404.

Adriaans BP, Westenberg JJM, van Cauteren YJ, Gerretsen S, Elbaz MSMM, Bekkers SCAM, Veenstra LF, Crijns HIGM, Wildberger JE, Schalla S.

Clinical assessment of aortic valve stenosis: comparison between 4D flow MRI and transthoracic echocardiography.

J Magn Reson Imaging 2020 Feb;5I (2):472-480 Adriaans BP, Heuts S, Rylski B, Mihl C, Bekkers SCAM, Olsthoorn JR, Natour E, Bouman HJ,
Berezowski M, Kosiorowska K, Crijns HJGM, Maessen JG, Wildberger JE, Schalla S, Sardari Nia P. Berezowski M, Kosiorowska K, Crijns HJGM, Maessen JG, Wildberger JE, Schalla S, Sardari Nia P.
Evaluating the diagnostic accuracy of maximal aortic diameter, length and volume for prediction of aortic dissection.

Heart 2020 Jun:106(12):892-897.

Heusinkveld MHG, Holtackers RJ, Adriaans BP, op 't Roodt J, Arts T, Delhaas T, Reesink KD, Huberts W.

Complementing sparse vascular imaging data by physiological adaptation rules.

Appl Physiol. 2021 Mar 1;130(3):571-588.

Ramaekers MJGF, Adriaans BP, Juffermans JF, van Assen HC, Bekkers SCAM, Kenjeres S, Lamb HJ, Wildberger JE, Westenberg JJM, Schalla $\mathrm{S}$.

Characterization of ascending aortic flow in patients with degenerative aneurysms: a 4D flow magnetic resonance study.

Invest Radiol, in press. 
Van Cauteren YJ, Smulders MW, Theunissen RALJ, Gerretsen S, Adriaans BP, Bijvoet GP, Mingels AM, van Kuijk S, Schalla S, Crijns HJGM, Kim RJ, Wildberger J, Heijman J, Bekkers SCAM. The diagnostic role of cardiovascular magnetic resonance as initial test in non-ST elevation myocardial infarction.

Cardiovasc Magn Reson, in press.

Adriaans BP, Ramaekers MJGF, Heuts S, Crijns HJGM, Bekkers SCAM, Westenberg JJM, Lamb HJ, Wildberger JE, Schalla S.

Determining the optimal interval for imaging surveillance of ascending aortic aneurysms.

Neth Heart J, in press.

Raafs AG, Verdonschot JAJ, Henkens MTHM, Adriaans BP, Derks K, Merken JJ, Abdul Hamid MA, Knackstedt C, van Empel VPM, Gonzàlez A, Díez J, Brunner-la Rocca HP, Brunner HG, Bekkers SCAM, Heymans SRB, Hazebroek MR.

Multilevel assessment of myocardial fibrosis in dilated cardiomyopathy: PICP blood levels and LGE at CMR are incremental predictors of outcome.

Submitted.

Tayal U, Verdonschot JAJ, Hazebroek MR, Newsome S, Gulati A, Pua CJ, Halliday BP, Lota AS, Whiffin N, Kanapeckaite L, Baruah R, Jarman JWE, Barton P, Ware JS, Pennell DJ, Adriaans BP, Bekkers SCAM, Donovan J, Frenneaux M. Cleland JGF, Cook SA, Heymans SRB, Deo RC. Prasad SK.

Multi-parametric phenomapping using machine learning identifies a novel subtype of dilated cardiomyopathy and highlights IL4R as novel prognostic biomarker.

Submitted. 
